\title{
Macroscopic and microscopic \\ characterization of non-reacting \\ diesel sprays at low and very high injection pressures
}

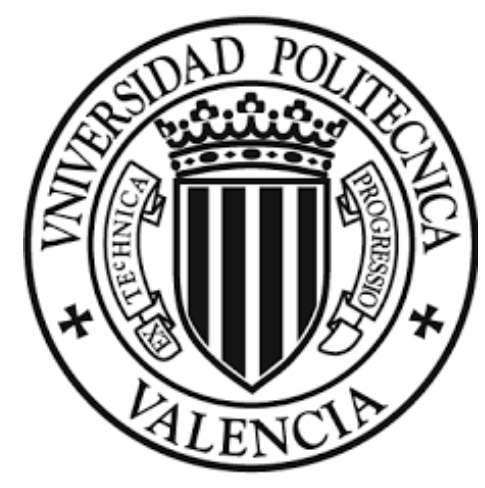

Jhoan Sebastián Giraldo Valderrama

Advisor: Prof. Raúl Payri Marín

DEPARTAMENTO DE MÁQUINAS Y MOTORES TÉRMICOS Universitat Politècnica de València

This dissertation is submitted for the degree of

\section{Doctor of Philosophy}



A mis padres y a mi hermano Nico, los amo. 



\section{Declaration}

I hereby declare that except where specific reference is made to the work of others, the contents of this dissertation are original and have not been submitted in whole or in part for consideration for any other degree or qualification in this, or any other university. This dissertation is my own work and contains nothing which is the outcome of work done in collaboration with others, except as specified in the text and Acknowledgements. This dissertation contains fewer than 60000 words including appendices, bibliography, footnotes, tables and equations and has fewer than 110 figures.

Jhoan Sebastián Giraldo Valderrama

November 2018 



\section{Acknowledgements}

Antes de comenzar con mis agradecimientos, quiero de antemano disculparme si me olvido de mencionar a alguna persona o suceso. Mi estancia en Valencia durante 4 años de mi vida fue tan enriquecedora y llena de tan grandiosos pasajes, que recordarlos todos de golpe, a una semana de hacer la entrega de mi libro, se me hace sumamente difícil.

En primer lugar me encantaría recordar a mi tio Octavio. Nuestras últimas conversaciones antes de su partida sin duda acentuaron un cuestionamiento existencial en mí y conllevaron a un notable cambio en la manera en que encaraba las diferentes situaciones, y contradicciones que trae habitualmente la vida. Por esta razón, le agradezco a la vida y a su familia, por el tiempo que se me permitió pasar junto a él y por el aprendizaje que un momento tan triste te puede traer. Esto me lleva a una segunda persona que debo agradecer y que él bien sabe por qué. Juan Manuel Mompo Laborda, mi primer y mejor amigo valenciano, al que debo agradecerle su apoyo incondicional durante toda mi etapa en Valencia. Muchas gracias por estar siempre ahí, yo intentaré pagarte en esta vida lo que hiciste por mí.

Agradezco a todas las personas que me acompañaron durante este viaje. Teresa, gracias por tu sincera e incondicional amistad, por hacer labor de niñera y de profesora de tango cuando me fracturé la columna. Daniel Estepa, mi primer compañero de piso, gracias por las interminables conversaciones de la vida en general, vos sos un ejemplo de sencillez. Leonardo Ramírez, Vincenzo y Marco, gracias hermanos por permitirme contar con su amistad y apoyo durante esta lucha conjunta para alcanzar el doctorado. 
Además a Dani Vaquerizo, sos una gran persona y brillante, el mejor compañero de estancia que pude tener, aprendí mucho de vos.

Por supuesto no me puedo olvidar de mis mejores amigos venezolanos, con los cuales se desenvolvieron interesantes discusiones y debates profundos sobre los orígenes de la "Arepa"; Alberto, Jesús, Armando, Juan Pa, y el Morocho. Los extraño mucho muchachos. Cabe además hacer una mención de honor a mi "ex-pancho", casi venezolano, Diego Quintana por el colosal almuerzo que nos trajo en su día de despedida.

Asimismo, me gustaría dar un agradecimiento a Christopher Powell por darme la oportunidad de realizar a estancia de investigación en Argonne National Laboratory y por toda la confianza depositada en mí. De igual manera agradezco al resto del equipo de Fuel Spray: Katarzyna Matusik, Daniel Duke, Alan Kastergren y Nicholas Sovis por su gran recibimiento, cooperación y buena disposición para compartir su conocimiento.

Mi más sincera gratitud al Instituto CMT-Motores Térmicos, y en particular a Francisco Payri, José María Desantes y Jesús Benajes, por la oportunidad de permitirme formar parte de este prestigioso grupo de investigación. Sus recursos tecnológicos, económicos y humanos han posibilitado la realización de esta tesis Doctoral. También gracias al resto de profesores, doctorandos y todos los miembros del equipo de Inyección de CMT, por su compañerismo y amistad durante todo este tiempo especialmente a; Abian, María, Mary, Gabriela, Marcos, Santi, Pedro, Jose Pedro, Javi, Joaquín y Mario. Gracias también a los técnicos encargados de las instalaciones experimentales, en especial a Omar, Borja, y por último José Enrique.

Un agradecimiento muy especial a mi director de tesis Raúl Payri Marín, quien ha hecho una brillante tarea de dirección, siempre guiando con gran certeza el camino por el que debía seguir y abogando ante cualquier dificultad que los doctorandos pudiéramos tener. Su capacidad de gestión es impresionante y siempre lo admiraré honestamente por ello. 
Por último y lo más importante a mi familia, comenzando por mis primos-hermanos David y Pablo. Los extraño mucho, no veo la hora de poder volver a compartir una pola con ustedes. También a mi papá Humberto de personalidad sencilla, juguetona, con gran corazón, y que ante todo hizo lo posible porque mi hermano y yo siempre tuviéramos lo necesario para alcanzar nuestras metas. A mi madre que es un ejemplo de "berraquera", alguien que no se conformó con una vida de casa y que hasta hoy siempre sale cada día para seguir luchando y trabajando por darnos lo mejor a mi hermano y a mí. A mi hermano Nico, gracias por escucharme durante tantas horas, sos de las cosas que más amo en este mundo. Los extraño.. 



\section{Resum}

En l'exploració de nous mètodes per al millorament de l'eficiència i rendiment del motor dièsel, és clar que un gran esforç s'ha enfocar en el procés d'injecció de combustible. L'eficiència de la combustió i les emissions, es veuen molt afectades pel procés d'atomització, i s'ha demostrat que increments en pressions d'injecció comporten un gran potencial per a millorar l'estalvi de combustible, produir millors mescles d'aire i combustible, i per tant menor generació d'emissions contaminants. Últimament, les pressions d'injecció han augmentat d'al voltant de $50 \mathrm{MPa}$ en els anys 70 fins a 250 MPa en els dies actuals. Pressions d'injecció molt altes (250-300 MPa) o inclús ultra altes (> $300 \mathrm{MPa}$ ) vénen sent matèria d'investigació a fi de ser implementades de manera comercial en un futur pròxim.

L'estructura i desenrotllament de l'esprai dièsel poden ser caracteritzats des d'un punt de vista microscòpic per mitjà del mesurament de la grandària de gotes de l'esprai i les seues velocitats. En condicions no-evaporatives, tècniques com el PDPA (Phase doppler particle analyzer) vénen sent utilitzades per a l'obtenció de perfils de diàmetres i velocitats de gota amb una alta resolució temporal.

Des del punt de vista macroscòpic, hi ha paràmetres específics que permeten caracteritzar a un doll dièsel, estos són: la penetració de vapor i la penetració líquida junt amb l'angle d'obertura del doll. La penetració líquida és un indicador clar de la capacitat d'evaporació del combustible utilitzat, mentres que la penetració de vapor, per la seua banda, és indicatiu del procés de mescla i la probabilitat de col · lisió amb les parets de la cambra de combustió; factors claus a l'hora de la generació d'emissions contaminants. En esta tesi s'estudia la influència de pressions d' injecció baixes, mitges i molt altes, 
sobre un ampli espectre de condicions i diagnòstics experimentals, i des del punt de vista macroscòpic i microscòpic. Es van realitzar experiments per a tres injectors diferents, 2 solenoides i un piezo elèctric, este últim amb la capacitat d'aconseguir pressions d'injecció pròximes a $270 \mathrm{MPa}$. Les medides inclouen una caracterització hidràulica, composta per taxa d'injecció; una visualització d'alta velocitat del doll líquid isoterm; una visualització d'alta velocitat del doll inert evaporativo, amb captura simultània de les fases líquida i vapor; i finalment, una caracterització microscòpica per mitjà de l'obtenció de distribució de grandària de gotes i les seues velocitats. Respecte als assajos microscòpics, es va desenrotllar una metodologia per a l'aïllament i alineació d'esprais amb un error de mesurament molt davall de $0,22^{\circ}$. Es van dur a terme mesuraments de velocitat de gotes, els resultats van mostrar bon ajust amb perfils teòrics de velocitat. De la mateixa manera, una correlació per a la grandària de gota SMD es va obtindre mostrant un alt nivell d'ajust i sent representativa per a tot el rang de pressions d'injecció estudiats.

En el cas de la caracterització macroscòpica del doll isoterm, s'han detectat variacions macroscòpiques en el desenrotllament del doll amb propietats de gas, inclusivament en condicions de motor comú. Per a estimar estos efectes i altres que altes pressions d'injecció tindrien sobre l'estructura del doll, es va incentivar l'aparició d'ones de xoc controlant la velocitat del so de l'ambient. Es van usar tres gasos ambientals $\left(\mathrm{SF}_{6}\right.$, $\mathrm{N}_{2}$ i $\mathrm{CO}_{2}$ ) amb diferents velocitats de so, promovent d'esta manera dolls supersònics en determinats casos. Al comparar assajos amb mateixes densitats i diferents gasos ambientals, es va trobar que totes les tendències pròximes a l'estat transónic $(0.8<\mathrm{M}$ $<1.2)$ tenien una major penetració i menor angle de doll. Respecte al doll evaporatiu, per a pressions d'injecció molt altes com 270MPa, els efectes dels paràmetres ambientals i d'injecció van romandre iguals respecte a totes les característiques macroscòpiques. 


\section{Resumen}

En la exploración de nuevos métodos para el mejoramiento de la eficiencia y rendimiento del motor diésel, es claro que un gran esfuerzo debe estar enfocado en el proceso de inyección de combustible. La eficiencia de la combustión y las emisiones, se ven muy afectadas por el proceso de atomización, y se ha demostrado que incrementos en presiones de inyección conllevan un gran potencial para mejorar el ahorro de combustible, producir mejores mezclas de aire y combustible, y por tanto menor generación de emisiones contaminantes. Últimamente, las presiones de inyección han aumentado de alrededor de $50 \mathrm{MPa}$ en los años 70 hasta $250 \mathrm{MPa}$ en los días actuales. Presiones de inyección muy altas (250-300 MPa) o incluso ultra altas (> $300 \mathrm{MPa}$ ) vienen siendo materia de investigación con el fin de ser implementadas de manera comercial en un futuro próximo.

La estructura y desarrollo del spray diésel pueden ser caracterizados desde un punto de vista microscópico por medio de la medición del tamaño de gotas del spray y sus velocidades. En condiciones no-evaporativas, técnicas como el PDPA (Phase Doppler Particle Analyzer) vienen siendo utilizadas para la obtención de perfiles de diámetros y velocidades de gota con una alta resolución temporal.

Desde el punto de vista macroscópico, existen parámetros específicos que permiten caracterizar a un chorro diésel, estos son: la penetración de vapor y líquida junto con el ángulo de apertura del chorro. La penetración líquida es un indicador claro de la capacidad de evaporación del combustible utilizado, mientras que la penetración de vapor, por su parte, es indicativo del proceso de mezcla y la probabilidad de colisión con las paredes de la cámara de combustión; factores claves a la hora de la generación 
de emisiones contaminantes.

En esta tesis se estudia la influencia de presiones bajas, medias y muy altas presiones inyección, sobre un amplio espectro de condiciones y diagnósticos experimentales, y desde el punto de vista macroscópico y microscópico. Se realizaron experimentos para tres diferentes inyectores, 2 solenoides y un piezo eléctrico, este último con la capacidad de alcanzar presiones de inyección cercanas a $270 \mathrm{MPa}$. Las medidas incluyen una caracterización hidráulica, compuesta por tasa de inyección; una visualización de alta velocidad del chorro líquido isotermo; una visualización de alta velocidad del chorro inerte evaporativo, con captura simultánea de las fases líquida y vapor; y finalmente, una caracterización microscópica por medio de la obtención de distribución de tamaño de gotas y sus velocidades.

Con respecto a los ensayos microscópicos, se desarrolló una metodología para el aislamiento y alineación de sprays con un error de medición muy bajo de $0,22^{\circ}$. Se llevaron a cabo mediciones de velocidad de gotas, cuyos resultados mostraron buen ajuste con perfiles teóricos de velocidad. De igual manera, una correlación para el tamaño de gota SMD se obtuvo mostrando un alto nivel de ajuste y siendo representativa para todo el rango de presiones de inyección estudiados.

En el caso de la caracterización macroscópica del chorro isotermo, se han detectado variaciones macroscópicas en el desarrollo del chorro con propiedades de gas, inclusive en condiciones de motor comunes. Para estimar estos efectos y otros que las presiones de inyección muy altas tendrían sobre la estructura del chorro, se incentivó la aparición de ondas de choque controlando la velocidad del sonido del ambiente. Se usaron tres gases ambientales $\left(\mathrm{SF}_{6}, \mathrm{~N}_{2}\right.$ y $\left.\mathrm{CO}_{2}\right)$ con diferentes velocidades de sonido, promoviendo de esta manera chorros supersónicos en determinados casos. Al comparar ensayos con mismas densidades y diferentes gases ambientales, se encontró que todas las tendencias cercanas al estado transónico $(0.8<\mathrm{M}<1.2)$ tenían una mayor penetración y menor ángulo de chorro. Con respecto al chorro evaporativo, para presiones de inyección muy altas como 270MPa, los efectos de los parámetros ambientales y de inyección permanecieron iguales con respecto a todas las características macroscópicas. 


\begin{abstract}
In the exploration of new methods for improving the efficiency and performance of the diesel engine, it is clear that a great effort should be focused on the fuel injection process. The efficiency of combustion and emissions are greatly affected by the atomization process, and it is considered that injection pressures increments have a great potential to improve fuel economy, produce better air and fuel mixtures, and thus low generation of polluting emissions. Lately, injection pressures have increased from around $50 \mathrm{MPa}$ in the 70 's to $250 \mathrm{MPa}$ in the current days, even very high injection pressures (250-300 $\mathrm{MPa}$ ) or ultra high pressures (>300 MPa) have been the subject of the scientific community in order to be implemented in future injection systems.

The structure and development of the diesel spray can be characterized from a microscopic point of view by means of estimation of droplets size and velocities. At nonevaporative conditions, techniques such as PDPA (Phase Doppler Particle Analyzer) are being used to obtain diameters and velocity profiles a with high temporal resolution.

From the macroscopic point of view, there are specific parameters that allow characterizing the diesel spray, these are: the liquid and vapor penetration along with the spray angle. The liquid penetration is a clear indicator of the evaporation capacity of the fuel used, whilst the vapor penetration, on the other hand, is an indicative of the mixing process and the probability of collision with the combustion chamber walls; key factors when generating polluting emissions.

In this thesis the influence of low and very high injections pressures over the macro and micro characteristics of the diesel spray is studied, over a wide spectrum of conditions and experimental diagnoses. Experiments were carried out for three
\end{abstract}


different injectors, two solenoids and one piezoelectric, the latter with the capacity to reach injection pressures close to $270 \mathrm{MPa}$. The measurements include a hydraulic characterization; a high speed visualization of the liquid spray at isothermal conditions; a high-speed visualization of the evaporative spray, with simultaneous capture of the liquid and vapor phases; and finally, a microscopic characterization.

Regarding the microscopic tests, a methodology was developed for the spray isolation and alignment with a very low measurement error of $0.22^{\circ}$. Droplets velocity measurements were carried out, the results showed good adjustment with theoretical velocity profiles. Similarly, a correlation for SMD droplet size was obtained showing a high level of adjustment and being representative for the entire range of injection pressures studied.

In the case of the macroscopic characterization of the isothermal spray, variations have been detected in the development of the jet with gas properties, even at common engine injection conditions. To estimate these effects and others that very high injection pressures would have on the spray structure, the apparition of shock waves was enhanced by controlling the speed of sound of the environment using three ambient gases with different speed of sound $\left(\mathrm{SF}_{6}, \mathrm{~N}_{2}\right.$ and $\left.\mathrm{CO}_{2}\right)$. When comparing tests with same densities and different ambient gases, it was found that all the tendencies near the transonic state $(0.8<\mathrm{M}<1.2)$ had a higher penetration and lower spray angle. With respect to the evaporative jet, for very high injection pressures like $270 \mathrm{MPa}$, the effects of the environmental and injection parameters remained the same with respect to all the macroscopic characteristics. 


\title{
Nomenclature
}

\author{
ASOE After start of energizing \\ $A S O I$ After start of injection \\ $\mathrm{CO}_{2}$ Carbon dioxide \\ $N_{2} \quad$ Nitrogen \\ $S F_{6} \quad$ Sulfur hexafluoride \\ $C F D$ Computational fluid dynamics \\ CPF Constant Pressure flow facility \\ DBI Diffused back illumination \\ $E C U$ Engine Control Unit \\ ECN Engine Combustion Network \\ ET Energizing time \\ DI Direct injection
}

$I R D C I$ Injection rate discharge curve indicator

LAS Laser Absorption Scattering

LDM Long Distance Microscopy

$M S D$ Mean Square Deviation

PECU Programmable Engine Control Unit

PDPA Phase Doppler Particule analyzer

PLIF Planar Laser Induced Florescence

ROI Rate of injection 
$S M D$ Sauter Mean Diameter

SOE Start of energizing

SOI Start of injection

VCO Valve covered orifice

\section{Greeks}

$\Delta P \quad$ Pressure difference

$\Delta P_{m}$ Pressure drop for minor losses

$\xi \quad$ Minor losses coefficient

$\beta \quad$ Angle between sprays

$\rho \quad$ Density

$\rho_{a} \quad$ Ambient density

$\rho_{f} \quad$ Fuel density

$\varphi \quad$ PDPA Scattering angle

$\gamma \quad$ Crossing angle between PDPA beams

$\lambda \quad$ Laser light wavelength

$\psi \quad$ PDPA Elevation angle

$\phi_{\text {visc }}$ Viscous dissipation

$\phi_{v i s c, m}$ Viscous dissipation for minor losses

$\phi_{v i s c, M}$ Viscous dissipation for major losses

$\Phi \quad$ Light scattered by reflexion

$\sigma \quad$ Surface tension

$\theta \quad$ Spray angle

$\mu_{f} \quad$ Fuel dynamic viscosity

$\mu_{a m b}$ Ambient dynamic viscosity 


\section{Latins}

$a_{f} \quad$ Fuel speed of sound

$A_{i} \quad$ inlet cross sectional area

$A_{o} \quad$ outlet cross sectional area

$A_{\text {eff }} \quad$ Effective area

$A_{t} \quad$ Tube cross-sectional area IRDCI

$A R \quad$ Nozzle area reduction factor

$C_{d} \quad$ Discharge coefficient

$C_{d \max }$ Maximum Discharge coefficient

$C_{a} \quad$ Area coefficient

$C_{c} \quad$ Contraction coeficient

$C_{e} \quad$ Entrainment coeficient

$C_{M} \quad$ Momentum coeficient

$C_{p, a i r}$ Specific heat air

$C_{p, l i q}$ Specific heat liquid fuel

$C_{v} \quad$ Velocity coeficient

$D \quad$ Characteristic length for Reynolds number

$D_{10} \quad$ Direct average of droplet diameters

$D_{20} \quad$ Surface area mean diameter

$D_{30} \quad$ Volume mean diameter

$D_{32} \quad$ Sauter mean diameter

$D_{d, 1} \quad$ Diameter of the largest droplet for $R e_{\text {coll }}$

$D_{d, 2} \quad$ Diameter of the smallest droplet for $R e_{\text {coll }}$

$d_{e} \quad$ Equivalent diameter

$D_{\text {eff }} \quad$ Effective diameter 
$D_{i} \quad$ Hole inlet diameter

$D_{o} \quad$ Hole exit diameter

$e \quad$ Absolute roughness

$f_{d} \quad$ Doppler frequency

$g \quad$ Gravity

H Total head

$h_{v a p} \quad$ Enthalpy of vaporization

I Intact length

$K \quad$ Cavitation number

$k-$ factor Orifice conicity factor

$K_{\text {crit }}$ Critical cavitation number

$K_{\text {fric }}$ Friction coefficient

$L \quad$ Channel or nozzle length

$L L_{v} \quad$ Liquid length

$\dot{m}_{f} \quad$ Mass flow rate

$\dot{m}_{f, t h}$ Theoretical mass flow rate

$\dot{M}_{f} \quad$ Momentum flux

$\dot{m}_{o} \quad$ Mass flow rate at the nozzle exit

$M R$ Mixture rate

$L \quad$ Orifice length

$L_{\text {core }}$ Intact liquid core length

$n_{\text {rel }} \quad$ Relative reflective index

$n_{p} \quad$ Particle reflective index

$n_{m} \quad$ Medium reflective index

Oh Ohnesorge Number

$P \quad$ Local pressure 
$p_{\text {back }} \quad$ Back pressure

$p_{i n j} \quad$ Injection pressure

$P_{v} \quad$ Vapor pressure

$r \quad$ Radial distance from spray axis

$r_{e} \quad$ Rounding radius

$R_{e} \quad$ Reynolds number

$R_{\text {coll }}$ Reynolds number for droplet collision

$R_{e l} \quad$ Local Reynolds number

$R_{e, t h}$ Theoretical Reynolds number

$S \quad$ Spray penetration

Sc Schmidt number

Ta Taylor Number

$T_{a m b}$ Ambient temperature

$T_{b} \quad$ Boiling temperature

$t_{b} \quad$ Break up time

$T_{f} \quad$ Fuel temperature at the exit nozzle

$U \quad$ Flow velocity

$U_{\text {axis }}$ Flow velocity at the spray axis

$u_{\text {eff }}$ Effective velocity

$u_{o} \quad$ Flow outlet velocity

$u_{t h} \quad$ Theoretical flow velocity

$v_{n} \quad$ Velocity component of the particle normal to the fringes

We Weber Number

$W e_{a m b}$ Ambient Weber Number

$W e_{\text {coll }}$ Weber number for droplet collision

$X \quad$ Axial distance from nozzle 
$Y_{f} \quad$ Concentration profile

$z \quad$ Elevation 


\section{Table of contents}

Nomenclature $\quad$ xvii

List of figures $\quad$ xxvii

List of tables $\quad$ Xxxiii

1 Introduction 1

1.1 General context . . . . . . . . . . . . . . . 1

1.2 Objectives and methodology . . . . . . . . . . . . . . 3

1.3 About this thesis . . . . . . . . . . . . . . . 5

2 Diesel injection systems, spray fundamentals and characterization $\begin{array}{ll}\text { techniques } & 7\end{array}$

2.1 Introduction . . . . . . . . . . . . . . . . . 7

2.2 Diesel injection systems f . . . . . . . . . . . . . . . 8

2.2 .1 Indirect injection systems . . . . . . . . . . . 10

2.2.2 Direct injection systems . . . . . . . . . . . . . . . 10

2.3 The common rail system . . . . . . . . . . . . . . . . . . . . . . . . . 12

2.4 The common rail injector . . . . . . . . . . . . . . . . 14

2.4.1 The solenoid actuated injector . . . . . . . . . . . 14

2.4.2 The piezoelectric actuated injector . . . . . . . . . 17

2.5 Internal Flow . . . . . . . . . . . . . . . . . . . . . . . . 19

2.5.1 Nozzle morphology . . . . . . . . . . . . . . . . . 19 
2.5.2 Nozzle orifice . . . . . . . . . . . . . . . . . . . 21

2.5.3 Characteristics of the flow and pressure losses . . . . . . . . 24

2.5.4 Hydraulic characterization . . . . . . . . . . . . . . . . . . 29

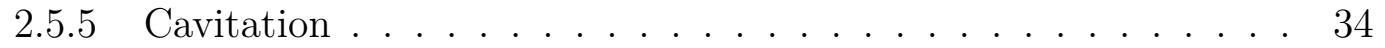

2.6 Diesel spray formation . . . . . . . . . . . . . . . . . . . . 36

2.6.1 Atomization and break-up processes . . . . . . . . . . . 38

2.7 Theoretical view of the diesel spray structure and its characteristics . . 48

2.7.1 Macroscopic characterization . . . . . . . . . . . . . 48

2.7.2 Microscopic characterization . . . . . . . . . . . . 55

3 Literature review $\quad 61$

3.1 Introduction . . . . . . . . . . . . . . . . . . 61

3.2 Overview of experimental macroscopic and microscopic characterization on diesel sprays . . . . . . . . . . . . . . . . . . . . . . . 61

3.2.1 Macroscopic technologies used for spray measurements . . . . . 62

3.2.2 Microscopic technologies used for spray measurements . . . . . . 69

3.3 Overview of experimental macroscopic and microscopic studies in diesel sprays at very high injection pressures . . . . . . . . . . . 73

3.4 Conclusions about the current state of knowledge . . . . . . . . . . . 75

4 Materials and methods $\quad 79$

4.1 Introduction . . . . . . . . . . . . . . . . . . . . . 79

4.2 Injection system . . . . . . . . . . . . . . . . . . . . . . . . 79

4.2 .1 Injectors . . . . . . . . . . . . . . . . 81

4.3 Mass flow measurement, methods and tools . . . . . . . . . . . . . 84

4.3.1 Signal treatment procedure . . . . . . . . . . . . 86

4.4 Test $\operatorname{rigs} \ldots \ldots \ldots \ldots \ldots$

4.4.1 High temperature and high pressure test rig . . . . . . . . . 89

4.4 .2 High density test rig . . . . . . . . . . . . . . . . . 93

4.5 Tools and methodology for macroscopic experiments . . . . . . . . . . . 93 
4.5.1 Schlieren technique and set-up . . . . . . . . . . . . 94

4.5.2 MIE-Scattering technique and set-up . . . . . . . . . . 98

4.5.3 Image processing . . . . . . . . . . . . . . . . . . . . . . . 99

4.5.4 Data averaging . . . . . . . . . . . . . . . 102

4.6 Tools and methodology for microscopic characterization experiments . . 102

4.6.1 PDPA system . . . . . . . . . . . . . . . . 102

5 Results and discussion: Internal flow 111

5.1 Introduction . . . . . . . . . . . . . . . . . . . 111

5.2 Injectors geometry characterization . . . . . . . . . . . . . . . 112

5.3 Rate of injection . . . . . . . . . . . . . . . . 113

5.3.1 Test plan definition . . . . . . . . . . . . . . . . 113

$5.3 .2 \quad$ Electric signal effect . . . . . . . . . . . . . . . . 114

5.3 .3 Multiple injections effect . . . . . . . . . . . . 116

5.3.4 Nozzle comparison and injectors behavior . . . . . . . . . . . . 118

5.3.5 Rail and ambient pressures influence on ROI . . . . . . . . . 123

5.3 .6 Injection duration study . . . . . . . . . . . . . . . . . . 123

5.4 Conclusions . . . . . . . . . . . . . . . . . . . 127

6 Results and discussion: Microscopic characterization 129

6.1 Introduction . . . . . . . . . . . . . . . . . . . . . . . . . 129

6.2 Test plan definition for PDPA measurements . . . . . . . . . . . . . 130

6.3 PDPA measurements setting . . . . . . . . . . . . . . . 131

6.4 Methodology for spray alignment and multi-hole injectors measurements 132

6.4.1 Methodology for spray of interest alignment . . . . . . . . . 135

6.4 .2 Preliminary measurements . . . . . . . . . . . . . . . 138

6.5 Fuel Droplet Size and Velocity Distribution . . . . . . . . . . . . . . . 138

6.5.1 Droplet velocities . . . . . . . . . . . . . . . 139

6.5.2 Droplet diameters . . . . . . . . . . . . . . . . . 142

6.5.3 Nozzle comparison . . . . . . . . . . . . . . . . . . . . . 147 
6.6 Conclusions . . . . . . . . . . . . . . . . . . . . . . . . . . 147

7 Results and discussion: Macroscopic characterization 151

7.1 Introduction . . . . . . . . . . . . . . . . . . . . 151

7.2 Spray development at isothermal conditions . . . . . . . . . . . 153

7.2 .1 Test Plan . . . . . . . . . . . . . . . . . . . . . . 154

7.2.2 Effect of ambient density and injection pressure on penetration and spray angle . . . . . . . . . . . . . . . 156

7.2.3 Effect of gas properties on penetration and spray angle . . . . . 159

7.3 Spray development at evaporative conditions . . . . . . . . . . . . 165

7.3 .1 Test Plan . . . . . . . . . . . . . . . 166

7.3.2 Effect of ambient density on evaporating diesel sprays . . . . . . 168

7.3.3 Effect of ambient temperature and injection pressure on vapor and liquid penetration . . . . . . . . . . . . . 169

7.3.4 Liquid length summary results . . . . . . . . . . . . . . . 171

7.3.5 Nozzle comparison . . . . . . . . . . . . . . . . . 174

7.4 Conclusions . . . . . . . . . . . . . . . . . . . 178

8 Conclusions and future work 183

8.1 Introduction . . . . . . . . . . . . . . . . . . 183

8.2 Summary and conclusions . . . . . . . . . . . . . . 183

8.3 Future works . . . . . . . . . . . . . . . . . . . 187

$\begin{array}{ll}\text { References } & 189\end{array}$ 


\section{List of figures}

2.1 Types of diesel injection systems . . . . . . . . . . . . . . 11

2.2 Components and layout of a typical common rail system . . . . . . . 13

2.3 Solenoid driven common-rail diesel injector . . . . . . . . . . . . . 15

2.4 Working principle of a solenoid driven diesel injector . . . . . . . . . 16

2.5 Piezo driven common-rail diesel injector . . . . . . . . . . . . . . . 17

2.6 Detail on the internal components of a Bosch CRI 3.1 piezoelectric driven injector . . . . . . . . . . . . . . . . . . . . . 18

2.7 Example of two different needle seat types . . . . . . . . . . . . . 20

2.8 Geometric parameters to define the orifice of an injector nozzle . . . . . 21

2.9 Typical nozzle hole geometries $[17] \ldots \ldots$. . . . . . . . . . 22

2.10 Variation of the maximum discharge coefficient with the length to

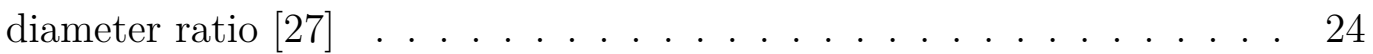

2.11 Schematic of the flow of a fluid through a pipe of variable section . . . 25

2.12 Inlet losses in an orifice from a deposit, in function of the rounding radius at the inlet of the orifice $(r)$ and its diameter $(D)$ for $R e>10^{4}$

2.13 Example of a typical discharge coefficient evolution as function of Reynolds number in the absence of cavitation [205] . . . . . . . . 31

2.14 Representation of the flow at the output orifice, (a) real flow, (b) simplified equivalent flow. $[205] \ldots \ldots$. . . . . . . . . . . . . . . . .

2.15 Representation of cavitation in an asymmetrical nozzle [52] . . . . . . . 34

2.16 Mass flow rate collapse at different rail pressures [205] . . . . . . . . 36 
2.17 Sample of the evolution of the discharge coefficient with respect to the square root of $\mathrm{K}[52,205] \ldots \ldots \ldots \ldots$

2.18 Structure of the diesel spray . . . . . . . . . . . . . . . . . . . 38

2.19 Macroscopic appearance of the diesel sprays of a 7-hole nozzle for different instants $\left(P_{i n j}=150 \mathrm{MPa}, \rho_{a}=25 \mathrm{~kg} / \mathrm{m}^{3}\right.$ and $\left.T_{a m b}=600 \mathrm{~K}\right) \ldots 39$

2.20 Atomization mechanisms at the nozzle exit $[17]$. . . . . . . . . . . . . 40

2.21 Dimensionless numbers and its relationship with spray atomization . . 41

2.22 Atomization regimes. B $\left(R e_{l}=790, W e_{a m b}=0: 06\right) ; \mathrm{C}\left(R e_{l}=5500\right.$, $\left.W e_{a m b}=2.7\right) ; \mathrm{D}\left(R e_{l}=16500, W e_{a m b}=24\right) ; \mathrm{E}\left(R e_{l}=28000, W e_{a m b}\right.$

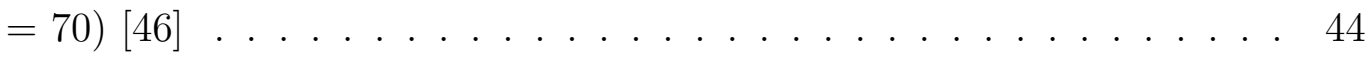

2.23 Drop-drop interaction $[17] \ldots \ldots \ldots \ldots$. . . . . . . . . . . 47

2.24 Map of coalescence modes . . . . . . . . . . . . . . . . . . . . 48

2.25 Spray penetration and spreading angle. . . . . . . . . . . . . . . . 49

2.26 Spray penetration and liquid length representation [14]. . . . . . . . . 54

3.1 Comparison DBI and MIE-Scattering optical arrangements [169] . . . . 65

4.1 Injection system used during internal characterization . . . . . . . . . 80

4.2 Solenoid signal f . . . . . . . . . . . . . . . . . . . 82

4.3 Piezo signal . . . . . . . . . . . . . . . . . . . . . . . . 82

4.4 Injector's signals variation with injection pressure . . . . . . . . . . . 83

4.5 Injection rate discharge curve indicator and its main parts [14] . . . . . 84

4.6 Mass flow rate estimation . . . . . . . . . . . . . . . 87

4.7 High temperature and high pressure test rig . . . . . . . . . . . . . . . 90

4.8 Sketch of the facility layout (High temperature and high pressure test rig). . . . . . . . . . . . . . . . . . . 91

4.9 High density test rig . . . . . . . . . . . . . . . . . . . . 94

4.10 Schlieren principle . . . . . . . . . . . . . . . . . . . 95

4.11 Schlieren optical arrangement . . . . . . . . . . . . . . . . . . . 96

4.12 MIE-Scattering optical arrangement for evaporative tests . . . . . . . . 99 
4.13 MIE-Scattering optical arrangement for non-evaporative tests . . . . 100

4.14 PDPA working principle . . . . . . . . . . . . . . . 103

4.15 PDPA signal processing . . . . . . . . . . . . . . . . . 104

4.16 The relationship between the phase difference and the droplet size . . . 106

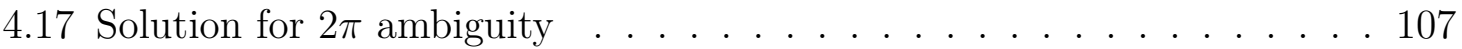

4.18 PDPA equipment, laser and Bragg cell . . . . . . . . . . . . . . . 107

5.1 Optical microscopy images of the three nozzle outlet orifices. . . . . . . 112

5.2 Strategy for opening angle estimation . . . . . . . . . . . . . . . . . . 114

5.3 Electric signal effect in the ROI signal, $P i n j=100 \mathrm{MPa}, P_{b a c k}=0.5$ $\mathrm{MPa}, \mathrm{ET}=1000 \mu \mathrm{s} \ldots \ldots \ldots \ldots$

5.4 Effect of increasing dwell time. Single injection (red) comparison with same ET in post injections (wine red) . . . . . . . . . . . . 117

5.5 Effect of increasing Pilot injection time. Single injection (red) comparison with same ET in post injections (wine red) . . . . . . . . . . . 119

5.6 ROI signals for the injectors, $\mathrm{ET}=500 \mu s . \quad \ldots \ldots \ldots$

5.7 Steady rate of injection as a function of the pressure drop across the

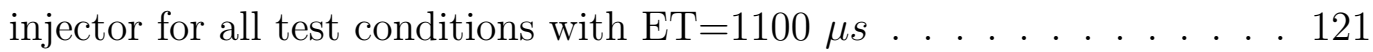

5.8 Discharge coefficients as a function of the pressure drop across the

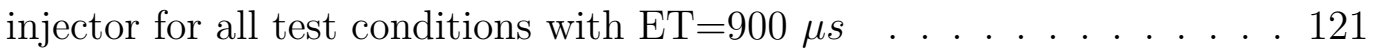

5.9 Shot-to-shot standard deviation from all test conditions and all injectors 122

5.10 Injection rate signals measured for the three nozzles, Injection pressure effect. . . . . . . . . . . . . . . . . . . 124

5.11 Injection rate signals measured for the CRI2-18 and CRI2-22 nozzles, ambient pressure effect. . . . . . . . . . . . . . . 125

5.12 Injection rate signals measured for the three nozzles, ET effect. . . . . . 126

6.1 Test plan positions for PDPA measurements on CRI3-27 piezo injector 132

6.2 Multi-hole diesel injector assembled in the test rig . . . . . . . . . . . 133 
6.3 Device for spray isolation (a) Device 3d view (b) Upper view with sprays (c) Upper view without the top cover. . . . . . . . . . . . . . . . . . 135

6.4 Designed bottom cover of the test rig. (a) Bottom cover of the test rig assembled with the injector (b) Bottom cover dimensions (c) Bottom cover dimensions, D-D View (d) Test rig assembly with the injector. . . 136

6.5 Centroid-Origin angle calculation for each repetition . . . . . . . . . 137

6.6 MIE- Scattering images acquired with the fast camera (a) Image at high exposure time of the spray and laser beams (b) Instantaneous contours used to calculate centroids. . . . . . . . . . . . . . . . . 138

6.7 Preliminary measurements, time-resolved evolution droplets velocities . 139

6.8 Transient velocity profiles $\rho_{a}=25 \mathrm{~kg} / \mathrm{m}^{3} \ldots \ldots \ldots \ldots$. . . . . . 140

6.9 Radial velocity profiles $\rho_{a}=25 \mathrm{~kg} / \mathrm{m}^{3}$. . . . . . . . . . . . . . . 142

6.10 Adimensional Radial velocity profiles with fitted theoretical profile $\rho_{a}=$ $25 \mathrm{~kg} / \mathrm{m}^{3}$.

6.11 Transient droplet diameter profiles $\rho_{a}=25 \mathrm{~kg} / \mathrm{m}^{3}$. . . . . . . . . . . 144

6.12 Radial droplet diameter profiles $\rho_{a}=25 \mathrm{~kg} / \mathrm{m}^{3}$. . . . . . . . . . . . 145

6.13 Axial droplet diameter profiles $\rho_{a}=25 \mathrm{~kg} / \mathrm{m}^{3}$. . . . . . . . . . . . 146

6.14 SMD trends injector comparison at several positions away from the nozzle.148

7.1 Raw data from visualization . . . . . . . . . . . . . . . . . . . . 152

7.2 Spray evolution captured by the MIE-scattering technique, $P i n j=90 \mathrm{MPa}$,

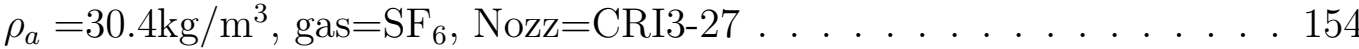

7.3 Effect of ambient density and injection pressure over spray penetration, Nozz $=$ CRI3-27 . . . . . . . . . . . . . . . . 156

7.4 Spray angle variation with $\rho_{a}$ and Pinj, Nozz=CRI3-27 . . . . . . . 157

7.5 Effect of gas properties on macroscopic characteristics of the spray, $\mathrm{Nozz}=\mathrm{CRI} 3-27 \ldots \ldots \ldots \ldots 1 . \ldots \ldots 1 \ldots \ldots \ldots$

7.6 Effect of gas properties on spray angle . . . . . . . . . . . . . . . 163

7.7 Experimental penetration versus predicted penetration by equation 7.2 considering exponents of tables 7.3 and $7.6 \ldots \ldots . \ldots 166$ 
7.8 Evaporative spray evolution (left) MIE-Scattering measurements, (right) Schlieren. $\rho_{a}=35 \mathrm{~kg} / \mathrm{m}^{3}$ Pinj=150MPa, T=800K, nozz=CRI2-18 . . . 167

7.9 Effect of ambient pressure on evaporative sprays, (Solid line) Schlieren (dashline) MIE-Scattering . . . . . . . . . . . . . . . 169

7.10 Effect of temperature and Pinj on evaporative spray, penetration(Solid line) Schlieren (dashline) MIE-Scattering . . . . . . . . . . . . . . 170

7.11 Effect of ambient temperature and Pinj on spray cone angle, Nozz=CRI2-22171

7.12 Compendium of $L L_{v}$ for all evaporative test carried out in all injectors 172

7.13 Experimental $L L_{v}$ versus predicted $L L_{v}$ by equation 7.3 considering exponents of table $7.8 \ldots \ldots \ldots 74$

7.14 Nozzle comparison, liquid and vapor penetration, (Solid line) Schlieren (dashline) MIE-Scattering . . . . . . . . . . . . . . 175

7.15 Shot to shot dispersion comparison for all injectors . . . . . . . . . 176

7.16 Spray to spray dispersion comparison for all injectors . . . . . . . . . . 177 



\section{List of tables}

2.1 Typical values for the geometrical and operating parameters in diesel injection nozzle orifices. . . . . . . . . . . . . . . . . . . . . 22

2.2 Typical $C_{d}$ expressions used in the literature . . . . . . . . . . . . 32

2.3 Definition of the transition between atomization regimes, for different

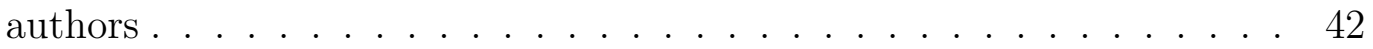

2.4 Breakup regimes of a single droplet $[171] \ldots \ldots$. . . . . . . . . . 46

2.5 Expressions used in the literature for spray penetration. . . . . . . . . . 51

2.6 Typical parameters and exponents used to estimate the spray penetration

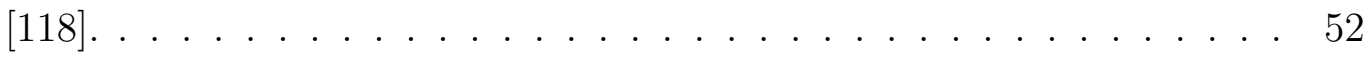

2.7 Definitions of mean diameters according to Mugele and Evans [116]. . . 56

4.1 Fuel utilized and its properties at $313 \mathrm{~K}$ and $101 \mathrm{kPa}$, all properties were extracted from the NIST Chemistry WebBook [94] . . . . . . . . 81

4.2 Constants for speed of sound correlation. . . . . . . . . . . . . . . . 85

4.3 Details of the optical setup and devices employed in the Schlieren arrangement. ............................ 97

4.4 Details of the optical setup and devices employed in the MIE-Scattering arrangement. ...................... 100

5.1 Injector hardware utilized and nominal nozzle geometries. . . . . . . . 113

5.2 Experimental conditions for the hydraulic characterization. . . . . . . . 115

6.1 Experimental conditions for the microscopic characterization. . . . . . . 131 
6.2 PDPA system software parameters . . . . . . . . . . . . . . . 133

7.1 Speed of sound of gases used in non-evaporative measurements at 293K .153

7.2 Experimental conditions for isothermal sprays. . . . . . . . . . . . 155

7.3 Typical parameters for penetration and exponents estimated from inert tests $\mathrm{SF}_{6} \ldots \ldots \ldots \ldots \ldots \ldots \ldots \ldots$

7.4 Typical parameters for penetration and exponents estimated from inert tests in $\mathrm{SF}_{6}$ without very high injection pressures. . . . . . . . . . . . 159

7.5 Penetration variations with ambient density and gas properties. . . . . 162

7.6 Typical parameters for penetration and exponents estimated from inert tests $\mathrm{CO}_{2}$ and $\mathrm{N}_{2} \ldots \ldots \ldots \ldots \ldots$. . . . . . . . . . . . . . . . . . . .

7.7 Experimental conditions for evaporative measurements. . . . . . . . . . 168

7.8 Exponents estimated from evaporative tests for $L L_{v}$ correlation. . . . . 173 


\section{Chapter 1}

\section{Introduction}

\subsection{General context}

Diesel engines have unquestionably strong points in terms of efficiency, reliability and adaptability. The applications of this kind of engine are spread over many fields (naval, electric generator, agriculture etc.), the automotive industry is one of the sector which boosted the most its development [27]. From the efficiency point of view in transportation sector, compression ignition engines are the best alternative compared to Otto engines, since they have a thermal cycle of higher efficiency. Because of the competitive market, together with the stringent emissions regulations imposed by the governments [61], engines have experienced several improvements throughout the industrialization history, being nowadays one of the most efficient combustion engines [61].

In the quest of improving the diesel engine performance and efficiency it is clear that a great effort should be focused on the injection process. These improvements can only be made if there is a fully and detailed understanding of all the processes implicated with the fuel mixture, evaporation and the subsequent combustion process. Multi-hole injectors have been employed in the present days in order to achieve a more homogeneous mixture and to decrease the droplet size and thus increase the liquid-gas contact surface [87]. For this reason, the use of multi-hole diesel injectors offers many 
advantages including a significant optimization of the combustion behavior and soot emissions [91]. Despite all these benefits, the spray atomization process behavior is not clearly identified for multi-hole injectors [1]. Accordingly, the characterization of multihole diesel injectors is still a topic of interest in the engine community [91, 143, 223].

Combustion efficiency and emissions are also greatly affected by the spray atomization process, and higher injection pressures have been considered to have great potential to improve fuel economy, produce better air-fuel mixtures, and lower exhaust emissions. Nowadays, injection pressures have risen from around $50 \mathrm{MPa}$ in the 70 's to around $250 \mathrm{MPa}$ and more in the present days. Super-high (250-300 MPa) or even ultra-high (>300 MPa) injection pressures may be realized in the near future [143].

Numerous studies, both theoretical and experimental, have been historically carried out in order to increase the knowledge about the injection phenomenon. These studies have paid attention to different features of the injection system. Thereby, the influence of the injector geometry (both in terms of internal ducts and nozzle orifices) on the internal flow characteristics, spray formation and fuel atomization has been deeply analysed [134, 186, 198, 209]. Currently, the primary and long term objective for researchers is to develop accurate predictive models capable of describing the injection/combustion event, with the aim of replacing (or at least reducing) the experimental practice with numeric simulation or analytical models. In the research applied to direct injection diesel engines, two main approaches can be identified:

- Engine research, oriented to the understanding of the injection combustion within the engine;

- Fundamental study, oriented to the study of the spray in simplified environments.

In the first approach, the tests are performed in real diesel engines with only slight modifications to gain optical access or to introduce specific probes: the results have immediate impact on the decisions to take during the engine calibration, since all the 
relevant phenomena are considered in the experiment. However, in this approach, the boundary conditions that remain unknown and somehow uncontrolled are many, for example, turbulence levels of incoming air.

In the fundamental studies the main objective is to investigate each single process in order to gain knowledge and control on it, for example studying the spray development avoiding the combustion, or the fuel atomization avoiding the opening and closing transient. Usually purpose-designed facilities are used to this end, these also have the fundamental advantage of being endowed with large optical accesses that simplify the implementation of the diagnostics. This second approach, therefore, is more oriented to the fundamental understanding of the process and the results provided have generally a more general extent $[14,130,163,193]$. The work developed in the present thesis follows this second approach.

\subsection{Objectives and methodology}

The present thesis was born from the requirement from Jaguar Land Rover to evaluate the behavior of diesel spray characteristics and injector features under very high injection pressures. Three injectors were supplied by the company, two solenoid- (CRI2-18, CRI2-22) and one piezo-actuated (CRI3-27) injectors. The solenoid actuated injectors were able to reach injection pressures up to $180 \mathrm{MPa}$ and $220 \mathrm{MPa}$ respectively, whilst the piezo injector up to 270MPa. The purpose of this thesis is to expand the knowledge and understanding of the phenomena related to the processes of injection and formation of air-fuel mixture, which take place within a diesel combustion chamber, making both macroscopic and microscopic characterizations of the diesel spray in non-reactive conditions, at low and very high injection pressures using multi-hole nozzles. The general objectives of the present thesis are summarized in the two following: 
Because of the nobility of using such high injection pressures in the department, it is important to reach the state of art of diesel injection systems and make improvements in the facilities in order to satisfy safety conditions and satisfactory measurements. This objective can be divided in several sub-objectives.

- Compilation of technical literature on diesel injection from the early state to the modern studies to acquire a global vision of the research topic.

- Reach the technical know-how to use and control and set-up the new hardware (multi-hole diesel injectors).

- Design of the equipment and study of new methodologies to perform the required experiments to obtain the desired data.

And the second objective, is to acquire experimental data using state of the art equipment and experimental techniques, in order to gather a large database with the purpose of expanding the knowledge of diesel sprays at conditions never tested before. And thus, contributing to the current understanding of the effects of the injection pressure over the diesel spray development, and over its macro and micro characteristics. This is carried out by collecting and performing extensive data and experimental analyses, respectively. This objective can also be divided in several sub-objectives:

- To carry out an external macroscopic characterization of the diesel injectors under evaporative and non-evaporative conditions by means of different spray visualization techniques.

- To carry out external microscopic characterization of diesel injectors under non-evaporative conditions using the PDPA technique.

- To analyze the different parameters that characterize the diesel spray (mass flow rate, liquid and vapor penetration, velocity and diameter of the droplets) for the three injectors. 
- To estimate the effect of different ambient gases on the macroscopic behavior on the diesel spray under non evaporative conditions.

\subsection{About this thesis}

The document is separated into 8 chapters including the present introduction (Chapter 1 ). In the second chapter, the injection process is discussed in the context of diesel engine and the critical requirement are presented together with trends and technological development. Finally, the macro and micro characteristics of the diesel spray are described. As mentioned earlier, this work focuses on the fundamental study of the injection process: Chapter 3 describes the theoretical background that represents the starting point of this work, and serves as a reference for the interpretation of the results obtained. To this end, the different characteristics taking place in the fuel injection are described including the flow through the nozzle, the liquid atomization and evaporation process. Expected trends for these parameters are stand out at low, high and very high injection pressures. Finally, the studies found in literature about the effect of very high injection pressures over the diesel spray are presented in a brief review.

The fourth chapter illustrates the experimental methodology followed and the equipment used in this work. The experiments performed are presented in detail. On one side outlining the physical principles behind the measurements. On the other side, describing the specific measurements performed, discussing the hardware, the processing techniques and the information made available by each experiment.

Chapters 5, 6 and 7 are devoted to the presentation of the experimental results. The fifth chapter presents all the results obtained for internal flow and the geometrical characterization of the injectors. Chapter six encompass the results obtained when studying the spray from a microscopic point of view at isothermal conditions: velocity and SMD trends are obtained and some empirical equations are estimated in other 
to probe its representativeness along the whole test plan. In the chapter seventh, the spray is studied from a macroscopic point of view, the liquid- and vapor-phase spray boundaries in isothermal and evaporative conditions are estimated and correlations of their behavior at different injection pressures and at gas properties variations.

The last chapter (Chapter 8) draws the main conclusions of this thesis contrasting all the new information brought and indicating the possible directions in which to orient to future studies. 


\section{Chapter 2}

\section{Diesel injection systems, spray}

\section{fundamentals and characterization techniques}

\section{$2.1 \quad$ Introduction}

One of the biggest goals during the last decade of the researchers dedicated to the automotive sector, was to reduce the fuel consumption and pollutant emissions produced by diesel engines [207]. Nonetheless, increasing concerns in pollutant emissions demand a critical and detailed evaluation of the combustion process, which is largely influenced by fuel-air mixing $[155,156]$. In order to improve the efficiency and performance of diesel engines, it becomes obvious that a great effort must be devoted to the fuel injection process, which is primarily responsible for the occurrence of a proper mixture between air and fuel inside the combustion chamber. Furthermore, the injection pressure is one of the most influential parameters in the pulverization of the fuel and thus in the homogeneity of the air-fuel mixture [35]. This leads to a continued interest of the automotive industry in increasing injection pressures in diesel systems. For this reason, characterizations of the injection process, at very high injection pressures, are necessary to evaluate their effect on emissions, efficiency and design of future 
automobiles.

There are two ways to characterize the diesel spray. From the macroscopic point of view, there are specific parameters to characterize the diesel spray: the liquid and vapor penetration, and the spreading angle. The liquid penetration is a clear indicator of the evaporation capacity of the fuel used. On the other hand, the vapor penetration is indicative of the mixing process and the probability of collision with the walls of the combustion chamber. The CMT-Motores Térmicos laboratory has managed to develop facilities and methodologies that allow estimating these parameters. Several studies exemplify the quality of the results obtained in its facilities. [132, 141]. Amongst the various optical techniques that are implemented at CMT laboratories, MIE-Scattering and Schlieren stand out when it comes to obtaining liquid and vapor penetration.

From a microscopic point of view, to measure the size of droplets and its velocities, in dense jets such as diesel spray and under non-evaporative conditions, requires techniques such as PDPA (Phase Doppler Particle Analyzer). This technique has several advantages; it does not require a calibration, it is a non-intrusive technique that does not affect the dynamics of the jet and the noise from these measurements can be eliminated correctly.

In this chapter all the techniques used in this thesis are presented together with the main parameters used for describing diesel sprays. Also some of the models used for predicting the spray development are presented from literature. These were developed for several conditions with injection pressures up to $200 \mathrm{MPa}$, but are expected to work with other critical conditions like very high injection pressures up to $270 \mathrm{MPa}$.

\subsection{Diesel injection systems}

The injection system in a diesel engine is responsible for the fuel supply within the combustion chamber. The injected diesel is the result of the pressure difference on both sides of the nozzle orifices. The basic tasks of this system are: first, to introduce the right amount of fuel following the mass flow rate law, which determines the behavior 
of the different combustion phases. Second, to atomize the fuel to increase its surface interaction with the hot air, enhancing evaporation after the compression stroke. And finally, to mix the fuel with the surrounding air inside the combustion chamber.

When analyzing these systems the following aspects must be taken into account:

- The combustion requires the fuel to be in a gas phase. The atomization must be as fast as possible to enhance the evaporation process, this will increase the surface interaction between fuel and the air.

- The mixture between the air and the evaporated fuel should be fast and efficient as possible.

- The injection process must be fast and synchronized with the piston movement.

In diesel injection systems, two main parts can be distinguished. The low pressure stage (from atmospheric conditions to $0.3 \mathrm{MPa}$ ) and the high pressure stage (from 10 up to $270 \mathrm{MPa}$, depending of the engine operating point). The main devices in the low pressure stage are:

1. Fuel deposit: Where the fuel is stored, connected directly with the low pressure pump.

2. Fuel filters: Intended to remove impurities and solid particles from the fuel.

3. Feeding or low pressure pump: generally placed in the fuel tank, this provides the high pressure pump mechanically connected to the engine with the fuel.

4. Pressure regulator: limits the pressure of the output line of the low pressure pump.

5. Low pressure lines.

The required pressure for the injection process, is generated through a high pressure circuit. Depending on how the fuel is injected during the engine cycle, the high pressure 
configuration will vary. This injection strategy could be classified as direct or indirect. In indirect injection the quality of the injected spray is not as important as it is in direct injection engines, that is why the injection pressures are relatively low (around 20 to $40 \mathrm{MPa})$.

\subsubsection{Indirect injection systems}

Two main parts can be distinguished in these configurations, the pre-combustion chamber and the main chamber. A small duct between the two chambers allow to increase turbulence in the air entrained during the compression stage of the 4-stroke cycle, which enhances the air-fuel mixture. The fuel is injected through a single-hole nozzle in the pre-combustion chamber, once the fuel come into contact with the surrounding air, an incomplete combustion is produced within this chamber. The high temperatures and pressures resulted from this primary combustion promote the mix and full evaporation of the unburnt fuel. Subsequently, the main ignition appears when the thermodynamical conditions are reached, and the complete combustion occurs in the main chamber where the output power is delivered.

As shown in figure 2.1a, the pre-combustion chamber is located in the cylinder head. With this geometry, the fuel is injected tangentially to the surface of the pre-combustion chamber which increase the turbulent behavior of the air-fuel mixture. Its lower thermal efficiency, high NOx emissions, noise, pressure losses and low performance in general compared with direct injection engines, have provoked the indirect injection technology to become obsolete and it is only employed for specific uses.

\subsubsection{Direct injection systems}

In direct injection systems (DI) the fuel is directly injected into de combustion chamber (figure 2.1b). Hence, the fuel is responsible for generating the mixture. To this end, the fuel must be injected at high pressure and properly atomized and spread. The 


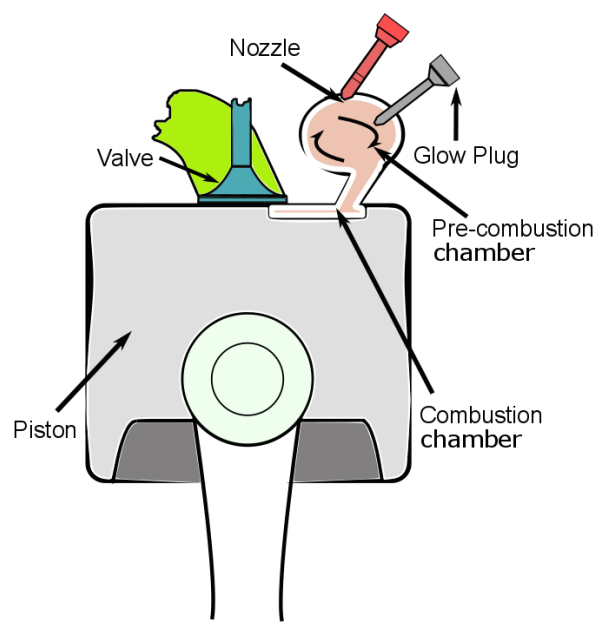

(a) Schematic of indirect injection system.

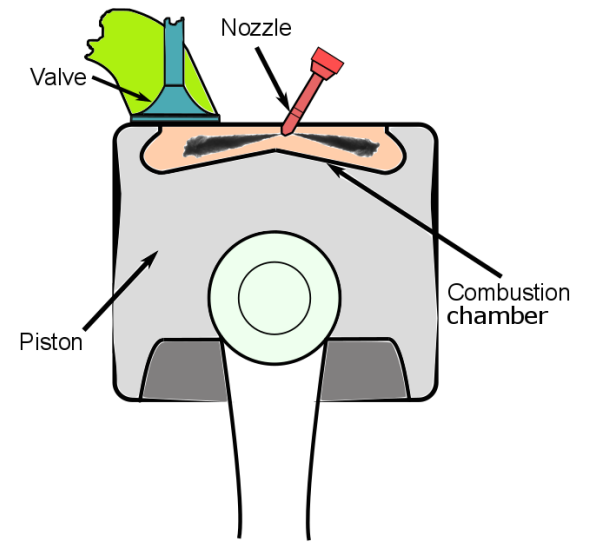

(b) Schematic of direct injection system.

Fig. 2.1 Types of diesel injection systems

need for a high quality injection system in response to these demands becomes evident. In DI systems, the injectors are more complex and make use of multi-hole nozzles with orifice diameters around $100 \mu \mathrm{m}$ and very high injection pressures, even greater than $270 \mathrm{MPa}$. Since there is not a pre-combustion chamber, all the implicit drawbacks of the indirect systems are reduced or eliminated.

In the past, the engines using direct injection were govern by mechanical assemblies, the high pressure pump was in charge of metering the exact fuel quantity to inject with the correct timing. The start of injection in these mechanical systems depended mainly in the pressure of the injector, which counteracts the force of a preloaded spring inside of it.

A brief description of the most common DI systems used for CI engines are listed bellow:

- Rotary pump: The only function of the injector in these systems merely consisted on the fuel atomization. A high pressure pump is in charged of delivering the fuel to the injector. In consequence, one of the main problems is the impossibility of neither regulating the injection pressure adequately nor keeping it constant along the process, since in this case, it depends on the pump speed. 
- Unit injector: In this configuration, the pump and the injector are included in the same device, placed at the cylinder head. The pump plunger is usually driven by the camshaft. The start of injection (SOI) and the injection duration are controlled by means of a solenoid valve placed inside each injector. The main advantages of this kind of systems are the possibility to electronically control the system through the Electronic Control Unit (ECU) and the high injection pressures reached.

- Unit pump: This system is a variant of the "Unit injector", The most significant difference is, that the pump and the injector are connected through a short high pressure line. As the previous system, the injection is controlled electronically by means of a solenoid valve, but in this case placed in the pump.

Because of the requirements of the governments regarding pollutant emissions and due to the adversities faced with mechanical systems, and together with technological advances, a new concept of diesel injection system arose, denominated common rail [14].

\subsection{The common rail system}

The common rail is the most employed injection system in diesel engines. In fact, at the current state of maturity, it is the system that matches the most of the requirements of the automotive market [21].

The figure 2.2 shows the configuration of a common rail system. Two circuits can be distinguished, the low pressure circuit (composed by the fuel tank, low pressure pump, pipes and filter) and the high pressure circuit (composed by the high pressure pump, the rail, the pressure regulator, the high pressure lines and the injectors)

The low-pressure pump, generally located in the fuel tank, supplies the fuel to the high-pressure pump. A filter is placed between the two pumps in order to remove any impurities and water traces that could damage the other components, especially the 


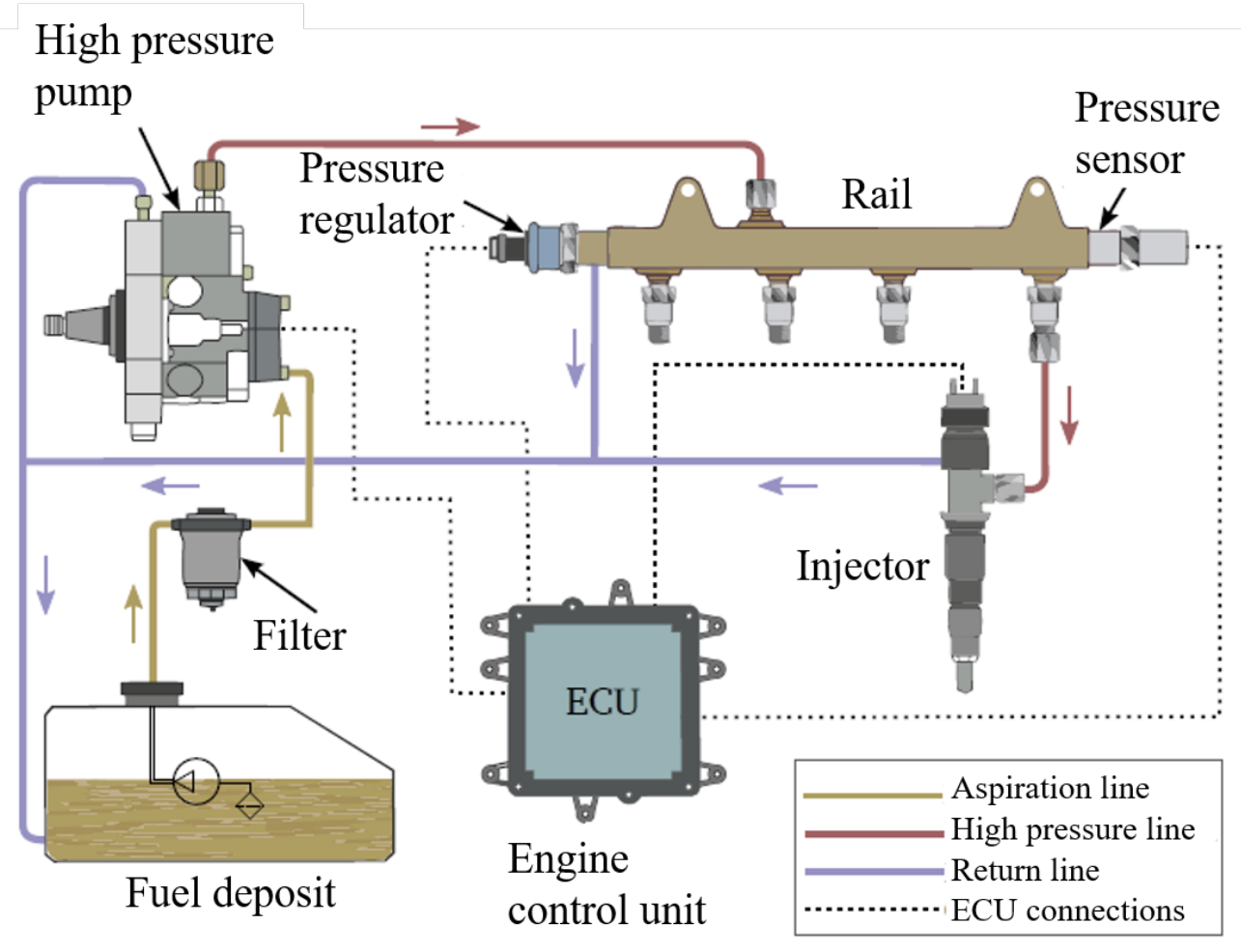

Fig. 2.2 Components and layout of a typical common rail system

high pressure pump (where the water could cause corrosion) and the injectors (whose nozzle orifices could be blocked).

The high pressure pump, which is mechanically connected to the engine, provides a certain fuel mass flow rate abundantly higher than the average fuel mass flow rate required by the engine. Usually, a radial type is used for small and fast engines. On the contrary, linear pumps are generally used for bigger engined vehicles. The radial pump presents the advantage of being compact while producing high pressure with a regulated flow rate, thus being efficient as it adapts itself to the engine's demand.

The fuel flow is directed to the rail and the high pressure pump pressurizes the fuel for the common rail. Then, the common rail distributes the fuel to the injectors thanks to the high pressure lines. Most of the fuel entering the injectors is directly injected into the combustion chamber of each engine cylinder, whereas a small portion is used to hydraulically control the injector opening and closing, this fuel is then returned to 
the fuel tank after the injection event. The injectors are actuated independently by the engine control unit (ECU).

A flow valve controlled by a pressure sensor regulates the pressure of the fuel inside the rail. In this manner, if the pressure is higher than the desired value, the valve opens redirecting the part of the fuel that is not injected back to the fuel tank. On the contrary, if the rail pressure is lower than expected value, the flow valve remains closed so that the pressure is raised thanks to the arrival of new fuel from the pump.

The rail acts as an accumulator and ensure only small variations of the injection pressure along the cycle in which up to seven injections can be performed. In this technology, the pressure in the injector does not govern the injection process directly but through an electronic command.

\subsection{The common rail injector}

Since the appearance of the common rail injection strategy, most efforts to improve its behavior are focused on the development of the injectors, which is the most complex device of these systems. With the latest advances, injectors have raised the maximum injection pressure limit up to $300 \mathrm{MPa}$, thus increasing the capability of delivering fuel in a short time and indirectly enhancing the air-fuel mixing efficiency [78]. Commonrail injectors may be classified in two big groups (depending on the actuator of the servo system), in solenoid or piezoelectric driven injectors. Their working principle is explained below.

\subsubsection{The solenoid actuated injector}

The elements composing a solenoid common rail injector are presented in the figure 2.3 and described below:

- Connecting rod: this part transfers the movement from the servo-actuated circuit to the nozzle needle. The top of needle pushes against the bottom part of this part. 
- Servo actuated system: This mechanism is composed by an solenoid actuator, a fuel valve and a control volume. This is the core of the injection and allows to generate the forces needed to move the needle effectively during the injection.

- Nozzle: In this element it is included also the needle, which has the function of controlling the fuel flow through the nozzle orifices. The injector nozzle generally has several orifices, (typically 5 to 10 in automotive applications). Multi-orifice injectors have been employed in the present days in order to achieve a more homogeneous mixture and to decrease the droplet size and thus increase the liquidgas contact surface [143]. For this reason, the use of multi-orifice diesel injectors offers many advantages including a significant optimization of the combustion behavior and soot emissions [115].

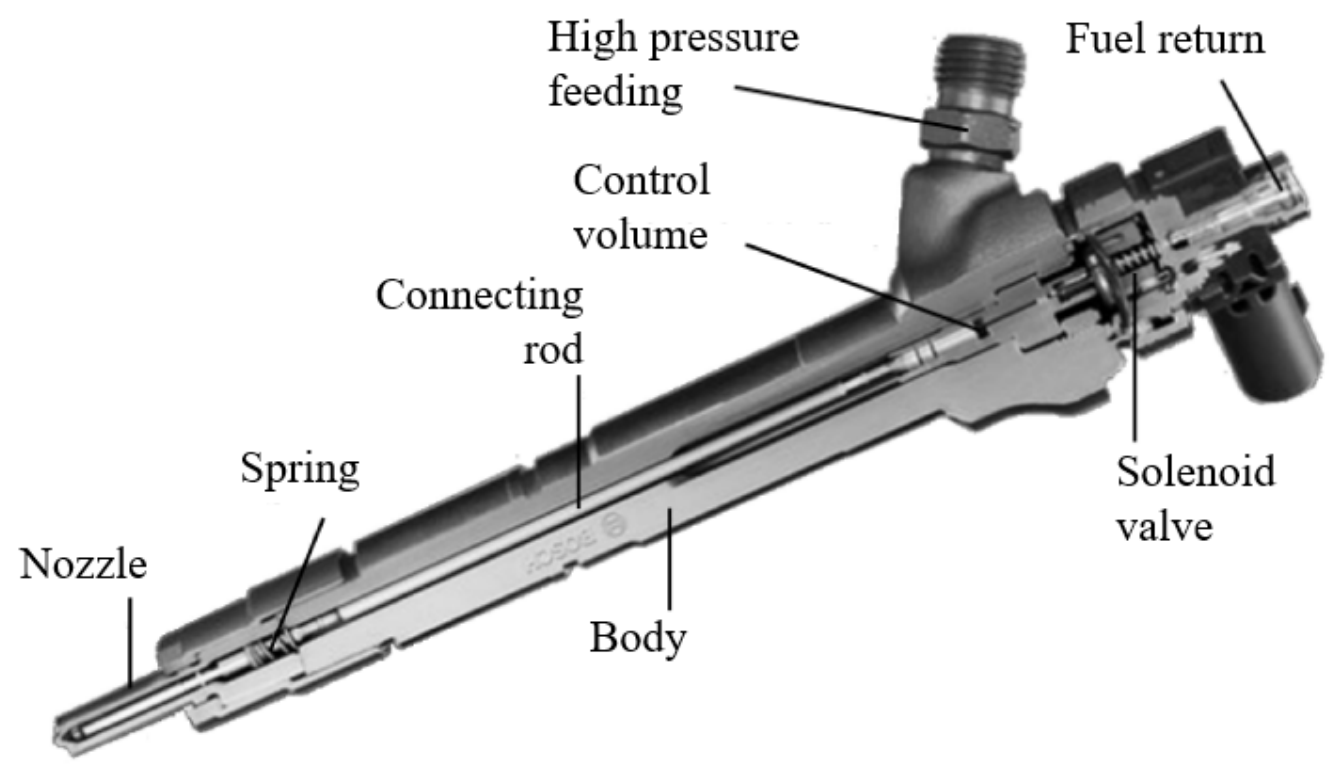

Fig. 2.3 Solenoid driven common-rail diesel injector

In these injectors the high pressured fuel coming from the rail, right after the entrance, is divided in two channels: one goes to the control volume and the another goes directly to the nozzle. The control volume, located at the top of the connecting rod, possess two calibrated orifices, the first one is connected to the injector entrance 
and the second one to the low pressure return line. The solenoid valve controls directly the flow that passes through the second channel.

During the rest condition of the solenoid (figure 2.4a), the small ball valve is closed and no flow can exit through the return line. In this case, the fuel pressure in the control volume is the same as the fuel pressure in the high pressure feeding line, considering that the area of the connecting rod is higher than that of the needle. This resultant force pushes the rod-needle toward the nozzle and in this way the orifices are blocked. Actually this position is conserved without pressure thanks to the pre-loaded spring.

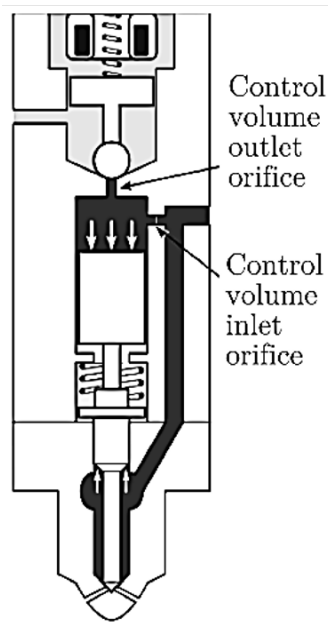

(a) Rest condition

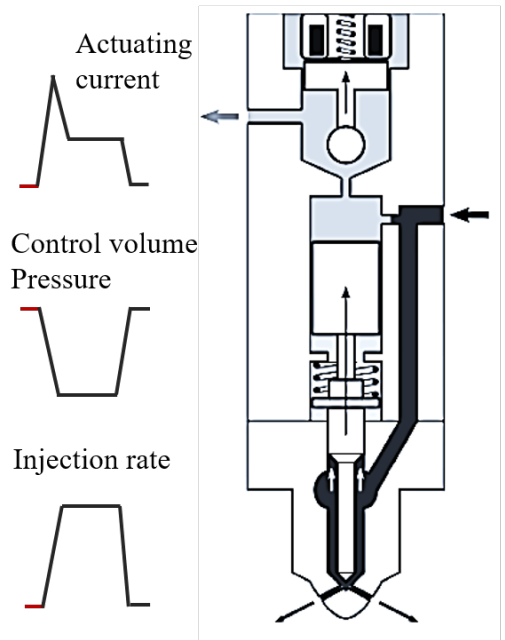

(b) Opening
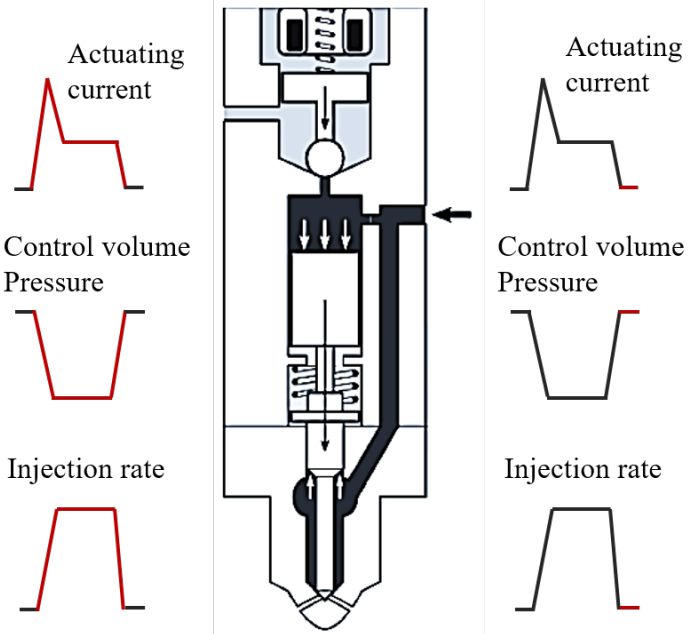

(c) Closing

Fig. 2.4 Working principle of a solenoid driven diesel injector

During the injection state (figure 2.4b), when the injection is requested, the ECU delivers an electric signal pulse to the injector. The duration of this pulse, usually called energizing time (ET), controls the injection time and, in this manner, the amount of injected mass. An ascending force is generated in the small ball valve by the intensity that goes through the solenoid coils. In this situation, the fuel flow evacuating the control volume induces a significant pressure drop in this region. For this reason, and knowing that the pressure at the lower part of the needle is the same as the high pressure feeding line, a resultant force drives the rod-needle set upwards. This action opens the nozzle and the injection begins (SOI). The injection remains until the 
solenoid is deactivated. Once the solenoid is deactivated (figure 2.4c), the flow through the outlet orifice of the control volume stops, causing the fuel pressure to rise again and leading the forces acting on the rod-needle system to the initial conditions. The needle is then pushed down until its seat blocking the fuel flow through the orifices, thus ending the injection.

\subsubsection{The piezoelectric actuated injector}

For the newer diesel injectors generations piezoelectric systems have become strong, offering: absence of attrition after millions of cycles, high accuracy (needle displacements of the order of magnitude of nanometers) and a better control for smaller injection timings, allowing faster action and potentially increasing the number of injections per cycle [108]. The figure 2.5 shows the main parts of a piezo driven diesel injector.

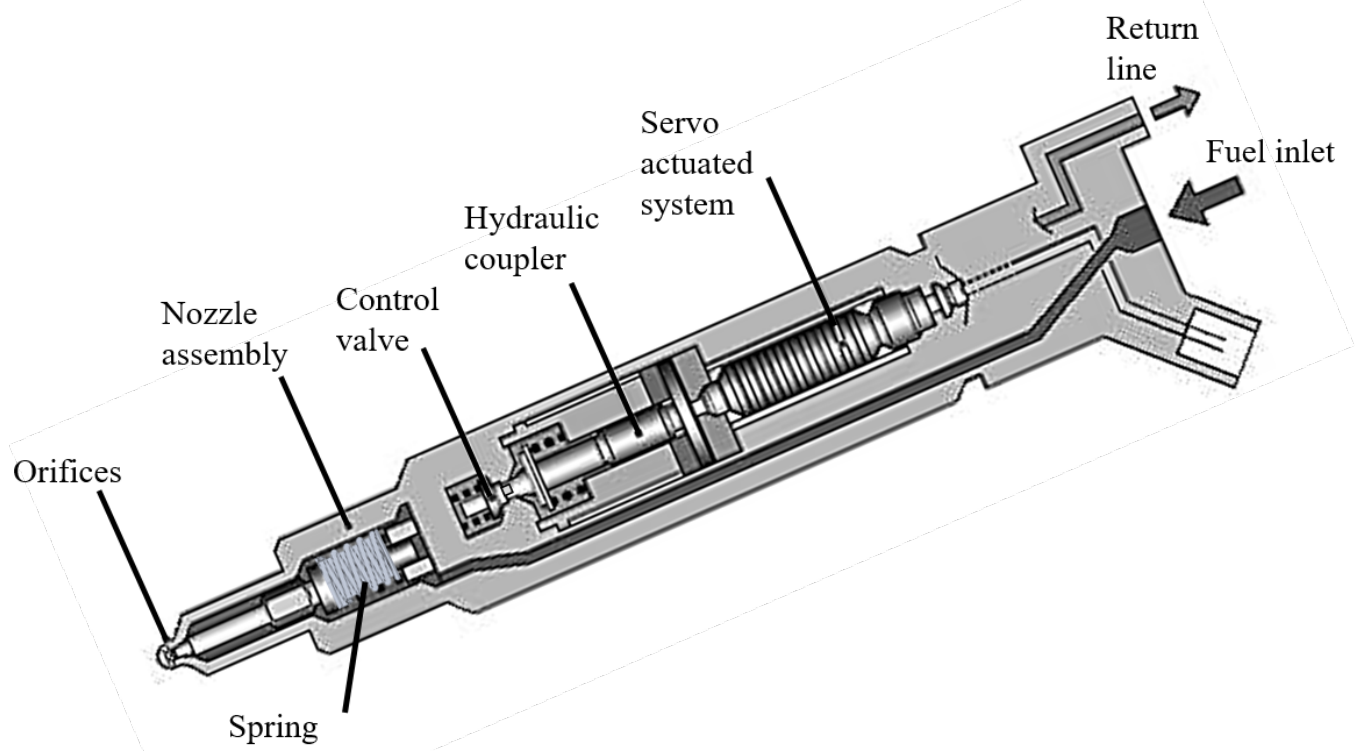

Fig. 2.5 Piezo driven common-rail diesel injector

The difference with these injectors resides in the opening of the control volume now performed by the deformation of a material with piezoelectric characteristics. In 
these injectors some of the mobile elements and the connecting rod are removed and replaced by this piezoelectric material, which is compressed or expanded in function of the applied electric field. In consequence, the control volume is placed directly over the needle, which improves the dynamic response of the injector and facilitates the introduction of multiple injection (up to eight consecutive injections) [52].

Piezoelectricity results from squeezing or applying pressure from certain crystal like materials or ceramics. If this process is reversed and electricity is applied to these same materials they will expand and return to their original size as soon as the electricity is cut off. The expansion of one crystal is too small to see with the naked eye, since the expansion of the piezocrystals is minuscule [89, 187].

In figure 2.6 the internal components of the piezo injector are shown in detail. Unlike the typical solenoid driven injector (which has two active orifices inside the control volume), the piezoelectric injector control volume has three orifices. One outlet and two inlet orifices, where the outlet orifice can also works as an inlet.

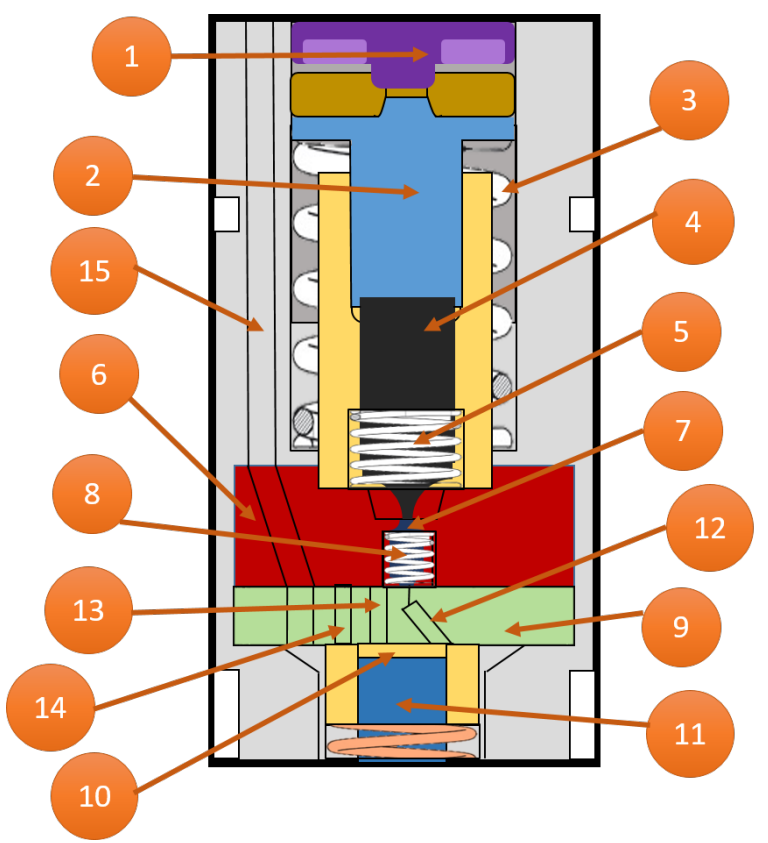

1. Piezoelectric actuator

2. Amplifier piston

3. Tube spring

4. Valve piston

5. Valve piston spring

6. Valve holder

7. Valve bolt

8. Valve spring

9. Control plate

10. Control volume

11. Needle

12. Bypass orifice

13. Inlet/Outlet orifice

14. Inlet orifice

15. Feed line

Fig. 2.6 Detail on the internal components of a Bosch CRI 3.1 piezoelectric driven injector

When the ECU sends the signal to the piezo-actuator, it expands and displaces the amplifier piston. This piston compresses the fuel located between the lower part and 
the upper part of the valve piston. The compression amplifies the vertical displacement of the command piston, causing the opening of the upper side of the control valve and closing the lower one, keeping the bypass orifice inactive. Once the upper side of the control valve is opened, the pressure downstream of the inlet/outlet orifice decreases so that the fuel at the control volume flows through it and also through the upper side of the valve bolt towards the return duct. The pressure drop in the control volume lifts the needle up, starting the injection event [27, 108].

When the ECU cuts off the signal, the piezo-actuator recovers its initial length thanks to the tube spring. The upper side of the valve bolt gets closed against its seat by the preloaded valve spring. The pressure in the control volume is then recovered as the fuel enters through the inlet and the inlet/oulet orifices, which becomes a new inlet orifice since it is connected to the now unlocked bypass orifice. The needle is therefore pushed back against its seat, blocking the nozzle orifices, thus cutting the injection $[27]$.

\subsection{Internal Flow}

After this brief description of the different injection systems and injectors typology, it is convenient to explore in depth all the processes taking place in the most critical part of the diesel injector, which is the nozzle [23, 89, 154]. An extensive work has been performed by Gimeno [52] on internal flow characterization and the objective of this section is to summarize and add recently published support to this work. A description of nozzle morphologies will be done and then the flow characteristics inside a diesel injector will be exposed.

\subsubsection{Nozzle morphology}

As it has been said before, one of the most important element during the injection process is the nozzle, its geometric features and functioning affect directly on the evolution and spray atomization $[20,83,137,140,149,200,205]$. Nowadays, two types 
of nozzles can be found; VCO (valve covered orifice) and regular sac. The last one has evolved in different typologies: minisac, microsac and even nanosac nozzles.

In the figure $2.7 \mathrm{a}$, it can be seen how VCO nozzles interrupt the injection by blocking the orifices directly. Small eccentricities in the needle movement for this kind of nozzles, produce considerable variations on the internal flow and also on sprays development, especially for small needle lifts [5, 12, 205]. However, one of its main advantages is that the fuel deliver is fast and accurate.

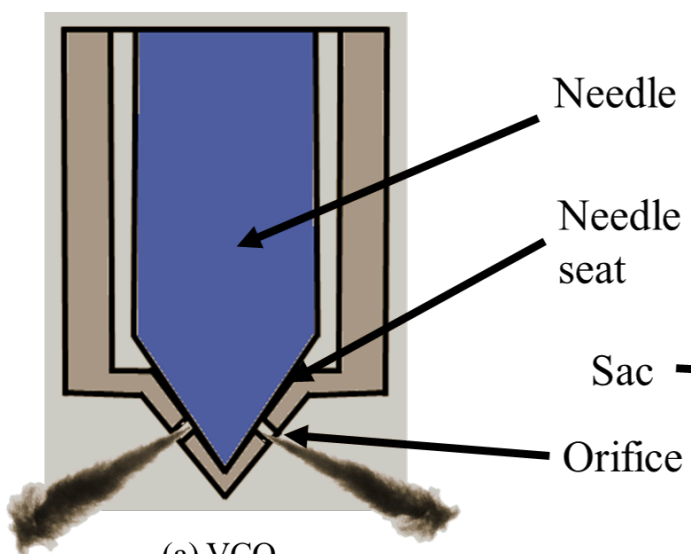

(a) $\mathrm{VCO}$

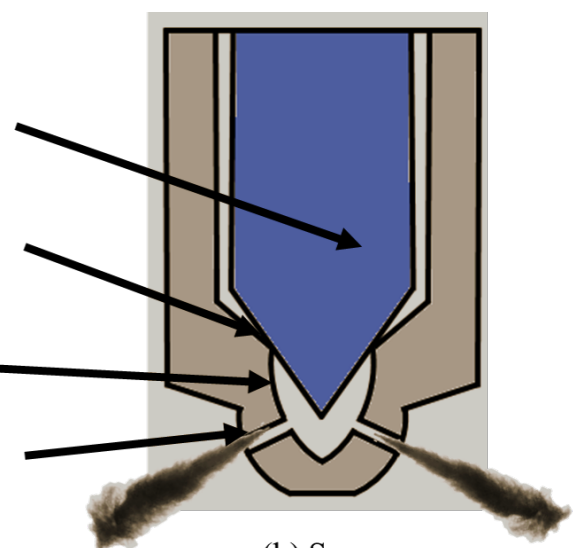

(b) Sac

Fig. 2.7 Example of two different needle seat types

For sac nozzles (figure 2.7b), the sealing of the needle is performed in a specific contact-area between needle and nozzle upstream of the orifices, while the orifices' inlet is placed in a specific volume called the sac. Within the sac, all possible variations in the internal flow caused by needle deformations are reduced, thanks to the backwater created between the needle and the sac. Its main disadvantage, is that the fuel stored within the sac can exit the nozzle even after the injection event has stopped, producing small and non-controlled combustions within the combustion chamber, therefore, increasing unburned hydrocarbons and soot.

Currently, microsacs nozzles are used to minimize the disadvantages of both nozzle typologies, delivering fuel in an accurate and fast way with low dispersion amongst orifices. 


\subsubsection{Nozzle orifice}

The nozzle orifices are where the potential energy generated by the pressure is converted into kinetic energy, by accelerating the flow that enters into the combustion chamber. As it has been said before, any microscopic feature in the orifices has a big repercussion in the diesel spray development, characteristics and, as a consequence, in the air-fuel mixing process.

In the figure 2.8 , the most important geometrical parameters of nozzle discharge orifices are defined: outlet and inlet holes ( $D_{o}$ and $D_{i}$ respectively), longitude $(L)$ and inlet rounding radius $\left(r_{e}\right)$. Typical values for the geometrical and operating parameters in diesel injection nozzle orifices are shown in table 2.1.

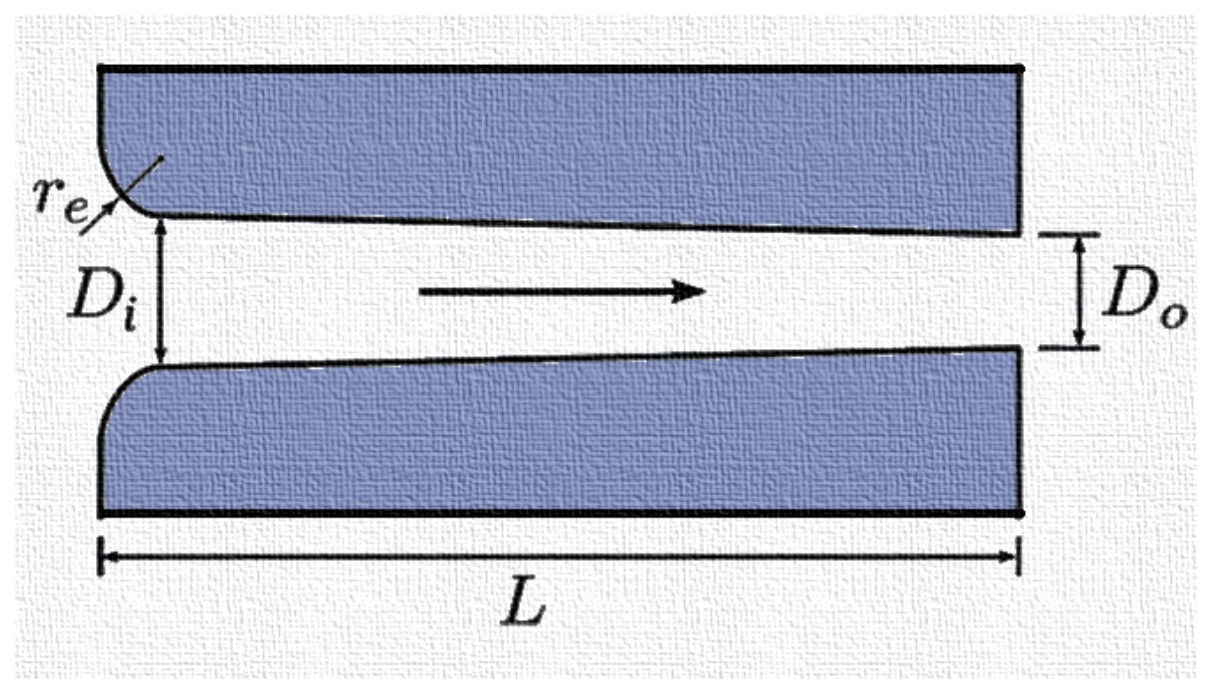

Fig. 2.8 Geometric parameters to define the orifice of an injector nozzle

Some relevant dimensionless parameters can be defined from the orifice dimensions so that any study involving nozzles can be generalized:

\section{Convergence}

The different nozzle hole geometries used today are shown in figure 2.9. The convergence expression or $k$ - factor (equation 2.1) [147], correlates both outlet and inlet sectional areas. In a convergent orifice, the inlet diameter is bigger than the outlet, this causes 


\begin{tabular}{lc}
\hline \hline Parameter & Typical value \\
\hline Area reduction $A R$ & $0-0.36$ \\
Orifice outlet diameter $\left(D_{o}\right)$ & $80-250 \mu \mathrm{m}$ \\
Inlet to outlet diameter ratio $\left(D_{i} / D_{o}\right)$ & $1-1.25$ \\
Length to outlet diameter ratio $\left(L / D_{o}\right)$ & $4-10$ \\
Orifice length $(L)$ & $0.6-1 \mathrm{~mm}$ \\
Rounding radius $\left(r_{e}\right)$ & $0-50 \mu \mathrm{m}$ \\
Number of orifices per nozzles & $5-12$ \\
Injection pressure $\left(P_{\text {inj }}\right)$ & $30-300 \mathrm{MPa}$ \\
Discharge pressure $\left(P_{b a c k}\right)$ & $3-9 \mathrm{MPa}$ \\
Flow outlet velocity $\left(u_{o}\right)$ & $150-600 \mathrm{~m} / \mathrm{s}$ \\
Reynolds number $(R e)$ & $6000-30000$ \\
\hline
\end{tabular}

Table 2.1 Typical values for the geometrical and operating parameters in diesel injection nozzle orifices.

an increase in velocity through the orifice. Convergence induces a higher pressure at the orifice inlet, leading to several consequences; the cavitation (explained with more detail later) is reduced as maximum for all conditions and also minor pressure losses are produced through the orifice, thus the mass flow rate is higher, as is the discharge coefficient [204].

$$
k-\text { factor }=\frac{D_{i}-D_{o}}{10[\mu m]}
$$

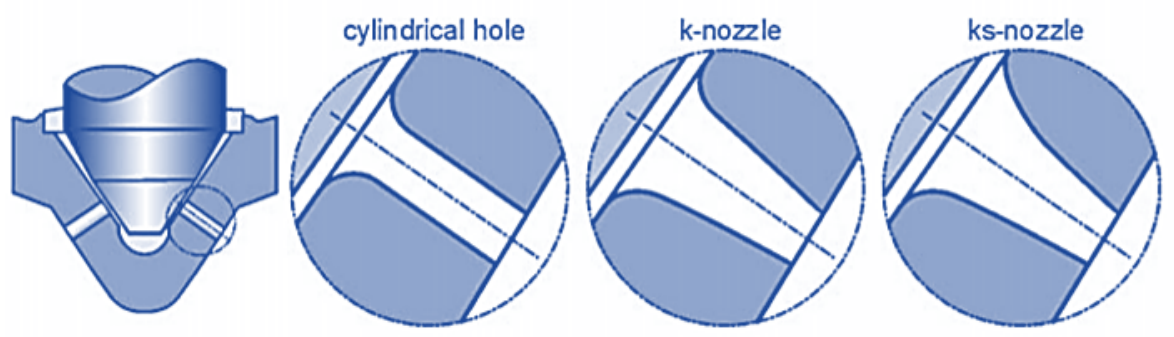

Fig. 2.9 Typical nozzle hole geometries [17] 
The main spray characteristics distinguishing the conical (k-nozzle) to the cylindrical nozzle can be summarized as follow $[25,105,131]$ :

- Improved spray stability thanks to the reduced cavitation intensity over the hole length.

- Reduced spray cone angle.

- Larger spray penetration.

Currently ks-nozzle geometries are been used in order to suppress cavitation completely. In these, the cross-sectional area depends on the distribution of mass flow. Furthermore, the conical hole shape is associated to a huge rounded edge at hole entrance obtained by a specifically designed hydro-grading (HG) process. The ks-hole design was studied to fulfill the following targets [25]:

- To increase the pressure/velocity conversion efficiency.

- To reduce the vapor generation at hole entrance by a reduction of the flow separation.

- To improve the k-nozzle benefit in reducing the Soot-NOx trade-off and the coked matter adhesion.

\section{Length to diameter ratio $\left(L / D_{o}\right)$}

Lichtarowicz [96] compared several orifice geometries and flow conditions. In this work, it was concluded that the maximum discharge coefficient obtained at high Reynolds numbers, decreases as the $L / D_{o}$ increases. In addition, a reduction in this ratio for values less than 2 , causes the discharge coefficient to decrease due to the flow detachment at the entrance. Furthermore, an increase of this ratio, causes for similar discharge pressure and mass flow, higher pressures at the orifice entrance leading to a lower probability of reaching the vapor pressure and thus cavitation. The figure 2.10 summarizes these results with a representation of the maximum discharge coefficient $\left(C_{d \max }\right)$ found depending on the value of $L / D_{o}$. 


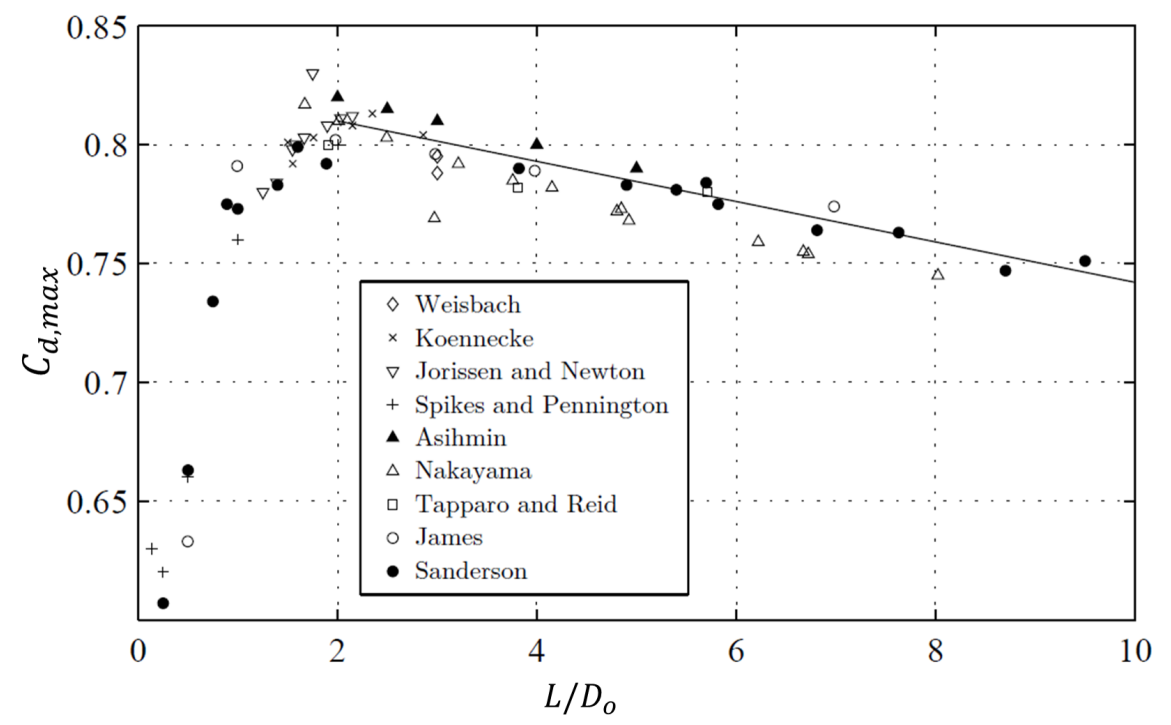

Fig. 2.10 Variation of the maximum discharge coefficient with the length to diameter ratio $[27]$

\section{Entrance edge radius to inlet diameter ratio $\left(r_{e} / D_{i}\right)$}

The high velocity of the fuel combined with a sudden change in the flow direction can produce a separation of the boundary layer. This phenomenon causes the main pressure losses at the orifice inlet. The introduction of a curvature at the entrance of the orifice helps to mitigate the detachment of the boundary layer. In consequence, due to the reduction of the pressure losses, higher discharge coefficients are obtained, and with it, less possibilities of cavitation. The inlets of the nozzle holes are usually rounded to enhance the inflow conditions and to produce abrasion in advance, which would otherwise occur during operation and change the spray characteristics [108]. For $r_{e} / D_{i}$ ratios higher or equal to 0.2 , the pressure losses generated are considered negligible [205].

\subsubsection{Characteristics of the flow and pressure losses}

To begin the analysis of the internal flow within the injector, let's consider first a fluid that flows through two sections (figure 2.11). The Bernoulli equation, product of the 
energy transport equation applied to non-viscous flow of incompressible fluids, can be then formulated (equation 2.2):

\section{Section 2}

$$
\left(\mathrm{z}_{2}, \mathrm{u}_{2}, \mathrm{p}_{2}\right)
$$

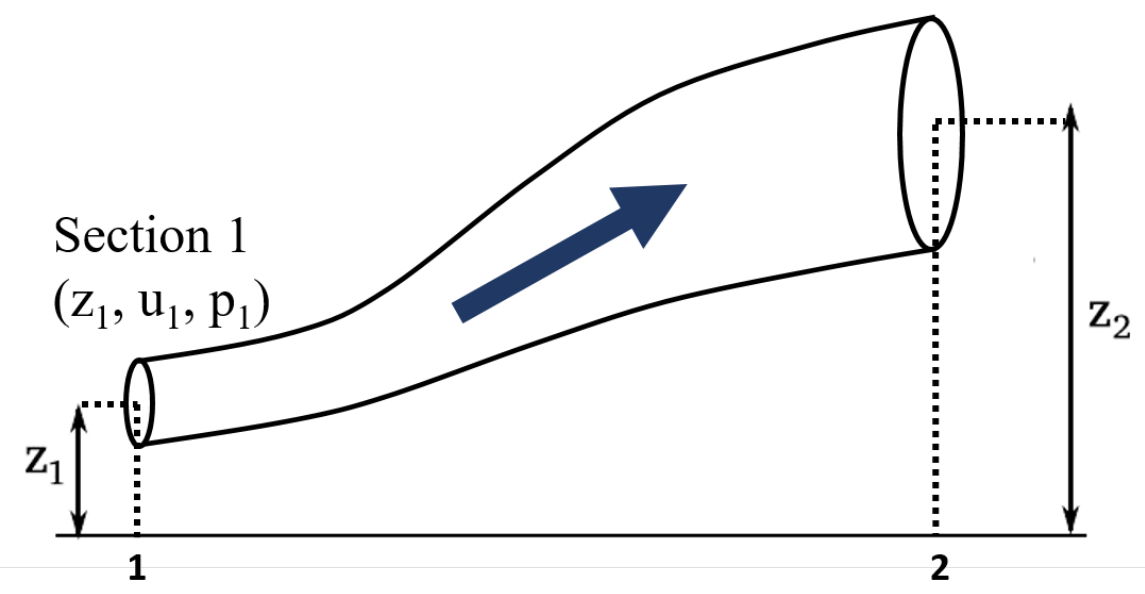

Fig. 2.11 Schematic of the flow of a fluid through a pipe of variable section

$$
H=\frac{P}{g \rho}+\frac{u^{2}}{2 g}+z=\text { const }
$$

The first term on the left hand side of the equation refers to the total head. On the right hand side three different contributions can be noted, the pressure head, the dynamic pressure and the elevation. Due to the modest elevation differences and the high pressure variations within common rail systems, the elevation term is commonly neglected. As it can be supposed, the equation 2.2 is only valid for ideal cases, where the viscous dissipation does not exist and all the potential energy is completely converted to kinetic energy. In our case the dissipation cannot be neglected and therefore, the flow transformation from section 1 to section 2 can be written including the dissipation term:

$$
\frac{P_{1}}{g \rho}+\frac{u_{1}^{2}}{2 g}+\not 11=\frac{P_{2}}{g \rho}+\frac{u_{2}^{2}}{2 g}+\not z 2+\phi_{v i s c}
$$


The viscous dissipation is the result of the sum of two terms: the minor losses and the major losses (equation 2.4). The minor losses or singular pressure losses, are caused to sudden changes in the shape or in the direction of the channel driving the flow. These changes can also produce a separation of the boundary layer, producing recirculation zones that restrain the flow creating a smaller section, this is usually called Vena contracta.

$$
\phi_{v i s c}=\phi_{v i s c, m}+\phi_{v i s c, M}
$$

Through the Vena contracta the flow speeds up, in consequence, energy dissipation and pressure losses are eventually generated. The pressure drop related to minor losses is normally expressed:

$$
\Delta P_{m}=\xi \frac{\rho}{2} u^{2}
$$

When the minor losses coefficient $\xi$ is equal to 0 where there is no pressure loss, while if $\xi$ is equal to 1 , means that the pressure drop is equivalent to the dynamic pressure. This coefficient can also be greater than 1 for some specific cases. $\xi$ depends mainly on the inlet geometry of the orifice and the Reynolds number $(R e)$. Due to analytical difficulties on the estimation of the $\xi$ coefficient, usually it is obtained experimentally. Thanks to experimental works like [72], losses for conventional geometries are already tabulated (figure 2.12).

In order to accurately predict the total pressure losses, it is necessary to estimate the flow regime. Two flow regimes are commonly distinguished: laminar and turbulent, which depend on the Reynolds number $[14,30]$. The Reynolds number is a dimensionless parameter that relates the inertial and viscous forces of a fluid and is defined as:

$$
R e=\frac{\rho u D}{\mu}
$$

For injector nozzles, the characteristic length $(D)$ is the diameter and $\mu$ is the dynamic viscosity of the fuel. For cylindrical straight ducts and only for fully developed flows (flow stabilized for certain distance of several diameters with no sudden changes 


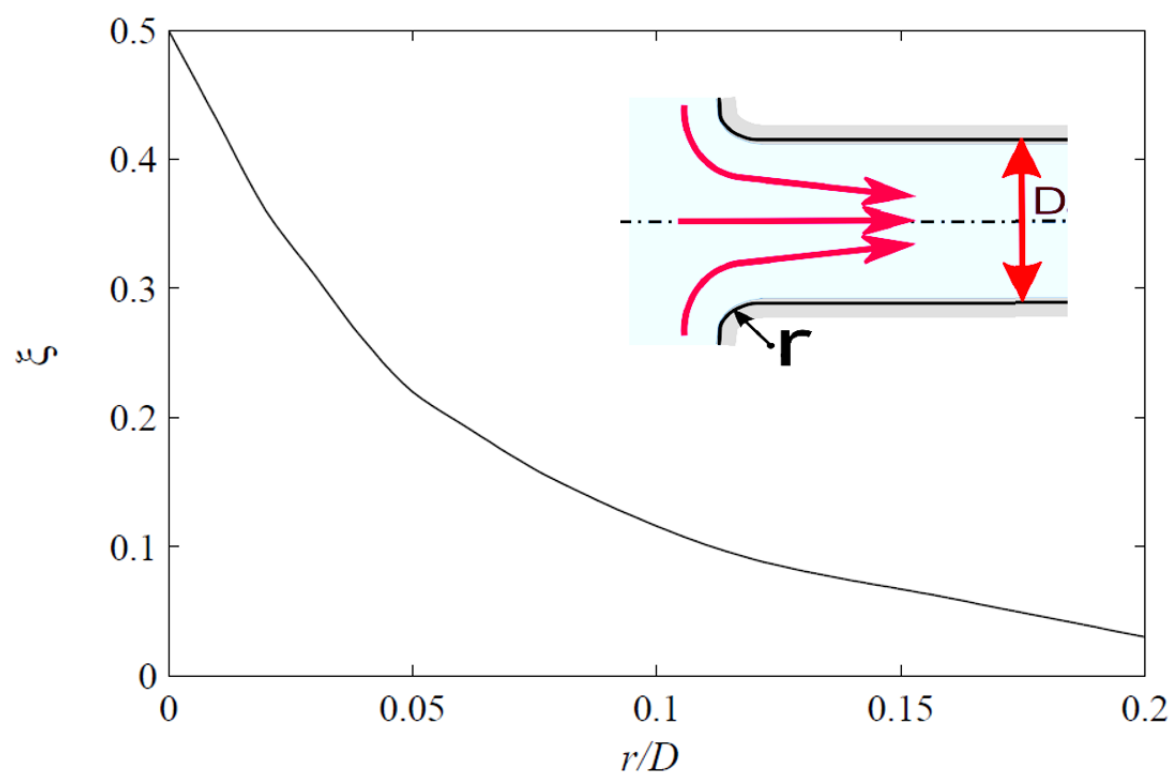

Fig. 2.12 Inlet losses in an orifice from a deposit, in function of the rounding radius at the inlet of the orifice $(r)$ and its diameter $(D)$ for $R e>10^{4}$

of direction), internal experimental observations have shown that the flow is laminar for values of Reynolds number below $R e<2300$ and turbulent for values above $R e>$ 4000. Re numbers between 2300 and 4000 are considered transitional regimes, where depending on the pipe roughness, the flow could be consider either laminar or turbulent. A sudden change of direction can produce local uniformities of the flow due to the fact that the boundary layer has to thicken to wall and it takes time to be stabilized.

In a laminar regime the length necessary to consider a flow stabilized can be calculated with the following expression $[106,189]$ :

$$
\frac{L}{D}=0.03 R e, R e<2300
$$

When the regime is turbulent $(R e>4000)$, the mixing intensity induced by the turbulence itself makes the necessary length shorter to get a developed flow. The formulation proposed by White [216] to calculate the length necessary to consider the flow stabilized in turbulent regime is: 


$$
\frac{L}{D}=4.4 R e^{1 / 6}, R e>4000
$$

As an example, for Reynolds number commonly used in the orifice of an injector $\left(10^{4}<R e<10^{5}\right)$, the length should be between 20 and 30 times the orifice diameter to get a fully developed turbulent flow. Independently of its regime, the flow will not be ever fully developed in an orifice from a diesel injector due to its typical dimensions (table 2.1 ), as this ratio is generally lower than $L / D \approx 10$. Thus, some considerations must be taken into account $[14,27,54,106,108,205]$ :

- The behavior of the flow will be directly related to the geometry of the entrance of the orifice and will affect the flow characteristics, e.g. thickness of the boundary layer (or separation), local pressure losses, etc. In this way, the velocity profiles and head losses in the orifice will strongly depend on the flow behavior at the entrance.

- As the flow is not completely developed, the standard limits used to characterize the regime as laminar or turbulent $(R e>4000)$ will not be valid in such an orifice. As a consequence, the Reynolds number is not the only parameter to take into account to characterize the regime and therefore the intensity of the turbulence.

- The fluid mechanic theories based on fully developed flow cannot be applied in this case. For example, the velocity profiles at the orifice outlet will not be almost constant in the whole section of the orifice exit as it would be if flow were stabilized.

In the case of the major losses, these ones are induced by the friction of the fuel on the channels wall and they depend on the length of the considered channel $(L)$. The pressure drop related to the major loss is defined as:

$$
\Delta P_{M}=K_{\text {fric }} \frac{L}{D} \frac{\rho}{2} \overline{u^{2}}
$$


where $K_{\text {fric }}$ is the friction coefficient, it depends on $R e$ and wall relative roughness. For fully developed flows with laminar regime $K_{\text {fric }}$ can be estimated as follows:

$$
K_{\text {fric }}=\frac{64}{R e}
$$

In turbulent regime, the interaction between the fluid and the wall changes, as well as the velocity profile. In this case the surface roughness effect has to be taken into account, for this reason, Colebrook [30] expressed $K_{\text {fric }}$ in terms of the $R e, D$ and the absolute roughness $(e)$ to determine $K_{\text {fric }}$ (equation 2.11). This expression is solved iteratively, and when $R e, L, D, e$, fuel density and mean velocity of the flow are known, the major losses can be calculated.

$$
K_{\text {fric }}=f\left(\operatorname{Re}, \frac{e}{D}\right) ; \frac{1}{\sqrt{K_{\text {fric }}}}=-2 \log \left(\frac{2.51}{R e \sqrt{K_{\text {fric }}}}\right)+\frac{\frac{e}{D}}{3.72}
$$

\subsubsection{Hydraulic characterization}

Theoretically, the mass flow through the orifice exit can be obtained by the equation 2.12, if density and velocity profiles are known.

$$
\dot{m}_{f}=\int_{A} \rho(U . n) d A
$$

The equation 2.12 becomes in the equation 2.13 , considering that the velocity component is perpendicular to the orifice exit area.

$$
\dot{m}_{f}=\int_{A} \rho u d A
$$

Furthermore, if the fluid is considered incompressible and inviscid (consequently with no boundary layer), the integral simplifies into the equation 2.14,

$$
\dot{m}_{f, t h}=\rho u_{t h} A_{o}
$$


Where, $u_{t h}$ is the theoretical velocity obtained from Bernoulli's formulation (equation 2.2). In which, $P_{i n j}$ is the injection pressure, $P_{b a c k}$ is the discharge pressure and the pressure drop is defined as $\Delta P=P_{i n j}-P_{b a c k}$ : .

$$
\begin{gathered}
\frac{P_{i n j}}{\rho_{f}}=\frac{P_{b a c k}}{\rho_{f}}+\frac{1}{2} u_{t h}^{2} \\
u_{t h}=\sqrt{\frac{2 \Delta P}{\rho_{f}}}
\end{gathered}
$$

The most common way to analyze the internal flow consists of mean parameters at the orifice exit and dimensionless coefficients such the discharge coefficient $C d[83,130]$. Once the theoretical mass flow ratio is obtained for a particular condition, the discharge coefficient can be calculated using the following expression:

$$
C_{d}=\frac{\dot{m}_{f}}{\dot{m}_{f, t h}}=\frac{\dot{m}_{f}}{A_{o} \sqrt{2 \rho_{f} \Delta P}}
$$

The discharge coefficient has been studied exhaustively for years $[49,84,96,149,185$, 199]. In these studies, it has became evident the asymptotic behavior of the discharge coefficient with the regime of the flow (figure 2.13). The flow may be regarded as laminar while the discharge coefficient grows almost linearly with $R e$, whereas it can be considered turbulent once the asymptotic value of the maximum discharge coefficient is practically achieved. Among these two regions, the flow is transitional and the discharge coefficient grows with $R e$ in a moderate way.

The figure 2.13 also depends on the orifice morphology. Different expressions have been proposed to describe the behavior of the discharge coefficient in the absence of cavitation (table 2.2):

The discharge coefficient measures the efficiency of an orifice in delivering certain fluid. This includes the wall friction pressure losses, the losses due to non-uniform velocity profile at the orifice exit, and also the cavitation phenomenon when it appears. Hence, the mass flow rate through the orifice may be expressed as: 


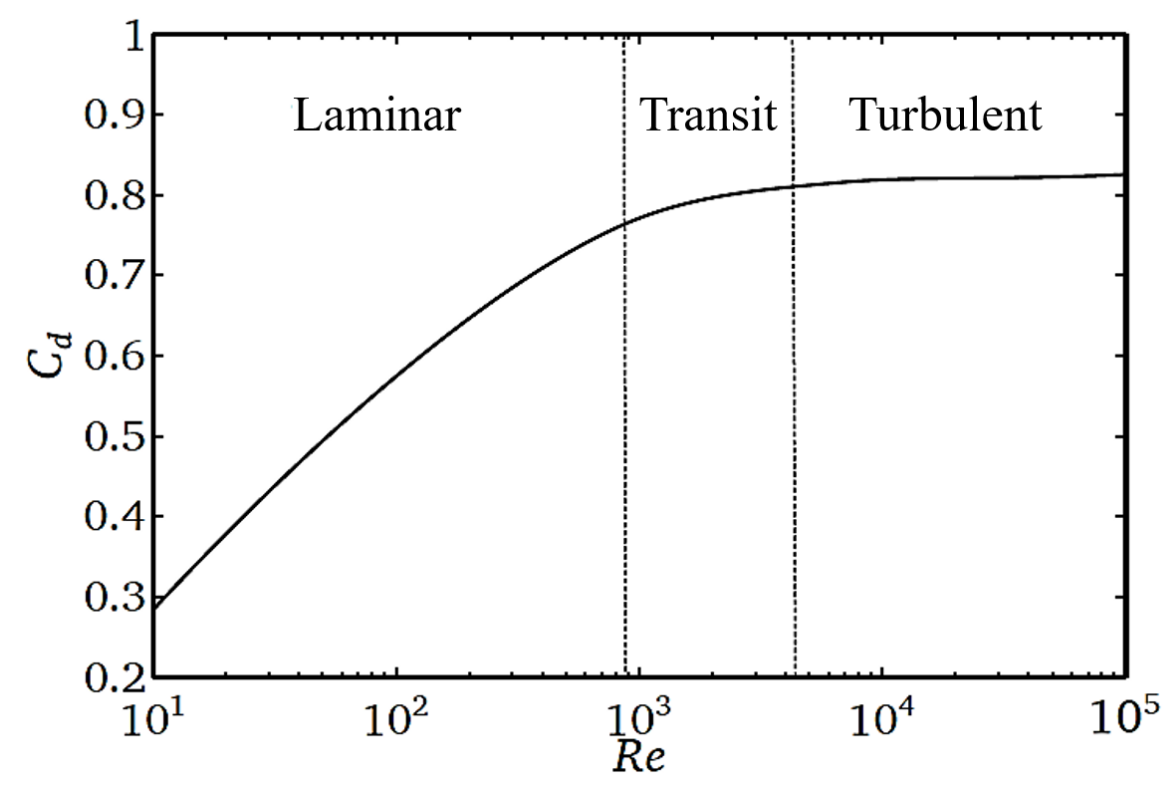

Fig. 2.13 Example of a typical discharge coefficient evolution as function of Reynolds number in the absence of cavitation [205]

$$
\dot{m}_{f, t h}=\rho_{f} C_{d} u_{t h} A_{o}
$$

In real conditions, the fuel crosses the area $\left(A_{o}\right)$ with a non-uniform velocity and density profiles (figure 2.14). Therefore, it is convenient to define an effective area $\left(A_{e f f}\right)$ in which an equivalent flow pass through, with a constant effective velocity $\left(u_{e f f}\right)$ and with a constant density ( $\rho_{f}$ corresponding to the liquid phase), preserving the same mass flow rate as the real flow [140]. Thus, the mass flow simplified is calculated with the equation 2.19:

$$
\dot{m}_{f}=\rho_{f} u_{e f f} A_{e f f}
$$

The losses included in the discharge coefficient are the product of other two (equation 2.20 ). The first one is the velocity coefficient $C_{v}$, which takes into account the energy or pressure loss. And the second one is the area coefficient $C_{a}$, which includes the 
Table 2.2 Typical $C_{d}$ expressions used in the literature

\begin{tabular}{|c|c|}
\hline Author & $C_{d}=f(R e$, geometry $)$ \\
\hline Nakayama [119] & $\begin{aligned} C_{d} & =\frac{R e^{5 / 6}}{17.11 D_{o}^{-1}+1.65 R e^{0.8}} \\
C_{d \max } & =0.868-0.0425 D_{o}^{-1 / 2}\end{aligned}$ \\
\hline Asihmin [10] & $\frac{1}{C_{d}}=1.23+\frac{58 L}{\operatorname{Re} D_{o}}$ \\
\hline Lichtarowicz $[96]$ & $\begin{aligned} \frac{1}{C_{d}}= & \frac{1}{C_{d \max }}+\frac{20}{R e}\left(1+2.25 D_{o}^{-1}\right) \\
& -\frac{0.0015 D_{o}^{-1}}{1+7.5(\log (0.00015 R e))^{2}}\end{aligned}$ \\
\hline Arcoumanis $[6]$ & $\begin{array}{c}C_{d}=\frac{1}{\frac{1}{C_{d \max }}+\frac{20}{R e}\left(1+2.25 \frac{1}{D_{o}}\right)} \\
C_{d \max }=f\left(L, D_{o}, r\right)\end{array}$ \\
\hline Salvador [185] & $C_{d}=0.98-\frac{0.07 D_{o}^{1.2}}{r^{0.49} d^{1.14} A R^{0.09}}-\frac{10.7}{R e^{0.5}}$ \\
\hline Imagine $[99]$ & $C_{d}=C_{d \max } \tanh \left(\frac{2 R e_{t}}{R e_{c r i t}}\right)$ \\
\hline
\end{tabular}

Hall [57] $\quad C_{d}=1-0.1874\left(\frac{L}{D_{o}}-1+1.11 R e^{0.25}\right)^{0.8} R e^{-0.2}$

loss of area due to non-uniform velocity profile, caused by cavitation bubbles reaching the exit and flow separation from the wall. Consequently, the $C_{v}$ is defined as the relationship between effective and theoretical velocity (equation 2.21), whereas the area coefficient relates the effective area with the geometrical area (equation 2.22).

$$
\begin{gathered}
C_{d}=C_{a} C_{v} \\
C_{v}=\frac{u_{e f f}}{u_{t h}}
\end{gathered}
$$




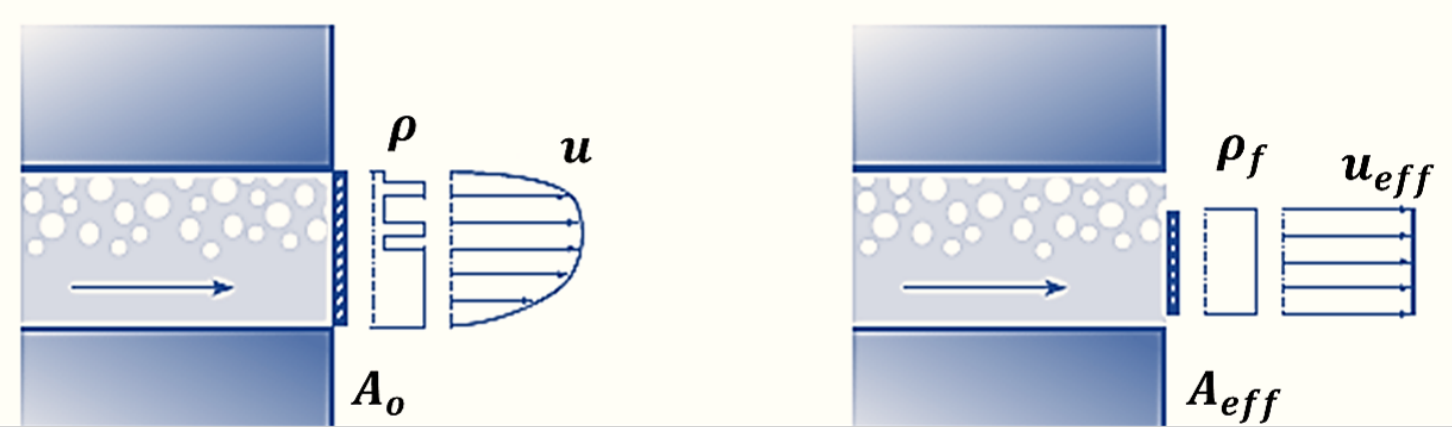

(a)

(b)

Fig. 2.14 Representation of the flow at the output orifice, (a) real flow, (b) simplified equivalent flow. [205]

$$
C_{a}=\frac{A_{e f f}}{A_{o}}
$$

Even though the $C_{d}$ can be easily obtained experimentally from mass flow rate measurements, obtaining the individuals $C_{a}$ and $C_{v}$ coefficients is more complicated. However, different methodologies to measure the momentum flux at the outlet orifice $[50,50,52,70,97,188]$ have been developed. Considering that the momentum flux $\dot{M}_{f}$ can be expressed in terms of the velocity and the effective area (equation 2.23), these coefficients can be estimated.

$$
\begin{aligned}
\dot{M}_{f} & =\dot{m}_{f} u_{e f f} \\
& =\rho_{f} A_{e f f} u_{e f f}^{2} \\
& =\rho_{f} C_{a} C_{v}{ }^{2} A_{o} u_{t h}^{2} \\
& =\rho_{f} C_{M} A_{o} u_{t h}^{2}
\end{aligned}
$$

Where the momentum coefficient $C_{M}$ is obtained with the measured momentum. Thus, the velocity coefficient and the area coefficient can be estimated with the equations 2.20 and 2.24 :

$$
C_{v}=\frac{C_{M}}{C_{d}}
$$




\subsubsection{Cavitation}

The recirculation zone between the orifice wall and the aforementioned Vena contracta near the entrance, provokes a depression due to the acceleration of the flow. This reduced static pressure can reach sometimes the vapor pressure of the fuel, causing a partial vaporization of the liquid, generating small bubbles of vapor cavities. The first time vapor bubbles appear inside the nozzle is called incipient cavitation.

Nurick [124] proposes a one-dimensional model validated with transparent scaled orifices in which several phenomena coming from cavitation can be explained. He defines three zones (figure 2.15): (i) upstream the orifice inlet where the velocity is negligible compared to those inside the orifice, (c) at the minimum cross-sectional area of the vena contracta, where the maximum velocity and the lowest pressure are reached and (b) at the exit of the orifice.

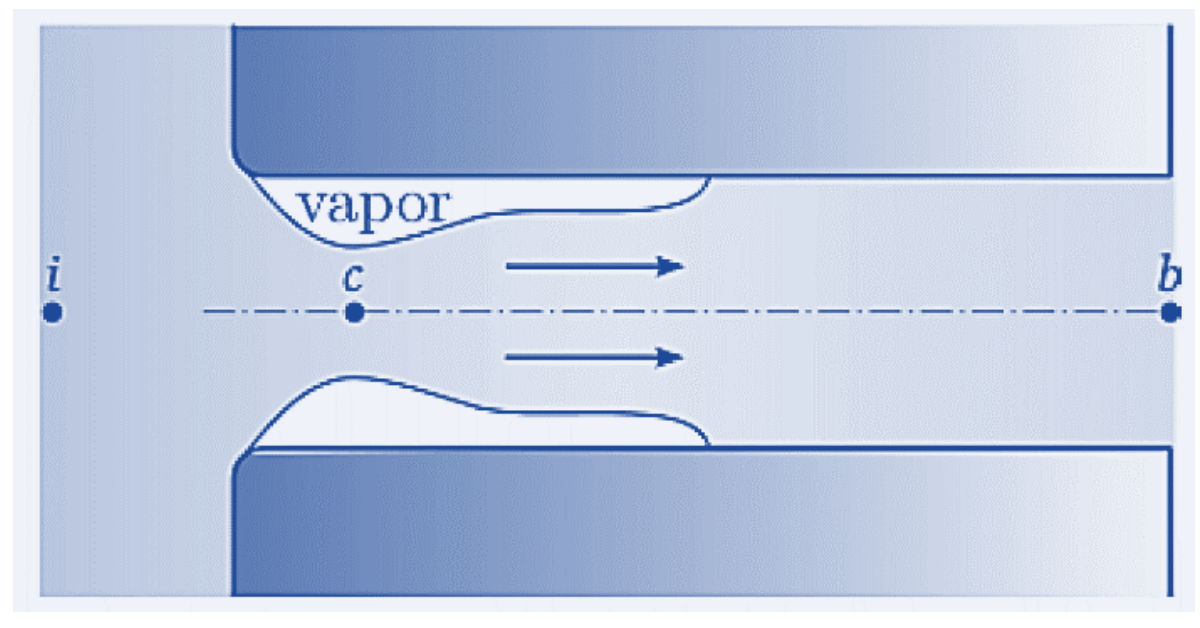

Fig. 2.15 Representation of cavitation in an asymmetrical nozzle [52]

Assuming that the area occupied by the vapor remains constant, starting at the inlet and not reaching the exit, the mass flow rate at the outlet of an orifice may be expressed as follows:

$$
\dot{m}_{f}=\rho_{f} u_{c} A_{c}
$$


Where $u_{c}$ and $A_{c}$ are the velocity and the sectional area at location $c . A_{c}$ can also be written as function of $A_{o}$ by the introduction of a contraction coefficient $C_{c}$ (equation 2.26). Its value depends on the geometry of the entrance of the orifice and may vary from 0.61 to 1 , where the lowest value is observed for sharp edges [190].:

$$
A_{c}=C_{c} A_{o}
$$

Applying the Bernoulli equation (2.2) between the points $i$ and $c$ (where the pressure is the vapor pressure of the fuel), the mass flow rate expression (equation 2.28) is obtained by the combination of this Bernoulli equation 2.27 with the equation 2.25:

$$
\begin{gathered}
P_{i}=P_{v}+\frac{1}{2} \rho_{f} u_{c}^{2} \\
\dot{m}_{f}=A_{o} C_{c} \sqrt{2 \rho_{f}\left(P_{i n j}-P_{v}\right)}
\end{gathered}
$$

Combining the equations (2.17) and 2.28, an equation which gives the discharge coefficient as function of injection and discharge pressures is obtained (equation 2.29). This expression allows definition of the cavitation number $(K)$ (equation 2.30).

$$
\begin{gathered}
C_{d}=C_{c} \sqrt{\frac{P_{i n j}-P_{v}}{P_{i n j}-P_{b a c k}}} \\
K=\frac{P_{i n j}-P_{v}}{P_{i n j}-P_{b a c k}}
\end{gathered}
$$

The mass flow rate under cavitating conditions is independent of the discharge pressure $P_{b a c k}$, and only depends on the injection and vapor pressures. For this reason, when the flow is cavitating, the orifice is collapsed and the mass flow rate does not increase anymore when the discharge pressure goes down (figure 2.16). This is usually called mass flow rate collapse and it has been experimentally observed before $[34,52,185,199]$. 


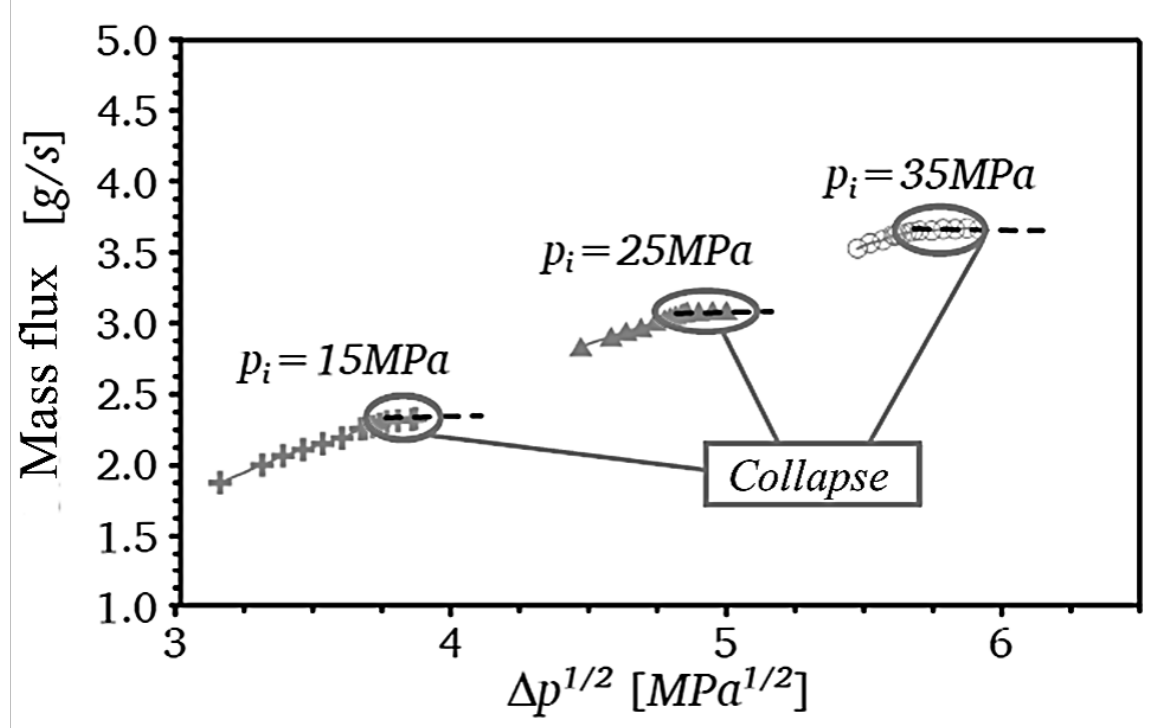

Fig. 2.16 Mass flow rate collapse at different rail pressures [205]

From the equations 2.29 and 2.30, the linear relationship between $C_{d}$ and the square root of $K$ can be observed for cavitating conditions. As $K$ grows, the flow becomes less cavitating, thus the linear relationship between $C_{d}$ and $K$ is not respected anymore (figure 2.17). The value of $K$ for which the transition from cavitating to non-cavitating conditions takes place is known as critical cavitation number, $K_{\text {crit }}$. Several studies carried out on $K_{\text {crit }}$ proved that this number was mainly dependent on orifice geometry (entrance radius, convergence or diameter of the orifice) and the injection pressure $[130,147,148,199]$.

\subsection{Diesel spray formation}

The diesel spray formation includes complex and heterogeneous processes, including high-velocity jet flow, liquid droplet break-up, atomization, and evaporation of a dense liquid spray in a turbulent flow environment. To ensure a good mixture between the air and the fuel, the spray must penetrate into the combustion chamber and atomize $[71,120,126,160,197,222]$. The small temporal and spatial scales resulted from these processes makes the study of the diesel spray evolution a complicated problem. 


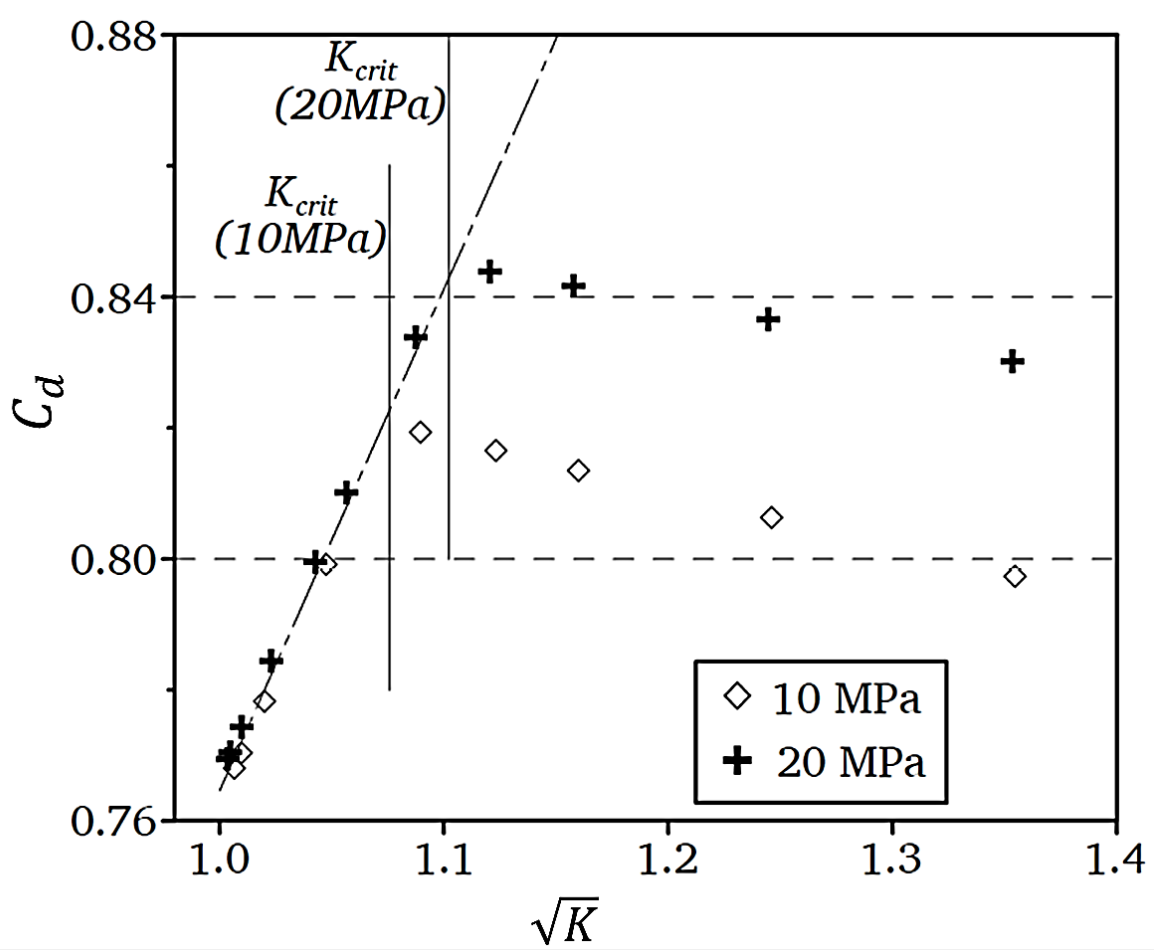

Fig. 2.17 Sample of the evolution of the discharge coefficient with respect to the square root of $\mathrm{K}[52,205]$

The spray region is usually defined starting from the orifice outlet in which the fuel is dispersed. The structure of the spray is described in the figure 2.18. The liquid core appears in the first millimeters from the nozzle and depending on the injection conditions the intact surface can be also observed, where the liquid vein remains intact without forming any droplet. Subsequently, a separation of the liquid core with the formation of relatively large liquid structures called ligaments happens, mainly caused by the aerodynamic instabilities at the liquid-gas boundaries, combined with the perturbations deriving from the turbulent flow. This process is called primary atomization.

Later on, the relative velocity of the ligaments to the surrounding gas and the related viscous interaction, lead them to a further aerodynamic instability that breaks them in smaller formations. This process is repeated until the surface tension of the fluid is enough to compensate the aerodynamic forces. This part of the process is 


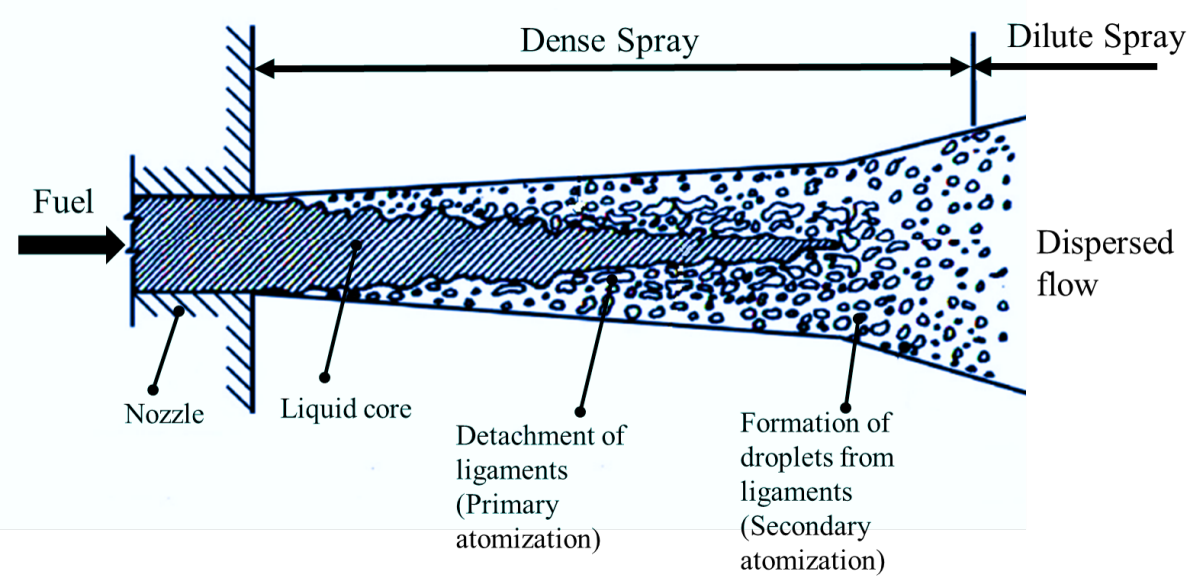

Fig. 2.18 Structure of the diesel spray

called secondary atomization [108]. These parts are followed by a dispersed flow, where discrete droplets are moving separately from each other in the gaseous phase [27]. As far as the macroscopic appearance of the diesel spray is concerned, two main parts of the spray can be identified, the dense and dilute regions. The first one (also called near field), is the area near the orifice outlet including the liquid core and ligaments where the spray is optically too dense to be studied using conventional optics. Some studies related to this part of the spray have been performed using x-ray techniques $[82,83,93,168,203]$. The second one, the dilute region, is normally referred to as the area where the atomization process is completed. Once steady pressure conditions are achieved upstream of the nozzle discharge orifices and due to the atomization and air entrainment processes, the diesel spray acquires a cone with a semi-elliptical tip shape (figure 2.19).

\subsubsection{Atomization and break-up processes}

The atomization process is important since the physical process of mixing, among the gas present in the combustion chamber and the fuel depends on it. The atomization strongly increases the contact surface between them, favoring the air entrainment. Generally speaking, atomization is the process in which the core of a liquid spray is 


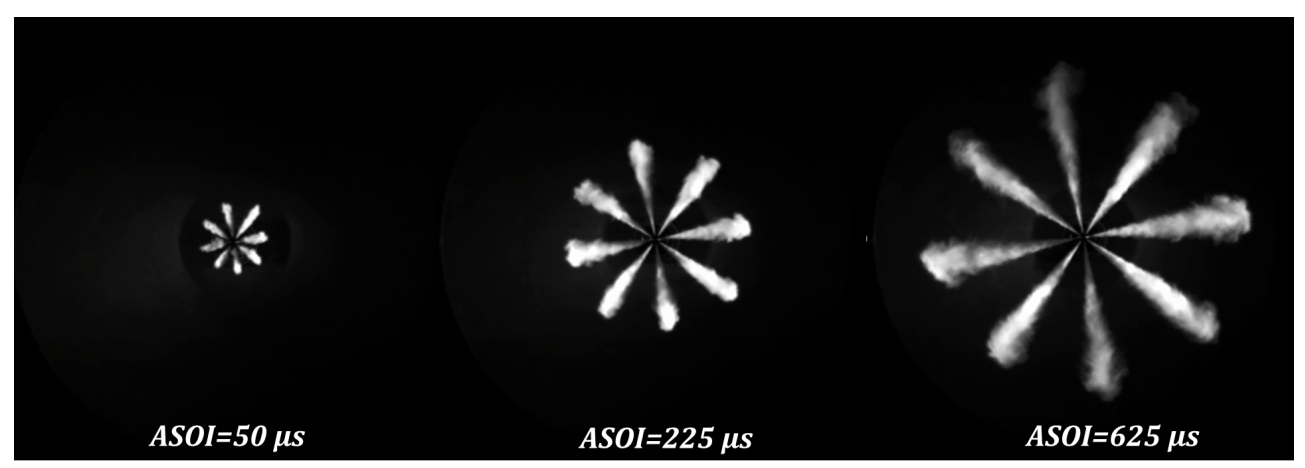

Fig. 2.19 Macroscopic appearance of the diesel sprays of a 7-hole nozzle for different instants $\left(P_{i n j}=150 \mathrm{MPa}, \rho_{a}=25 \mathrm{~kg} / \mathrm{m}^{3}\right.$ and $\left.T_{a m b}=600 \mathrm{~K}\right)$

broken up into droplets. This is caused by internal forces such as liquid turbulence; inertial or jet velocity profile rearrangement effects, liquid supply pressure oscillations and cavitation in competition with surface tension (figure 2.20).

Subsequently, the liquid surface area seen by the gas phase increases, enhancing subsequent processes such as vaporization or momentum transfer. The main physical processes taking part in the fuel atomization are [14, 27, 108]:

- Liquid surface tension: the resulting force causes the liquid vein to remain intact or to form droplets.

- Surface instabilities: the liquid vein is in unstable condition passing from forced to free-flow. This means that the surface tension resulting force is in equilibrium only if the cylindrical shape of the liquid vein is maintained. A minimum perturbation is amplified and causes the initial shape to disappear.

- Turbulence inside the orifice: Depending on the flow regime, the fuel may have a different level of radial velocities. The resulting inertial forces tend to spread the liquid in the chamber.

- Aerodynamic interaction: the relative movement between the liquid and the surrounding gas causes friction forces that, among other things, are strongly dependent on the shape of the liquid vein. 


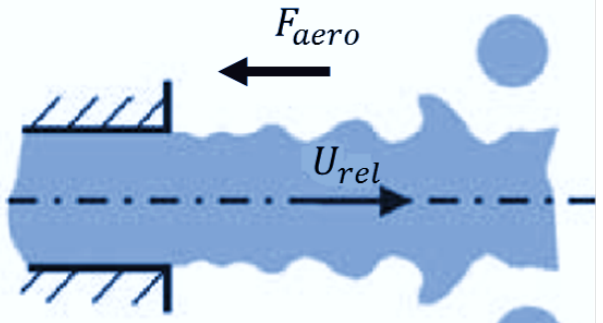

Growth of surfaces waves due to aerodynamic forces

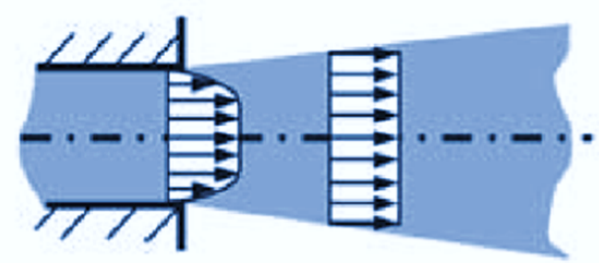

Relaxation of the velocity profile

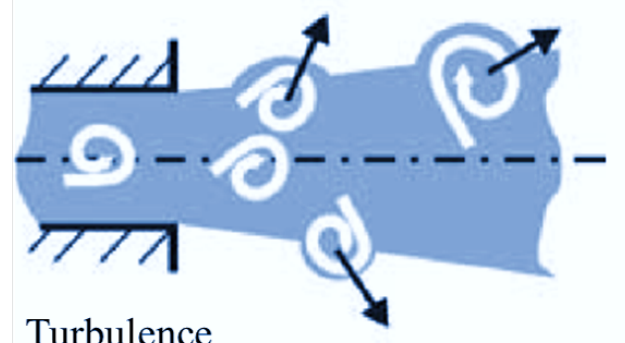

Turbulence

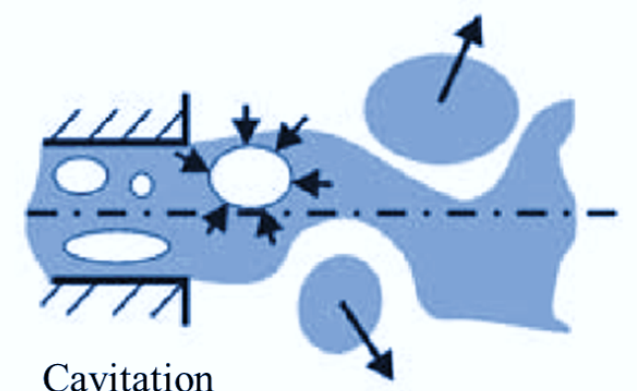

Fig. 2.20 Atomization mechanisms at the nozzle exit [17]

\section{Dimensional analysis of the atomization process}

Based on the information available in the literature, the parameters mainly affecting the atomization process are: the ambient density $\left(\rho_{a}\right)$, fuel density $\left(\rho_{f}\right)$, jet velocity (or relative velocity between fuel and air) $\left(u_{e f f}\right)$, effective nozzle diameter $\left(D_{e f f}\right)$, the surface tension $(\sigma)$ and the fuel viscosity $\left(\mu_{f}\right)$. These six parameters contain three fundamental quantities (length, mass and time). Thus, following the $\pi$ theorem of Buckingham, the influence of all the parameters above can be simplified using three dimensionless group of parameters. Usually, the dimensionless parameters most employed in the literature are the density ratio $\rho_{f} / \rho_{a}$, the Reynold's number and one of the three following:

Ohnesorge number;

$$
O h=\frac{\mu_{f}}{\sqrt{\rho_{f} \sigma D_{e f f}}}
$$


Weber number;

$$
W e=\frac{\rho_{f} u_{e f f^{2}} D_{e f f}}{\sigma}
$$

Taylor number;

$$
T a=\frac{\rho_{f}}{\rho_{a}}\left(\frac{R e}{W e_{a m b}}\right)^{2}
$$

The Ohnesorge dimensionless number (equation 2.31) represents the ratio between the viscous forces and the liquid inertia combined with the surface tension. Reitz and Bracco [176] classified the different break up regimes based on this number [214]. It is clear that the density ratio affects the atomization process only at low values. This means that when the air density is low with respect to fuel density, this parameter has no effect on the atomization (figure 2.21a). For that reason, it is common to represent the atomization regimes separation as function of only Reynolds and Ohnesorge number for high density ratios, as done in 2.21b, for an iso-surface obtained from figure 2.21a.

The Weber number $(W e)$ (equation 2.32) is often used to analyze fluid flows where there is an interface between two fluids, whilst the taylor's number $(\mathrm{Ta})$ (equation 2.33 ) is a dimensionless quantity that characterizes the importance of inertial forces due to rotation of a fluid about an axis, relative to viscous forces.

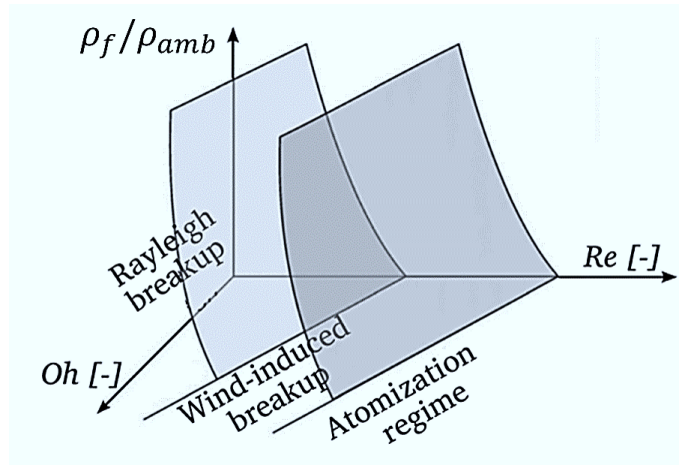

(a) Qualitative separation of the atomization number using the three dimensionless parameters required by the $\pi$ theorem [176]

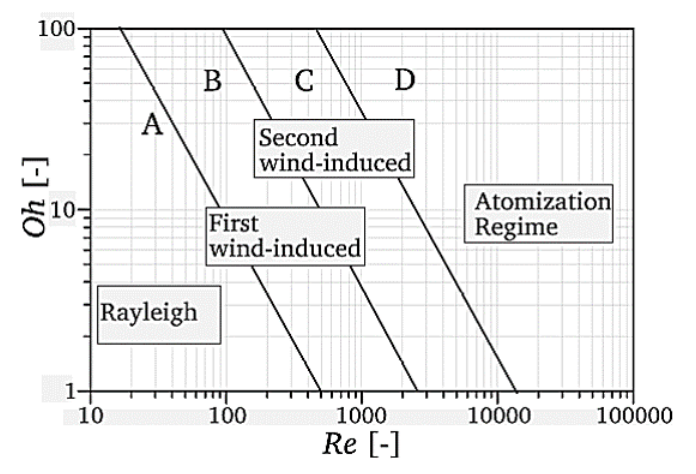

(b) Separation of the atomization regimes for high values of the ratio $\rho_{f} / \rho_{a}[176]$

Fig. 2.21 Dimensionless numbers and its relationship with spray atomization 
Table 2.3 Definition of the transition between atomization regimes, for different authors

\begin{tabular}{ccc}
\hline \hline Regime & Equation & Author \\
\hline A-B & $W e_{a m b}=0.4$ & Ranz [174] \\
& $W e_{a m b}=1.2+3.41 O h^{0.9}$ & Sterling and Sleicher [201] \\
\hline B-C & $W e_{a m b}=13$ & Ranz [174] \\
\hline & $W e_{a m b}=40.3$ & Meisse [112] \\
C-D & $\frac{\rho_{f}}{\rho_{a}}=\frac{\sqrt{A}-1.15}{744} f(T a)^{-2}$ & Reitz [177] \\
& $f(T a)=\frac{\sqrt{3}}{6}[1-\exp (-10 T a)]$ & \\
&
\end{tabular}

The quantification of the atomization regimes borders has been studied for decades. The table 2.3 shows some of the existing criteria to define them.

The equation proposed by Reitz [177] for the transition to the complete atomization regime is presented. The constant A is calculated from the spray angle, which has to be experimentally measured. Thus, internal flow parameters, which are key to determine the atomization at high Weber numbers, are somehow considered.

\section{Atomization regimes and its influence on the intact liquid core}

Lord Rayleigh [175] presented a theory on jets instability. In his work, non viscous liquids were injected at low velocities and atomization occurred when surface tension was exceeded. Weber [191] extended Rayleigh's theory to viscous liquids and the effects of aerodynamic interaction when injection velocity increases. Reitz and Bracco [179] proposed the following atomization regimes as a function of increasing injection velocity: 
- Rayleigh mechanism of breakup (B): It occurs at low velocities, disintegration into drops of fairly uniform size are caused by the axisymmetric oscillations growing on the surface due to surface tension. Drop size is proportional to liquid viscosity and inversely proportional to jet velocity. Drop diameter is higher than jet diameter.

- First regime due to aerodynamic interaction (C): At higher velocities, the break up into drops is caused by the growth of small oscillations on the surface. Thus, breakup is caused by oscillations of the jet as a whole with respect to the jet axis. Drop diameter is similar to orifice diameter.

- Second regime due to aerodynamic interaction (D): As jet velocity increases, the surface forces due to the relative velocity with air are greater. Thus, smaller waves on the surface become detached from the jet surface to form ligaments. Drops generated from the ligaments are much smaller than the initial orifice diameter.

- Atomization (E): The initial perturbations, combined with the aerodynamic forces, cause the droplets to form in the immediate proximity of the orifice and their size is, as in the second regime, much smaller than the orifice diameter. In this case, the intact surface length is zero, which means that the surface is broken right at the orifice outlet. Nevertheless, in the atomization regime the intact core can still be present. For this reason two atomization regimes are commonly indicated: incomplete and complete atomization, whereas the intact core can be observed or not.

Some works characterized the break-up regimes based on the measured of the intact liquid core length $\left(L_{\text {core }}\right)[46,184]$. It has been noticed that the predominance of one force or the other is reflected on the behavior of this quantity. In the Rayleigh regime (figure 2.22), $L_{\text {core }}$ increases gradually since the jet velocity goes along with the gravitational forces and helps the liquid vein to extend farther from the outlet. The aerodynamic forces gain relevance contrasting the aforesaid effect. When the 

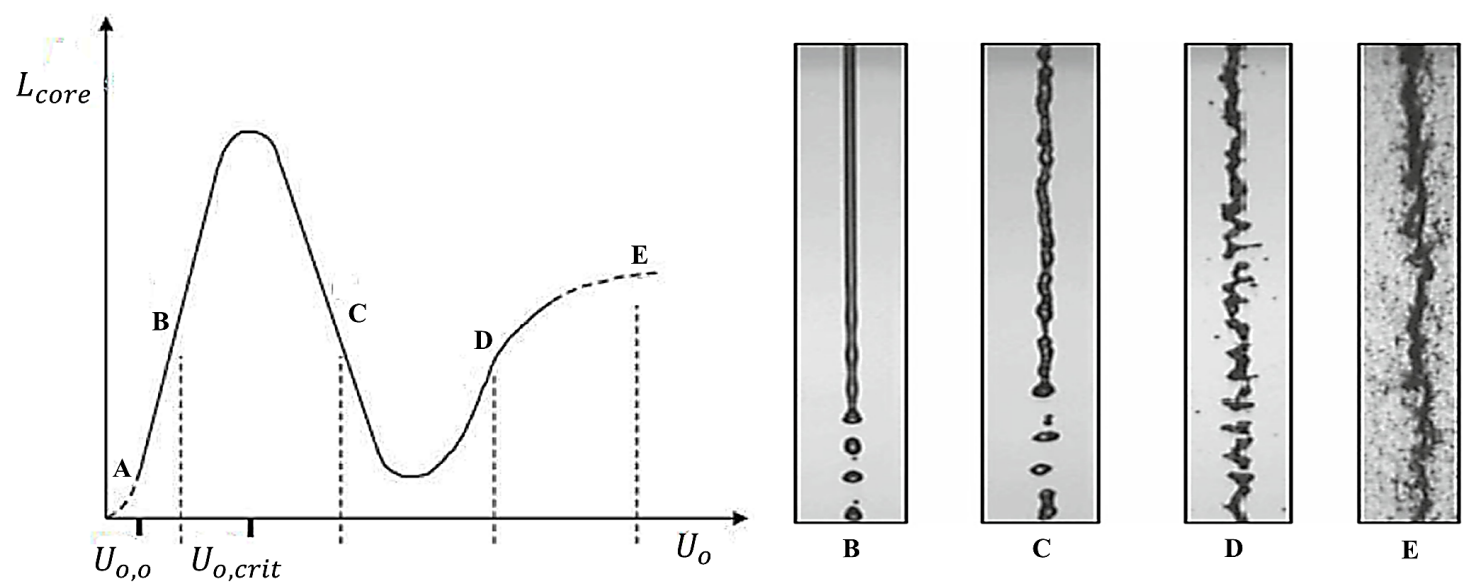

E

Fig. 2.22 Atomization regimes. B $\left(R e_{l}=790, W e_{a m b}=0: 06\right) ; \mathrm{C}\left(R e_{l}=5500, W e_{a m b}=\right.$ $2.7) ; \mathrm{D}\left(R e_{l}=16500, W e_{a m b}=24\right) ; \mathrm{E}\left(R e_{l}=28000, W e_{a m b}=70\right)[46]$

gravitational and the aerodynamic forces are balanced the intact core length reaches its maximum. At this point is defined the onset of the first-wind induced break-up. For these reasons, the $L_{\text {core }}$ decreases until a local minimum is reached. Finally, this effect is balanced again by the increasing of aerodynamic forces, causing a final reduction of $L_{\text {core }}$. The last part of the curve in figure 2.22 is dashed above certain value of velocity because the intact core length becomes difficult to measure especially at diesel injection conditions.

Under current operating conditions, diesel spray is under the last two regimes (D,E). At the last regime, $L_{\text {core }}$ has no dependency on injection velocity or droplet size [8]. There are few points of agreement about $L_{\text {core }}$ under in-cylinder conditions. At the least, $L_{\text {core }}$ depends on the geometry of the nozzle, the presence cavitation, and the density ratio between the liquid injected and the air [31, 179].

\section{Formation of droplets}

After the first disintegration (liquid core breaking up into liquid structures), a second stage appears breaking up again the droplets into smaller round ones. This secondary breakup occurs while droplets are traveling at relatively high speed into the discharge 
volume, thus suffering from deformation due to gas density. The smaller droplets favor the evaporation rate as they are of smaller size and it is said that this secondary breakup controls the mixing rate of the dilute spray in the evaporation zone [67]. The droplet breakup process is generally influenced by several parameters, like the first breakup; including the droplet size, droplet size relative velocity, liquid and gas densities, fluid viscosity and surface tension.

The disintegration of the droplets can be also classified in 5 break up regimes widely related with the $W e$ number. The first regime also called "deformation and flattening", it is generally observed for $W e<12$. The second regime, for $12<W e<80$, the droplet is disintegrated according to the bag drag process. For $W e \approx 80$, the third regime occurs, the shear break up process, where a boundary breakup process is present and the extremity of the bag created by the aerodynamic forces is disintegrated into small droplets. The fourth regime for $100<W e<350$, the stripping break up, the droplet is broken into several smaller and this gives consequence to the catastrophic breakup for values of $W e$ above 350 (the fifth regime). The table 2.4 provides a quick summary of the different breakup regimes with its illustration.

\section{Collision and coalescence}

Coalescence is an antagonistic process to atomization, where droplets join together making bigger ones [9]. The occurrence of this process depends on the relative velocity of the droplets and the fuel concentration. Therefore, collision is more frequent in the near-field and the axis of the spray, in other words, in the dense part [98, 180].

Regarding the collision mechanisms, these are complex considering that several types of droplet-droplet interaction are possible and they may not end up in permanent coalescence (figure 2.23). In this regard, researchers agree on the difficulty to measure droplet-air relative velocity and coalescence rate inside the dense region, specially because the spatial resolution is limited and the flow is opaque to optic diagnostic $[9,114]$. However, collision has a direct influence on the average diameter, dispersion and velocity of the droplets. 
Table 2.4 Breakup regimes of a single droplet [171]

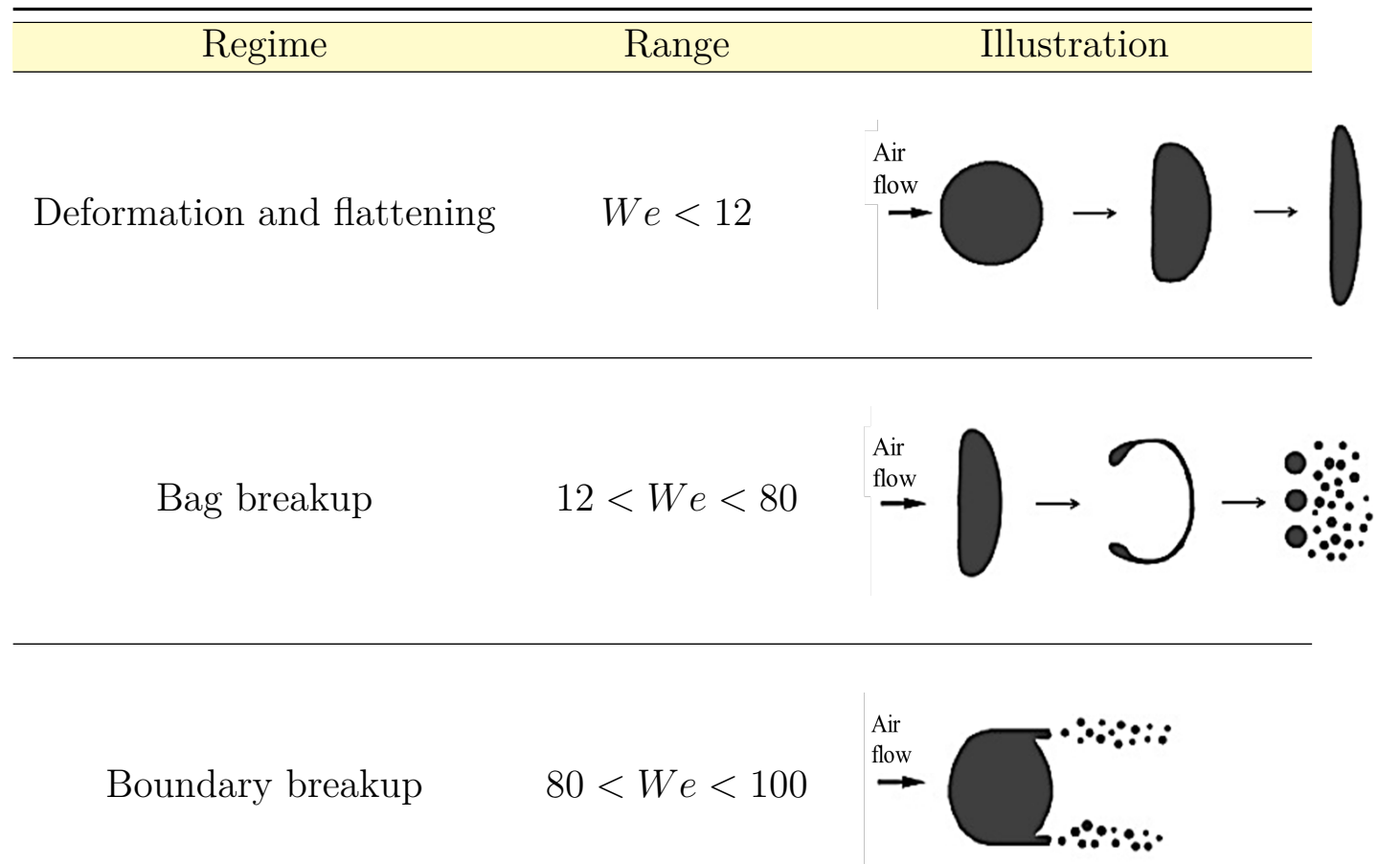

\begin{tabular}{|c|c|c|}
\hline Stripping breakup & $100<W e<350$ & $\stackrel{\text { fllow }}{\longrightarrow}$ \\
\hline Catastrophic breakup & $W e>350$ & flow \\
\hline
\end{tabular}

The collision frequency may be estimated from kinetic theory considerations. The outcome depends on the impact energy, the ratio of droplet sizes, and ambient conditions; like gas density, gas viscosity, and the gas-fuel ratio of the gas surrounding the droplets during impact. There are four dimensionless parameters governing the collision phenomenon; the impact parameter $(B)$, which varies from 1 to 0 , if $B=1$ a head-on collision is occurring and the relative velocity vector coincides with the center-to- 


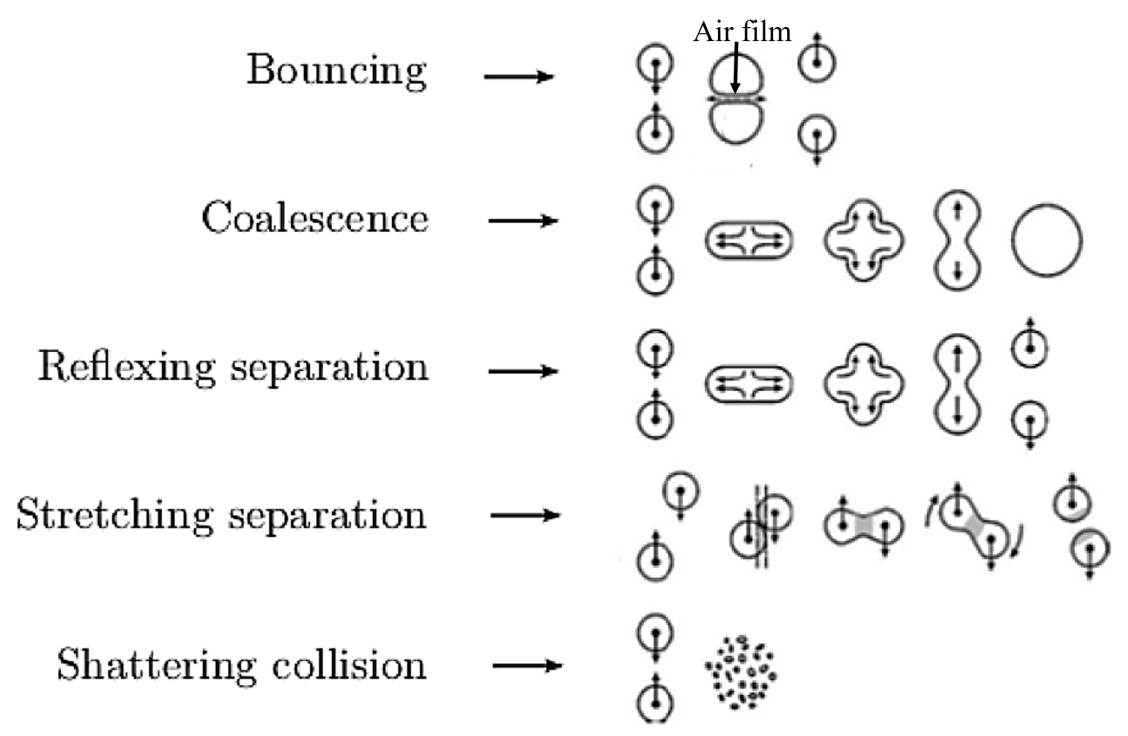

Fig. 2.23 Drop-drop interaction [17]

center line. If $B>0$ the collision is off axis, and if $B=1$ a tangential of grazing collision is happening. The second dimensionless parameter is the droplet diameter ratio $D_{d, 2} / D_{d, 1}$, where $D_{d, 1}$ and $D_{d, 2}$ are the diameters of the largest and the smallest droplet respectively. The last two parameters are the Reynolds and Weber numbers and are estimated as follows:

$$
\begin{gathered}
R e_{\text {coll }}=\frac{\rho_{f} u_{r e l} D_{d, 1}}{\mu_{f}} \\
W e_{\text {coll }}=\frac{\rho_{f} u_{r e l}^{2} D_{d, 2}}{\sigma}
\end{gathered}
$$

Collision may result in bouncing, coalescence, reflexive separation, stretching separation or shattering collision, and a criterion has to be specified to determine which one occurs. Qian and Law [173] defined the transition between these five collision regimes qualitatively in terms of the collision Weber number and the impact parameter (figure 2.24). 


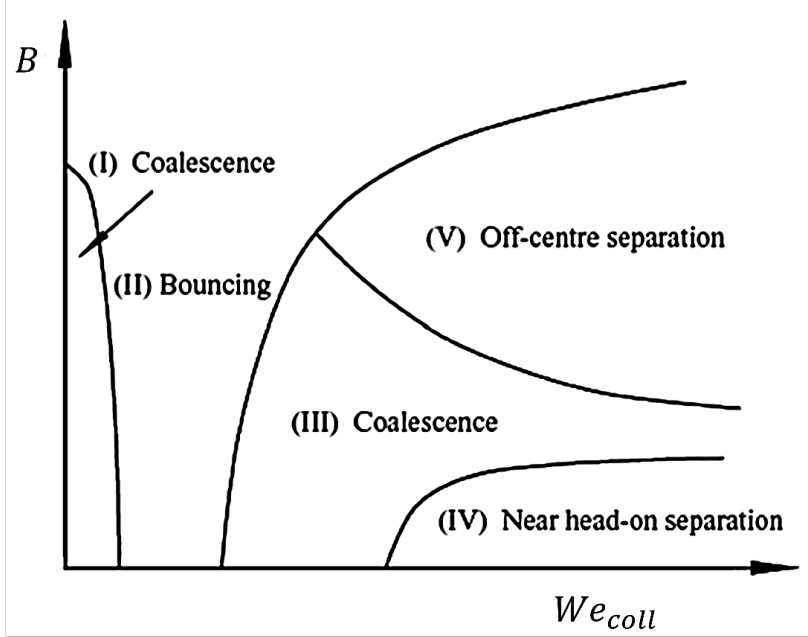

Fig. 2.24 Map of coalescence modes

\subsection{Theoretical view of the diesel spray structure and its characteristics}

For a diesel spray characterization there are several parameters that allow to determine both its appearance and structure. Usually, two points of view are used for the characterization: the macroscopic one (for basic geometrical characteristics and the global shape of the spray) and the microscopic one (for internal characteristics of the spray).

\subsubsection{Macroscopic characterization}

The macroscopic characterization view of the spray permits an understanding of the global interaction of the spray with its surrounding air. The main macroscopic parameters usually measured are; the spray penetration, spreading angle, entrained air volume, liquid length and the intact length. 


\section{Vapor spray penetration}

The vapor penetration largely determines both the mixing process and the probability of collision against the chamber walls. It depends essentially on the instantaneous momentum of the spray in the nozzle. The penetration refers to the distance traveled by the spray tip into the combustion chamber, while the spreading angle is the opening angle included between the two sides of the spray. The definition of spray penetration $(S)$ and spreading angle $(\theta)$ are indicated in the figure 2.25.

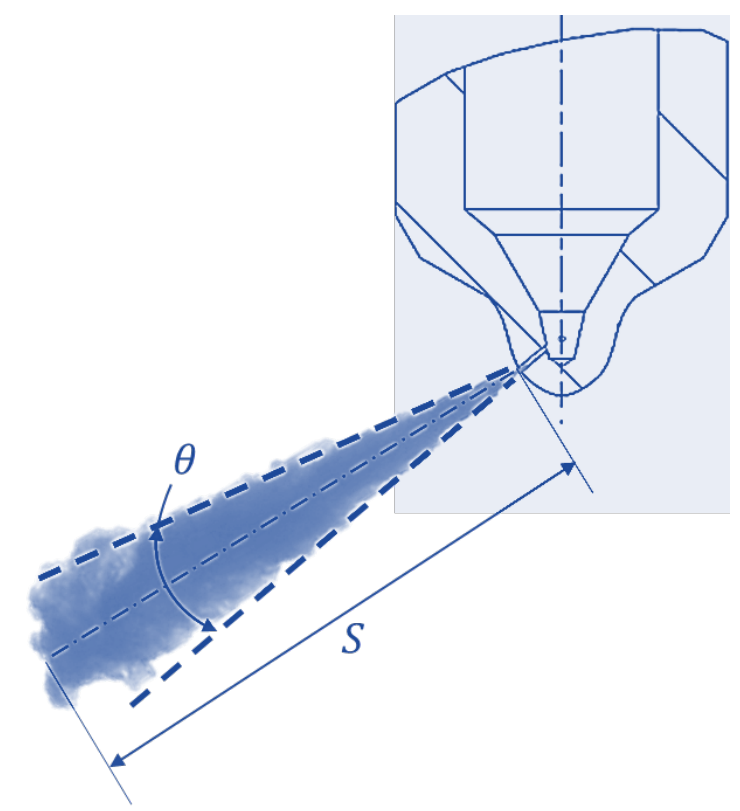

Fig. 2.25 Spray penetration and spreading angle.

A wide range number of studies in the literature have linked the spray penetration with the boundary conditions such as the pressure drop through the orifice, the ambient density, the orifice diameter, etc. Most of the correlations presented in these works have the form of the equation 2.36 [31, 64, 118, 130, 211]. Hay and Jones [59] highlighted as the best correlations the ones presented by Dent [36] and Wakuri et al. [210].

$$
S \propto \rho_{a}^{-1 / 4} \Delta P^{1 / 4} D_{o}^{1 / 2} t^{1 / 2}
$$


Wakuri et al. [210] extended that expression, including the discharge coefficient of the nozzle, $C_{d}$, and the spray spreading angle, $\theta$; where the last one is inversely proportional to the spray penetration, proposing the correlation:

$$
S(t)=\frac{\left(2 C_{d}^{3}\right)^{1 / 4}}{(\tan \theta / 2)^{1 / 2}} \rho_{a}^{-1 / 4} \Delta P^{1 / 4} D_{o}^{1 / 2} t^{1 / 2}
$$

From these studies can be concluded that the penetration is proportional to the square root of time. Nevertheless, the relationship $S(t) \propto t^{1 / 2}$ is applicable only after a transition time, before this time the behavior of $S$ is linear with $t$. The moment where the penetration changes its behavior is usually called the break-up time $\left(t_{b}\right)$, which is the instant when the complete atomization regime starts. Some studies have related this $t_{b}$ with the break-up length [64] and also it has been defined as the period where the spray is dominated by the injected liquid (before being dominated by the entrained gas) [118]. For Desantes et al. [44] $t_{b}$ is the instant moment when the penetration is influenced by the increasing mass flow rate (or more generally momentum flux) due to the dynamic behavior of the injector.

Naber and Siebers [118] added some other variables to these correlations, based on the hydraulic coefficients of internal flow, such as $C_{v}$ and $C_{a}$, as well as the spreading angle. In their work, $t_{b}$ is equivalent to the transition time, and $a$ is a constant value ( $a \approx 0.66$ ) based on a best fit of the correlation to their non-vaporising data. After the definition of the $t_{b}$, it is clear that the penetration law must be expressed in two different equations. The table 2.5 gives a summary of the expressions most used in the literature, for instants before and after the $t_{b}$.

To determinate the influence of each parameter on the spray penetration, Naber and Siebers [118] summarize the typical parameters and its exponents in the penetration law (table 2.6). Taking into account those exponents, and for the transient part the following conclusions can be made:

- There is a linear dependency between the penetration and the injection time. 
Table 2.5 Expressions used in the literature for spray penetration.

\begin{tabular}{|c|c|c|}
\hline Author & Time Interval & $S(t)$ \\
\hline \multirow[t]{3}{*}{ Arai and Hiroyasu [64] } & for $t<t_{b}$ & $S(t)=0.39 \sqrt{\frac{2 \Delta P}{\rho_{f}}} t$ \\
\hline & $t \geq t_{b}$ & $S(t)=2.95 \rho_{a}^{-1 / 4} \Delta P^{1 / 4} D_{o}^{1 / 2} t^{1 / 2}$ \\
\hline & $t_{b}$ & $t_{b}=28.65 \frac{\rho_{f} D_{o}}{\left(\rho_{a} \Delta P\right)^{1 / 2}}$ \\
\hline \multirow[t]{3}{*}{ Naber and Siebers [118] } & for $t<t_{b}$ & $S(t)=C_{v} \sqrt{\frac{2 \Delta P}{\rho_{f}}} t$ \\
\hline & $t \geq t_{b}$ & $S(t)=\frac{C_{v}^{1 / 2}\left(2 C_{a}\right)^{1 / 4}}{(a \tan \theta / 2)^{1 / 2}} \rho_{a}^{-1 / 4} \Delta P^{1 / 4} D_{o}^{1 / 2} t^{1 / 2}$ \\
\hline & $t_{b}$ & $t_{b}=\frac{\left(2 C_{a}\right)^{1 / 2}}{C_{v} a \tan \theta / 2} \frac{\rho_{f} D_{o}}{\left(\rho_{a} \Delta P\right)^{1 / 2}}$ \\
\hline Desantes et al. [44] & $t>t_{b}$ & $S(t)=0.652 \frac{\Delta P^{0.254} D_{o}^{0.417} t^{0.513}}{\rho_{a}^{0.268} \tan \theta / 2^{0.5}}$ \\
\hline Payri et al.[159] & $t \geq t_{b}$ & $S(t)=0.018 \rho_{a}^{-0.256} \Delta P^{0.516} t^{1.044}$ \\
\hline
\end{tabular}

- An increment on the pressure difference $\Delta P$ (or in the injection velocity), produces an increment on the penetration.

- Neither $\rho_{a}$ nor $D_{o}$ affects the penetration.

Whereas for the developed zone, it is confirmed that:

- The penetration is proportional to the square root of time.

- Same as before, an increment on $\Delta P$ will increase the penetration, but with a different exponent value.

- As ambient gas density increases, spray penetration decreases. 
- Higher nozzle diameters increase the spray penetration.

- An increment in the spray cone angle produces a reduced spray penetration.

Table 2.6 Typical parameters and exponents used to estimate the spray penetration [118].

\begin{tabular}{cc}
\hline \hline Parameter & Fit exponent interval $(n)$ \\
\hline$t^{n}$ & $0.48-1.0$ \\
$D_{o}{ }^{n}$ & $0.0-0.5$ \\
$\left(P_{\text {inj }}-P_{b a c k}\right)^{n}$ & $0.25-0.5$ \\
$\rho_{a}{ }^{n}$ & $-0.5-0.0$ \\
$\rho_{f}{ }^{n}$ & $-0.5-0.26$ \\
\hline
\end{tabular}

\section{Spreading angle of the spray}

A basic representation of the spray could be a cone and a semi-sphere placed at the end, where the semi-sphere is considered the more transient part of the spray. The conical shape is a region of the spray that is considered quasi-stationary and it extends from the nozzle to approximately $70 \%$ of the total penetration $[33,39,86]$. The spray is defined from two straights lines adjusted to the spray contour (in the quasi-stationary region) and the cone vertex which is located in the nozzle exit. There are other different definitions of the spray cone angle in literature. Bae et al. [12] set the spray angle as the angle between two lines connecting the nozzle tip and the spray boundary at $50 \%$ of the spray penetration. Other authors obtain this value at $60 \%$ of spray tip penetration $[92,154]$. However, and despite any reference (i.e. 50\% - 70\%) or the technique used, the spray angle depends on the air-fuel density ratio $[35,39,118,174,178,217]$ (equation 2.38). Under non-evaporative conditions, the exponent of the density ratio varies from 0.2 to 0.5 , although for Naber and Siebers [118] is 0.19 the exponent that better fits the experimental measurements.

$$
\tan ^{-0.5}(\theta / 2) \propto\left(\frac{\rho_{a}}{\rho_{f}}\right)^{0.19}
$$


As the penetration, spray angle changes under evaporative and reactive conditions. Under evaporative conditions, spray angle suffers a contraction. Conversely, and increase in the spreading angle is caused by the increase of temperature, as a consequence of the heat release associated to the combustion process $[27,114]$.

\section{Entrained air volume}

The volume of air entrained allows to quantify the mixing process of the fuel with the air surrounding it. It is a clear indicator of the fuel overall concentration and a key factor in the spray evaporation process. There are two entrainment functions to quantify such process:

- Mixture rate $(M R)$ : López [100] assesses the air entrainment based on the evolution of mass fraction on the spray axis. In this work the $M R$ was defined as follows:

$$
M R(x)=d_{e q} \frac{\partial\left(1 / Y_{f, c l}(x)\right)}{\partial(x)}
$$

Where the equivalent diameter $\left(d_{e q}\right)$ is calculated as:

$$
d_{e q}=d_{0} \sqrt{\frac{\rho_{f}}{\rho_{a}}}
$$

- Entrainment coefficient $\left(C_{e}\right)$ : Several studies have experimentally measured the entrainment with this coefficient for turbulent round jets, under no iso-dense conditions $[58,181]$. The common expression to determine this coefficient is:

$$
C_{e}(x)=\frac{d_{e q}}{\dot{m}_{0}} \frac{\partial \dot{m}_{f}(x)}{\partial x}
$$

where $\dot{m}_{0}$ is mass flow rate of fuel at the nozzle exit. The entrainment coefficient was determined to be 0.32 for the steady part of the jet. 


\section{Liquid length}

Under evaporative conditions, the injected fuel is vaporized after a certain amount of time in the discharge chamber. As a consequence, the spray liquid phase initially penetrates until it reaches a steady value (figure 2.26). This steady value, can also be called as liquid length and is strongly affected by temperature and fuel properties. Some correlations have been reported in the literature and they generally show the dependence of some other parameters like nozzle diameter, ambient density or pressure drop. The behavior of the liquid length is generally well described using the 1D mixing limited models or by empirical correlations obtained by different authors in the literature $[117,139,159]$. For reference, the following correlation from the 1D study by Pastor et al. [128] is presented:

$$
L L_{v}=\frac{K_{p} C_{a} d_{0}}{C_{m v} \tan \left(\frac{\theta}{2}\right)}
$$

where $K_{p}$ is a constant depending on ambient conditions, $C_{a}$ is the area coefficient, and $C_{m v}$ is a coefficient depending on the fuel and ambient properties.

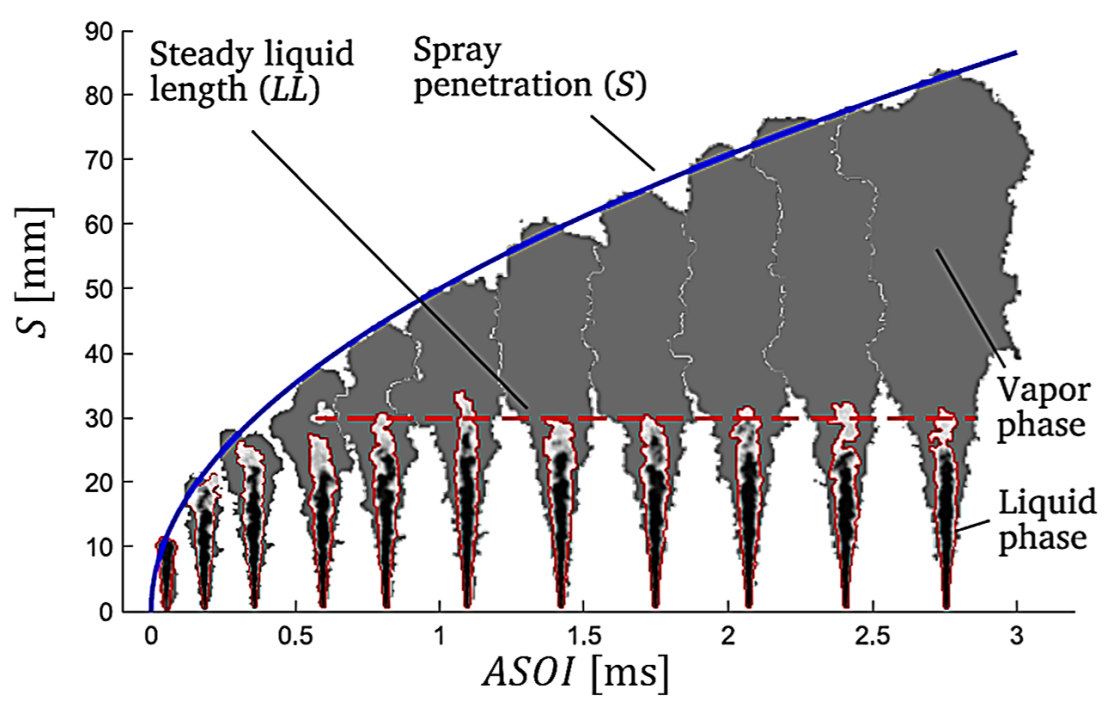

Fig. 2.26 Spray penetration and liquid length representation [14]. 


\section{Intact length}

It is generally defined as the distance between the orifice exit and the location where the first droplets appear due to the atomization process. Even though this feature is listed in the macroscopic characteristics of the spray, the length of this intact core $(I L)$ can be less than $1 \mathrm{~mm}$. Numerous studies have shown the variability of the intact core length depending on the $\rho_{f} / \rho_{a}$ and the $L / D_{0}$ ratios, the temperatures of both fluids and the physical and chemical properties of the fuel $[2,26,28,34,47,56,64,118,193,194,218]$.

\subsubsection{Microscopic characterization}

The microscopic parameters, explained bellow, are fundamental for the validation and development of spray models and CFD simulations. These characteristics help to the understanding of what is within of the spray boundaries. Some difficulties related to the diesel spray measurements of microscopic characteristics as: high temperature/pressure conditions, dense spray, short time scale, etc., make the access to these microscopical quantities a constant scientific-technological challenge [143]:

\section{Droplet size}

The measurement of the droplet size is important for the understanding of the atomization process and of the droplet-air momentum transfer. Nevertheless, the droplet diameter cannot be treated as a deterministic measurement since the droplets formed span over a wide range of diameters, and the evaporation process reduces the size of the droplets while traveling inside the combustion chamber. As a consequence, an statistical approach is usually employed to characterize the droplet diameters; the spray is mapped in time and space and each point in space is related to a histogram. By representing the effective experimental measurements on the histogram, the related probability density functions (PDF) are obtained. However, the analysis of the PDF generally does not provide any crucial information except regarding spray non-uniformity. Concerning these characterization difficulties, Mugele and Evans [116], 
found another way to describe the atomization quality, defining the characteristic diameters shown in table 2.7.

Table 2.7 Definitions of mean diameters according to Mugele and Evans [116].

\begin{tabular}{ccccc}
\hline \hline Notation & Physical meaning & factors & Formulation \\
\hline$D_{10}$ & Avg. geometrical diameter & Diameter & $\frac{\sum_{i} N_{i} D_{i}}{\sum_{i} N_{i}}$ & \\
& & & & \\
$D_{20}$ & Avg. surface area & Surface & $\left(\frac{\sum_{i} N_{i} D_{i}{ }^{2}}{\sum_{i} N_{i}}\right)^{1 / 2}$ & \\
& & & & \\
$D_{30}$ & Avg. Volume / mass & Volume & $\left(\frac{\sum_{i} N_{i} D_{i}{ }^{3}}{\sum_{i} N_{i}}\right)^{1 / 3}$ & \\
& & & & \\
& & & & \\
$D_{32}$ & Volume/surface ratio & Volume/surface & $\frac{\sum_{i} N_{i} D_{i}{ }^{3}}{\sum_{i} N_{i} D_{i}{ }^{2}}$ & \\
& & & & \\
\hline
\end{tabular}

$D_{10}$ is the direct average of droplet diameters. This is the simplest and most intuitive parameter. Another indicator is the $D_{20}$, whose formula insures that if all droplets had the diameter equal to it, the sum of all the droplets' surface area would remain the same. Similar to $D_{20}, D_{30}$ is calculated such that if all droplets had this diameter their total volume would be the same. $D_{30}$ can prove very useful for spray researchers because by virtually replacing all the droplets with ones having this size also the injected mass is preserved, as well as local air/fuel ratios [196].

The most employed for diesel spray studies is the $D_{32}$, also called Sauter Mean Diameter $(S M D)$. It represents the diameter of the droplets of a mono-disperse spray with the same volume to surface ratio as the characterized poly-disperse spray. Hence, the lower the $S M D$, the higher the droplet surface with respect to its volume, thus leading to a greater efficiency of the mixing and evaporation processes. 
For droplet size prediction some correlations for $S M D$ have been obtained experimentally, through techniques like Planar Laser Induced Fluorescence (PLIF) [76] and its derived techniques [85], which relate the fluorescence signal, proportional to the droplet volume, to the scattering signal, that is a function of the droplet surface. Or Phase Doppler Particle Analyzer (PDPA) (this technique will be explained in detail further on). Hiroyasu $[64,65]$ engaged a campaign to extensively study the size of the droplets in the spray under non-evaporative conditions. These works provided an expression of the Sauter Mean Diameter valid for a location where the disintegration process is considered to be complete (65 mm downstream) (equation 2.47). All the terms with the $p$ subindex are in reference to the droplets:

$$
\frac{S M D_{65 m m}}{d_{0}}=0.38 R e_{p}^{0.25} W e_{p}^{-0.32}\left(\frac{\mu_{p}}{\mu_{a m b}}\right)^{0.37}\left(\frac{\rho_{p}}{\rho_{a}}\right)^{-0.47}
$$

Since the previous expression is not suitable for points closer to the injector and short injection times of approximately $1000 \mu \mathrm{s}$, some other authors have proposed other expressions to link crucial factors like drag and injection conditions with the SMD. Levy et al. [95] proposed the following expression:

$$
S M D=K_{d r a g} \mu_{a m b}{ }^{-0.37} \rho_{a}^{0.11}
$$

Where $K_{d r a g}$ is a constant that could represent the selection by drag that takes place and the time from the start of injection. They concluded that the SMD increases with the distance to the nozzle, so the constant $K_{\text {drag }}$ could reflect that as well. They found that for a $20 \mathrm{~mm}$ distance $K_{\text {drag }}=0.245 \times 10^{-6}$ and right at the exit $K_{\text {drag }}=0.233 \times 10^{-6}$. Hiroyasu [65] and Vlad [196] also proposed expressions linking the injected mass and other injection parameters with $S M D$, being the first expression the most referenced in the literature:

$$
S M D=2.33 x 10^{-3} \Delta P^{-0.35} \rho_{a}^{0.121} \dot{M}_{f}^{0.131}
$$




$$
S M D=1.67 \Delta P^{-0.18} \rho_{a}{ }^{0.311} d_{0}{ }^{0.3} x^{0.282}
$$

Considering that to build these correlations a weak amount of experimental data has been used and large variations have been obtained on the predictions, care must be taken at the moment of using them.

\section{Velocity and concentration profiles}

The characterization of the velocity and concentration profiles of the spray allows to asses and understand the process of air-fuel mixing. Several equations that describe velocity profiles for diesel sprays can be encountered in literature [37, 63, 143, 189]. Desantes et al. [37] emphasize that despite of all these profiles are very accurate, the following equation would be the best option in terms of MSD (Mean Squared Deviation):

$$
U(x, r)=U_{\text {axis }}(x) \exp \left(-\alpha\left(\frac{r}{R}\right)^{2}\right)
$$

Desantes et al. [42] have estimated that $\alpha$ value is equal to 4.6. And $\mathrm{R}$ can be defined as:

$$
R=x \tan \left(\frac{\theta}{2}\right)
$$

The velocity is often related to concentration, in a gaseous jet, velocity and concentration have similar profiles in any cross-section [13]. The radial velocity profiles can be then extended to concentration profiles by means of the Schmidt number defined in the equation 2.53 as the relationship between the diffusion of momentum and mass $[41]$.

$$
S c=\frac{\mu_{f}}{\rho_{f} K_{D}}
$$

Where the mass diffusivity coefficient $K_{D}$ is theoretically solved thanks to the Flick's laws of diffusion. This coefficient is proportional to the molecular diffusivity in a 
medium and mainly depends on kinetic energy, droplet diameter and viscosity of the medium. This means that temperature and pressure of both the liquid and the gases affect the mass diffusivity coefficient and thus the Schmidt number.

Finally, the concentration profile can be expressed as follows:

$$
Y_{f}(x, r)=Y_{f, a x i s}(x) \exp \left(-\alpha S c\left(\frac{r}{R}\right)^{2}\right)
$$





\section{Chapter 3}

\section{Literature review}

\subsection{Introduction}

This chapter describes the theoretical background that represents the starting point of this work, and serves as a reference for the interpretation of the results obtained. To this end, the different characteristics taking place in the fuel injection are described including the flow through the nozzle, the liquid atomization and evaporation process. Expected trends for these parameters are stand out at low, high and very high injection pressures. Finally, the studies found in literature about the effect of very high injection pressures over the diesel spray are presented in a brief review.

\subsection{Overview of experimental macroscopic and mi- croscopic characterization on diesel sprays}

It is well known that fuel injection pressure, drag force, physical properties of the fuel and ambient pressure govern fuel atomization and spray tip penetration [55]. Thus, it is important to estimate the effects caused by these parameters on spray development. For this reason, numerous studies have analyzed the effect of the environment, injection 
conditions and fuel properties on macroscopic and microscopic characteristics of the spray.

\subsubsection{Macroscopic technologies used for spray measurements}

Traditional spray testing in the research community has been focused largely on macroscopic characteristics; spray visualization, penetration (axial and radial) [107, 167], cone angle, mass flow rate (rate of injection) [22, 104, 158, 169], mass distribution $[81,135]$, and momentum flux $[43,140,150]$. Optical imaging has been used for a century and continues to be used with volume illumination, back-illumination, shadowgraph and schlieren [161] techniques. These approaches, now using digital cameras, are still prominent [48]. Schlieren is normally used in combination with MIE-scattering for vapor and liquid spray imaging respectively. These optical experimental techniques, used for macroscopic analysis, have been employed in the characterization of multi-hole and single-hole nozzles [24, 195].

\section{Mass flow rate}

The rate of injection (ROI) is derived from the combination of different parameters such as: nozzle diameter, injection pressure, injection duration, and some fuel properties such as: density, viscosity and bulk modulus. The main purpose of the internal characterization is to determine the injection rate curve and thus the instantaneous mass flux. The importance of this parameter decays on engine performance, emissions and even engine noise. Therefore, the measurement and control of the mass flow rate has been subject to a multitude of research works in the field of diesel injection. $[18,29,60,80,101,102,123,138,144,158,169,208]$. Desantes et al. [40] compared diesel and biodiesel fuels in a single-hole conical nozzle, for a variation of pressure difference between injection pressure and back-pressure from 15 to $40 \mathrm{MPa}$. They concluded that density is the unique property driving the mass flow rate and the effective velocity. Viscosity only impacted the opening and closing of the injector. Armas et al. [7] carried out a preliminary study about the effect of the main injection 
3.2 Overview of experimental macroscopic and microscopic characterization on diesel sprays

parameters using different alternative fuels. They concluded that the back pressure does not produced any significant effect on the rate of injection. Also, they found that, as higher the density, injection pressure and energizing time as greater the total fuel mass injected.

\section{Spray visualization}

For vapor spray visualization and for the study of axially drilled single-orifice nozzles, the single-pass Schlieren arrangement is typically used, since experimental vessels with multiple optical accesses regularly allow line of sight visualization. This has been shown by Pickett et al [166], for analyzing vapor and liquid characteristics. They used various diagnostics combined with high-speed single pass shadowgraph/schlieren imaging to elucidate the details of diesel spray from a single-hole nozzle injector, under non-vaporizing, non-reacting and reacting conditions in an optically accessible vessel. They concluded that the refractive index, caused by temperature gradients at the wall or within the ambient gases of the combustion vessel, are significant and unavoidable in the shadowgraph/schlieren imaging.

Multi-hole nozzles have a wide range of applications in the fuel supply system of modern diesel engines, although single-hole nozzles dominate basic internal flow and spray research. As it has been specified before, the interest of this work is centered on multi-hole injectors. These injectors achieve a more homogeneous mixture and decrease the droplet size and thus increase the liquid-gas contact surface [87]. For this reason, the use of multi-hole diesel injectors offers many advantages including a significant optimization of the combustion behavior and soot emissions [115]. Despite all these benefits, the spray atomization process behavior is not clearly identified for multi-hole injectors [87], accordingly, the characterization of these injectors is still a topic of interest in the engine community [115, 162, 223].

Contrarily to single-hole nozzles, measurements on multi-spray nozzles are commonly performed through a single optical access, in which case a double-pass arrangement 
is employed [127, 161]. Pastor et al. [127], for example, carried out an extensive analysis on double-pass Schlieren set-ups for multi-hole nozzles under evaporative conditions. In addition, it was also presented a parametric study of a six-hole micro-sac nozzle, varying ambient density and temperature. They found that characteristics of the Schlieren images taken, showed a high dependence on the details of the optical arrangement used. Mainly of the angle between the optical axis of the reception part of the Schlieren system and the axis of the illumination beam, since it determines the potential for filtering information in the Fourier plane.

Apart from the geometric advantages offered by the double-pass arrangement for multi-hole nozzles, Payri et al. [161] highlight some others. They used a three orifice nozzle (Spray B from ECN) and performed vapor phase visualization of a diesel spray with both single and double-pass Schlieren optical arrangements, to compare their capabilities of determining macroscopic spray variables for the same injection event. The double-pass setup produced images with a sharper spray contour and more contrast. Additionally, for the range of data studied, due to its higher sensitivity, the double pass configuration captured vaporized fuel in regions where the difference between the local density of the spray and its surroundings is low, and thus the deflection angle is small.

Bardi [14], in his work, studied the effect of needle lifting controlling using a direct acting multi-hole diesel injector piezo-driven. The objectives of this work were to detect the macroscopic effects of needle controlling on the spray development. Bardi used the MIE-Scattering technique to get liquid contours and liquid length, and a double pass Schlieren set up for vapor characteristics using a high-temperature mirror. The set-ups were able to detect vapor and liquid contours. All the measurements showed typical behavior when studying the effect of conventional boundary conditions (ambient parameters and injection pressure).

For liquid spray visualization, the MIE-Scattering optical technique is widely used by the engine community due to its simplicity [107]. The main drawback of this arrangement is that the illumination as well as the experimental conditions affect the 
3.2 Overview of experimental macroscopic and microscopic characterization on diesel sprays

measured scattered light, thus inducing errors on the results. For example, Pickett at al. [165] compared MIE-Scattering with eight other diagnostics to measure liquid length and showed that the results were strongly dependent upon the optical setup and the strategy defined to process the data. On the other hand, Manin et al [107]. have highlighted that MIE-Scattering was able to provide semi-quantitative measurements of the liquid length as long as the optical setup remains the same, thus enabling the researcher to study liquid penetration while changing operating condition. Pickett et al. [165, 169] have shown that there are sensitivities to MIE-Scattering lighting and thresholding that change the computed liquid length. For example, processing using a $3 \%$ threshold of maximum light intensity in the core of the spray, produces about a $1 \mathrm{~mm}$ longer liquid length than when using only $0.3 \%$. However with a $3 \%$ thresholding, as suggested by Siebers [194], the penetration trends were similar that the ones obtained with other techniques like, diffused back illumination (DBI) and Long-distance microscopy (LDM) (figure 3.1).

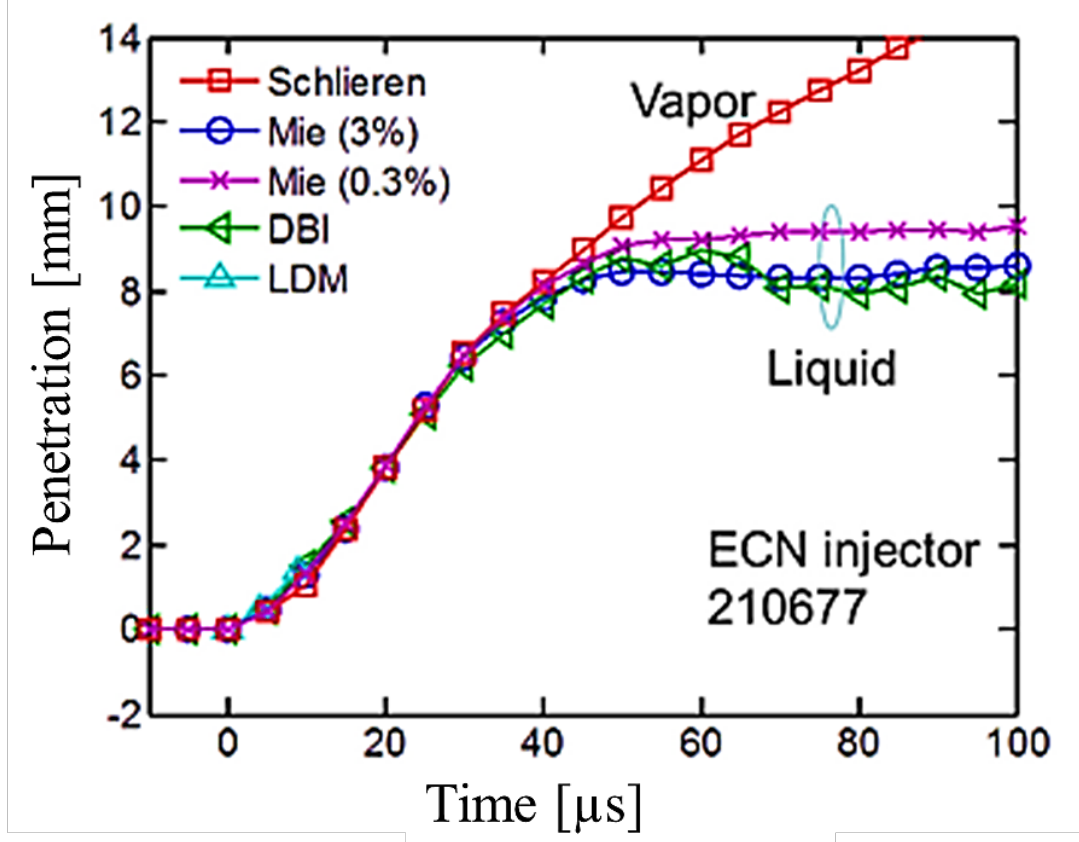

Fig. 3.1 Comparison DBI and MIE-Scattering optical arrangements [169] 


\section{Expected trends in spray visualization}

Throughout the years, basic studies have been made in order to investigate the effects on spray liquid length and vapor phase location induced by engine parameters such as orifice diameter, ambient gas conditions, injection pressure and fuel characteristics [141]. The most common expected trends for the macroscopic parameters, described in section 2.7, were studied more than 20 years ago by Naber and Siebers [118, 193, 194]:

For vapor spray visualization and cone angle the most expected trends are:

- As ambient gas density increases, spray dispersion increases, which results in more entrained air in the spray. The larger entrained mass leads to a slower penetration velocity based on conservation of momentum, and therefore, reduced penetration.

- Vaporization reduces penetration by as much as $20 \%$ relative to non-vaporizing sprays.

- When ambient temperature is modified (keeping constant ambient density), measured penetration remains the same, where only slight differences become appreciable [132].

- An increase in $\Delta P$ causes an increase in the cone angle up to a maximum value.

- An increase in the relation of densities $\left(\rho_{a} / \rho_{f}\right)$, causes an increase in the cone angle due to an increase in the aerodynamic interaction, according to Arrègle et al. [9], nevertheless, for values greater than $\left(\rho_{a} / \rho_{f}>0.04\right)$ the cone angle tends to be independent of this parameter. Gimeno et al. [53] used two ECN (Engine Combustion Network) single-hole nozzle injectors and single pass Schlieren imaging to determine the influence of ambient conditions under inert atmosphere, using n-dodecane and commercial diesel. Ambient temperature promoted the evaporation and mixing processes with negligible influence in inert vapor devel- 
3.2 Overview of experimental macroscopic and microscopic characterization on diesel sprays

opment. Density affected the aerodynamic interaction between the spray and the ambient and also enhanced the mixing and incrementing the spreading angle.

- Increasing the ambient temperature, increases the evaporation process in the sprays exterior zone, consequently a decrease in the angle of the cone is produced [66].

And for liquid spray visualization [110]:

- The ratio $\left(L / D_{o}\right)$ influences the liquid length penetration when the pressure of the control volume is low and the fuel is injected at atmospheric conditions. However, when this pressure is high, the influence of this parameter in liquid length penetration decreases [56].

- Liquid length is linearly dependent on orifice diameter and approaches a value of zero as orifice diameter decreases toward zero.

- Orifice aspect ratio has a small and inconsistent effect on liquid length. Nevertheless, any orifice design parameter that can affect the orifice flow can affect the liquid length [110] . Payri et al. [151, 159] also evaluated the effect nozzle of the geometry, with a combination of different imaging techniques (Double-pass Schlieren, MIE-Scattering and $\mathrm{CH}$ chemiluminiescence). Three different six-hole sac injectors with different orifice degrees of nozzle conicity were used. From $L L_{v}$ results obtained with MIE-Scattering, it was observed that the cylindrical nozzle provided the highest $L L_{v}$ at a low injection pressure (30 MPa), because of its higher diameter and the absence of cavitation. On the other hand, when comparing the two conical nozzles, no clear differences were found between them.

- Injection pressure has no significant effect on liquid length.

- An increase on the ratio of densities $\left(\rho_{a} / \rho_{f}\right)$ produces a decrease in liquid length due to an increase in the aerodynamic interaction between the spray and the environment. 
- The ambient temperature is one of the thermodynamic properties that strongly affect $L L_{v}$, since the rate of combustible vaporization is directly related to the energy content of the working fluid, and to the degree of the mixture of both fluids (fuel-gas/air). Nevertheless, this parameter diminishes its effect at high pressure injection because both, an increase in the speed of injection and the amount of fuel injected, ease the effect with respect of low pressures. Also an increase of this temperature at constant density causes an increase in the specific energy of the latter and therefore a decrease in liquid length during spray penetration $[2,28]$. This is a consequence of high drag of vap-orization energy towards the fuel [47]. Payri et al. [139] analyzed the effect of the fuel temperature on the diesel spray $L L_{v}$ in inert and reacting conditions. They found that an increase in fuel temperature led to a lower $L L_{v}$, which is justified by the fact that a lower amount of heat needs to be transferred to the fuel droplets in order to evaporate them than to the ones at low temperature.

- The fuel temperature is a variable that greatly affects liquid length penetration, in such a way that with increasing the temperature of fuel, the liquid length tends to decrease lineally. It has been proven that at under conditions of low temperature and fuel density there are more significant effects that under high conditions of temperature and density [194].

- The liquid length increases with decreasing fuel volatility and decreases with increasing fuel temperature. Physical-Chemical properties of the fuel (i.e., density, viscosity and volatility) have a considerable impact on liquid length penetration with volatility being the most influential property on penetration. Siebers et al. $[193,194]$ observed that a low volatility fuel requires more energy to be heated and then evaporate than a high volatile fuel. Therefore, for a low volatile fuel, liquid length penetrates much more than a more volatile fuel because the amount of energy dragged towards the fuel depend basically on the process of evaporation. 
3.2 Overview of experimental macroscopic and microscopic characterization on diesel sprays

\subsubsection{Microscopic technologies used for spray measurements}

The information related to the microscopic characterization (velocities and droplet diameters) is fundamental for the development and validation of spray models and CFD simulations [14]. Laser Doppler velocimetry is a well-known and powerful technique able to measure the velocity and, under certain hypotheses, also the size of spherical particles like fuel droplets in the air [195].

The application of Phase Doppler Anemometry in a diesel spray is quite challenging because of the specific characteristics of a diesel spray $[140,196]$. The high density of the diesel spray is a physical limitation for the PDPA technique that can only be overcome if the measurement volume is small enough to avoid the passing of multiple droplets at the same time. Several studies have mentioned these difficulties. Arrègle et al [9], measured the SMD for single-hole nozzles with injection pressures from 30 to $110 \mathrm{MPa}$, and ambient densities from 10 to $30 \mathrm{~kg} / \mathrm{m}^{3}$. They found rather difficult and unreliable the velocity measurements in the quasi-stationary part of the spray. Contrarily, the spray front and its tail were easier to measure and might present valid diameter measurements but the velocity data is obviously much lower than in the main part. Hung et al. [69], carried out measurements with a $240 \mu m$ orifice nozzle with two injection pressures: $21 \mathrm{MPa}$ and $105 \mathrm{MPa}$. It was observed that at $10 \mathrm{~mm}$ and $20 \mathrm{~mm}$ from the orifice measurements on-axis with the high injection pressure were impossible.

There are however other system parameters that also have to be chosen properly in order to eliminate noise and erroneous measurements. For the setting up of the equipment, Payri et al. [136] carried out a PDPA system optimization for the measurement of diesel sprays. The purpose of this work was to understand exactly the influence of each system parameter, and to find the best setup enabling measurements in the spray zones that are densest and closest to the injector. This work was the base for the set up PDPA configuration for this thesis (section 4.6.1). Consequently, the optimized parameters were used and adjusted for multi-hole injectors.

Notwithstanding these difficulties, PDPA measurements on diesel spray applications, single and multi-hole nozzles, are still being a focus of interest in the research community, 
due to the advantages that a transient optical technique and non-intrusive brings with it. Li et al [220], performed experiments for microscopic spray characteristics of diesel, rapeseed methyl ester (biodiesel) and Gas-to-Liquid fuels in atmospheric conditions at different fuel injection pressures (80MPa to $120 \mathrm{MPa}$ ) and measuring positions varied from $20 \mathrm{~mm}$ to $70 \mathrm{~mm}$ downstream of nozzle using PDPA technique and a single-hole injector. Data rate was observed to be quite low in regions near the nozzle and at high injection pressures. SMD of all fuel droplets decreased with increasing the injection pressure. However, diesel spray showed a smaller SMD when injection pressure was increased to $120 \mathrm{MPa}$.

Yao et al. [221] study the effect of nozzle geometry on spray and combustion characteristics under high injection pressure (40-120 MPa) with a common rail fuel injection system. To avoid the interference among multi-hole sprays, only single-hole nozzles were tested. In this study the droplet size distribution shows that the SMD reduces with the increase of the distance from injector tip, and also increases on some region in the axis direction. Meanwhile the SMD of the central axis is bigger than that of the side. With the injection pressure going higher, the SMD of all tested nozzles decreased.

In the case of multi-hole injectors, a series of experimental microscopic tests on diesel fuel spray characteristics were carried out by Pribicevic and Sattelmayer [172] in a constant volume vessel, to investigate the atomization and mixing process by applying PDPA. Two eight-hole injectors were used for this purpose. The sprays were injected in a nitrogen atmosphere at back pressures of ambient conditions and 2.5 MPa. An increase of the injection pressure produced an increase of the droplet velocities and diameters along and near the spray axis, which at ambient conditions can be explained by the reduced aerodynamic forces due to the increased velocity of the entrained gas. At 2.5 MPa of back pressure, an increase of the droplets occurred and was attributed to the increase of droplet coalescence. Towards the spray periphery the influence of aerodynamic forces became dominant, resulting in slightly smaller droplets 
3.2 Overview of experimental macroscopic and microscopic characterization on diesel sprays

at higher injection pressure. By increasing the back-pressure from ambient to $2.5 \mathrm{MPa}$ an increase of the droplet size by on average $30 \%$ was observed. Thereby the droplet velocity decreased dramatically. Gupta and Argawal [55], carried out a macroscopic and microscopic analysis over a six-hole spray injector, evaluating Karanja biodiesel blends and mineral diesel. MIE-Scattering and PDPA techniques were used to this end. The study suggests that findings on biodiesel blends are comparable to mineral diesel, as far as microscopic and macroscopic spray characterization is concerned. The SMD and the arithmetic mean diameter $D_{10}$ decreased with increasing injection pressure, however they increased with increasing biodiesel concentration in the test fuel.

Doudou and Maslouhi [45] exposed quite well the expected trends for velocity and droplet diameters. In this study the MIE-Scattering and PDPA optical techniques were used. The sprays were characterized in an environment, which simulates in-cylinder air density of the actual diesel engine when the injection starts. A wide parametric study was done generating evidence needed to quantify the influence of the common-rail pressure, nozzle hole diameter and environment gas density on the macroscopic evolution of sprays (spray tip penetration and spray cone angle) as well as microscopic behaviour (spatial and temporal evolution of drop size, drop velocity and drop concentration distributions). The following trends were found for microscopic parameters under non-evaporative conditions:

- The SMD increases with the rate of injection, since an increase in the volume of the injected liquid produces a greater air entrainment, the aerodynamic interaction grows and the critical size of the droplets increases. Aside from this, increasing the numeric population of droplets intensifies de coalescence, resulting in a growth in the geometry of the droplets [109].

- The relation of densities $\left(\rho_{a} / \rho_{f}\right)$ produces two opposing effects on the size of the droplets, intensification of atomization and the possibility of coalescence. If this 
ratio is augmented a greater aerodynamic interaction will exist, which causes the droplets to slow down and an increase in the numerical population in their field.

- SMD and droplet velocity are not correlated.

- The SMD has time dependence. For the evolution of the diameter of droplets during time is generally considered that the sizes of the droplets tend to diminish at the beginning of the injection and grow at the end [109]

- Larger droplets concentrations exist on the spray axis with a decay as the radial distance increases

- Aerodynamic forces decrease by increasing radial distance, coalescence effects increase near the spray axis because of the higher droplets concentration.

- The radial distribution of the SMD is almost constant for a given time. The axial distribution of the SMD shows a bathtub profile with a decrease followed by an increase.

- An increase of the injection pressure lead to an increase of the droplet velocities and diameters along and near the spray axis

- Towards the spray periphery the influence of aerodynamic forces becomes dominant, resulting in slightly smaller droplets at higher injection pressure.

- By increasing back pressure higher coalescence is expected and therefore higher diameters. 
3.3 Overview of experimental macroscopic and microscopic studies in diesel sprays at very high injection pressures

\subsection{Overview of experimental macroscopic and mi- croscopic studies in diesel sprays at very high injection pressures}

High injection pressures are considered the most efficient method for improving fuel economy, with low exhaust emissions in the modern high-pressure common rail injection systems [113]. Wang et al. [213] and Nishida et al. [121] suggest that the combination of micro-hole nozzles and ultra-high injection pressures can provide an effective way to reduce soot formation in the combustion chamber of diesel engine, since this combination avoids the interference of liquid length and lift-off length.

Over the past few decades, high-pressure fuel spray underwent a significant development, the injection pressure of common rail system has been going up, such as that of system developed by Bosch was $135 \mathrm{MPa}$ for the first generation, $160 \mathrm{MPa}$ for the second generation, $180 \mathrm{MPa}$ for the third generation, and $220 \mathrm{MPa}$ for the fourth generation. Nowadays, the injection pressure of commercial injection systems has been reached up to $250 \mathrm{MPa}$, and the pressure of injection system in the laboratory even has been elevated up to $400 \mathrm{MPa}[68,73]$.

Several studies have evaluated macroscopic characteristics of diesel sprays under very high injection pressures. Wang et al. [212], evaluated experimentally and analytically spray characteristics of bio-diesels (from palm and cooked oil) and diesel under ultrahigh injection pressures up to $300 \mathrm{MPa}$ and non-evaporating conditions. The properties were measured using a Light scattering method to visualize fuel spray in a constant volume vessel using a high speed video camera. In this study was concluded that high injection pressures are an effective way to mitigate the poor atomization characteristics of biodiesels.

Delacourt et al. [35] investigated the effect of injection pressure on the macroscopic spray characteristics for a wide pressure range (up to $250 \mathrm{MPa}$ ), recording images obtained with a fast camera using direct illumination of the spray. They proved that at very high injection pressures as $250 \mathrm{MPa}$, correlations (table 2.5) still describe 
penetration trends properly. The same range of injection pressures were studied by Quinglin and Min [219], however, they analyzed the spray under evaporative and nonevaporative conditions, using the Schlieren and MIE-Scattering techniques respectively (these are explained in detail in Chapter 4). In addition, they applied a backlit imaging technique to capture the detailed structure of initial spray near the nozzle. No significant variations on macroscopic characteristics were found. Nevertheless, they concluded that an increase of injection pressure improves the injector response sensitivity. When the injection pressure was elevated from $50 \mathrm{MPa}$ to $250 \mathrm{MPa}$, the response time and the injection cut time were reduce by $58 \%$ and $49 \%$ respectively.

Wang et al. [212] did a comparative analysis on spray configuration, penetration and cone angle under three elevated injection pressures of 100, 200, and $300 \mathrm{MPa}$ using diesel and biodiesel. It was observed that the penetration of the spray tip increased with injection pressure, but the increasing amplitude decreased. However, the cone angle was expected to remain consistently near $20^{\circ}$ and was less affected by the injection pressure.

With such high injection pressures, other studies have highlighted the predominant effect of shock waves on the evolution. Lee et al.[90] characterized a free diesel spray from a single nozzle injector with injection pressures up to $300 \mathrm{MPa}$. The spray was visualized by the Schlieren technique and a high speed camera. In particular, it is found that shock waves are present and propagated along the edge of spray in the downstream direction. The measured spray penetration length increases gradually with the injection pressure, but its increasing rate is decreased as the injection pressure increases.

Ming et al. [73], carried out an experimental study to investigate the effects of ultra-high injection pressure on the penetration characteristics of diesel sprays and leading edge shock waves generated around the sprays. The visualization of the spray field was done through a high-speed photography and the Schlieren imaging technique was used to visualize the shock waves. The Schlieren images obtained under $200 \mathrm{MPa}$, $300 \mathrm{MPa}$, and $400 \mathrm{MPa}$ show no evident differences between the cone angles as a 
function of over injection pressure due to the ambient air atmosphere. The experimental results validated the penetration model proposed by Hiroyasu and Arai (table 2.5) in terms of both curvilinear trends and data dispersion.

To provide more information on spray characteristics under super high injection pressures, Ming et al. [75] investigated both macro and micro-characteristics with injection pressures up to $300 \mathrm{MPa}$. Spray penetration and spray cone angle were measured using a high speed camera and a Schlieren set up. The microscopic characteristic of SMD was obtained via Malvern Spray Tec to analyze the influence of super high injection pressure on diesel spray atomization, induced shock waves were also captured using the Schlieren system. The SMD at $20 \mathrm{~mm}$ away from the orifice rapidly decreased with increasing injection pressure from $100 \mathrm{MPa}$ to $200 \mathrm{MPa}$, and then slowly reduced from $200 \mathrm{MPa}$ to $300 \mathrm{MPa}$. For the cone angle, the experimental data shows a good agreement with the empirical equation proposed by Hiroyasu and Arai [66]. Super high injection pressure generated larger slope of spray penetration curves but the amplification over pressure decreased.

A similar study was carried out by Nishida et al. [122], with the same range of injection pressures, but in this case a laser absorption-scattering (LAS) technique was used to analyze the effect of micro-hole nozzles on the equivalence ratio distributions, SMD and spray tip penetration length. The ultra-high injection pressure of $300 \mathrm{MPa}$ combined with a micro-hole diameter, were very effective to increasing the turbulent mixing rate and reducing the droplet size.

\subsection{Conclusions about the current state of knowl- edge}

An extensive review of the existing works regarding macroscopic and microscopic diesel spray characterizations under low and very high injection pressures has been performed. As a result, it has been noticed that MIE-Scattering and Schlieren techniques are the most common used optical arrangements for characterizing the spray from a 
macroscopic point of view. From this arrangements, the following conclusions can be made:

- For single-hole nozzles, single-pass Schlieren visualization is usually applied. Its main drawback is the unavoidable refractive index, caused by temperature gradients at the wall or within the ambient gases of the combustion vessel. This is usually solved with a proper image processing.

- Double-pass Schlieren visualization is generally used for multi-hole nozzles, since studies on these injectors are commonly performed through a single optical access. The vessels for these arrangements are usually equipped with a mirror able to endure under high temperatures inside the chamber. Consequently, the light crosses the test section twice, and the optical sensitivity theoretically increases by a factor of two [161].

- The main drawback of the MIE-Scattering optical technique is that the illumination as well as the experimental conditions affect the measured scattered light. However as long as the optical setup remains the same, this technique is able to provide semi-quantitative measurements of the liquid length.

- With the proper configuration and image processing (3\% thresholding, as suggested by Siebers [194]), the penetration trends are similar that the ones obtained with other techniques like, DBI and LDM. Therefore, reliable results for $L L_{v}$ that can be obtained with a more simple optical configuration.

Regarding microscopical arrangements, the following conclusions can be made.

- Despite all the difficulties related with PDPA measurements on diesel sprays, great attempts are being made for the optimization and application of this technique for dense sprays. This is due to the remarkable advantages that this transient and non-intrusive optical technique, brings with it. 
- It has been observed that shorter distances than $20 \mathrm{~mm}$ from the orifice measurements on-axis with the high injection pressure are quite challenging. Also near the spray axis, less droplet acquisition is usually reported.

- At higher injection pressures the density of the spray increases compromising a little bit more the amount of data acquisition.

Furthermore, the most common expected trends for microscopic and macroscopic parameters (mass flow rate, vapor and liquid penetration, cone angle, droplet velocities and droplet diameters) were explored as well in this chapter. From the literature consulted, and for characterizations carried out with injection pressures up to $250 \mathrm{MPa}$, it can be concluded that temperature has a strong effect over the $L L v$ but not to much on vapor penetration, affecting also the cone angle. Also, ambient density, back pressure, nozzle geometry and fuel properties affect all macroscopic parameters. In the case of microscopic characterization, it has been found that, SMD increases with ROI and it is affected also by the ambient density. In addition, injection pressure also has repercussions over the velocity and SMD. Different correlations have been formulated in some of these works for these parameters.

From characterizations with injection pressures greater than $250 \mathrm{MPa}$, it can be concluded that most of these works are focused on the study and analysis of shock waves and its effect on the spray development. Nevertheless, the spray structure and the study of macro and micro characteristics trends at such high injection pressures has not yet been extensively studied.

In this thesis the behavior of the diesel sprays micro and macro characteristics under low and very high injections pressures (up to $270 \mathrm{MPa}$ ) is analyzed, using three different multi-hole nozzles. Schlieren, MIE-Scattering, mass flow rate measurements and PDPA are the tools chosen. The PDPA configuration used by Soare [196] is adapted for multi-hole nozzles and for very high injection pressures as well. 



\section{Chapter 4}

\section{Materials and methods}

\subsection{Introduction}

In this chapter a detailed description of the experimental equipment used and the methodology followed to perform the measurements and data analysis is presented. The first section is dedicated to describe the injection system, while each of the remaining sections introduces the experimental facilities and methods to characterize the spray under macroscopic and microscopic point of views. The experimental configurations used in each of the installations and the steps taken to process the raw data are described here. All the results presented in this document have been measured in experimental facilities at CMT-Motores Térmicos laboratories.

\subsection{Injection system}

The feeding system of fuel, used in this thesis, consists in a high pressure volumetric pump (Bosch CP4), driven by an electric motor and a common-rail with pressure regulator controlled by a PID system. Two rails are installed within the circuit in order to solve problems with high-pressure fittings and, at the same time, to increase the volume of the high pressure system reducing the fluctuation due to the pump cycles. This system can generate relatively high rail pressures of up to $300 \mathrm{MPa}$ and maintain 
it at the set value while injecting fuel. The system was adapted to laboratory use and features have all the variables under control while experiments are performed. This is also important since the fuel injection amount is very low, thus there is a high proportion returning to the fuel tank, causing a gradual temperature rise. This is avoided using a well designed intercooler placed between the returning lines and the fuel tank (figure 4.1).

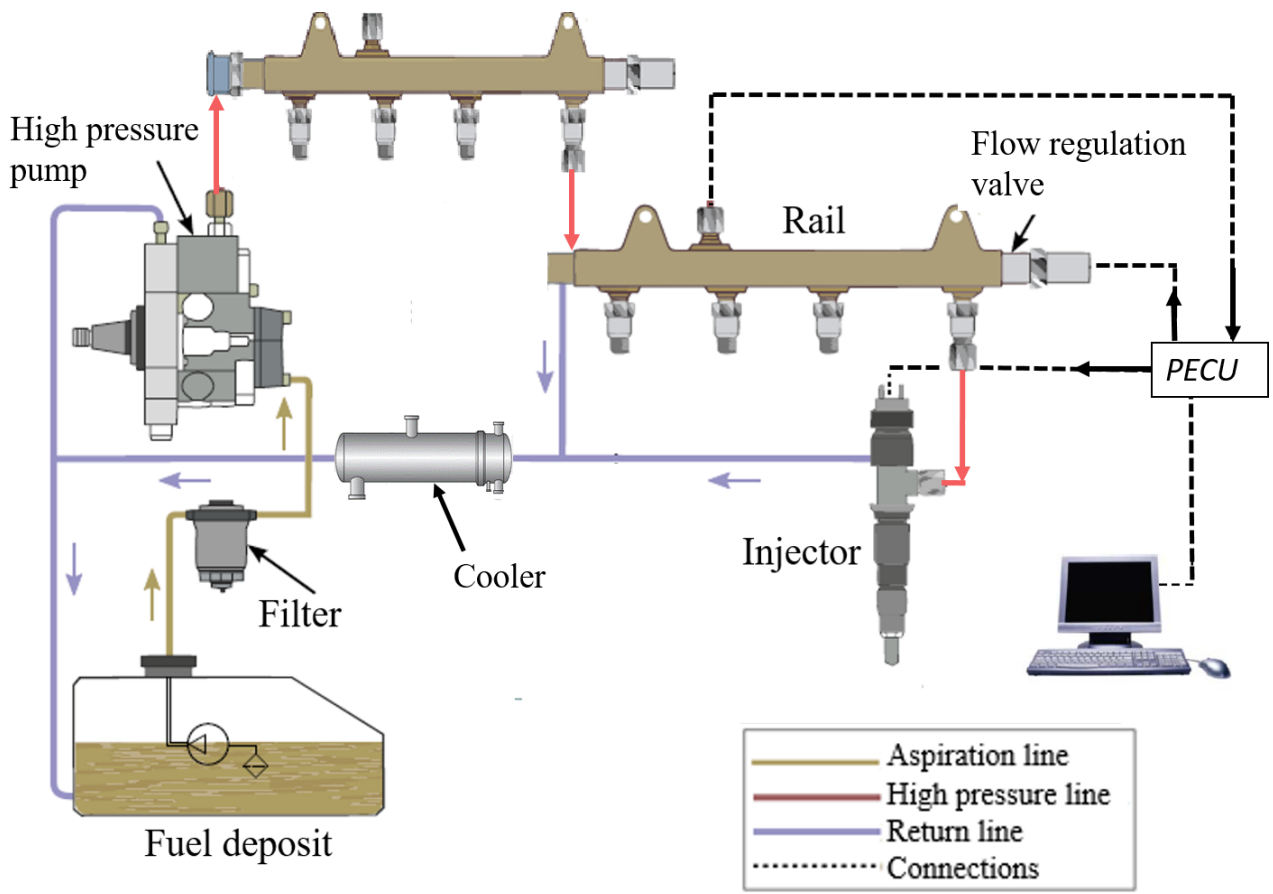

Fig. 4.1 Injection system used during internal characterization

A programmable engine control unit (PECU) controls all the settings of the injection system. A closed loop is formed by the pressure sensor and a flow regulation valve, installed in a second rail controlling its pressure. Furthermore, the PECU is mapped with the shape of the electrical signal to be sent to the injector at the different conditions tested. 


\subsubsection{Injectors}

All experiments are performed for three different nozzles, two solenoid actuated injectors CRI2-18 and CRI2-22 able to reach up to $180 \mathrm{MPa}$ and $220 \mathrm{MPa}$ respectively, and one piezo-electric actuated CRI3-27 able to reach up to $270 \mathrm{MPa}$.

Moreover, special injector holders have been designed specifically for this work, for each injector and for each test rig: these devices maintain the injector in direct contact with a liquid flowing at controlled temperature. The liquid temperature is controlled by means of a PID system able to feed the liquid at temperatures ranging from 15 to $90{ }^{\circ} \mathrm{C}$. This temperature was kept constant at $60{ }^{\circ} \mathrm{C}$ for all measurements. Finally, commercial diesel fuel was used (EU standard EN590). Fuel properties relevant to this study are summarized in the table 4.1.

Table 4.1 Fuel utilized and its properties at $313 \mathrm{~K}$ and $101 \mathrm{kPa}$, all properties were extracted from the NIST Chemistry WebBook [94]

\begin{tabular}{cc}
\hline \hline Property & Value \\
\hline Density $\left(\mathrm{kg} / \mathrm{m}^{3}\right)$ & 812 \\
kinematic viscosity $\left(\mathrm{mm}^{2} / \mathrm{s}\right)$ & 2.06 \\
Surface tension $(\mathrm{N} / \mathrm{m})$ & 0.022 \\
Boiling Point K & 450 to 520 \\
$C_{p, l i q}(\mathrm{~J} / \mathrm{kg} / \mathrm{K})$ & 2002 \\
$h_{\text {vap }}(\mathrm{kJ} / \mathrm{kg})$ & 232.6 \\
\hline
\end{tabular}

\section{Electrical signals}

For solenoids injectors the needle movement is composed of three phases or periods; the needle opening triggering the start of injection, the steady period when the needle lift is maximum and finally, the closing of the injector, when the needle is going back to its initial position. As introduced earlier, the opening and closing stages are transient periods and therefore, depending on the equipment and the methodology of the experimental technique, they may provide different results. Solenoid type injectors, need a peak of intensity to start the movement of the needle, an intermediate intensity to end the movement of the needle, and a smaller intensity to keep the needle raised 


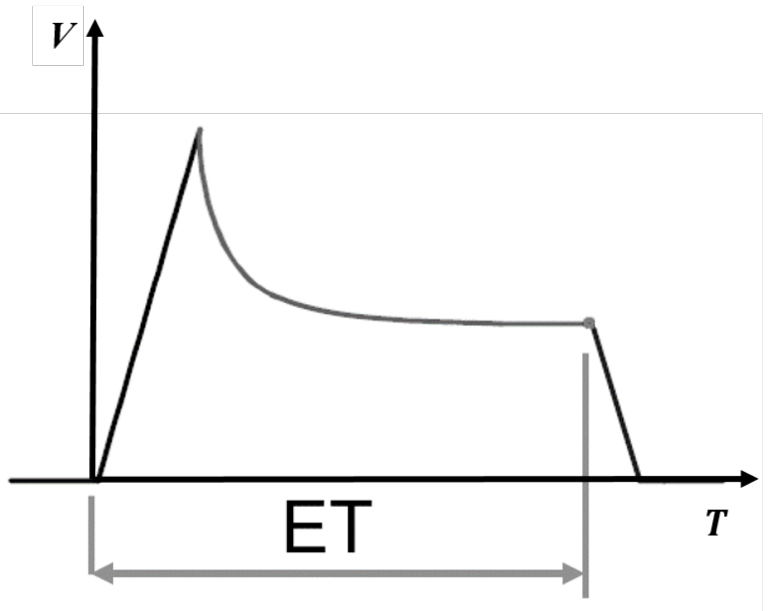

Fig. 4.2 Solenoid signal

(figure 4.2). Unlike the solenoid type, the piezo-electric injectors need a constant voltage to maintain injection time plus the aperture and closing slopes to obtained the desired injection pressure (figure 4.3).

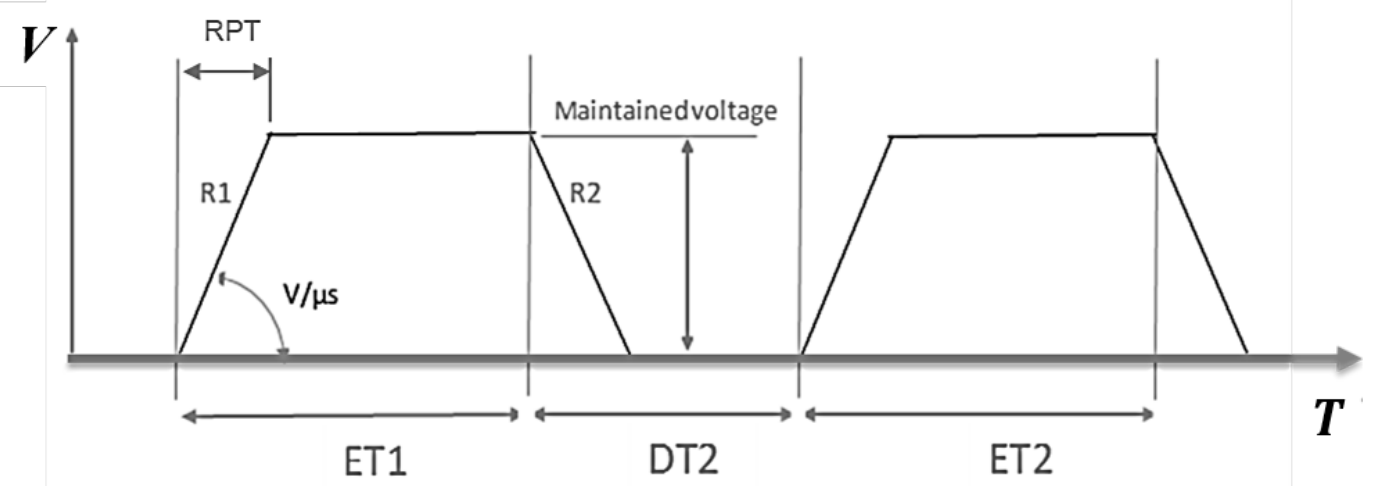

Fig. 4.3 Piezo signal

In the case of the piezo driven injector, the diesel is in constant contact with the piezo-electric crystal within the injector. Thus, the crystal is compressed and submitted to the rail pressure. Consequently, the higher injection pressure target is, the higher will be the signal voltage need it to inject the fuel. In the figure $4.4 \mathrm{~b}$, are shown the reference electric signals used for several injection pressures. As it can be seen whereas the time (RPT) is kept constant around $0.09 \mathrm{~ms}$, the aperture, closing slope and the 
voltage vary. For the solenoid, the hydraulic behavior of the injector is what determines when the injection conditions are achieved and when the needle closing and opening occur. Therefore, in this case the electrical signal is constant and it does not depend on the injection pressure target (figure 4.4a).

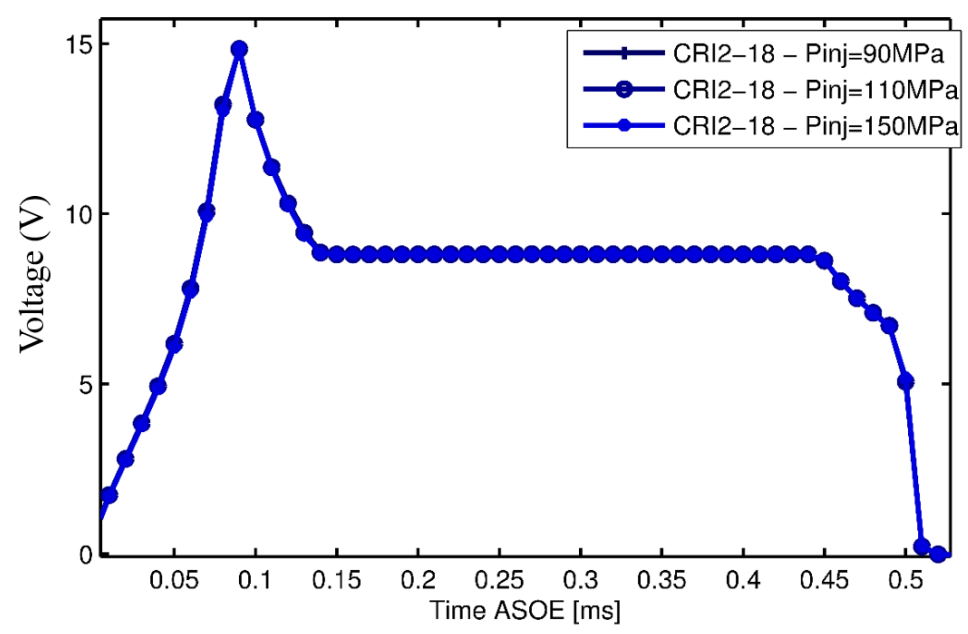

(a) Solenoid signal, Nozz $=$ CRI2-18, ET $=500$ $\mu \mathrm{s}$

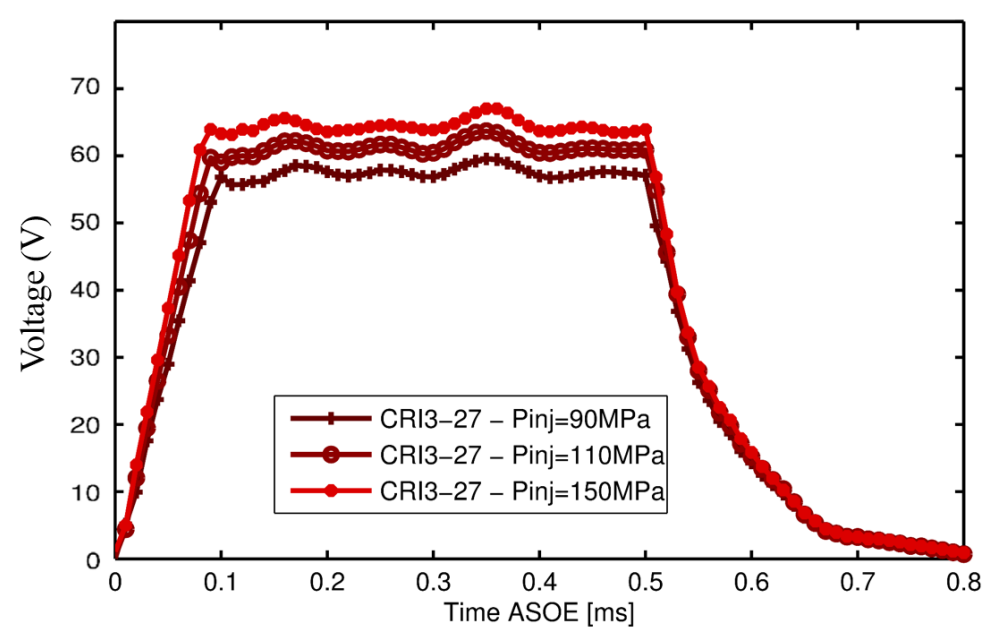

(b) Piezo signal, Nozz $=$ CRI3-27, ET $=500 \mu \mathrm{s}$

Fig. 4.4 Injector's signals variation with injection pressure 


\subsection{Mass flow measurement, methods and tools}

A commercial injection rate discharge curve indicator (IRDCI) from IAV was employed in this thesis to measure and record the ROI temporal evolution during an injection event. This equipment used for these measurements allows displaying and recording the data, describing the chronological sequence of an individual fuel injection event. The device, illustrated in the figure 4.5, makes use of the Bosch long tube method [22], whose working principle is based on the theory of pressure wave propagation in a liquid column.

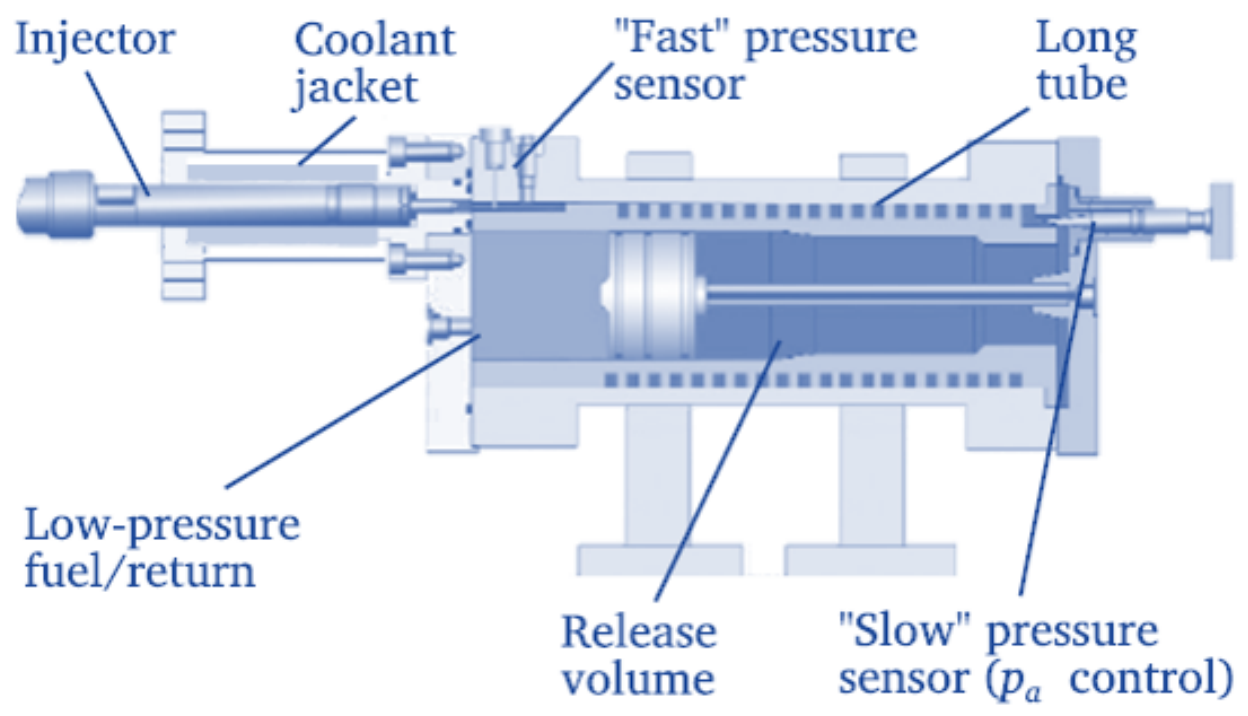

Fig. 4.5 Injection rate discharge curve indicator and its main parts [14]

The injector discharges the fuel towards the IRDCI, filling the total volume of it in order to have an accurate control on the pressure wave propagation. The entire device is constituted by a deposit and a long tube. The long tube filled with fuel has a setting pressure that simulates the pressure inside a real engine combustion chamber. This pressure is usually called back-pressure $\left(p_{\text {back }}\right)$ and it is adjusted through a flow valve controlled by a PID. This system guaranties controlled and steady pressure conditions before the start of the injection. When the injector is energized and the injection of fuel starts, it generates a pressure wave that travels with a velocity equal to the 
speed of sound, from the nozzle tip until a small fuel deposit where it is damped. The pressure wave causes a pressure variation that is related to the liquid flow velocity (equation 4.1) valid a for a simple pressure wave in steady flows:

$$
\Delta P=a_{f} \rho_{f} u
$$

where $\Delta P$ is the pressure increment with respect to the steady pressure, $a_{f}$ is the fuel speed of sound, $\rho_{f}$ is the fuel density and $u$ is the liquid fuel velocity. This equation is valid for a simple pressure wave in steady flows. It must be added that the speed at which the sound travels in the fuel depends on the pressure and temperature conditions of the same. Therefore, a correlation to estimate the speed of sound is needed. The correlation that will be used in this thesis has been used in previous works [153] and it is the following:

$$
a_{f}=k_{1}+k_{2}\left(T-T_{0}\right)+k_{3}\left(P-P_{0}\right)+k_{4}\left(P-P_{0}\right)^{2}+k_{5}\left(P-P_{0}\right)\left(T-T_{0}\right)
$$

where $T=298 \mathrm{~K}, P=0.1 \mathrm{MPa}$, and the constants for the commercial diesel are:

Table 4.2 Constants for speed of sound correlation.

\begin{tabular}{ccccc}
\hline$k_{1}$ & $k_{1}$ & $k_{1}$ & $k_{1}$ & $k_{1}$ \\
\hline 1363.05 & -3.11349 & 4.1751 & -0.00696763 & 0.00940137 \\
\hline
\end{tabular}

The pressure variation is captured by a piezoelectric sensor located as close as possible to the nozzle tip (33 $\mathrm{mm}$ from the nozzle tip approximately) in order to avoid a delay between the injection event and the acquisition time, and also to avoid the friction attenuation effect. For this reason, the injector must be placed directly on the tube with constant diameter, avoiding any extra volume that could perturb the wave propagation generated by the injection. The signal directly obtained from this set-up, is a pressure measurement proportional to the injection event; and the injection rate can be obtained obtained from: 


$$
\dot{m}_{f}(t)=\frac{A_{t} \Delta P}{a_{f}}
$$

where $\dot{m}_{f}$ is the injection rate, $A_{t}$ is the tube cross-sectional area and $p$ is the dynamic pressure in the measurement tube. With the purpose of corroborating the total injected mass quantity obtained with the IRDCI, a scale is placed downstream of the device. All the fuel flow passing through the measurement device, is measured with it during a certain time. That value should correspond to the integral of the mass flow rate for a recorded sequence of injections events. The experimental errors were tested with several repetitive measurements carried out at the same test point (energizing time, rail pressure, and backpressure), and it was found that it was less than $0.6 \%$, as is explained in detail in [152]. For each test condition, 50 injection events were recorded in order to obtain a reliable indication of the average value and of the shot-to-shot dispersion.

\subsubsection{Signal treatment procedure}

After the pressure measurement is converted to an injection rate magnitude with the equation 4.3, and since several repetitions are acquired for each test point, the following step is to calculate an average of the mass flow rate signal. With this procedure the random noise that the signal could have is eliminated. This noise mainly comes from the turbulent character inherent to the injection process. The average of a brute signal is illustrated in the figure 4.6a, and now the curve is almost ready for its use.

After removing the signal noise, there are some curious behavior that appear in the signal mentioned below and must be corrected. First, in the stabilization zone, a cumulative phenomenon can be seen; the injection rate signal increases steadily during the injection event. Nevertheless, the injection pressure is decreasing as shown in the upper part of the figure 4.6a, the injection rate has an opposite behavior to the injection pressure, although this is theoretically impossible. Second, when the injection is finished, the signal remains charged, indicating an unreal value of mass flow rate 


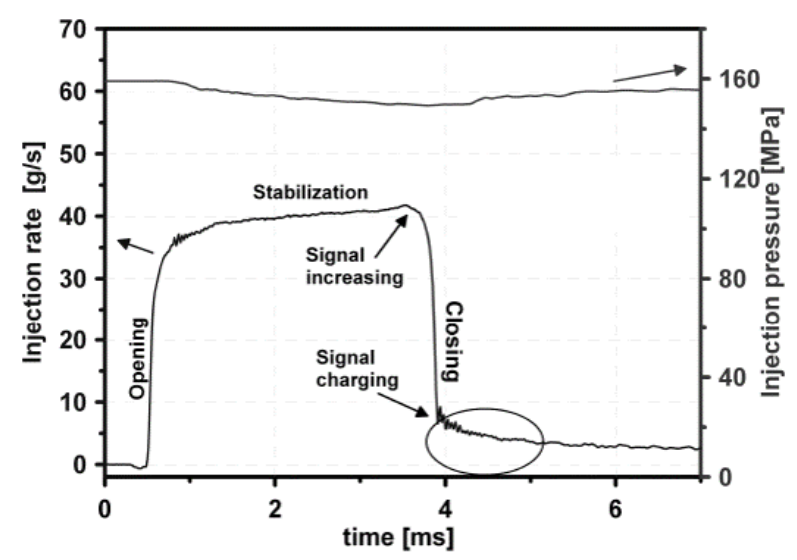

(a) Brute signal of the injection rate. [23]

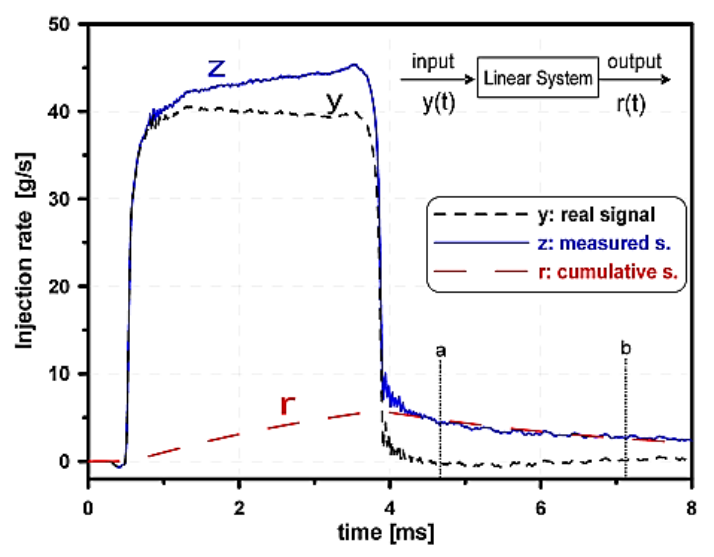

(b) Measured mass flow signal with typical cumulative phenomenon and final processed curve.

Fig. 4.6 Mass flow rate estimation

because at this moment the needle is completely closed and the injected mass should be zero. This problem becomes more obvious when the total injected mass amount increases for longer energizing times. The main reason for this behavior is a hydraulic and temperature phenomenon inside the measurement equipment that produces a slight pressure increase influencing the acquired data and generating the cumulative phenomenon.

In order to eliminate the cumulative phenomenon on the injection rate, a methodology based on numerical solutions and iterative techniques is used [152]. The method is based on the assumption that the measured signal $z$ can be represented as the sum of the real injection rate signal $y$ and the cumulative phenomenon signal $r$ (equation 4.4). The $r$ variable follows a first order linear behavior, so the linear system responds to an input signal $y$ and yields the function $r$ (output signal). This is described in equation 4.5, where $\omega$ and $K$ are coupling constants. The procedure is described in the figure $4.6 \mathrm{~b}$, where $y$ has a square-like shape.

$$
z=y+r
$$




$$
\frac{d r}{d t}+\omega r=K y
$$

The main objective is to find $y$. As $z$ is already known, once $r$ is calculated, it is possible to solve the system. So, constants $\omega$ and $K$ must be calculated. The first step is to calculate $\omega$. In the figure $4.6 \mathrm{~b}$ a sub-domain in the tail of the curves, from $a$ to $b$ is defined and delimited using the fact that when the injection ends $y$ must be zero $(y=0)$. Subsequently, in this sub-domain the equation 4.5 becomes to the homogeneous form expressed in the equation 4.6. The analytical solution for this expression is shown in equation 4.7. Because $y=0$ in the tail, $r$ and $z$ are equal in this zone, so $A$ and $\omega$ can be obtained making an exponential fit in the tail sub-domain of $z$.

The $K$ calculation is based on the equation 4.8 , which is a combination of the equations 4.4 and 4.5, however, this equation does not have an algebraic solution. But, once $K$ is known, $r$ can be numerically obtained using the receding-difference notation for any measured signal $z$ [79]. Since $K$ is unknown and $r$ is calculated by means of $K$, an iterative method is used, calculating an $r^{\prime}$ curve starting from an arbitrary chosen $K^{\prime}$ value.

$$
\begin{gathered}
\frac{d r}{d t}+\omega r=0 \\
r=A e^{-\omega t} \\
\frac{d r}{d t}+(\omega+K) r=K z
\end{gathered}
$$

In order to define the convergence condition $C$, the fact that when the injection is over, the measured signal $z$ and the cumulative signal $r$ must be equal $(z=r)$ is taken into account. This assumption is fulfilled in the tail sub-domain, so $C$ is calculated from $a$ to $b$ using equation 4.9. In order to find this $K$ value the iterative false position 
method is used. The problem is solved when an iterative false position method finds a $K^{\prime}$ with a value which satisfies $C=0$ condition.

$$
C=\left|z-r^{\prime}\right|_{a}^{b}
$$

Once the accumulation phenomenon is corrected for the injection rate curve, the integral value of the signal $y$ is then compared with the value of the scale placed downstream of the IRDCI.

\subsection{Test rigs}

In this thesis two main vessels were used for macro and micro-characterizations, both of them are explained in detailed in this section.

\subsubsection{High temperature and high pressure test rig}

The visualization experiments were carried out in a test vessel classified as a constantpressure flow (CPF) facility (figure 4.7), where the thermodynamic conditions of the engine combustion chamber can be reproduced [206]. Compared to other facilities, this test rig has the unique feature of obtaining nearly quiescent and steady thermodynamic conditions in the test section, providing an important reduction in the time required for the tests and an improved control on the boundary conditions. This test rig allows a maximum ambient temperature, pressure and density of $1000 \mathrm{~K}, 15 \mathrm{MPa}$ and $53 \mathrm{~kg} / \mathrm{m}^{3}$ respectively. The gas at high pressure and temperature continuously flow through the chamber at $0.3 \mathrm{~m} / \mathrm{s}$. The test rig has three large windows (128 mm diameter) that give full optical access, and the big chamber diameter $(200 \mathrm{~mm})$ minimizes the spray-wall interaction. In this study, the vessel has been filled with nitrogen to guarantee the evaporative but non-reacting conditions sought. 


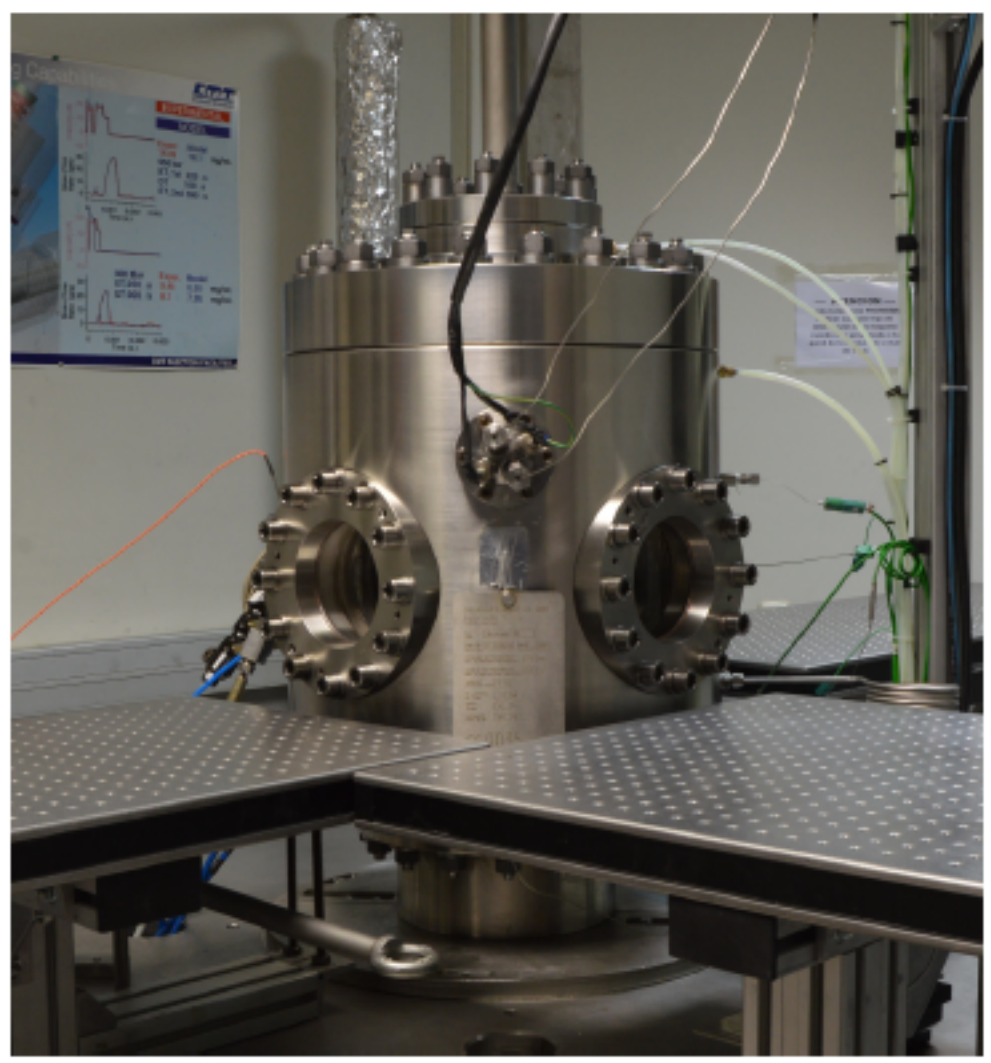

Fig. 4.7 High temperature and high pressure test rig

The facility is composed of four parts: gas compressors, gas heaters, test vessel and control system. The gas is stored by volumetric compressors in high pressure reservoirs and flows continuously through the test chamber. To keep the gas in the test section at the desired temperature, $30 \mathrm{~kW}$ electrical heaters are placed upstream of the chamber. The control system is a closed loop PID that adjusts both the pressure in the chamber and the power of the heaters to obtain the test conditions required for the experiments.

The main components of the test rig facility are presented together with the path followed by the continuously flowing gas in the figure 4.8. This facility is composed by: 1) air compressors, 2) high pressure tanks, 3) main valve, 4) high pressure filter, 5) pressure gauge 6) pressure regulator 7) PLC control system 8) main heater, 9) test chamber, 10) injector cooling system, 11) test rig cooling system, 12) heat exchanger, 


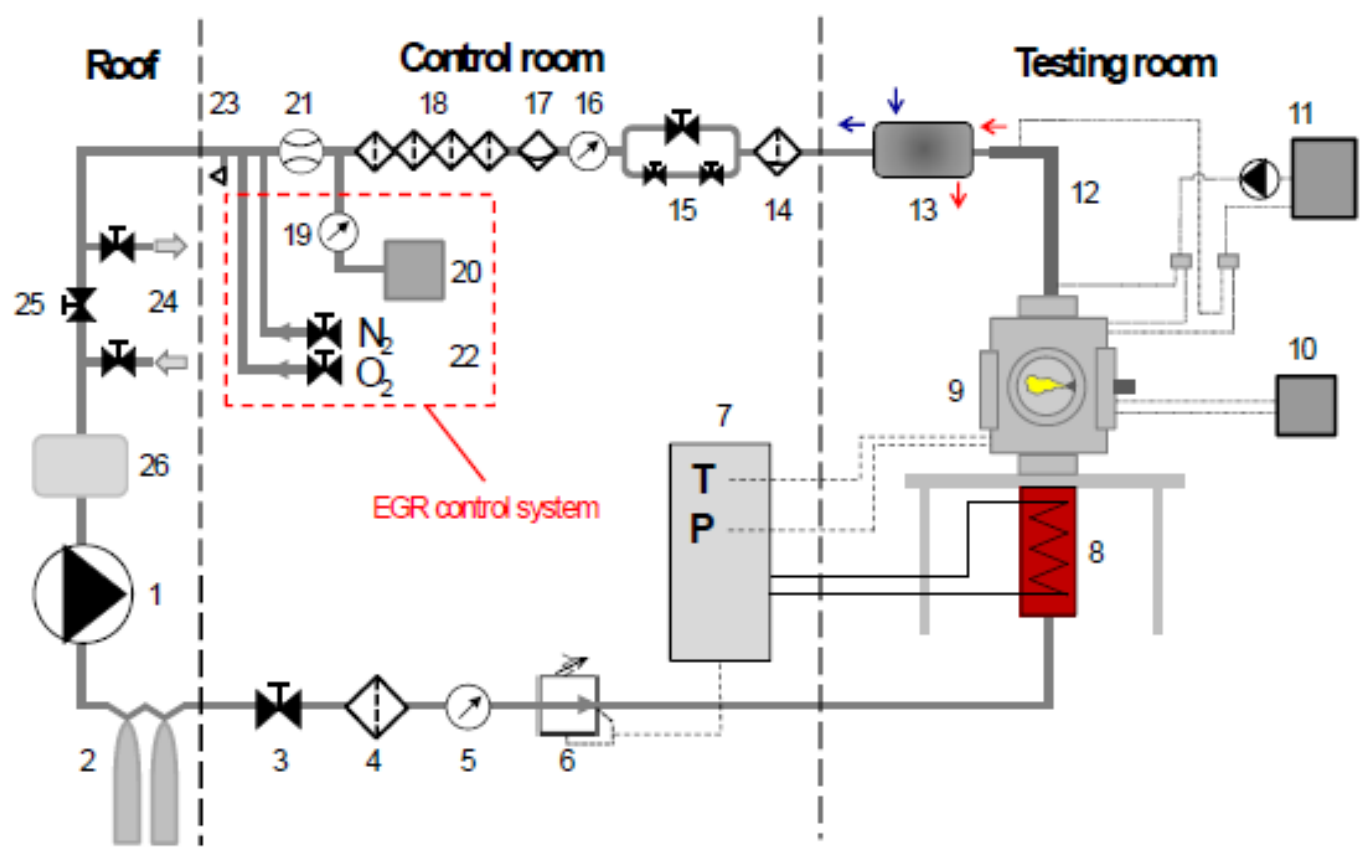

Fig. 4.8 Sketch of the facility layout (High temperature and high pressure test rig).

13) heat exchanger 14) high pressure filter with drain, 15) flow regulation valve, 16) pressure gauge, 17) centrifugal filter, 18) group of 4 low pressure filters, 19) pressure gauge, 20) broadband O2 sensor, 21) flow meter, 22) oxygen/nitrogen reintegration, 23) low pressure drain, 24) open circuit valve ext, 25) open circuit valve int, 26) low pressure tank. Bardi [14] described in detail all these physical features and the functioning of heating system, test chamber, and the temperature control in the chamber and near the nozzle in his $\mathrm{PhD}$. dissertation. The setup is divided into three parts:

- The roof area: There are two groups of compressors (1), which are the ones in charge of providing a continuous flow of up to $80 \mathrm{~m}^{3} / \mathrm{h}$ of air or nitrogen to the chamber, at a maximum pressure of $15 \mathrm{MPa}$.

- The control area: The pressure of the compressors is regulated by a Siemens PLC control system (7), and the flow rate is regulated by the user manually by means of flow control valves (15). Other parameter that can be controlled in the vessel is the temperature. Two resistances (8) are used for this purpose. 
The main resistance is controlled by a PLC control system and the other one by the operator, and their main function is to keep the temperature as steady as possible.

- Testing room: The Siemens PLC control system has three data inputs, one pressure and one temperature sensors inside the test chamber (9) and another temperature sensor in the gas input flow line to the vessel. In this way and acting on the resistance (8) and the flow regulator (6), it is possible to maintain the chamber at a specific pressure and temperature, and therefore density. The exhaust line from the chamber, has two heat exchangers (12 and 13), needed to reduce the temperature of the gas right at the chamber exit. A tubular counter-current heat-exchanger is placed right at the chamber outlet and it is encharged to reduce the gas temperature to about $150^{\circ} \mathrm{C}$ : this temperature is below the limit provided by the high pressure pipes data sheet and therefore their mechanical resistance is guaranteed. The second heat exchanger, shell and tube type, is placed further downstream and its function is to further reduce the gas temperature at a health safe limit (about $40^{\circ} \mathrm{C}$ ).

The facility is also designed to simulate EGR conditions. To this end, the circuit can be set in two different configurations by acting on the open/closed loop valves (24) in order to control the oxygen content within the chamber; in the open loop configuration, tests with atmospheric air at $21 \%$ oxygen are enabled. Atmospheric air will be fed to the compressors while the test rig outlet will be discharged. In this case, the gas composition is not measured since it is considered to be constant. Whilst, when testing in closed loop, the oxygen concentration can be reduced to test with an oxygen concentration ranging between 0-21\%, the discharged gas is recirculated; the gas oxygen content is measured through a broadband lambda sensor placed downstream of the test chamber and it can be adjusted adding either pure nitrogen or air by the reintegration system. 


\subsubsection{High density test rig}

It consists of a purpose-built test rig manufactured mainly in steel and used in a previous work [132], featuring an optical access which allows the laser beams from PDPA system to get into the chamber. The test rig offers better optical access than a normal engine but can still reproduce the ambient density from the combustion chamber at the moment of injection. As the behavior of non-evaporative sprays mainly depends on chamber density [136, 178], ambient conditions are achieved with a gas with high molecular mass (Sulphur hexafluoride-SF6) and varying ambient pressure. Due to its high molecular mass, this gas can reach the density values that normally occur in a diesel engine at the moment of the injection $\left(10\right.$ to $\left.40 \mathrm{~kg} / \mathrm{m}^{3}\right)$ at much lower ambient pressures $(0.2$ to $0.5 \mathrm{MPa})$. Temperature was kept constant at $25^{\circ} \mathrm{C}$ (figure 4.9).

The gas is continuously circulated, passing through filters that remove the injected fuel and then through the roots compressor that sends it back to the testing section. The flow velocity next to the injector is lower than $2 \mathrm{~m} / \mathrm{s}$ [132], so that it does not affect the diesel spray.

\subsection{Tools and methodology for macroscopic exper- iments}

As it has been said before, macroscopic parameters like vapor penetration and liquid length are important to get information on the evaporation capacity of the fuel, mixing process, probability of collision against engine chamber walls and even emissions. In this section the tools, the macroscopic techniques and the methodologies used in this thesis are being described. 


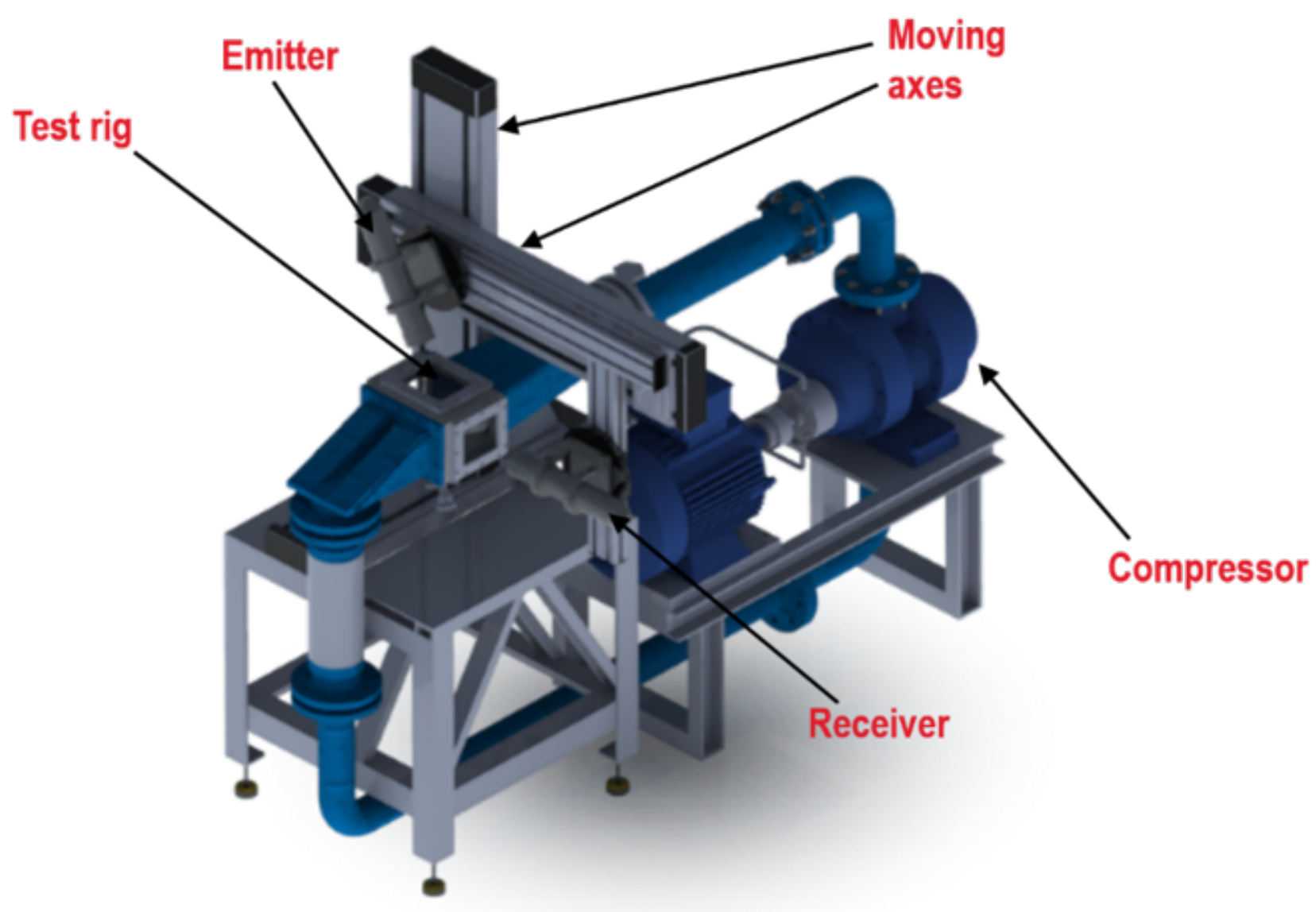

Fig. 4.9 High density test rig

\subsubsection{Schlieren technique and set-up}

The Schlieren effect was first observed by Robert Hooke in the XVII century, mentioned in his famous book Micrographia. His experiment consisted in observing the thermal disturbance in the air produced by a lit candle. For this, he used two candles, one remote to illuminate and the second one that would produce the disturbance to be observed, and a concave lens between the second candle and the human eye (figure 4.10a). The flame of the candle that is between the lens and the illumination, refracts some rays of light so that they do not go to the eye. This reveals the column of hot air 
that gives off the flame, which is otherwise transparent. The layout used by Hooke in his experiment can be seen in the figure 4.10a and its results in figure 4.10b [192].

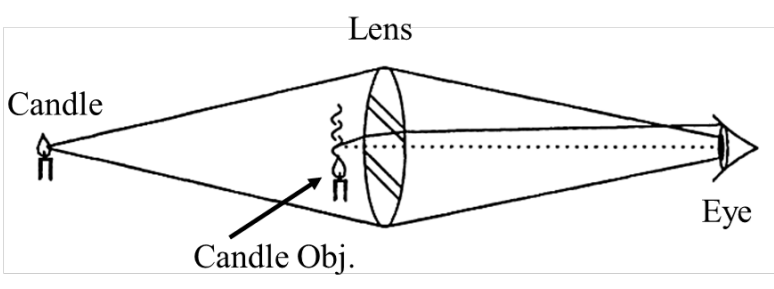

(a) Hooke experiment configuration $[192]$
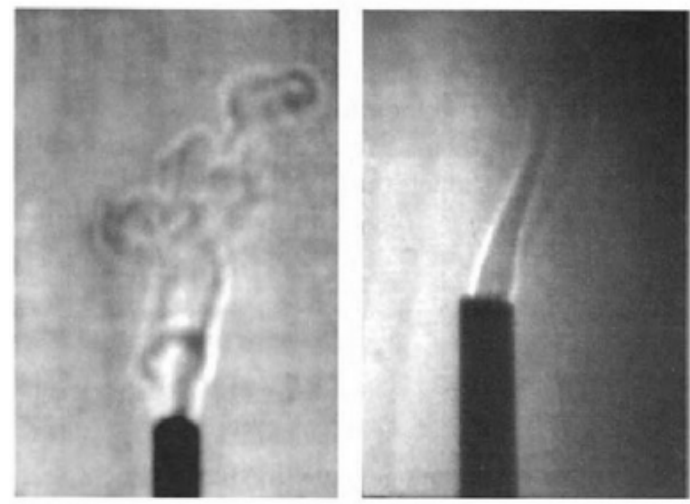

(b) Results from Hooke's experiment [192]

Fig. 4.10 Schlieren principle

In conclusion, this technique relies on the deviation of a light beam produced when light passes through non-homogeneous fluids. When a beam of parallel rays of light is directed into the region of interest, the refractive index gradient will cause the deviation of some rays. Placing a spherical lens to collect the beam, only the parallel rays will converge to the focus point of the lens, while the others will have some offset, the rays deviated can be identified at this point. For example, the use of a diaphragm at the focus point allows to clip the deviated rays, and the regions characterized by refractive index gradient will appear with a lower intensity, producing eventually a shadowgraphic image [14]. Moreover, in a real injection system, the optical arrangement sketched in figure 4.10a cannot be used with multi-hole nozzles. Instead, a double-pass arrangement is an alternative way to visualize the fuel sprays [127]. For the experiments carried out in this thesis, a double-pass Schlieren configuration using a high temperature mirror has been used.

\section{Schlieren optical arrangement}

The main difference of the optical arrangement for a double-pass Schlieren setup, is the fact that the rays are passing two times through the test section, being reflected by 
a mirror placed right behind the test section. Since the light is reflected by the mirror toward the same direction it is coming from, a beam-splitter is required to complete the setup and reflect the image to the camera.

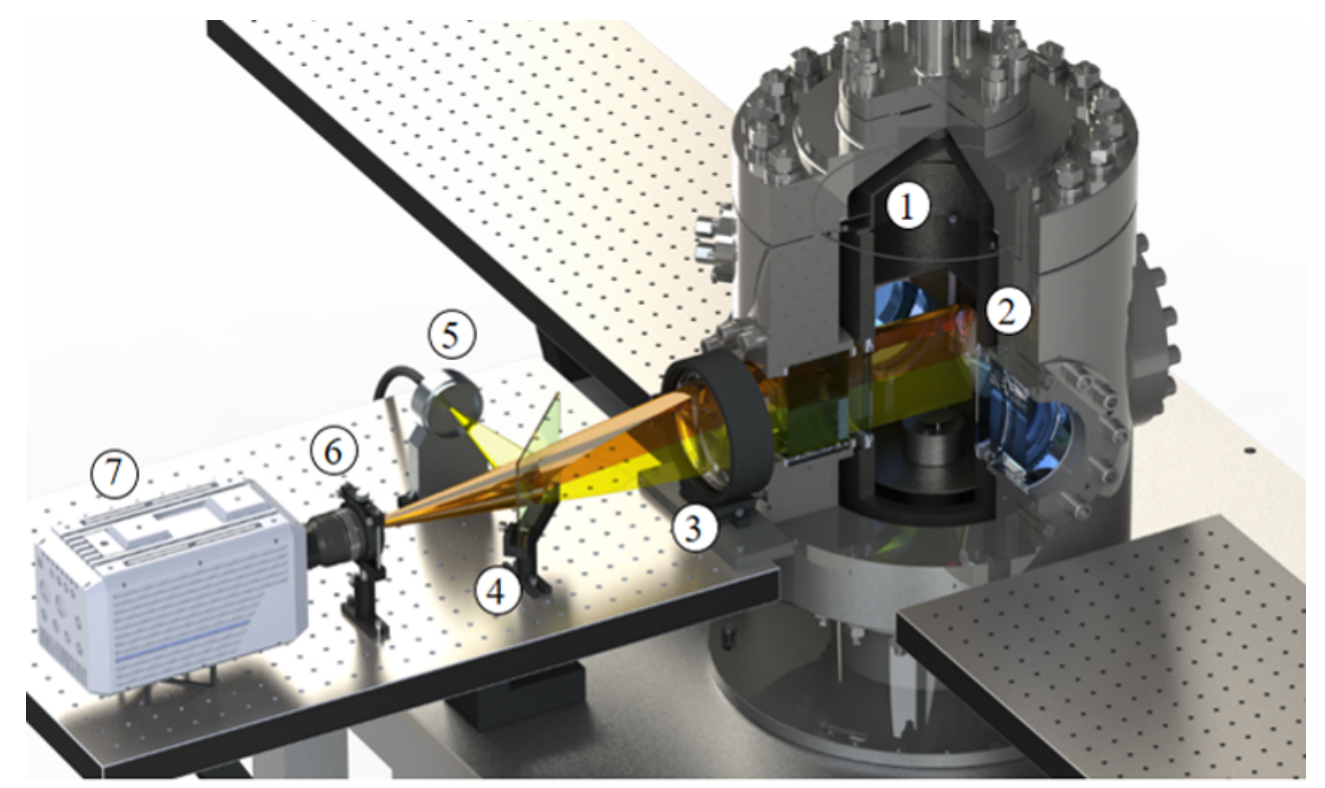
1. Test rig
2. Mirror
3. Convex Lens
4. Beam splitter

5. Light font

6. Diaphragm

7. Fast camera

Fig. 4.11 Schlieren optical arrangement

Illumination is achieved by means of a stroboscopic xenon flash lamp system by STORZ NoVA 300. The end of the light source is kept in the correct direction by being placed in a convergent duct, whose entrance is the size of the fiber and its outlet has a diameter of approximately $1.5 \mathrm{~mm}$. The purpose of this convergent duct is to center the beam of light, which at the exit of the light source is divergent, as much as possible at the focal point.

The focal point is right in the beam splitter, so that only the $50 \%$ of the light passes through and is lost, whilst the other $50 \%$ is reflected. The beam splitter is positioned with an orientation of 45 degrees with respect to the initial direction of the light, thus, the reflected light takes a perpendicular direction from its original path, towards the 
interior of the optical access of the test rig. After passing through the focal point, the light beams acquire a divergent behavior, for this reason, a biconvex lens is placed in between the beam splitter and the optical access of the test rig, its function is to obtain parallel beams big enough to provide a homogeneous illumination before they reach the interior of the chamber.

The parallel beam that illuminates the sprays is reflected on the metallic mirror placed at the injector mount and comes back along the same optical path. Subsequently, the light that carries the information of the sprays goes back through the biconvex lens where the parallel beams become convergent towards the focal point again. As before, when the light hits the beam splitter, $50 \%$ of the light is reflected (in this case lost) and the other $50 \%$ is the one that transports the information towards the camera.

Before the light beams reach the fast camera, a diaphragm configured with an opening diameter of $6 \mathrm{~mm}$ is placed, which has the function of letting pass only the beams that have not varied their direction, obtaining the shadowgraphic image. In the table 4.3 a brief description of the devices and experiment characteristics for each injector used in this work are shown.

Table 4.3 Details of the optical setup and devices employed in the Schlieren arrangement.

\begin{tabular}{cccc}
\hline \hline Element/Injector & CRI2-18 & CRI2-22 & CRI3-27 \\
\hline Camera & \multicolumn{3}{c}{ FastCam SA x-2 } \\
Light source & STORZ Xenon NoVA 300 \\
Camera lens & Nikon 50mm \\
Biconvex lens & TSI 450mm \\
Beam splitter & Edmund Optics 50:50 \\
Mirror & Custom made \\
Image size (pixels) & $768 \times 712$ & $768 \times 712$ & $640 \times 640$ \\
Frame rate (fps) & 24000 & 24000 & 30000 \\
Pixel/mm ratio & 5.75 & 5.75 & 5.9 \\
Shutter speed $(\mu \mathrm{s})$ & 6.25 & 6.25 & 1.25 \\
Test repetitions & 10 & 10 & 10 \\
\hline
\end{tabular}




\subsubsection{MIE-Scattering technique and set-up}

This imaging technique is widely used by the engine community for the visualization of the fuel spray liquid phase. Basically, it consists in illuminating the fuel droplets with a light source (pulsed or continuous) and collecting the light scattered with a camera. The scattering phenomenon, related to the interaction between the light and transparent particles of sizes including the typical fuel droplet diameter, is described by MIE theory and it is called MIE-Scattering [111]. In the literature several examples of use and calibration of this technique can be found $[159,165,193]$.

This technique is used to detect the liquid phase boundary, since the fuel evaporation yields a severe reduction of the intensity of the light scattered due to the transition from MIE to Rayleigh scattering regime [111]. A good MIE-Scattering optical setup enables to detect a signal in all the spray region where non-vaporized fuel is still existent.

The MIE-Scattering technique makes it possible to measure either spray penetration $(S)$ or liquid length $\left(L L_{v}\right)$ depending on the range of ambient temperature tested. When testing at low ambient temperature $\left(T_{a m b} \approx 400 \mathrm{~K}\right)$, the fuel evaporation is negligible and the liquid phase boundaries overlap the whole boundary of the spray. However, when $T_{a m b}$ is progressively increased, fuel evaporation becomes important and a significant difference appears between liquid and vapor-phase boundaries, separating the spray penetration from the liquid length.

\section{MIE-Scattering optical arrangement}

In the optical experiments carried out within the high temperature and high pressure test rig, the sprays have been illuminated by the lateral windows with two continuous Xe-arc lamps and the light scattered backward was collected by a high speed FastCam SA x-2 camera aligned with the injector axis (figure 4.12).

For a macroscopic analysis of the injection under non-evaporative conditions for low and very high injections pressures the high density test rig was used (figure 4.13). Furthermore, this technique is also used for spray alignment during PDPA measurements (section 4.6.1). In this case the spray was illuminated by a light source. 


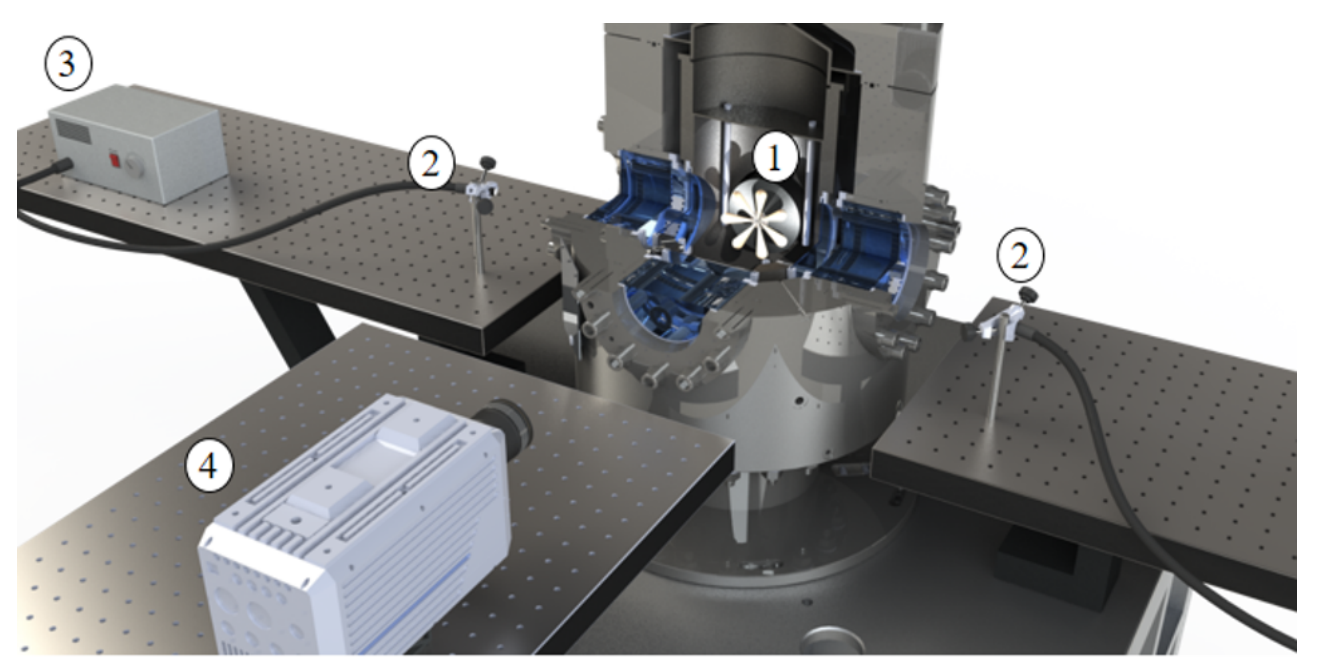

1. Test rig

2. Light source
3. Light font

4. Fast camera

Fig. 4.12 MIE-Scattering optical arrangement for evaporative tests

A fast camera image the scattered light from the fuel droplets. Images were acquired with a high speed CMOS camera Phantom V12, equipped with a $100 \mathrm{~mm}$ focal length ZEISS lens. The image resolution of the pictures was set in 680 x 304 pixels. For tests carried out in this test rig, the illumination used was a continuous light source provided by a $150 \mathrm{~W}$ quartz-halogen illuminator (Dolan-Jenner PL800), supplied by $8 \mathrm{~mm}$ optic fiber bundles positioned at $\sim 200 \mathrm{~mm}$ from the spray, sharply collimated and focused on the studied area. Each picture pixel corresponds to $3.1 \mathrm{~mm}$. A picture of the test rig and MIE-Scattering set-up for spray alignment and non-evaporative tests is shown in the figure 4.13. In the table 4.4 a brief description of the devices and experiment characteristics for each injector used during MIE-Scattering tests are shown.

\subsubsection{Image processing}

Each image recorded in both experiments (MIE-Scattering and Schlieren) is first divided in sectors, one for each outlet orifice and thus one spray. In this way, each spray is processed separately by applying mask to isolate the spray of interest. The algorithm used for the processing is described in $[103,146]$. The image is inverted in order to 
Table 4.4 Details of the optical setup and devices employed in the MIE-Scattering arrangement.

\begin{tabular}{ccccc}
\hline \hline Element/Injector & CRI2-18 & CRI2-22 & CRI3-27 & $\begin{array}{c}\text { Isothermal Measurements } \\
\text { All injectors }\end{array}$ \\
\hline Camera & & FastCam SA x-2 & & $\begin{array}{c}\text { Phantom V12 } \\
\text { Dolan-Jenner PL800 }\end{array}$ \\
Light source & & $\begin{array}{c}\text { Xenon NoVA 300 } \\
\text { Nikon 50mm }\end{array}$ & $680 \times 304$ \\
Camera lens & & $640 \times 610$ & $640 \times 640$ & 18000 \\
Image size (pixels) & $640 \times 616$ & 32000 & 30000 & 3.1 \\
Frame rate (fps) & 32000 & 5.41 & 5.9 & 55 \\
Pixel/mm ratio & 5.41 & 10 & 3.75 & 10 \\
Shutter speed $(\mu \mathrm{s})$ & 10 & 10 & 10 & \\
Test repetitions & 10 & & & \\
\hline
\end{tabular}

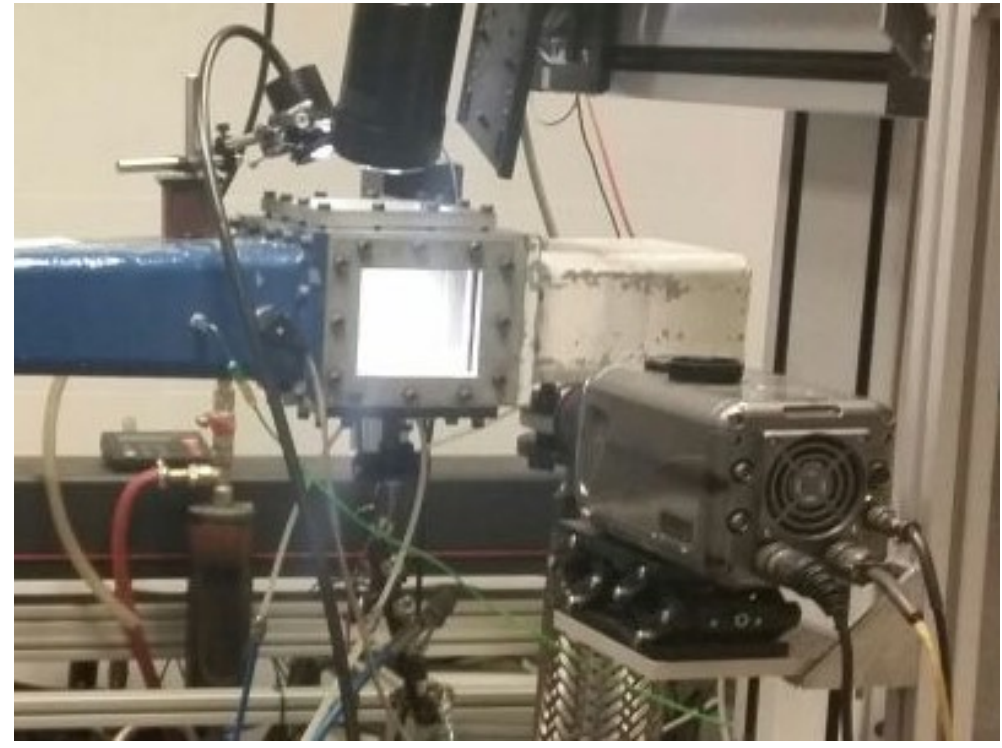

Fig. 4.13 MIE-Scattering optical arrangement for non-evaporative tests

have the spray as the high luminosity area and the threshold is calculated as the $3 \%$ of that image's dynamic range [146, 158]. Consequently, small areas that come from background noise are ruled out and finally the spray contour is "cleaned" free of small noise fluctuations through a pixel connectivity evaluation. This last step could be seen as a contour smoothing. Liquid penetration and vapor penetration are calculated by detecting the pixel on the contour that is the furthest from the outlet orifice; the 
penetration is then calculated as the axial distance from the injector outlet to the furthest point [142].

\section{For MIE-Scattering}

The steps followed in the image processing for the MIE-Scattering study are summarized below [146]:

1. The image acquired right before the start of injection is arithmetically subtracted from the spray images, in order to remove reflections and background artifacts.

2. In order to analyze each spray individually, the image has been divided in sectors.

3. The contour of each spray is obtained using a variable threshold (ths). The threshold is calculated as the $3 \%$ of the dynamic range of the sector.

4. Applying the threshold the image is binarized. The connectivity algorithms are employed to distinguish between the spray and the artifacts due to sensor noise $[103,146]$.

5. The spray boundary is finally obtained as the contour of this area.

\section{For Schlieren}

For the image segmentation, it was used the same approach followed in MIE-Sscattering tests: the image was separated in sectors to process each spray separately, the background subtraction was applied and a black and white image was obtained using a scaled threshold as in MIE-Scattering. However, the images obtained in Schlieren are characterized by features that required to modify the processing routine used for the MIE images. Some considerations about this kind of tests are [146]:

1. The spray appears darker than the background, therefore an inversion of the image and of the background is convenient. 
2. The temperature/density gradient related to the turbulent flow appears in the background and caused fluctuations over a wide range of counts level. Connectivity algorithms have been modified to obtain accurate spray boundaries.

\subsubsection{Data averaging}

In order to obtain the mean value of the vapor spray penetration and to filter the experimental noise, a moving average technique has been implemented. In each single experiment, a data point $y_{i}$ is obtained at an instant $t_{i}$, which corresponds to the time elapsed after the start of the injection. The average value $y_{i}$ at the instant $t_{i}$ is obtained following this procedure [146]:

- The data set falling in the interval $t_{i} \pm \Delta t / 2$ is considered. An optimal time window $\Delta t$ of $150 \mu$ s has been chosen for the current test.

- Over the data set selected, a linear fit is applied and the value of $y_{i}$ is obtained substituting $t_{i}$ in the equation obtained in the linear fit.

- This algorithm is repeated moving $t_{i}$ along the time line with $15 \mu$ s time step; then the averaged curve is obtained.

\subsection{Tools and methodology for microscopic charac- terization experiments}

\subsubsection{PDPA system}

\section{Principle}

This system can measure, simultaneously, the size, velocity and concentration of spherical particles, typically liquid sprays. Simultaneous measurement of both size and velocity allows correlations to be made between these two quantities. The characteristics 
of moving particles are obtained by utilizing laser Doppler anemometry technique. This system emits one beam which is separated in two components of equal intensity but with different phase. These beams are then intersected creating a probe volume where the measures will be made. A lens is used to focus and intersect the beams at the point where measurements will be made. The intersection of these beams form a fringe pattern. When a particle traverses the control volume, the amount of light received fluctuates with the fringes.

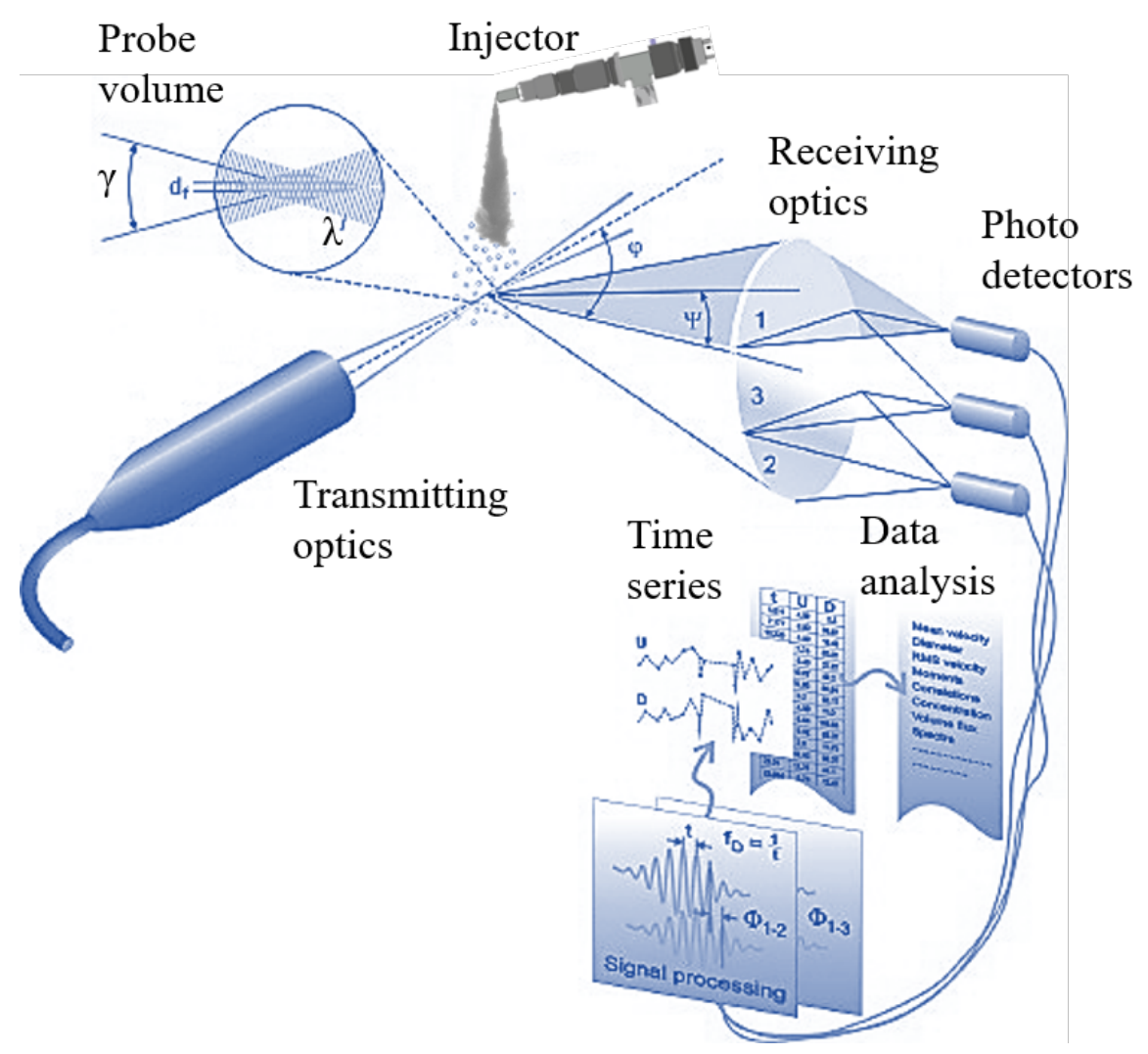

Fig. 4.14 PDPA working principle

The light fluctuations intensities are then collected by another lens and focused onto a photo-detector which converts these into fluctuations of a voltage signal (figure 4.14). The frequency of this fluctuation is proportional to the velocity of the particle, and it is usually known as the Doppler Shift, frequency given by: 


$$
f_{d}=\frac{2 v_{n} \sin (\gamma / 2)}{\lambda}
$$

Where $v_{n}$ is the velocity component of the particle normal to the fringes, $\gamma$ is the crossing angle between the two beams and $\lambda$ is the wavelength of the laser light [196].

The electronic signal given out by the photo-detector contains periods of silence randomly interrupted by bursts of signal (figure 4.15). The overall shape of the burst is a consequence of the fact the energy is normally-distributed in the laser beams producing the measurement volume, and as such they are stronger at their center than at their edges. The fluctuations are not centered about zero because light intensity cannot be negative. As a consequence the signal can be split into two parts: a low frequency part called the "pedestal" and a high frequency part that actually contains the Doppler signal. There are also higher frequencies that represent noise and have to be removed by a low-pass filter.

The Doppler frequency $f_{d}$ can be determined by measuring the period of the Doppler signal. If the laser wavelength and the angle of intersection of the two beams are known, the droplet velocity can then be calculated according to equation 4.10.

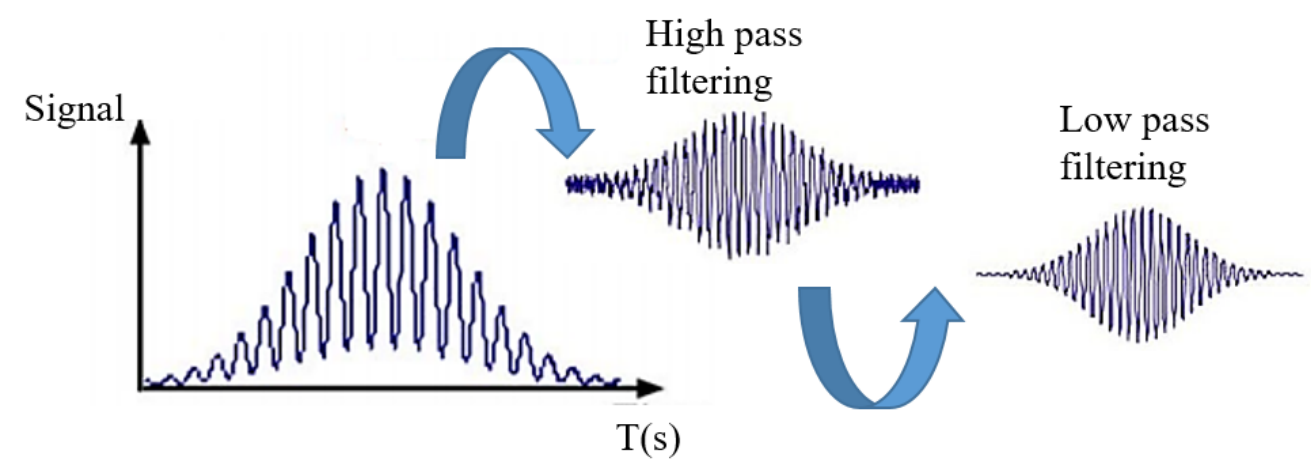

Fig. 4.15 PDPA signal processing

The phenomena of light scattering in this technique can be visualized by ray tracing. The light which is incident on a fuel droplet is partially reflected from the surface and partially transmitted and refracted in both forward and backward directions after one 
internal reflection. The scattered light intensity is not uniform in all directions and also depends on the relative refractive index:

$$
n_{r e l}=\frac{n_{p}}{n_{m}}
$$

where $n_{p}$ and $n_{m}$ are the reflective indexes of the particle and the medium respectively. Bachalo and Houser [11] showed that if two photo-detectors collecting light simultaneously are employed, the Doppler burst signal produced by each detector will be the same but with a phase shift between them. The droplet diameter is derived from the phase difference $\Delta \Phi$ between the signals from two detectors.

If light scattered is dominated by reflection the signal is:

$$
\Phi=\frac{2 \pi D}{\lambda} \frac{\sin \gamma \sin \psi}{\sqrt{2(1-\cos \gamma \cos \psi \cos \varphi)}}
$$

And if light scattered is dominated by refraction is:

$$
\Phi=\frac{-2 \pi D}{\lambda} \frac{n_{r e l} \sin \gamma \sin \psi}{\sqrt{2(1+\cos \gamma \cos \psi \cos \varphi)\left(1+n_{r e l}^{2}-n_{r e l} \sqrt{2(1+\cos \gamma \cos \psi \cos \varphi))}\right.}}
$$

Where $\varphi$ is the scattering angle and $\psi$ the elevation angle. The figure 4.16 shows the signal received from the scattered light and the relationship between the phases difference from the intensity signals. For example, in order to obtain the droplet size of $D_{1}$, detector 1 and 2 are located at different angles $(\varphi)$. The signals received by detector 1 and 2 are shown on the right of the figure. The phase difference between signal 1 and 2, due to the different optical paths inside the droplet, is proportional to the droplet diameter. Thus the droplet size can be calculated in this way. However, the aspect of the $2 \pi$ ambiguity cannot be ignored in this method. For example, for the smaller droplets $D_{1}$ and $D_{2}$, there is no problem since the phase difference is within the range of $2 \pi$. However the situation begins to change when the droplet is bigger. For the droplet $D_{3}$, as is shown in the figure 4.16, the phase difference is beyond $2 \pi$; it is difficult to tell which one is the true value between $D_{3}$ and $D_{3}$ '. To solve the problem 


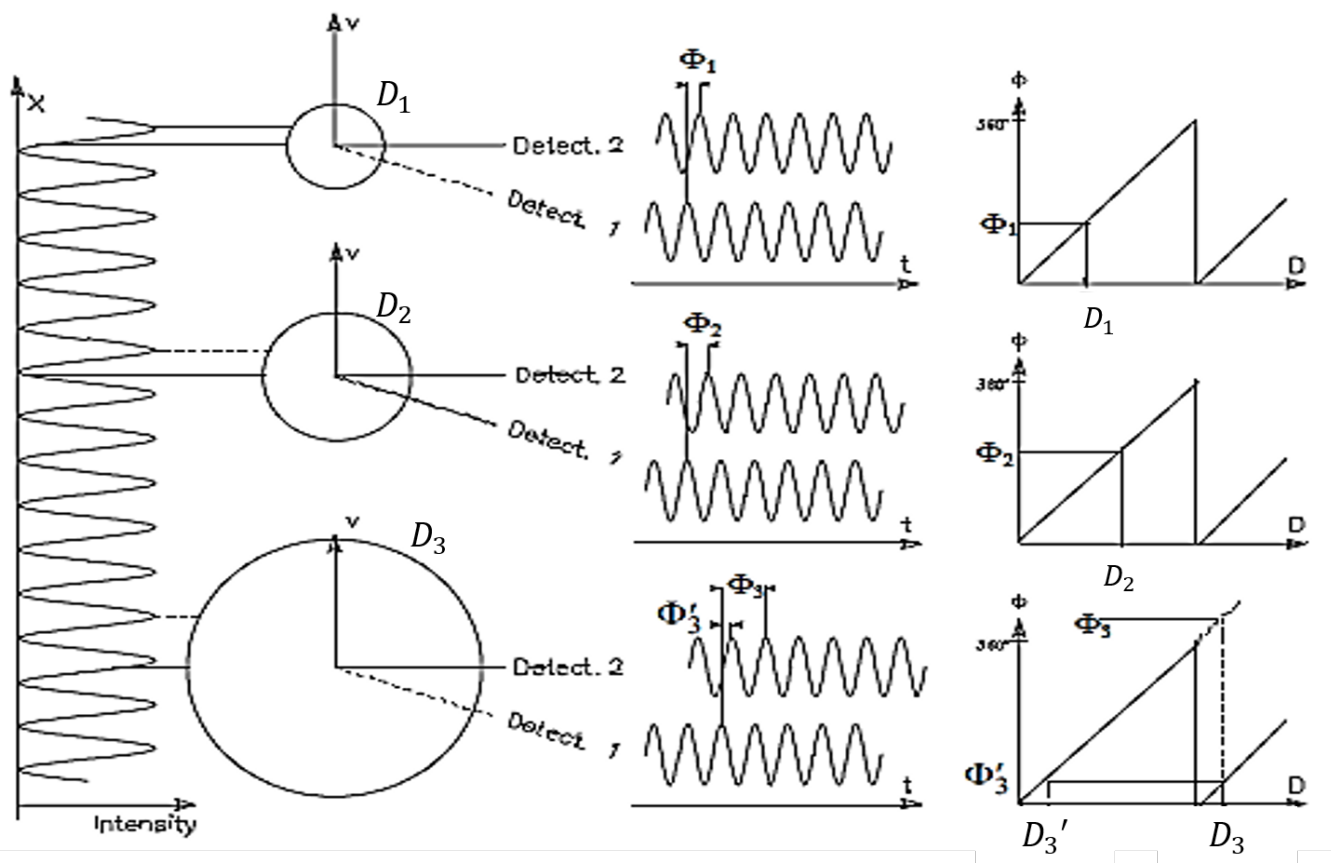

Fig. 4.16 The relationship between the phase difference and the droplet size

caused by this ambiguity, a third detector is added to the system. The figure 4.17 depicts the principle of the solution. With the help of the third detector, an additional phase difference $\phi_{13}$ is used to recognize the true value; $\phi_{13}$ indicates a larger droplet size range, but with a lower resolution; and it can be used to determine in which cycle is the signal phase difference. While $\phi_{12}$ has a higher resolution, but with a lower size range, it can tell the true value of the droplet size. Thus, with the help of the third detector, the test range can be extended while the resolution is still at a higher level $[77]$.

\section{Equipment}

The instrument used in this work is a PDPA system with an FSA4000 digital processor manufactured by TSI Inc (figure 4.18). It is set to emit green light with $514 \mathrm{~nm}$ wave length. 

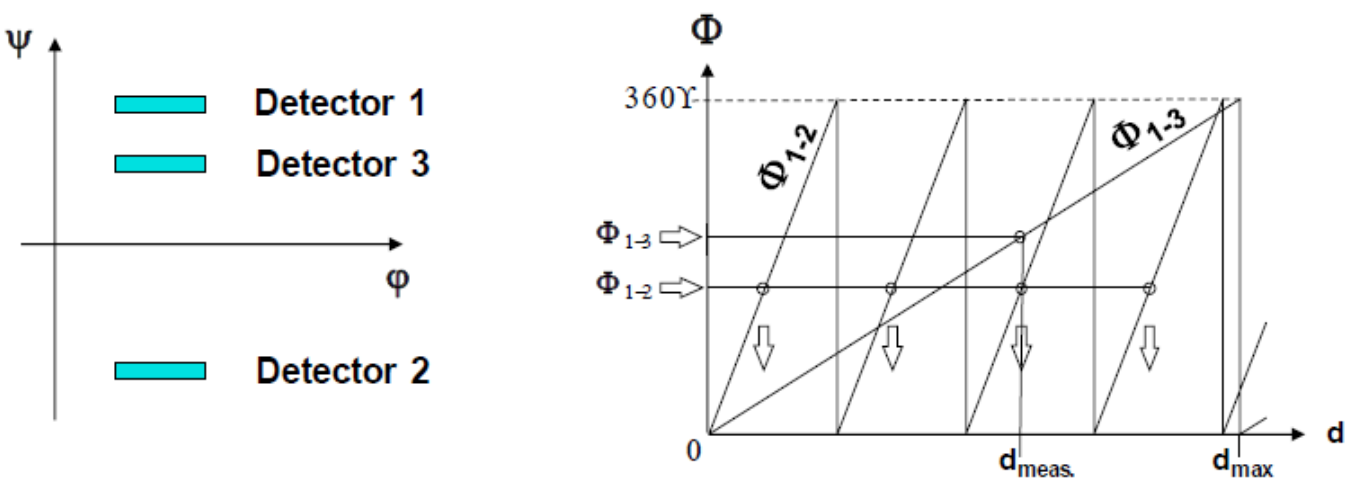

Fig. 4.17 Solution for $2 \pi$ ambiguity

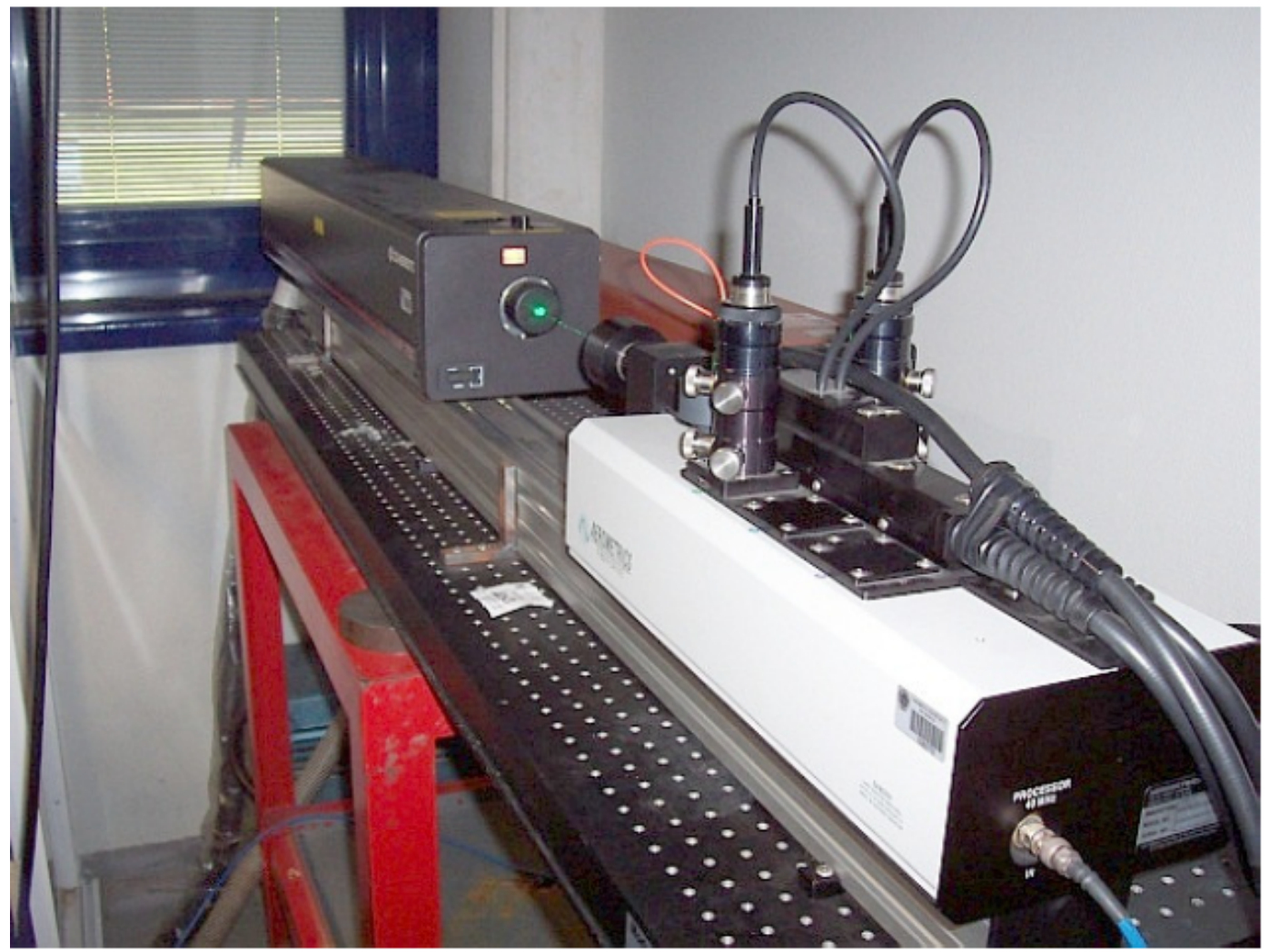

Fig. 4.18 PDPA equipment, laser and Bragg cell

The power output was set to $900 \mathrm{~mW}$, which means that each beam has $110 \mathrm{~mW}$ at the point where they cross each other. The $76 \%$ losses occur mainly in the optic fiber leading from the Bragg cell beam splitter box (white box) to the emitting optics. The Bragg cell operates at a frequency of $40 \mathrm{MHz}$, which induces the corresponding phase 
difference between the two beams. This causes the fringe pattern to move, preferably in the opposite direction of the measured flow. This has two positive consequences. The first is that a stationary droplet will be detected as it will produce a $40 \mathrm{MHz}$ signal due to the fringe movement. The second is that it allows distinguishing between droplets that move in opposite directions, since the ones moving against the fringe pattern (and in the preferential direction of the flow) will produce a Doppler frequency higher that $40 \mathrm{MHz}$ and the others a frequency between 0 and $40 \mathrm{MHz}$. In this thesis the PDPA was used with the following configuration:

- Bragg cell frequency (frequency shift) : $40 \mathrm{MHz}$

- Transmitting optic focal length: $200 \mathrm{~mm}$

- Beam separation at the frontal lens: $57.6 \mathrm{~mm}$

- Beam diameter (1/e2) at the frontal lens, after beam expander: $2 \mathrm{~mm}$

- Fringe spacing: $1.8 \mu \mathrm{m}$

- Focused beam waist, nominal measurement volume diameter (1/e2): $65 \mu \mathrm{m}$

- Receiving optic focal length: external $300 \mathrm{~mm}$, internal for refocusing $250 \mathrm{~mm}$

- Scattering angle: $70^{\circ}$

- Slit aperture: 100, 50, $25 \mu \mathrm{m}$ (refocused on the measurement volume to $+20 \%$.)

- Velocity range: -36 to $244 \mathrm{~m} / \mathrm{s}$ (with maximum filter bandwidth 20-175 MHz, without down- mixing)

- Diameter range: up to $70 \mu \mathrm{m}$, with fuel refractive index 1.44 .

- Slit aperture: $25 \mu \mathrm{m}$

The main parameters for the equipment were optimized in previous works $[4,136$, 196]. In those studies the angle between emitter and the receiver from the PDPA system was optimized and then settled in $110^{\circ}$, which means that $\varphi$ was optimized to 
$70^{\circ}$. They also concluded that a very narrow slit aperture (the smallest available that was $25 \mu \mathrm{m}$ ) was necessary to see inside the denser part of the spray. In this thesis the photomultiplier amplification voltage was set in the range of 400-500 $\mathrm{V}$ and the burst detection threshold between 100-200 mV. This configuration was obtained by Araneo et al. [4] in order to find their optimum values leading to an increased data rate. 



\section{Chapter 5}

\section{Results and discussion: Internal}

\section{flow}

\subsection{Introduction}

This chapter presents the results of the internal geometry, internal flow, and near nozzle flow of the diesel injectors analyzed during this work. The results comprise the geometries of several diesel spray injectors and the hydraulic characterization of these injectors through rate of injection measurements. The chapter follows a linear approach in the presentation of the measurements from the inner part (geometry) to the internal flow characteristics (mass flow measurements) and injectors behavior. The analysis of the hydraulic performance is one of the first steps towards characterizing a particular nozzle geometry in diesel injectors. Rate of injection and geometry characterizations are not only important for boundary conditions in CFD or 1D model development, but also provide valuable data for experimental analysis [27], being determinant to the combustion performance of a diesel engine. Most of the measurements done in the current work have been done extensively in diesel research field [14, 23, 52, 206].

For all the tests described and presented in this chapter, the injector coolant temperature was fixed at $343 \mathrm{~K}$. The injector body temperature was maintained close to 
target using a special injector holder designed to have coolant flowing at a controlled temperature in direct contact with the injector body

\subsection{Injectors geometry characterization}

This section presents the internal geometry of the several diesel nozzles that were measured for this thesis. The figures 5.1a to 5.1c show the extracted images from the microscopy study developed for the nozzles of the three injectors.

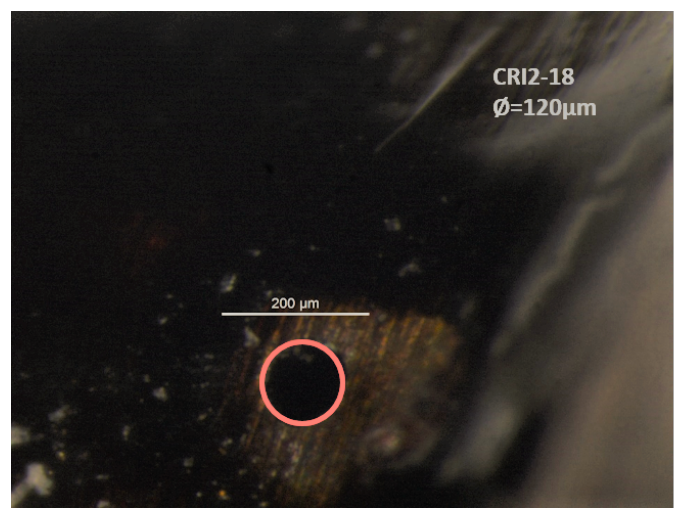

(a) CRI2-18

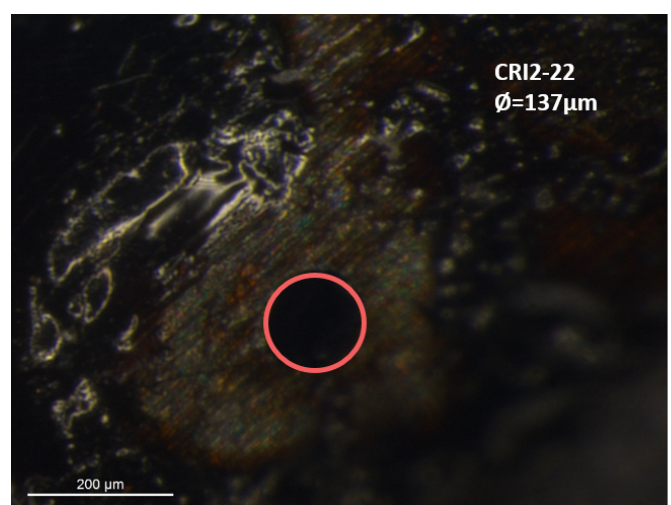

(b) CRI2-22

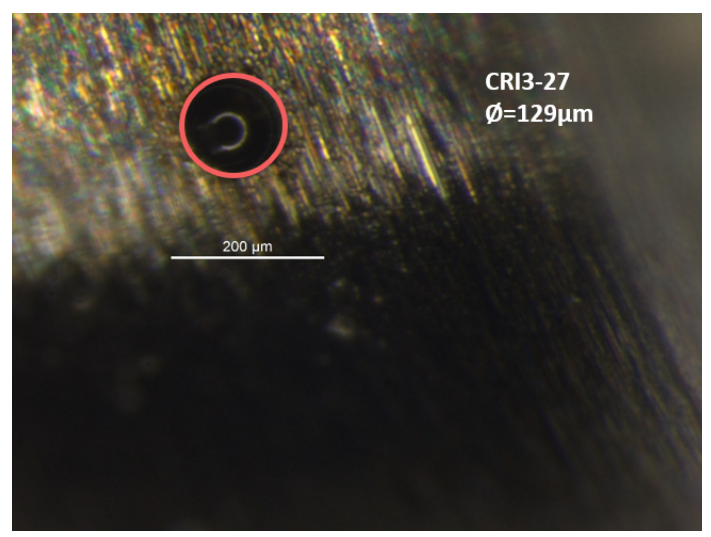

(c) CRI3-27

Fig. 5.1 Optical microscopy images of the three nozzle outlet orifices.

The angle among all sprays $(\beta)$ (figure $5.2 \mathrm{~b}$ ) were $158.8^{\circ}, 153.9^{\circ}$ and $153.5^{\circ}$ for CRI2-18, CRI2-22 and CRI3-27 respectively. This opening angle was obtained injecting diesel at $90 \mathrm{MPa}$ over several paper sheets as shown in figure 5.2a. These injections 
were made at atmospheric conditions, accordingly, sprays have a needle like shape provoked by the low transfer of momentum between the spray and the atmosphere. The sprays perforate the paper sheet. With the axial and radial distance between these holes and the nozzle tip position the angle among sprays can be estimated by applying simple trigonometry. This strategy was repeated with five paper sheets, consequently, the obtained angles were averaged. The standard deviation of this angle calculation was in average $0.5^{\circ}$. The table 5.1 summarizes the injectors utilized and their nominal nozzle outlet diameters and geometries.

Table 5.1 Injector hardware utilized and nominal nozzle geometries.

\begin{tabular}{ccccc}
\hline \hline Injector REF. & $d_{0}[\mu \mathrm{m}]$ & Opening Angle $(\beta)$ & Number of holes & Total flow area $\left[\mathrm{mm}^{2}\right]$ \\
\hline CRI2-18 & 120 & 158.8 & 8 & 0.0905 \\
CRI2-22 & 137 & 153.9 & 8 & 0.1179 \\
CRI3-27 & 129 & 153.5 & 7 & 0.0915 \\
\hline
\end{tabular}

\subsection{Rate of injection}

The main goal of the study of the rate of injection for the injectors was to evaluate how the common variables subject to change in normal engine operation affect the ROI for the type of hardware in use here. With this purpose, the effects of injection pressure, ambient pressure, energizing time, and even the electrical signals were individually tested, resulting in a large conditions matrix and long experimental campaign. The methodology followed to complete the rate of injection work was described in section 4.3.

\subsubsection{Test plan definition}

For the internal flow characterization different injection conditions have been tested. Experiments were carried out for a variety of representative engine values of injection pressures (90, 110,150, 180, 200, 220, 250 and $270 \mathrm{MPa})$ and back pressures (3, 4.5, 7.5 and $10 \mathrm{MPa}$ ). The ambient temperature was the standard of $298 \mathrm{~K}$ used as a 


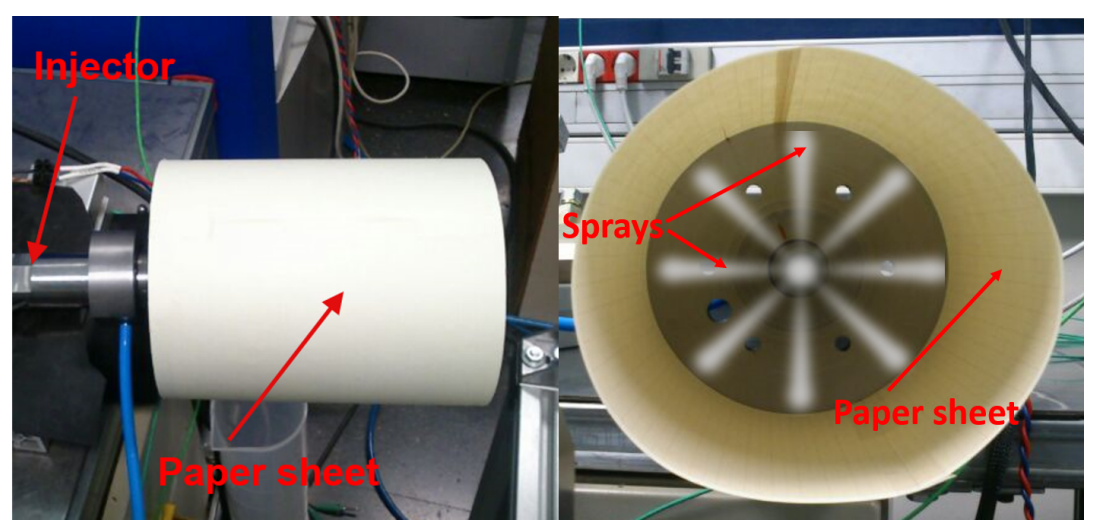

(a) Technique description

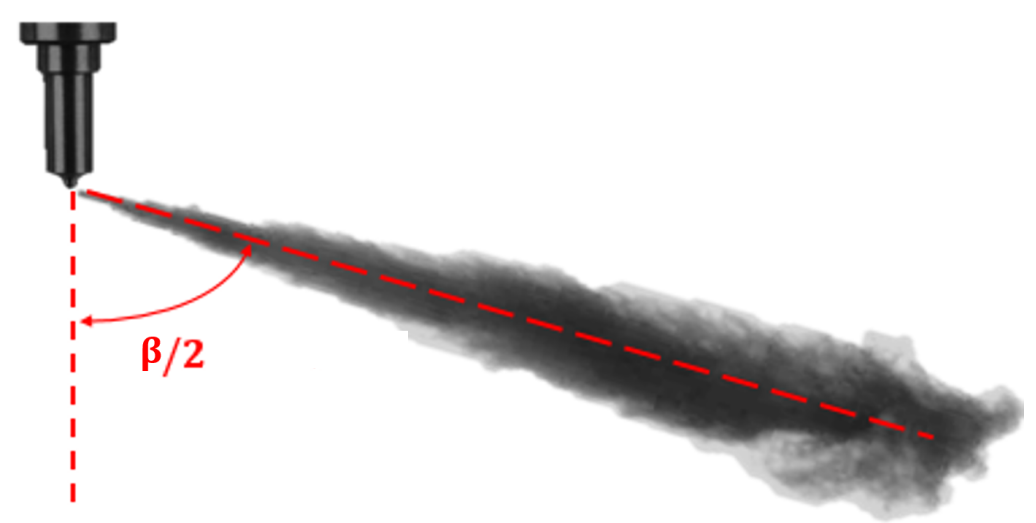

(b) Opening angle

Fig. 5.2 Strategy for opening angle estimation

reference in the majority of internal flow studies found in the literature. A resume of the test matrix is presented in table 5.2, where all the wide range of possible operating pressure conditions of a common-rail system are covered. For each operating points 50 repetitions were acquired and analyzed. Furthermore, in order to understand the behavior of the ROI with the ET, a sweep using low (that would be relevant for certain operating conditions in an engine like idle or multiple injection strategies) and high ET's has been made.

\subsubsection{Electric signal effect}

In this section the effect of varying a slope of the electric pulse in the piezo-electric injector (CRI3-27) is shown. The signals in the figure 5.3 present the mass flow rate 
Table 5.2 Experimental conditions for the hydraulic characterization.

\begin{tabular}{lcc}
\hline \hline Parameter & Injector & Testing Conditions \\
\hline & CRI2-18 & $90 / 110 / 150 / 180$ \\
Injection Pressure [MPa] & CRI2-22 & $90 / 110 / 150 / 180 / 220$ \\
& CRI3-27 & $25 / 35 / 50 / 70 / 90 / 110$ \\
& & $150 / 180 / 200 / 250 / 270$ \\
\hline & CRI2-18 & $4.5 / 7.5$ \\
& CRI2-22 & $4.5 / 7.5$ \\
Back Pressure $[\mathrm{MPa}]$ & CRI3-27 & $3 / 10$ \\
\hline & CRI2-18 & $0.25 / 0.5 / 0.75 / 1.5 / 3$ \\
& CRI2-22 & $0.25 / 0.5 / 0.75 / 1.5 / 3$ \\
& CRI3-27 & $0.5 / 0.18 / 1.5$ \\
\hline
\end{tabular}

recorded by the experimental equipment available, the initial ramp of the injection corresponds to the needle opening and the final decay, before the mass flow rate drops down to zero is the closing of the needle.

The analysis has been carried out for an injection pressure of $100 \mathrm{MPa}$ and a back pressure of $0.5 \mathrm{MPa}$, conserving an ET of $1000 \mu \mathrm{s}$. The ROI provided by the electrical slope recommended by the manufacturer $(1.12 \mathrm{v} / \mu \mathrm{s})$ is then compared with both a higher and lower slope. The most remarkable result over the ROI, is that the smaller slope, the greater the total injected mass. This is logical, since with a smaller slope the needle opening and closing times (RTP) are longer and thus the injection time is longer. Nevertheless, it is typical that multi-injection events are present at real engine conditions. Thus, even though the total mass injected turns to be incremented by decreasing the electrical slope, the fact that the needle closing and opening times are 
diminished brings along some negative consequences in the transient behavior of the needle during multi-injection events.
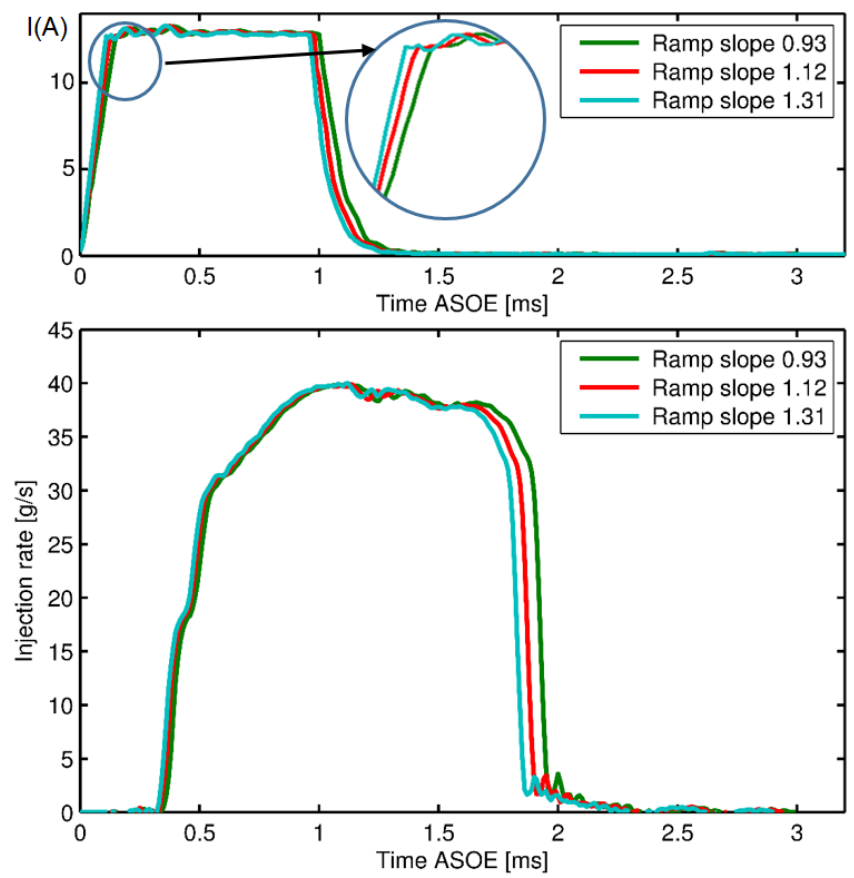

Fig. 5.3 Electric signal effect in the ROI signal, Pinj= $100 \mathrm{MPa}, P_{b a c k}=0.5 \mathrm{MPa}, \mathrm{ET}=1000$ $\mu s$

It is also interesting to see that the closing time is significantly delayed by decreasing the slope. Taking into account that more mass is passing through the nozzles, is harder for the needle to comeback to its original position.

\subsubsection{Multiple injections effect}

Multiple injection strategies are outside the scope of this thesis. Nonetheless, given the increasing interest in multiple injections for combustion strategies research, several tests were made also at very high and low pressures to complement the rate of injection campaign for the injector CRI3-27. An analysis regarding the effect on pilot injections on the ROI is carried out.

In this study, the fuel mass with single injection strategy is employed as the baseline. When comparing the single injection rate signal (red) from the figure 5.4a with the 
same ET in the post-injection (wine red), dwell time of $387 \mu$ s and a Pinj=110 MPa, it can be clearly seeing that in post-injections the mass flow decreases from 35.1 to 30.4 mg (around $-13 \%$ ). Nevertheless, by increasing the injection pressure up to very high injection pressures (270MPa) (figure 5.5a), conserving a dwell time of $387 \mu$ s and even decreasing ET's for the post and single injections, the mass flow of the post injection kept the same behavior, but in this case the difference between the single injection and the post injection was higher (from 24.1 to $14.6 \mathrm{mg} \sim-39 \%$ ).

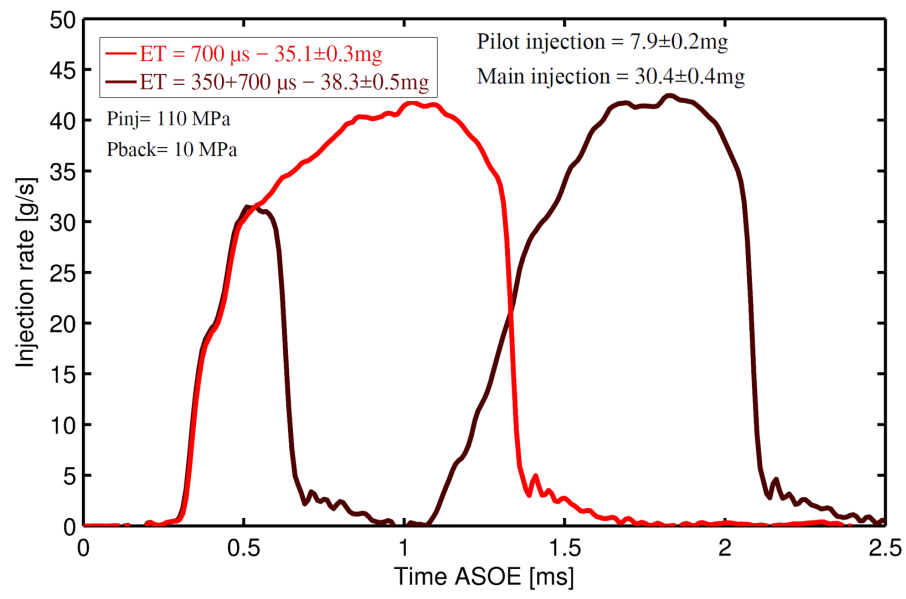

(a) Pinj=110 MPa, Dwell time $387 \mu \mathrm{s}$

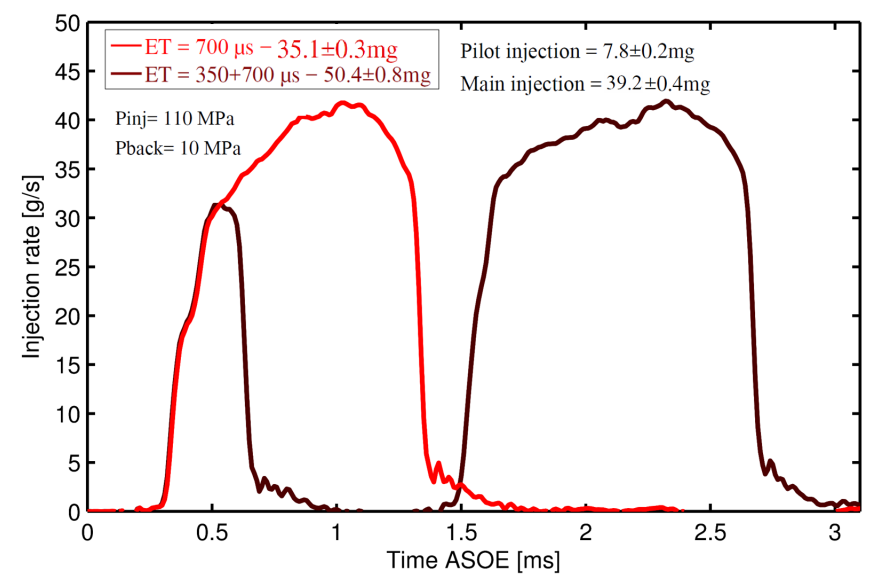

(b) Pinj=110 MPa, Dwell time $800 \mu \mathrm{s}$

Fig. 5.4 Effect of increasing dwell time. Single injection (red) comparison with same ET in post injections (wine red) 
Furthermore, when the interaction between injections (splits) was weak (short injection duration or long dwell interval like $800 \mu \mathrm{s}$ ) and they become non-continuous, like in the figure $5.4 \mathrm{~b}$, the post-injection mass flow increments from 35.1 to 39.2 (around $+11 \%)$.

To analyze an increase of the interaction between the splits and with respect to the conditions, the ET of the pilot injection was augmented up to $500 \mu \mathrm{s}$ (figure $5.5 \mathrm{~b}$ ). Due to the injector hydraulics, the needle is still open for the pilot injection when the energizing signal of the second injection arrives. This means that the fuel is still continuously flowing during the dwell time, resulting in the increase of effective injection duration that caused an increment of $+48 \%$ in the mass flow of the post with respect to the single injection. This is coherent regarding the behaviors found by Wang et al [215], where for very shorts dwell times or high peaks interaction the fuel mass in the post injection incremented reaching a mass flow above the single injection. When the dwell time was augmented, a sudden decrease of the mass flow appeared, dropping until it reached its lowest point below the mass flow of the single injection, and lately, for very high dwell times it had a continuous increment until the second injection reached and independent state. Notwithstanding all these variations found in this section, these trends vary from injector to injector,nevertheless it can be concluded that the dwell time variation causes a bathtub trend over the mass flow that depends mainly on injection pressure, pilot injection ET and fuel properties [215].

\subsubsection{Nozzle comparison and injectors behavior}

The figure 5.6 depicts examples of rate of injection signals comparing nozzles. Low and high rail pressures are also shown to illustrate its effect for all nozzles over the ROI. The rates of injection measured present the expected responses to both rail and back pressure. Consistently throughout the test matrix, nozzle CRI2-18 presented slightly lower stabilized mass flow rates, which is attributed to its smaller total flow area. In 


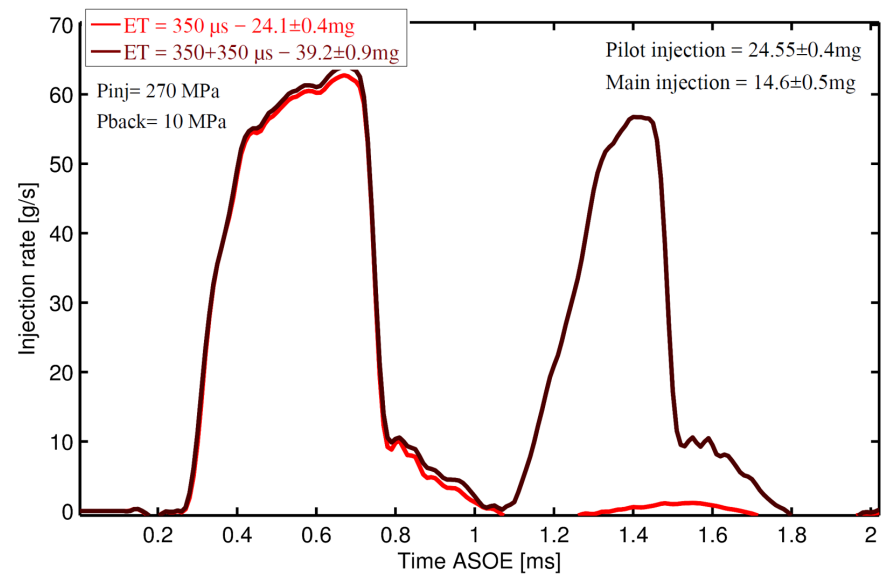

(a) Pinj=270 MPa, Pilot $=350 \mu$ s, Dwell time $387 \mu \mathrm{s}$

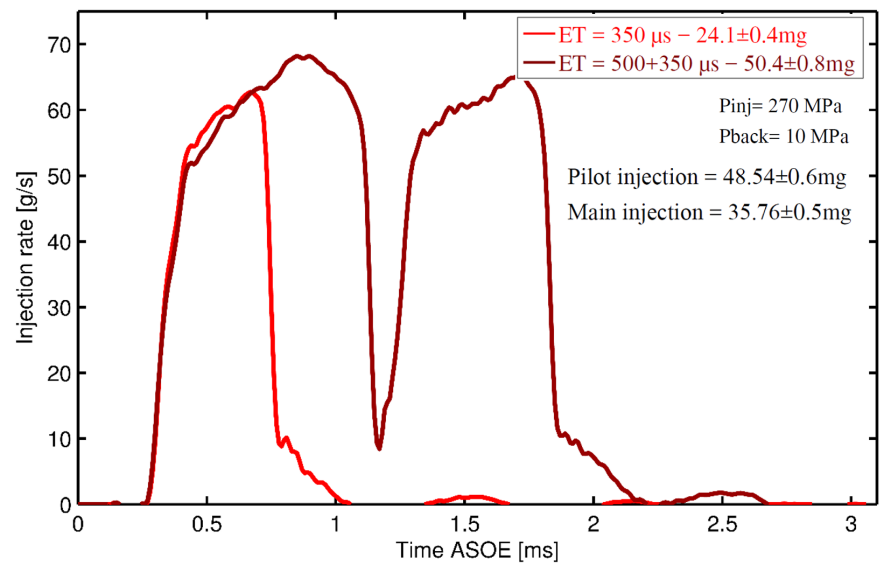

(b) Pinj $=270 \mathrm{MPa}$, Pilot $=500 \mu \mathrm{s}$, Dwell time $387 \mu \mathrm{s}$

Fig. 5.5 Effect of increasing Pilot injection time. Single injection (red) comparison with same ET in post injections (wine red)

summary, the higher the nozzle total flow area, the higher the mass flow rate and the injected mass. The dynamic response (needle opening-SOI) is specially different for CRI2-18 as it will be explained is the in section 5.3.5. Besides, notwithstanding the similar total flow area between the piezo injector (CRI3-27) and the solenoid injector CRI2-18, the injection duration of the piezo-driven injector is longer. This can be attributed with longer needle displacement. 


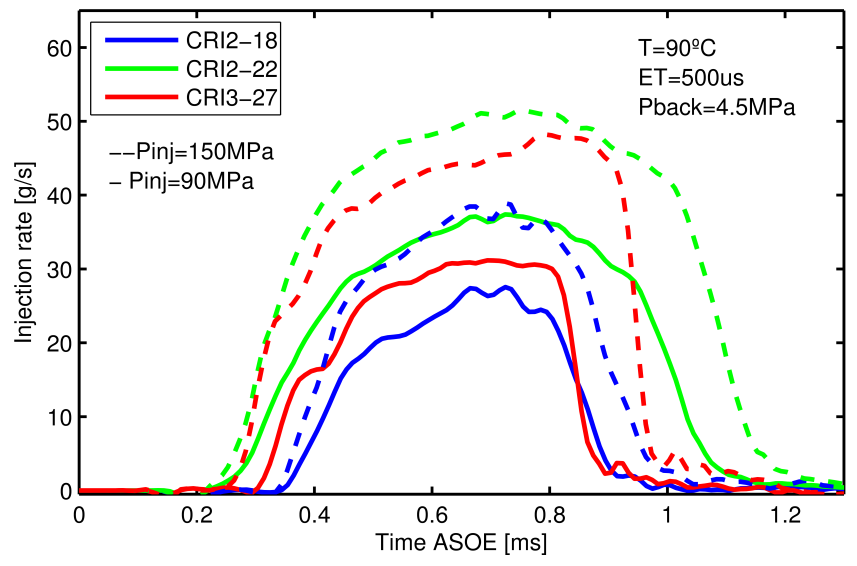

Fig. 5.6 ROI signals for the injectors, $\mathrm{ET}=500 \mu s$.

\section{Discharge coefficients}

For the estimation of these coefficients, the steady-state stage of the injection event is defined as the time interval in which the mass flow is higher than the $95 \%$ of the maximum fuel rate. Thus, the real fuel rate the discharge coefficient is calculated by averaging the mass flow in the previous interval [38].

Although the needle opening and closing time periods are really important for the development of the spray and air entrainment, they cannot be used to extract the hydraulic coefficients in a quantitative way. Accordingly, figure 5.7 presents the mean value of the mass flow rate as a function of the square root of the pressure drop $\Delta P$, which should be linear theoretically as described by the equation 2.17.

As the mass flow rate follows a linear tendency, it can be concluded there are not restrictions for the flow at the outlet orifice, this means that no cavitation phenomenon is observed for all the injectors and for all conditions tested.

The discharge coefficient is another way to represent the mass flow rate. This dimensionless parameter is represented in figure 5.8 as a function of the theoretical Reynolds number [23]. The discharge coefficient presents a first linear behavior (Injector CRI3-27) for relatively lower Reynolds number $\left(R_{e}<15000\right)$ and then, the evolution seems to be more controlled with a slightly increasing linear tendency. This behavior 


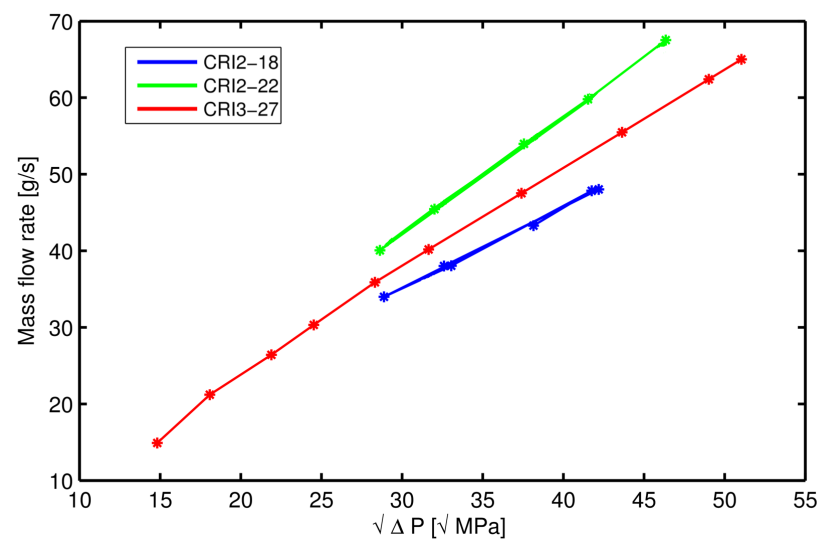

Fig. 5.7 Steady rate of injection as a function of the pressure drop across the injector for all test conditions with $\mathrm{ET}=1100 \mu \mathrm{s}$

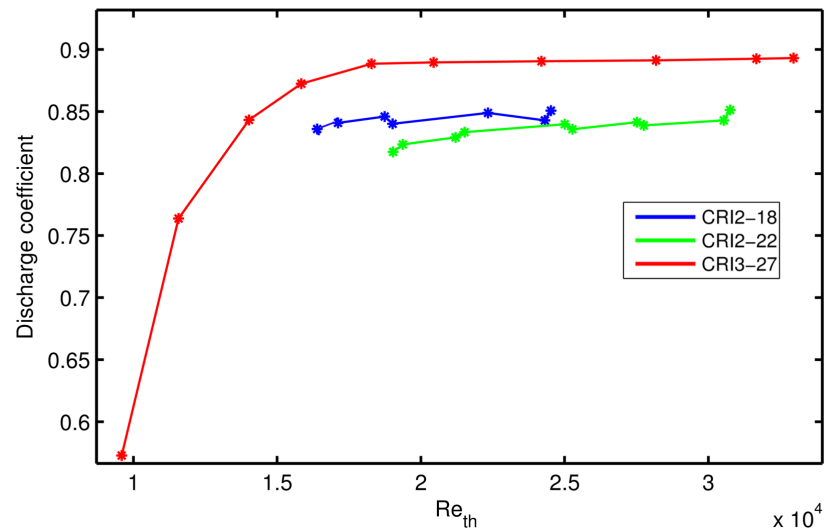

Fig. 5.8 Discharge coefficients as a function of the pressure drop across the injector for all test conditions with $\mathrm{ET}=900 \mu \mathrm{s}$

has been observed by other researchers $[96,125,130]$ who attributed those two distinct tendencies in the evolution of the $C_{d}$ to the fact that the flow goes from laminar (or within the transition zone) to turbulent while $R_{e}$ increases.

In this research, the internal geometry of the nozzles could not be measured and characterized for reasons of confidentiality. Nevertheless, some conclusions about the internal geometry can be made by observing the obtained mass flow measurements and discharge coefficients. Benajes et al. [19] conducted an experimental study to analyze the influence of conical and cylindrical nozzle orifices on injection rate behavior of a 
common-rail fuel injection system at maximum needle lift in a cavitation test rig. They observed that compared to a cylindrical orifice, a conical orifice reduces cavitation, increases flow efficiency (discharge coefficient) and exit velocity, although the fuel injection rate is reduced due to the smaller exit area. Regarding discharge coefficients found, it can be concluded that due to its smaller discharge coefficient, injection rate and its higher droplet diameters (as it can be seen later in chapter 6.5.3), it is probable that CRI2-18 possesses a lesser conicity than injector CRI3-27. No conclusions can be made regarding the injector CRI2-22 since its total mass flow area is indubitably higher and it is not comparable with the other two injectors.

\section{Injected mass dispersion}

An accurate control on the amount of fuel injected is a paramount requirement for an injector. The figure 5.9 shows the shot-to-shot standard deviation obtained from all test conditions. As the needle is throttling the fuel flow (low ET's), the accuracy on the injected mass decreases.

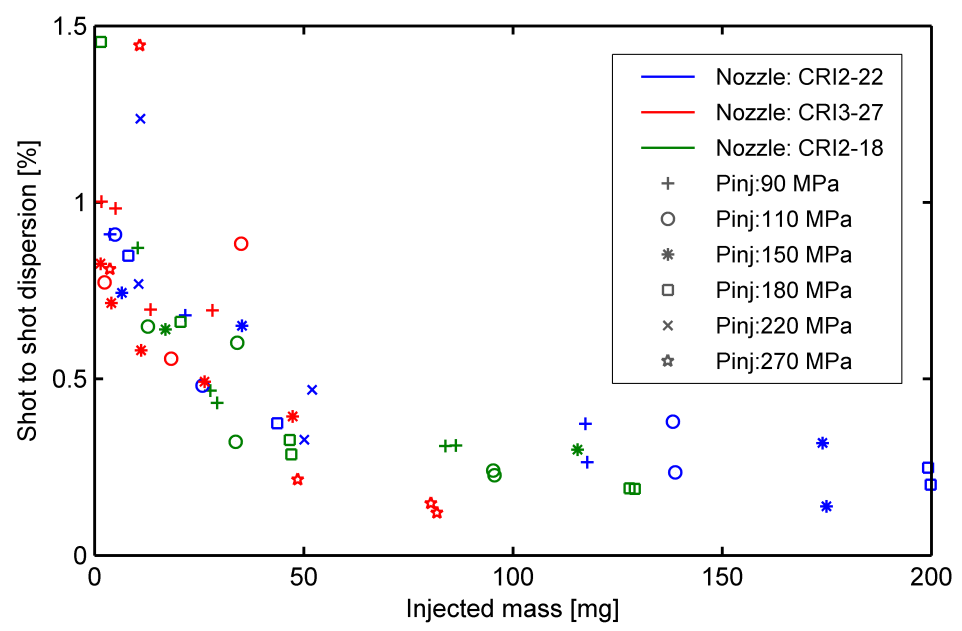

Fig. 5.9 Shot-to-shot standard deviation from all test conditions and all injectors

For all the injectors and test conditions, the relationship between the shot-to-shot dispersion and the injection pressure coincides with what is normally obtained with new generation commercial injectors; the greater the injection pressure the greater 
the accuracy of the injector [19]. In addition, the shot-to-shot dispersion amongst injections has not exceeded $5 \%$, this is usual also for new generation injectors.

\subsubsection{Rail and ambient pressures influence on ROI}

The figures 5.10a to 5.10c show the injection rate for a sweep of rail pressure for the three injectors, and also its effect over the mass flow rate. A higher injection pressure will produce a higher rate of injection rate mainly due to the rise in the flow velocity. The effect of injection pressure on ROI is well known for diesel injectors, the relationship of proportionality between injection pressure and the rate of injection is $\dot{m} \approx \sqrt{\Delta P}[52]$.

It can also be noted how the SOI is augmented with the rail pressure for injectors CRI2-22 and CRI3-27 as is generally the case in diesel hardware [52]. This behavior is provoked by the pressure difference between the return duct of the injector (usually between 0.1 and $0.6 \mathrm{MPa}$ ) and the control volume of the injector (equal to the injection pressure). The higher this pressure difference the faster the control volume will be emptied, and the faster the needle lift will be [106]. This variation with injection pressure is smaller for the injector CRI2-18, this is probably because the force applied to the needle by the coil is considerably higher than the one opposing force caused by the pressurized fuel. The figures 5.11 a to $5.11 \mathrm{~b}$ show results of injection rate shapes for back pressure variations. The back pressure sweep produced no significant differences over the curves of ROI, which is consistent with the literature consulted.

\subsubsection{Injection duration study}

In the curves in figures 5.12a to 5.12c, the energizing time effect for each injector over the ROI is represented. For the injector CRI3-27, injection pressures of $50 \mathrm{MPa}$ and $270 \mathrm{MPa}$ are presented, the latter being especially important, being the first time that this pressure is tested at CMT. 

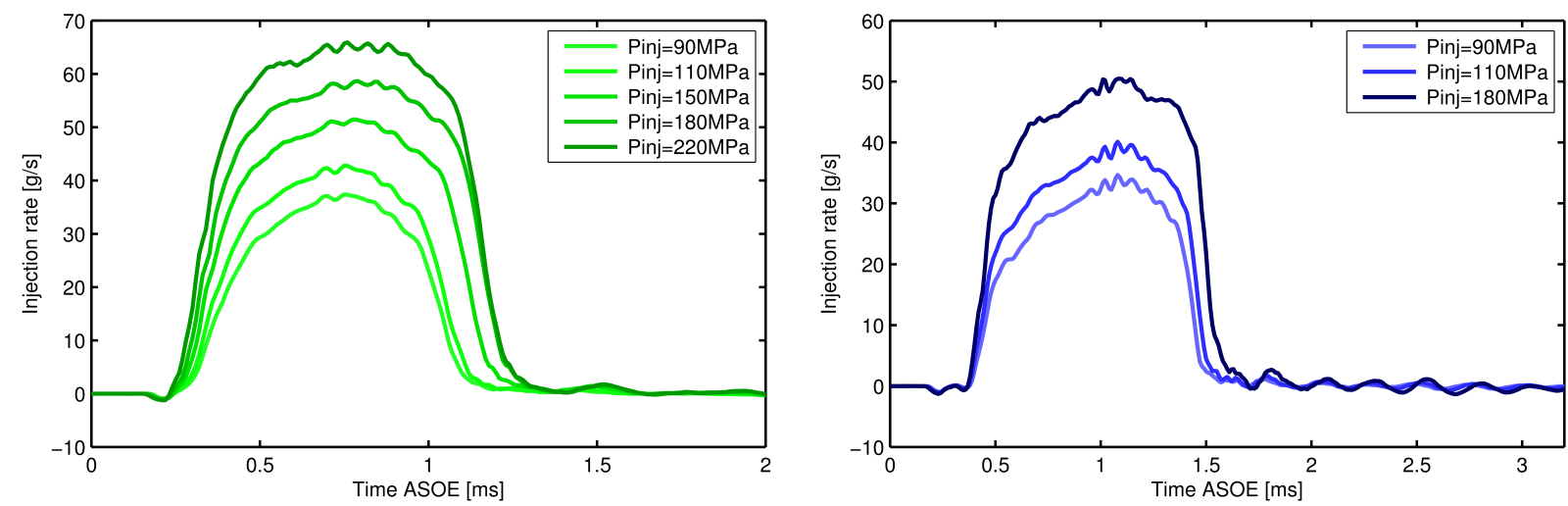

(a) Solenoid Nozz $=$ CRI2-22, $P_{\text {back }}=4.5 \mathrm{MPa}$, $\mathrm{ET}=0.5 \mathrm{~ms}$

(b) Solenoid Nozz=CRI2-18, $P_{\text {back }}=4.5 \mathrm{MPa}$, $\mathrm{ET}=0.75 \mathrm{~ms}$

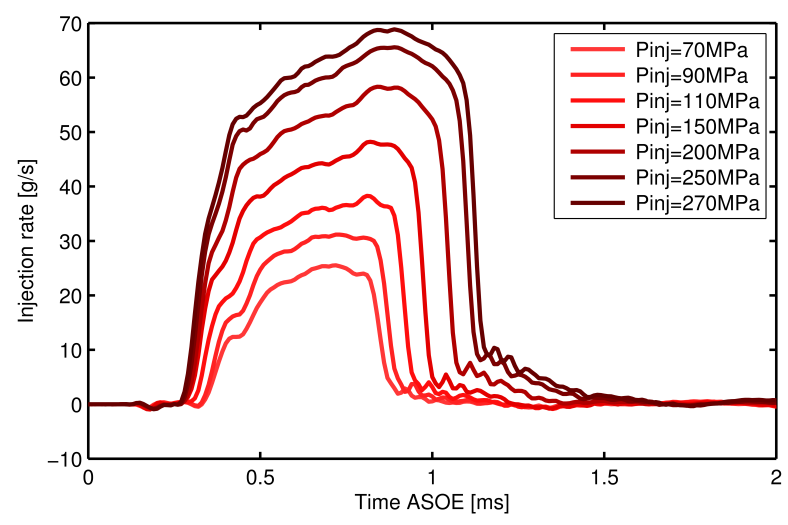

(c) Piezo Nozz $=$ CRI3-27, $P_{\text {back }}=4.5 \mathrm{MPa}$, $\mathrm{ET}=0.5 \mathrm{~ms}$

Fig. 5.10 Injection rate signals measured for the three nozzles, Injection pressure effect.

For low injection pressures (50 MPa) and low ET's, specifically between 180 and $250 \mu \mathrm{s}$ (ET's mostly used in pilot injections), the injector practically does not inject, thus the pressure sensor of the IRDCI only shows a non-legible pressure signal. Naturally, it is also observed in all figures that, the higher the ET the longer the ROI signal. Therefore, the more amount of mass injected due to the simple fact that by having more ET, the needle is lifted for more time and therefore, allowing the fuel to escape from the nozzle for longer time.

As it can be seen in the graphs, values of less than $500 \mu s$ were not enough to 


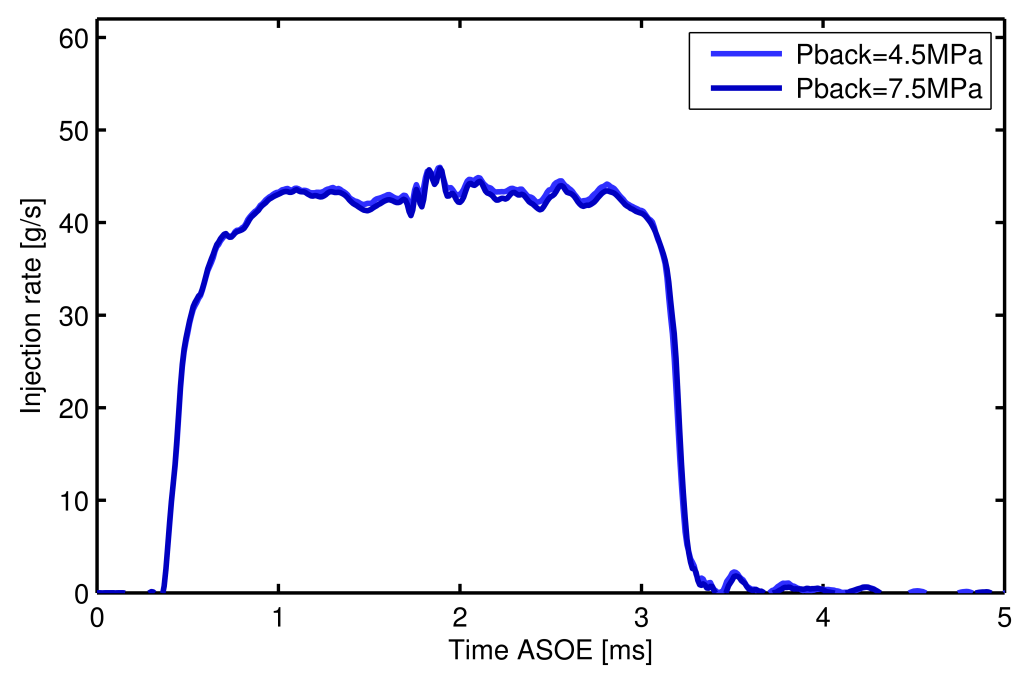

(a) Solenoid Nozz=CRI2-18, $P_{b a c k}=1.5 \mathrm{MPa}$, $\mathrm{ET}=1.5 \mathrm{~ms}$

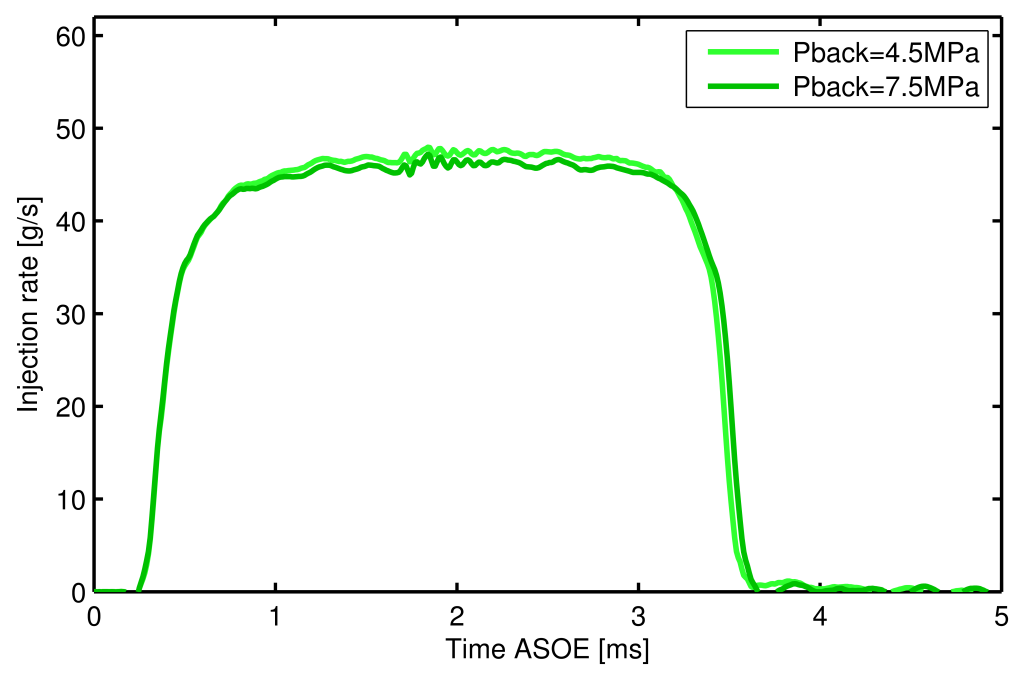

(b) Solenoid Nozz=CRI2-22, Pinj=110 MPa, $\mathrm{ET}=1.5 \mathrm{~ms}$

Fig. 5.11 Injection rate signals measured for the CRI2-18 and CRI2-22 nozzles, ambient pressure effect.

reach a stable operating condition. Even though the shortest ET's values (180 and 250 $\mu s)$ lift the needle enough to allow the nozzle to deliver fuel, the operation with this short injections is not stable and the injected quantity is very unreliable. In conclusion the ET that allowed stable operation was $500 \mu s$ as it can be seen in the graphs, thus, the effect of this parameter was important to analyze with the objective of setting 
the ET's for the macroscopic spray visualization, because it is ensured that with ET's greater than $500 \mu s$ the penetration of the spray will not vary.
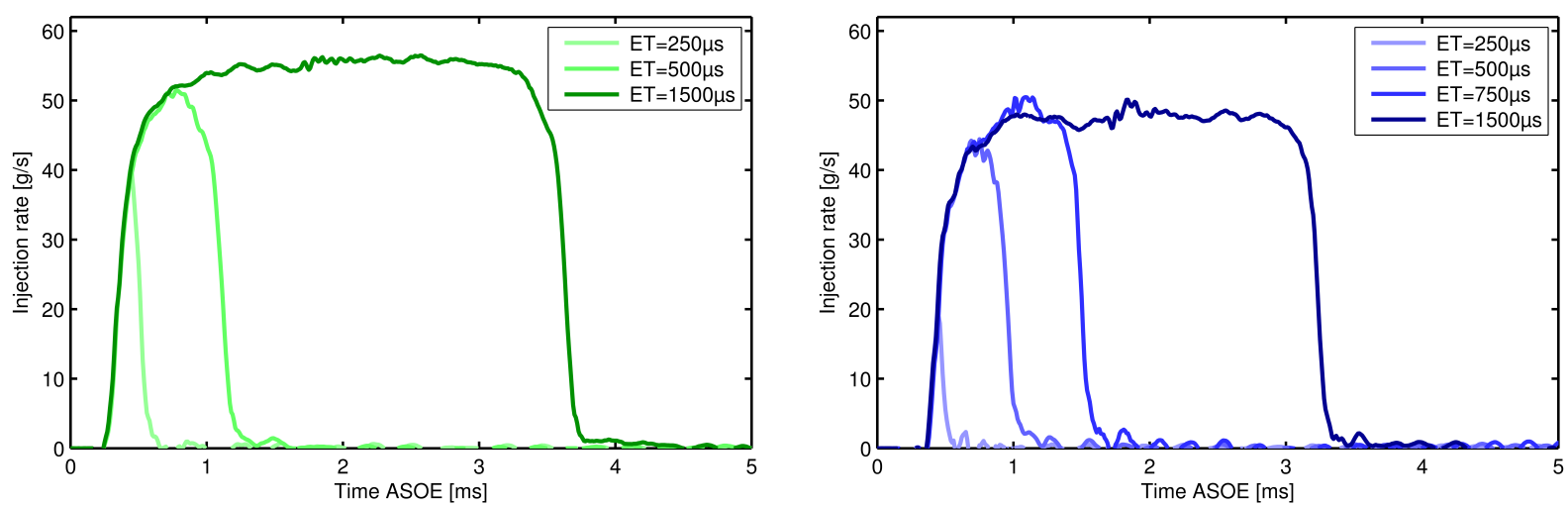

(a) Solenoid Nozz $=$ CRI2-22, $P_{\text {back }}=4.5 \mathrm{MPa}$, Pinj=150 MPa

(b) Solenoid Nozz $=$ CRI2-18, $P_{\text {back }}=4.5 \mathrm{MPa}$, Pinj=180 MPa

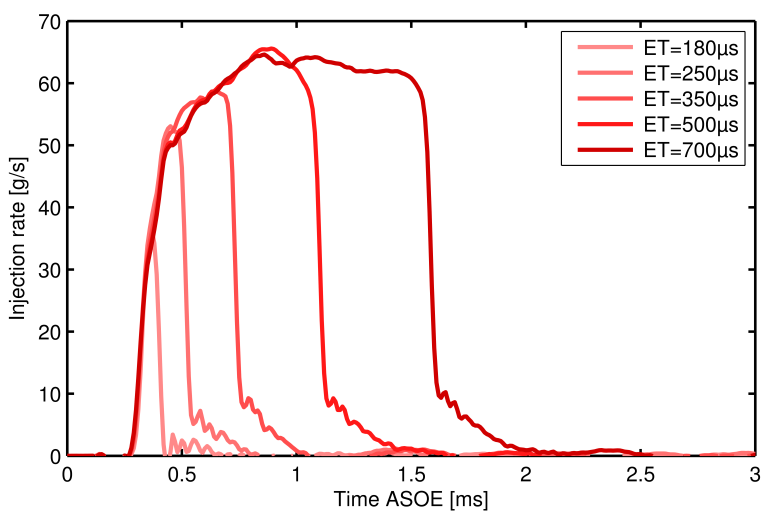

(c) Piezo Nozz $=$ CRI3-27, $P_{b a c k}=10 \mathrm{MPa}$, Pin$\mathrm{j}=270 \mathrm{MPa}$

Fig. 5.12 Injection rate signals measured for the three nozzles, ET effect.

It is also interesting to point out that, unlike what happened with the pressure variation, a variation of the ET does not produce any change in the hydraulic delay nor in the opening or closing times of the needle. 


\subsection{Conclusions}

This section summarizes the chapter and presents the main conclusion extracted from the internal flow experimental results. Three diesel injectors (two solenoid and one piezo driven) have been hydraulically characterized. The nozzle diameter from each injector were extracted thanks to microscopy. Regarding the electrical signal the most remarkable result over the ROI, is that the smaller slope, the greater the total injected mass, nevertheless, the fact that the needle closing and opening times are diminished brings along some negative consequences in the transient behavior of the needle during multi-injection events.

Regarding multiple injections, the effects caused by pilot injections over the main injection in the piezo-electrical injector were tested as well. It was concluded that the dwell time variation causes a bathtub trend of the ROI over the total mass flow of the post-injection. This variation depends mainly on injection pressure, pilot injection ET and fuel properties.

Any restrictions were found for the flow at the outlet orifice, as the mass flow rate follows a linear tendency with the root of the pressure delta. Consequently, no cavitation was observed for all the injectors and for all conditions tested [23]. Discharge coefficients were estimated for each nozzle. This coefficient presented a first linear behavior for relatively lower Reynolds number $\left(R_{e}<15000\right)$. For higher Reynolds it presented a slightly increasing linear tendency. These tendencies are attributed to the fact that the flow goes from laminar (or within the transition zone) to turbulent while $R_{e}$ increases. In conclusion, at high Reynolds numbers $\left(R_{e}>15000\right)$, the $C_{d}$ slows its upward trend showing a much more stabilized behavior except for a slight growth when increasing the $R_{e}$. The value of the stabilized $C_{d}$ is known as maximum or last $\left(C_{d \max }\right)$ [96]. This maximum value reached is different for each nozzle and it is higher with a greater nozzle diameter and thus with small $L / D$ ratios. Furthermore, it can be concluded that due to its smaller discharge coefficient, injection rate and 
its higher droplet diameters (chapter 6.5.3), it is probable that CRI2-18 possess a lesser conicity than piezo injector CRI3-27. No conclusions can be made regarding the injector CRI2-22 since its total mass flow area is indubitably higher and it is not comparable with the other two injectors.

Throughout the test matrix, the injector CRI2-18 presented lower stabilized mass flow rates, which is attributed to its smaller total flow area and to its great losses probably caused by its internal geometry. The shot-to-shot dispersion amongst injections did not exceeded $1.5 \%$ for all injectors. This behavior is usual also for new generation injectors.

Furthermore, the SOI was augmented with injection pressure increments for injectors CRI2-22 and CRI3-27. Nevertheless, this variation with injection pressure was smaller for the injector CRI2-18. This was likely caused by the force applied to the needle coming from the coil that is considerably higher than the one opposing force caused by the pressurized fuel. 


\section{Chapter 6}

\section{Results and discussion:}

\section{Microscopic characterization}

\subsection{Introduction}

From a microscopic point a view, some techniques quantify spray parameters like droplets size and velocities. As it has been said before, Phase Doppler Anemometry (PDPA) is usually used to measure these parameters. Being a non-intrusive technique to acquire droplet diameters and velocities from multi-phase flows, make this technique interesting for diesel spray characterization $[3,196]$.

The application of this technique to diesel sprays is not a new idea, however it has always been a complicated problem due the extreme droplet concentration typical for these sprays and to a lesser degree to their high droplet velocities. The high density of the diesel spray is a physical limitation for the PDPA technique that can only be overcome if the measurement volume is small enough to allow a single droplet passing through it at the time $[3,196]$.

There are two things that have to be considered when a multi-hole diesel injector is analyzed with a PDPA system. First, operating conditions must be established in order to obtain reliable results congruent with the physics of the spray at actual engine conditions. It is generally accepted that the behavior of the spray mainly depends 
on ambient density, not on ambient pressure [178]. For this reason a test rig able to achieve engine chamber densities is enough to carry out this kind of study.

Second, to have the proper optical access in the test rig is essential. In this manner, laser beams from the PDPA system are allowed to get into the chamber and create a control volume in the spray that will be measured.

In this chapter a methodology for PDPA measurements on a multi-hole diesel injector is presented. Since only one of the sprays was planned to be measured, and with the objective of that both incident and receiver beams of the PDPA can generate the control volume in any part of this spray of interest, a device for spray isolation has been designed. A preliminary lined up of the spray of interest was made by means of the MIE-Scattering optical technique. The image processing has been performed through a purpose-built Matlab code. Preliminary measurements on the three injectors used in this thesis are analyzed as well. The methodology presented here can be applied to any PDPA measurement for a multi-hole diesel injector.

\subsection{Test plan definition for PDPA measurements}

For the microscopic characterization different injection conditions have been tested. Experiments were carried out for a variety of representative engine values of injection pressures $(90,110,150,180,200,220,250$ and $270 \mathrm{MPa})$ and ambient densities (25 and $35 \mathrm{~kg} / \mathrm{m}^{3}$ ). The ambient temperature was the standard of $298 \mathrm{~K}$ used as a reference in order to study the spray under no-evaporating conditions. A resume of the test matrix is presented in table 6.1, where all the wide range of possible operating pressure conditions of a common-rail system are covered. For each operating point, the objective was to gather at least 3000 droplets to get representative data. The graph reported in the figure 6.1 shows the location points for the measurements. Due to the high droplets concentration common for these sprays, measurements at axial distances below $20 \mathrm{~mm}$ are almost impossible [136]. Therefore, three axial locations were studied (30, 40 and $50 \mathrm{~mm}$ from the nozzle tip). Moving the measuring probe volume across the spray and 
Table 6.1 Experimental conditions for the microscopic characterization.

\begin{tabular}{lcc}
\hline \hline Parameter & Injector & Testing Conditions \\
\hline & CRI2-18 & $90 / 110 / 150 / 180$ \\
Injection Pressure $[\mathrm{MPa}]$ & CRI2-22 & $90 / 110 / 150 / 180 / 220$ \\
& CRI3-27 & $/ 900 / 1100 / 150 / 180 / 200 / 250 / 270$ \\
\hline & CRI2-18 & $25 / 35$ \\
& CRI2-22 & $25 / 35$ \\
Rho $\left[\mathrm{kg} / \mathrm{m}^{3}\right]$ & CRI3-27 & $25 / 35$ \\
& CRI2-18 & 1.5 \\
& CRI2-22 & 1.5 \\
Energizing Time $[\mathrm{ms}]$ & CRI3-27 & 0.7 \\
\hline & CRI2-18 & $30 / 40 / 50-0 / 2.9 / 4.04 / 5.88 / 8$ \\
& CRI2-22 & $30 / 40 / 50-0 / 2.9 / 4.04 / 5.88 / 8$ \\
& CRI3-27 & $30 / 40 / 50-$ five radial positions (figure 6.1$)$ \\
\hline
\end{tabular}

along the radial direction at $-45^{\circ}$ in the $\mathrm{Y}-\mathrm{Z}$ plane, to limit as much as possible the passing of the beams through the spray.

\subsection{PDPA measurements setting}

Due to the difficulty presented by the measurements taken in the dense parts of the spray, the set-up chosen was mainly determined by the necessity to improve those measurements. As it has been mentioned before, Vlad [196] maximized the system droplet acquisition. The parameters obtained from this investigation and used in this thesis are summarized in section 4.6.1. The software-type parameters are showed in the 


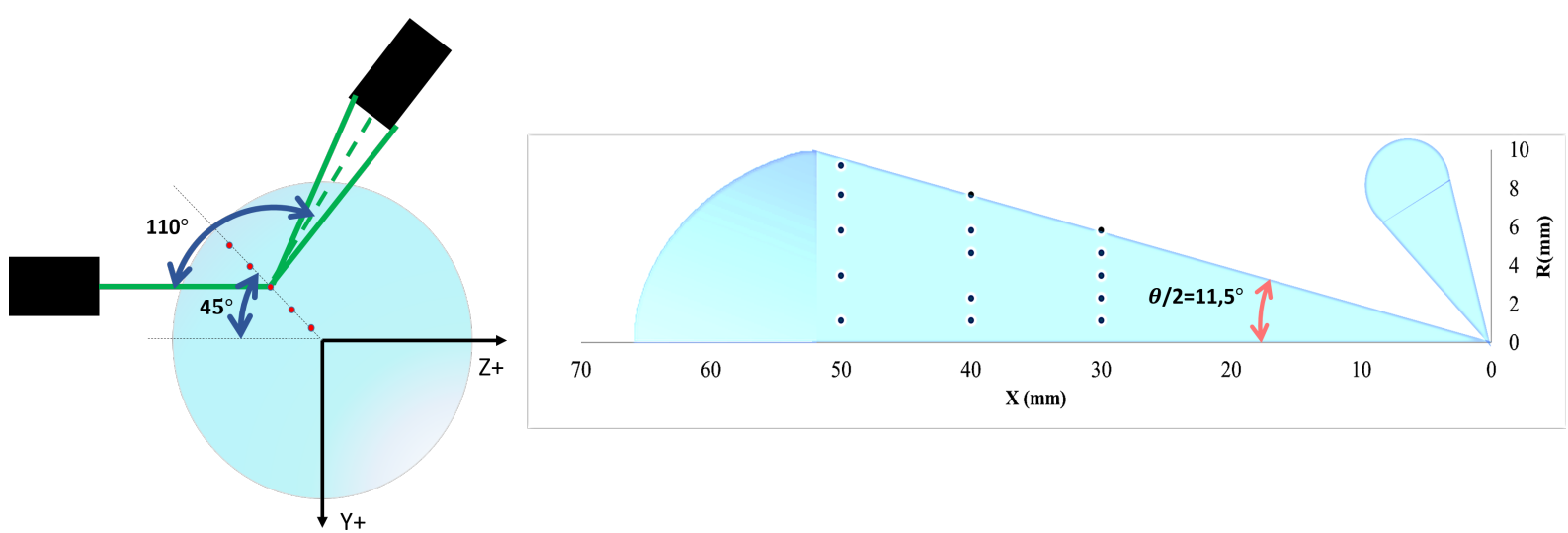

Fig. 6.1 Test plan positions for PDPA measurements on CRI3-27 piezo injector

table 6.2 (SNR, the burst threshold, the bandwidth filter and the voltage applied to the photomultipliers). Although the laser power is of hardware-type, it should also be included here because it contributes to the signal visibility. An increase of laser power is usually the solution preferred in order to increase data acquisition because it preserves the signal-to-noise ratio whereas the increase of the photomultipliers voltage, due to the logarithmic-type of amplification, tends to bring the weak signals closer to the level of the stronger ones, making it more difficult to distinguish between noise and valid droplets [196]. Also in this work was found that a of $40-120 \mathrm{MHz}$ filter produced the less amount of nosier data. Furthermore, the higher velocities that could be measured in theory with the $20-175 \mathrm{MHz}$ filter can only be found in those parts of the spray that are so dense that the PDA measurements are practically impossible.

\subsection{Methodology for spray alignment and multi- hole injectors measurements}

As it has been said before, the angle between the emitter and receiver in the PDPA system must be $110^{\circ}$. The experimental set-up was adapted to satisfy this requirement (figure 6.2a).

Considering the diesel injector geometry and the way that the spray of interest will be measured, some parts were designed and manufactured in order to adapt its 
Table 6.2 PDPA system software parameters

\begin{tabular}{cc}
\hline \hline Parameter & Magnitude \\
\hline Laser Power & $800 \mathrm{~mW}$ \\
\hline PMT voltage & $450 \mathrm{~V}$ \\
\hline Bragg cell frequency & $40 \mathrm{MHz}$ \\
\hline
\end{tabular}

Frequency band filter 40-120MHz $(0-144 \mathrm{~m} / \mathrm{s})$
Downmix frequency
$0 \mathrm{MHz}$

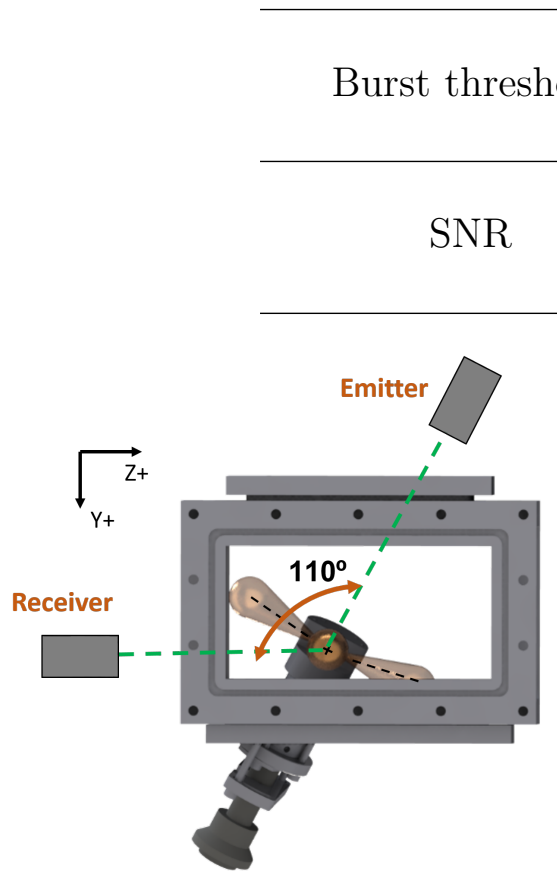

(a)

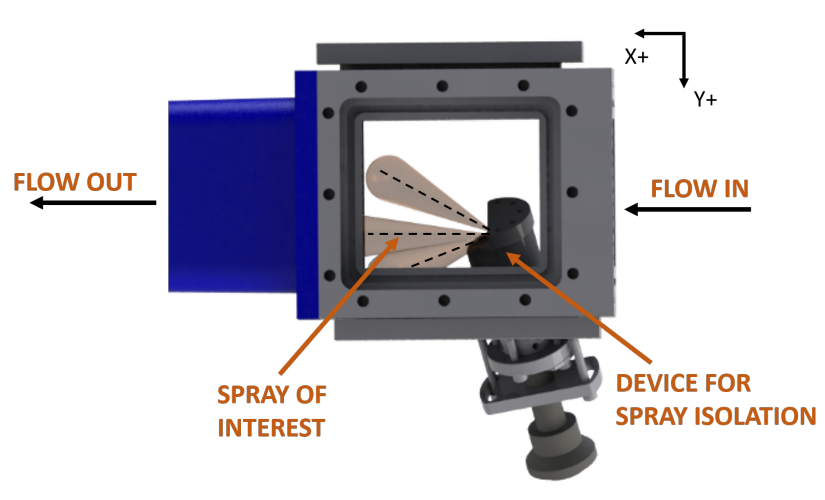

(b)

Fig. 6.2 Multi-hole diesel injector assembled in the test rig

geometry with the test rig and based on the following requirements: (1) the injectors have between 7 and 8 orifices, however only one of these sprays will be analyzed (any of these sprays can be selected for measurements). (2) The probe volume generated 
by the PDPA system must be able to be located at any section across the spray of interest to acquire data of droplet velocities and diameters in these locations. (3) The windows must be clean during PDPA measurements. Furthermore, (4) the spray to be measured was thought to come out from the nozzle horizontally (figure 6.2b) to ease the way that the probe volume is located across the spray.

The soiling of the test rig windows with diesel is a big problem in PDPA measurements for multi-hole injectors, as the sprays are usually directed towards them. These windows provide the optical access needed for the laser beams, to get into the chamber and create the probe volume. Impregnated diesel in the windows could preclude the measurements. For this reason it was also thought to obstruct all the orifices of the injector except for three of them, in order to avoid sudden changes in the structure of the spray of interest. But considering that the obstruction of some holes changes the internal nozzle flow and thereby the spray structure [51], it was decided to collect them instead. Hence, a device for isolate sprays was designed, to collect mainly those who have no direct effect on the spray of interest (figures 6.3a to 6.3c). The device was dimensioned taking into account the number of orifices that the injector had. In the figure $6.3 \mathrm{c}$ the device dimensions for the injector used in this work can be observed. The sprays are collected in a small chamber where the residual diesel is evacuated through several holes in the top cover of the device.

PDPA laser beams enter into the test rig through the top window of the test rig generating the control volume probe, the photo-detector receiver captures light frequency of the droplets passing through the probe. Therefore, both the top and lateral (in front of the receiver) windows shall be kept clean. The bottom cover of the test rig, where the injector is placed, has been designed so that the sprays will not impinge the most crucial windows for these measurements (figures 6.4a to 6.4c). In the figure $6.4 \mathrm{a}$, the bottom cover is shown assembled with the diesel injector. It can be seen that the sprays are far enough from the lateral window (near the receiver). The 


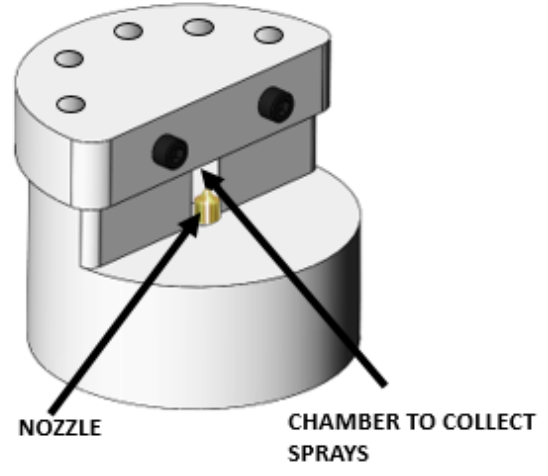

(a)

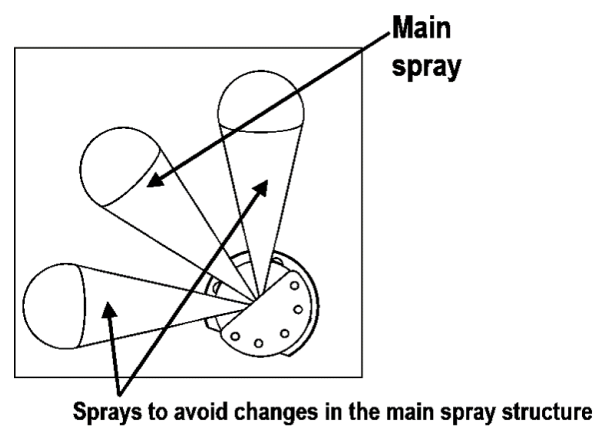

(b)

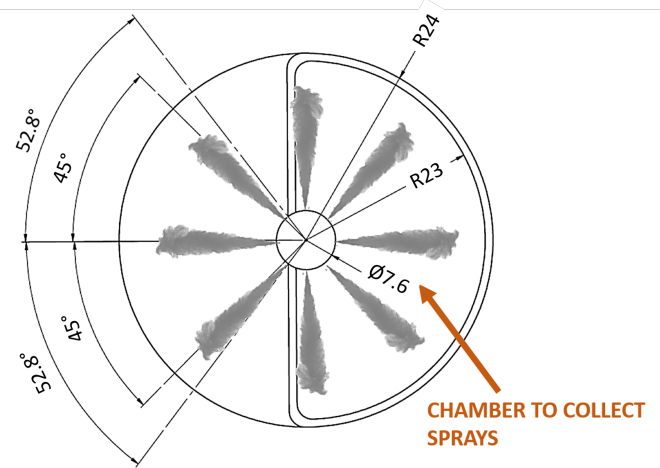

(c)

Fig. 6.3 Device for spray isolation (a) Device 3d view (b) Upper view with sprays (c) Upper view without the top cover.

injector is also connected with a holder (figure 6.4d) provided with several internal ducts used to keep the temperature of the injector constant during the measurements.

\subsubsection{Methodology for spray of interest alignment}

The alignment of the spray of interest was made by means of MIE-Scattering visualization. The main idea was to find the spray axis by detecting the spray contour. For contour detection, an image segmentation was done first [103]. A fixed threshold method has been used, which corresponds to $3 \%$ of the maximum digital level obtained in the core of the spray. Then this threshold is employed for image binarization after a background arithmetical subtraction. This method is extensively used in MIE-Scattering imaging since it scales the sensitivity to the illumination intensity 


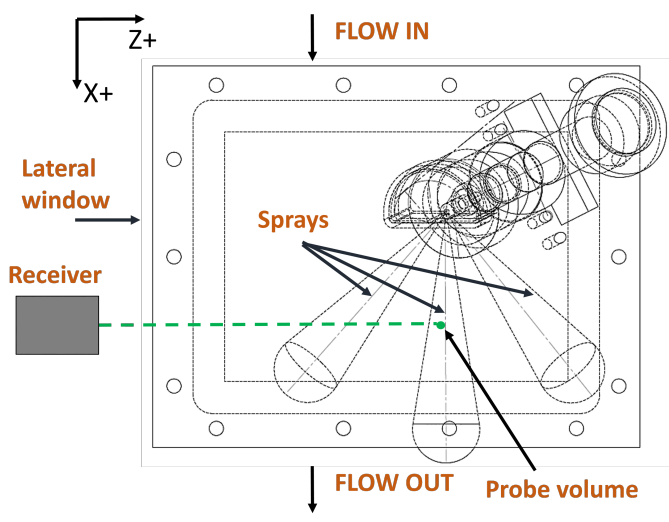

(a)

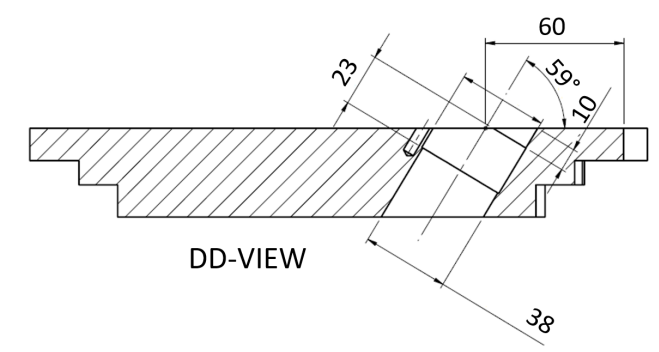

(c)

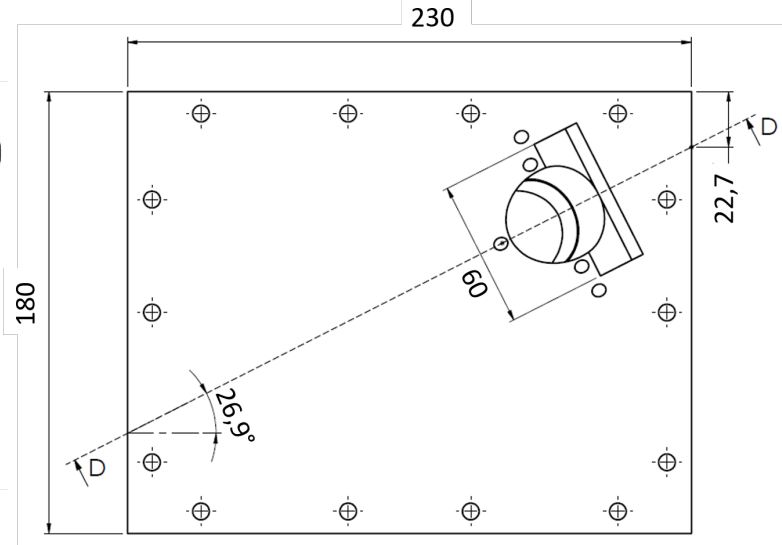

(b)

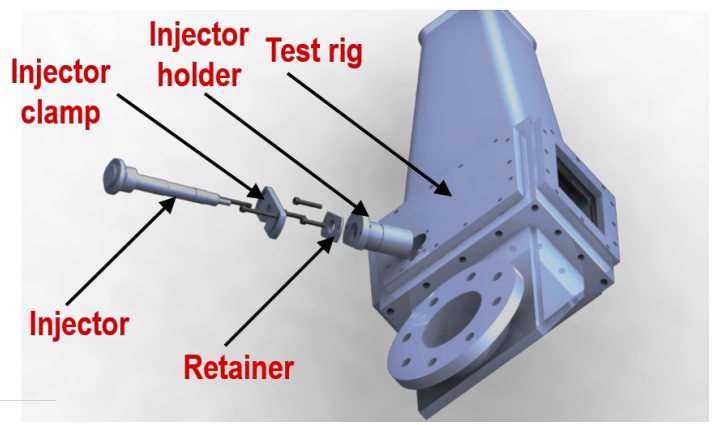

(d)

Fig. 6.4 Designed bottom cover of the test rig. (a) Bottom cover of the test rig assembled with the injector (b) Bottom cover dimensions (c) Bottom cover dimensions, D-D View (d) Test rig assembly with the injector.

[103, 132, 146] . With the PDPA system off, 10 injections were recorded using 18000 fps and an exposure time of $55 \mu \mathrm{s}$. For each injection event 60 images were acquired and for each time step a centroid was calculated using the contoured area of the spray (fig. 6.6b). The angle formed by the junction centroid-spray origin and a horizontal line at each time step can be estimated. In the figure 6.5, it can be seen these calculated angles for each injection event. Afterwards, centroid angles between $1 \mathrm{~ms}$ and $3 \mathrm{~ms}$ are averaged, since angle variations in this range are minimized. In this example the angle was $-0.13^{\circ}$ and the standard deviation was $0.22^{\circ}$.

In the test rig, the injector is then gently rotated until this inclination vanishes. Since uncertainties in PDPA measurements for velocities have been reported in some cases to be up to $5 \%$ [196], an uncertainty of $\pm 1^{\circ}$ has been defined as acceptable to 


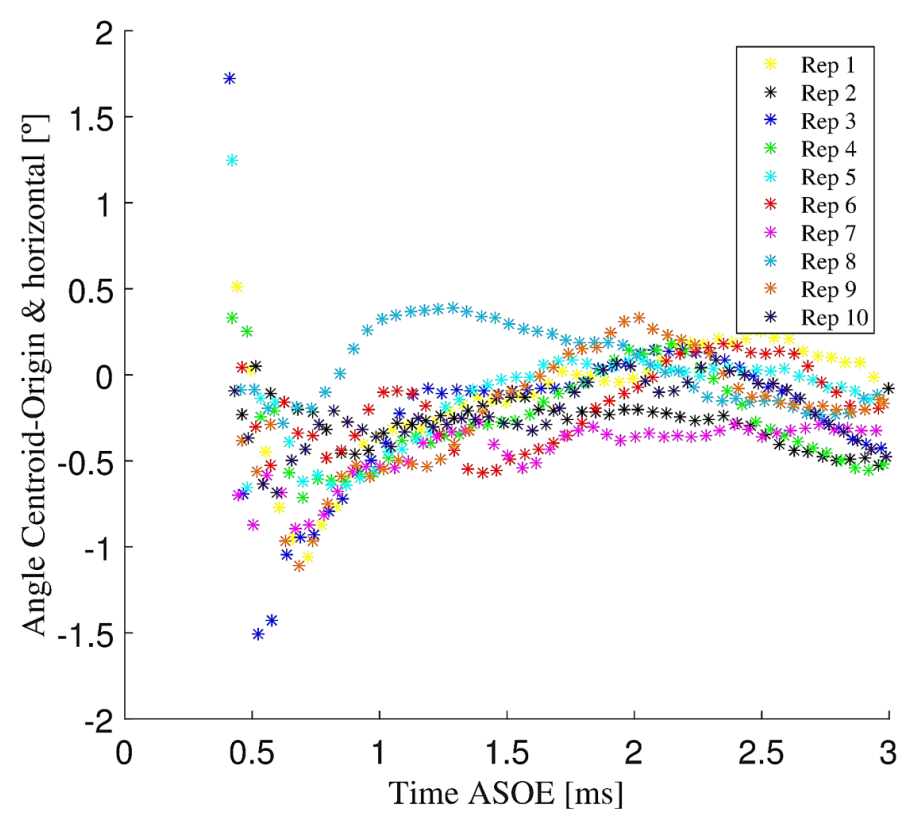

Fig. 6.5 Centroid-Origin angle calculation for each repetition

consider the spray "horizontal". After the alignment, the PDPA system is turned on. A single picture is taken at $1100 \mu$ s after start of injection, using 4000 fps and an exposure time of $400 \mu$ s (figure 6.6a). Images at this high exposure time are more saturated and thereby the laser beams from PDPA can be clearly seen. In this image the probe volume created by the interference of the laser beams from the PDPA system can be located. The pixel $/ \mathrm{mm}$ and the image resolution was preserved for all measurements, consequently the perpendicular distance between the probe volume and the spray axis can be also known. From this point any position of the PDPA control volume can be referenced with the spray axis.

Furthermore, the cone angle of the spray $\theta$ was also estimated with the spray contours obtained in the previous section. It was defined as the angle included between the two lines that fit the points on the spray contour in a specific region, and are forced to go through the outlet orifice. The region of the spray contour that is fitted goes from a $25 \%$ to $60 \%$ of the liquid spray penetration. 


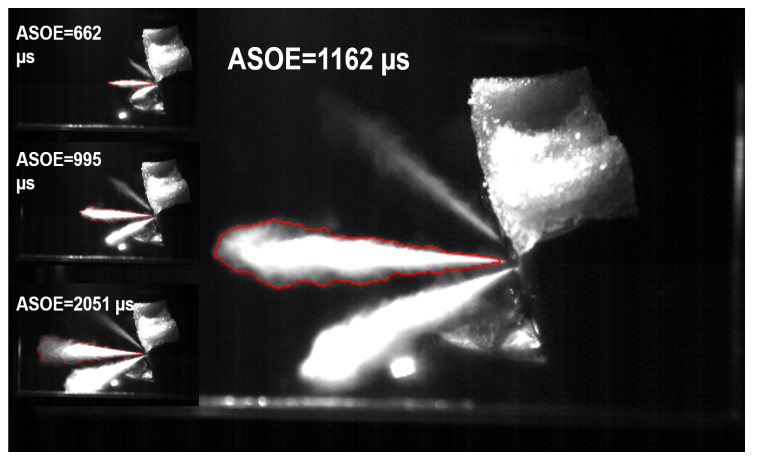

(a)

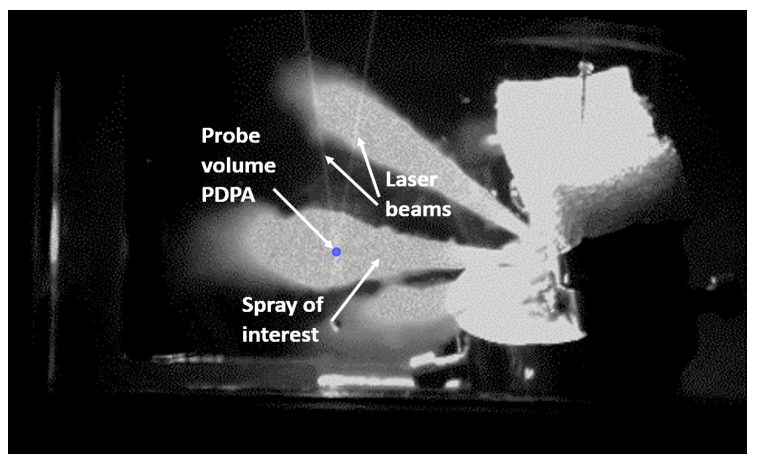

(b)

Fig. 6.6 MIE- Scattering images acquired with the fast camera (a) Image at high exposure time of the spray and laser beams (b) Instantaneous contours used to calculate centroids.

\subsubsection{Preliminary measurements}

In order to confirm the effectiveness of the alignment methodology, some velocity measurements with the PDPA system has been carried out at several axial distances using an ambient density of $25 \mathrm{~kg} / \mathrm{m}^{3}$. The figure 6.7 shows a typical time-resolved evolution of the axial velocity and droplet diameter over time after start of energizing. The energizing time was set to $1.5 \mathrm{~ms}$. The evolution of each measurement can be divided in 4 phases: (1) The spray tip, (2) the quasi-stationary phase at the fully open nozzle, (3) quasi-stationary phase at the fully open nozzle with coalescence, (4) and the spray tail. A brief description of each of them is presented in [88]. The average velocity is obtained on data from the spray tip and both quasi-steady parts, therefore, in the case of the figure, only velocities within 1 and $3 \mathrm{~ms}$ are included in this average.

\subsection{Fuel Droplet Size and Velocity Distribution}

After the injector alignment the test plan is executed and droplet diameters and velocities are obtained. The distribution of droplet size and velocity in sprays is a crucial parameter needed for fundamental analysis of practical spray systems. Detailed information regarding droplet size and velocity distributions in sprays is of ultimate importance for the design, operation, and optimization of spray systems [95]. Specifica- 


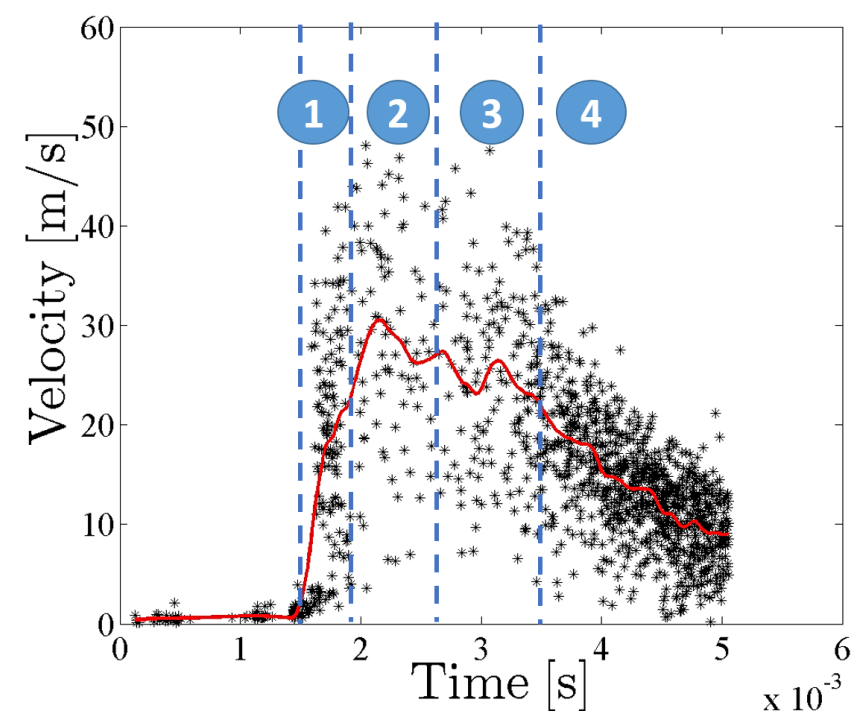

Fig. 6.7 Preliminary measurements, time-resolved evolution droplets velocities

tion of droplet size and velocity distributions in the immediate downstream of spray is also essential as boundary conditions for advanced computational fluid dynamics (CFD) based on two-phase spray transport calculations. In the following sections sections it will be exposed the analysis and limitations of the PDPA technique, regarding the macroscopic characterization of the three multi-hole nozzles used in this thesis. It is important to point out, as it has been mentioned before, that a conventional estimation of the accuracy of the results in the diesel spray is not possible because there are not another proven experimental method to deliver the same information as the PDPA technique. Furthermore, the theoretical formulas and the CFD simulations are never able to predict with the required precision the spray behavior [4].

\subsubsection{Droplet velocities}

In figures $6.8 \mathrm{a}$ to $6.8 \mathrm{e}$ transient velocity profiles are shown for the piezo and one of the solenoid injectors. The red line represents the moving average velocity over time (time window $=0.0002 \mathrm{~s}$ delta $=5 \mathrm{e}-07 \mathrm{~s})$. Those profiles demonstrate the aforementioned effect of dense or highly droplet concentrated zones, as it can be observed along the quasi-stationary phase at the fully open nozzle (zone 2) and at the quasi-stationary 
phase at the fully open nozzle with coalescence (zone 3), where the data concentration is significantly decreased by the injection pressure increment.

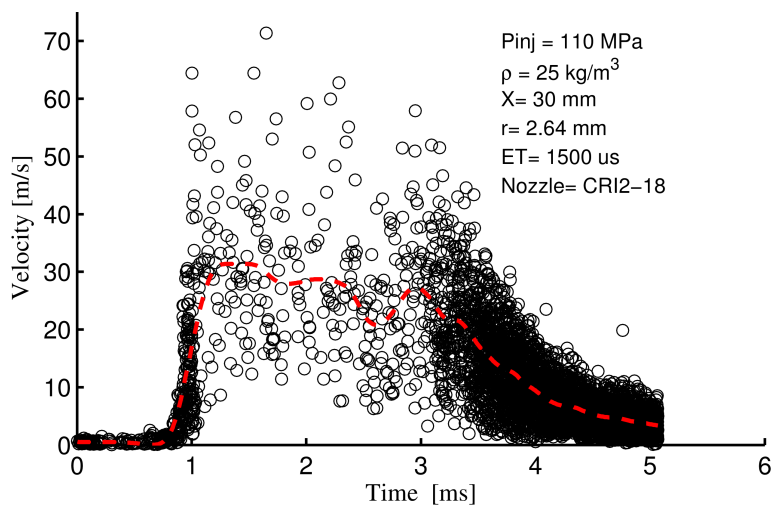

(a) Pinj $=110 \mathrm{MPa}, \mathrm{Nozz}=\mathrm{CRI} 2-18$

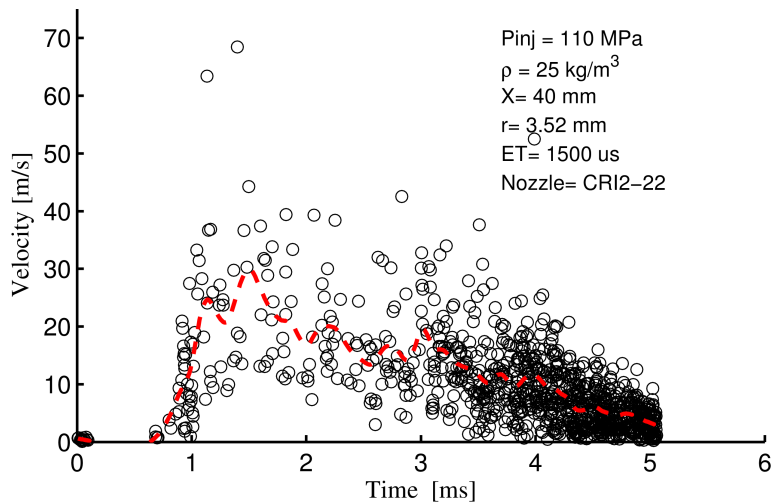

(c) Pinj $=110 \mathrm{MPa}$, Nozz $=$ CRI2-22

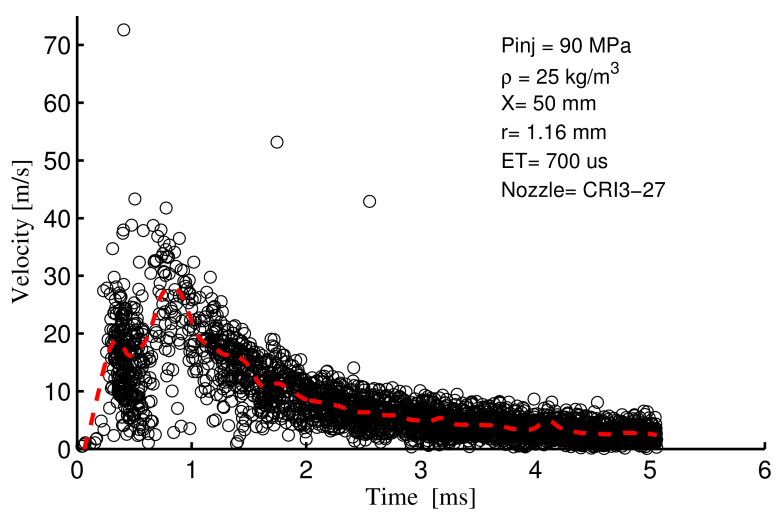

(e) Pinj $=90 \mathrm{MPa}$, Nozz $=$ CRI $3-27$

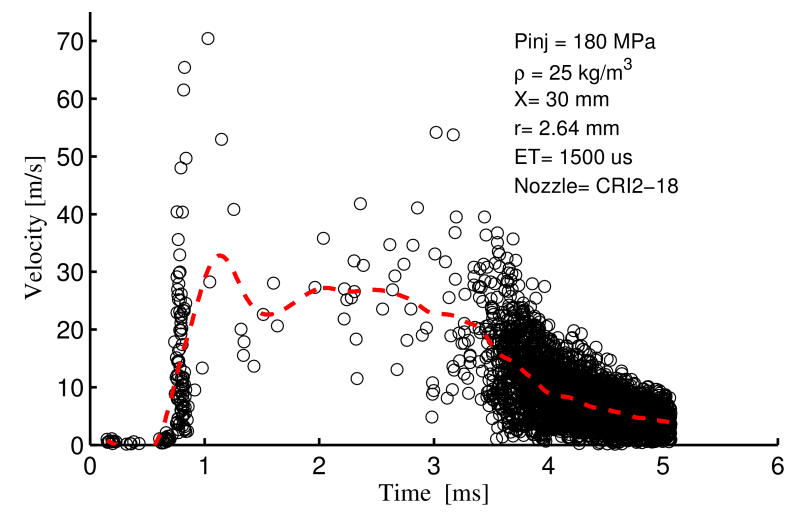

(b) Pinj= 180MPa, Nozz $=$ CRI2-18

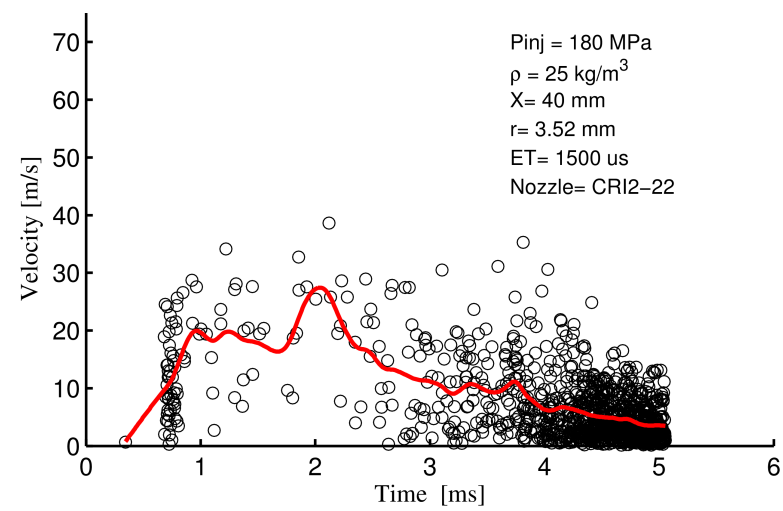

(d) Pinj= 180MPa, Nozz=CRI2-22

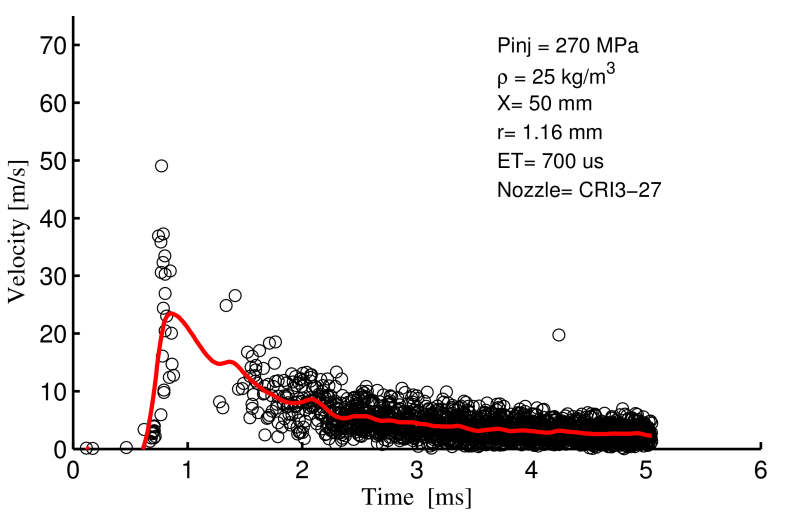

(f) $\operatorname{Pinj}=270 \mathrm{MPa}, \mathrm{Nozz}=\mathrm{CRI} 3-27$

Fig. 6.8 Transient velocity profiles $\rho_{a}=25 \mathrm{~kg} / \mathrm{m}^{3}$ 
In order to give an idea of the changes in the spatial structure of the spray under injection pressure variations; the figures $6.9 \mathrm{a}$ and $6.9 \mathrm{~b}$ show the effect of the injection pressure on the radial velocity profiles at several positions away from the nozzle. For these plots the velocities have been calculated by averaging the zones 3 and 4 of the transient velocity profile (section 6.4.2). Generally, the trends exhibit an increment in the velocity of the droplets with injection pressure as expected. Furthermore an increment in the distance between the nozzle and the control volume caused lower velocity profiles, this is due to the loss of momentum of the spray droplets during their movement, the aerodynamic resistance force acts on the droplets and slow down their velocity. On the other hand, the breakup of the spray droplets will also consume their kinetic energy and reduce their momentum. Meanwhile, the smaller droplets produced by these breakups can be slowed down more easily during the transportation. Nevertheless some exceptions where found especially near the spray axis $(r=0)$ and at very high pressures, where these trends were not strictly respected. This was not expected and is maybe caused by the PDPA constraints, the "slit aperture width" in the receiver affects the size of the measuring volume in which particles are detected. Expanding the slit aperture means less acquisition of validated droplets as there is more chance that two droplets pass through the control volume at the same time. Contracting the slit aperture means more validated droplets, however, the droplets with higher velocities could be missed. Those droplets are responsible for the highest velocities on the spray axis.

Radial velocity profiles were compared with a theoretical trend (equation 2.51) in order to check if the spray of interest was measured properly. The figures $6.10 \mathrm{a}$ and $6.10 \mathrm{~b}$ show the radial mean velocity profiles, $U / U_{\text {axis }}$, normalized with the axial velocity of the spray centerline. The dotted lines are the theoretical radial velocity profiles obtained with $90 \mathrm{MPa}$, an ambient density of $25 \mathrm{~kg} / \mathrm{m}^{3}$ and a spray angle $\theta$ of $23^{\circ}$ (obtained from visualization measurements). The R-square factor that correlates the theoretical profiles with the measured mean velocities were $96.6 \%$ and $89.9 \%$ for 
the piezo and solenoid injectors respectively. Consequently, the spray of interest was well aligned and presents a typical behavior.

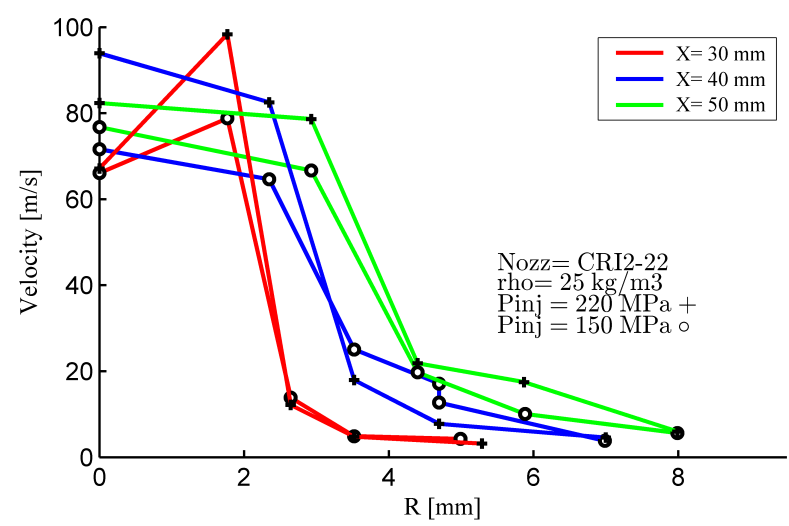

(a) Droplet velocities radial profile CRI2-22

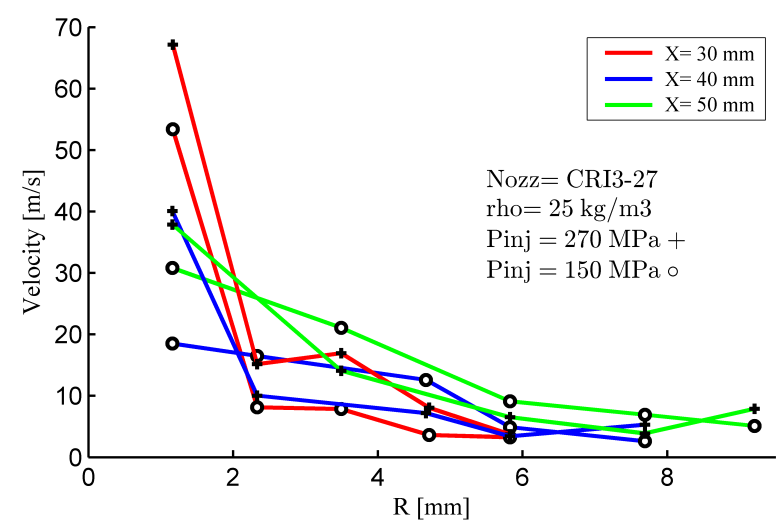

(b) Droplet velocities radial profile CRI3-27

Fig. 6.9 Radial velocity profiles $\rho_{a}=25 \mathrm{~kg} / \mathrm{m}^{3}$.
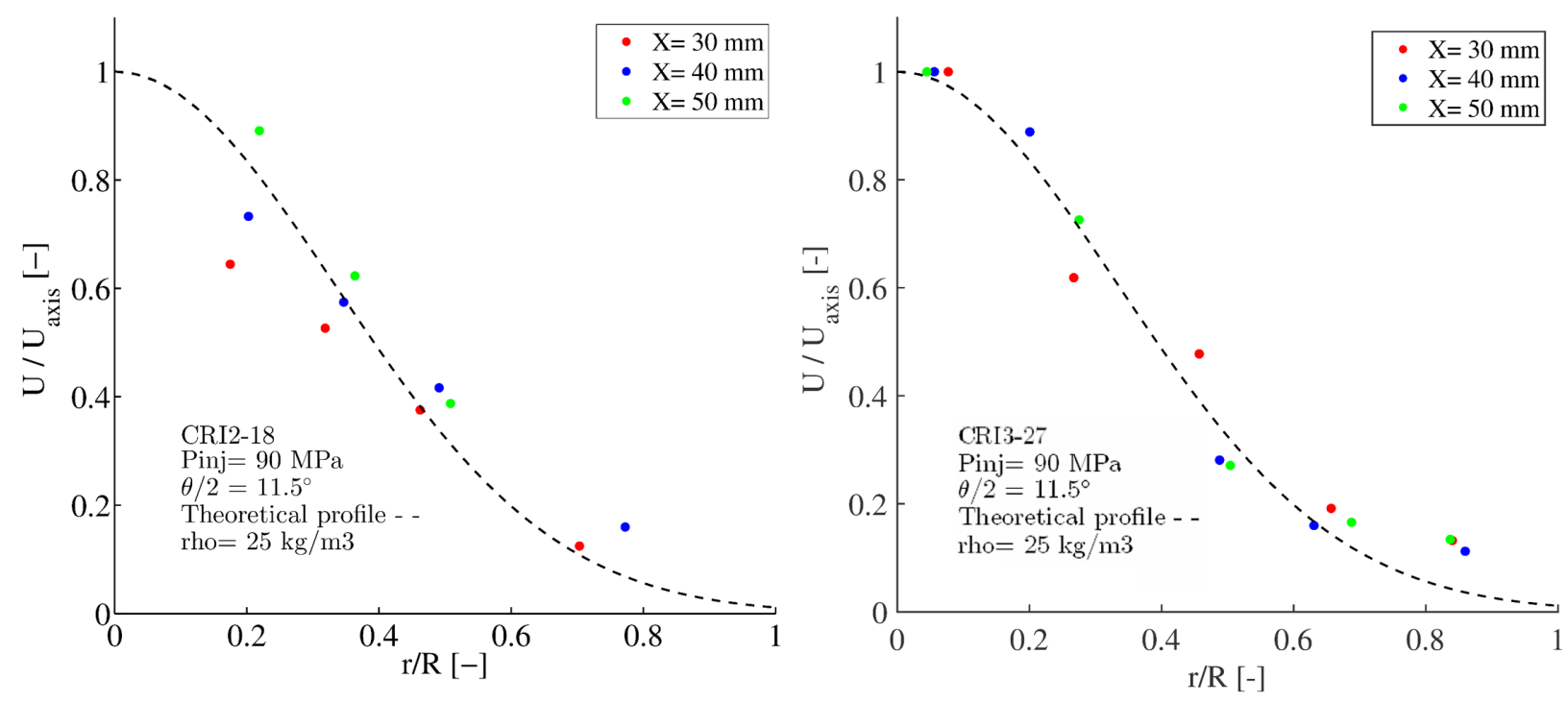

(a) Droplet velocities radial profile CRI2-18

(b) Droplet velocities radial profile CRI3-27

Fig. 6.10 Adimensional Radial velocity profiles with fitted theoretical profile $\rho_{a}=25 \mathrm{~kg} / \mathrm{m}^{3}$.

\subsubsection{Droplet diameters}

In the transient droplet diameter profiles, shown in the figures $6.11 \mathrm{a}$ to $6.11 \mathrm{f}$, it can be also noted the effect of dense or highly droplet concentrated zones, in time gaps where 
the droplet acquisition is scarce (figures $6.11 \mathrm{~b}$ between 1 to $3 \mathrm{~ms}$ and $6.11 \mathrm{f}$ between 1 to $2 \mathrm{~ms}$ ). The red line represents the moving average with the same characteristics of the transient velocity profiles, and the blue line represents the SMD diameter based on the equation 2.46. The lowest drop sizes in general were measured at the leading edge of the spray, showing the capital importance of aerodynamic forces in the spray tip (zone 1). The largest drop sizes were measured at the trailing edge of the spray where coalescence and weaker aerodynamic interaction were responsible for this behavior. Along the trailing edge (zone 4) the SMD remained constant, which is consistent with the observed in several research works $[45,86,170]$

The radial distribution of the SMD is presented in the figures $6.12 \mathrm{a}$ and $6.12 \mathrm{~b}$ for one solenoid and the piezo actuated injector respectively. It can observed in the velocity profiles shown before (figures $6.9 \mathrm{a}$ and $6.9 \mathrm{~b}$ ), that the SMD and velocity trends are not correlated. This has been observed in other research works $[32,45,196]$. The trends show clearly that the droplet diameter's evolution is inversely proportional to that of the injection pressure, which is in total agreement with the observations of other researchers. The SMD has time dependence, as explained before, but a very weak radial dependence. The SMD showed a nearly constant value along the spray radius or maximum variations of less than $15 \%$. These results are in agreement with results in similar conditions obtained by $[32,45,196]$ under non-vaporization conditions. Droplet diameters tend to be higher near the spray axis due to the aerodynamic forces that decrease by increasing radial distance, and the coalescence effects increase near the spray axis because of the higher droplets concentration.

The axial distribution profiles of the SMD in figures 6.13a and 6.13b, show a bathtub profile with a decrease followed by an increase, this behavior has been also reported in $[32,45,196]$. The starting point for this increase coincides roughly with the axial distance $\mathrm{x}=40 \mathrm{~mm}$ from both injectors in this case. In other words, the atomization process is more efficient than that of coalescence for low axial distances $(\mathrm{x}<40)$, while coalescence efficiency is higher for the high axial distances $(\mathrm{x}>40)$. 


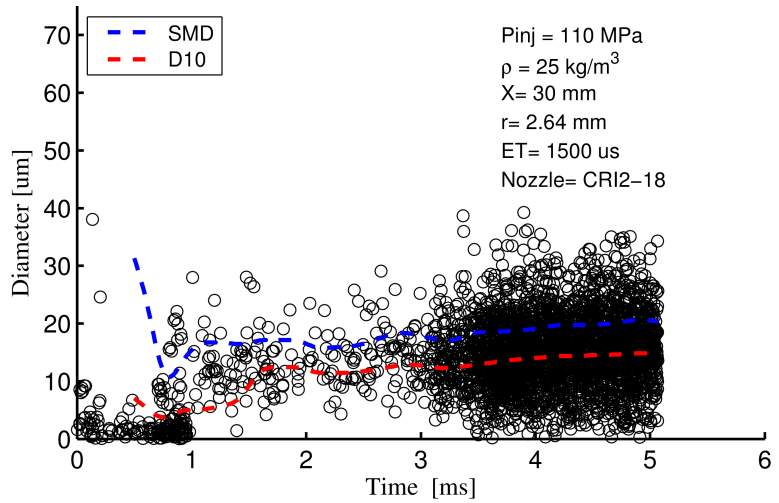

(a) Pinj= 110MPa, Nozz=CRI2-18

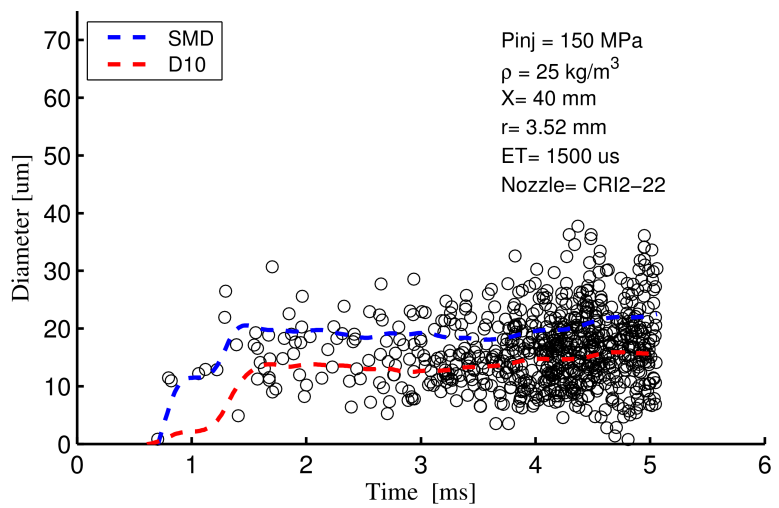

(c) Pinj $=150 \mathrm{MPa}$, Nozz=CRI2-22

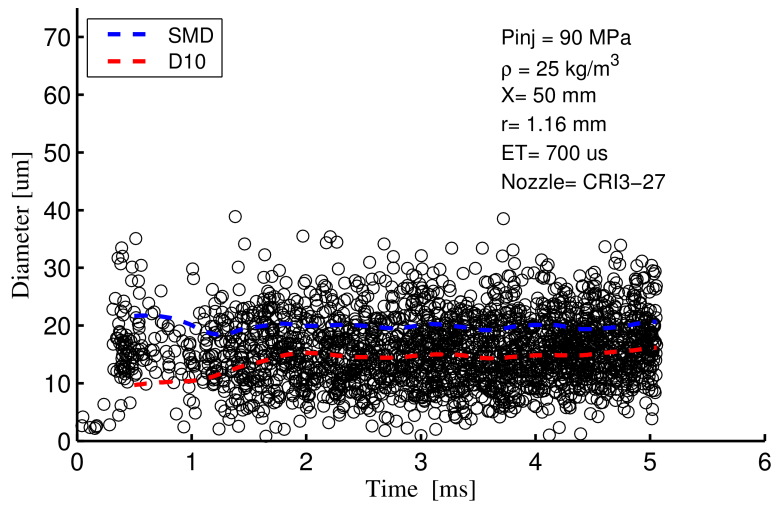

(e) Pinj= 90MPa, Nozz=CRI3-27

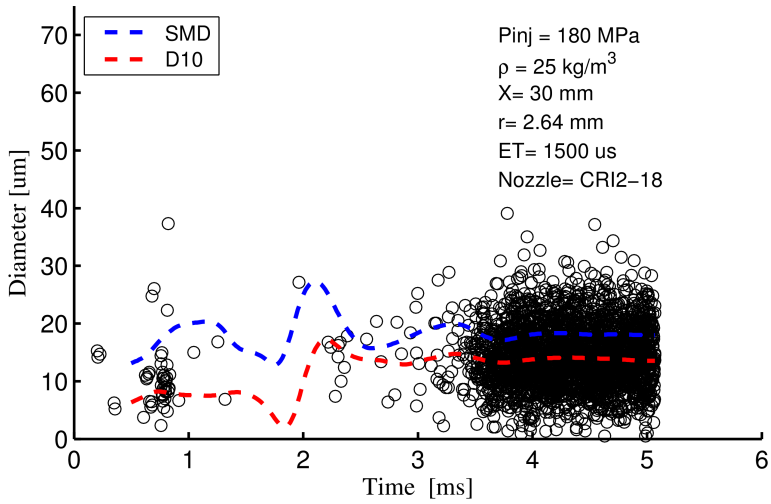

(b) Pinj= 180MPa, Nozz=CRI2-18

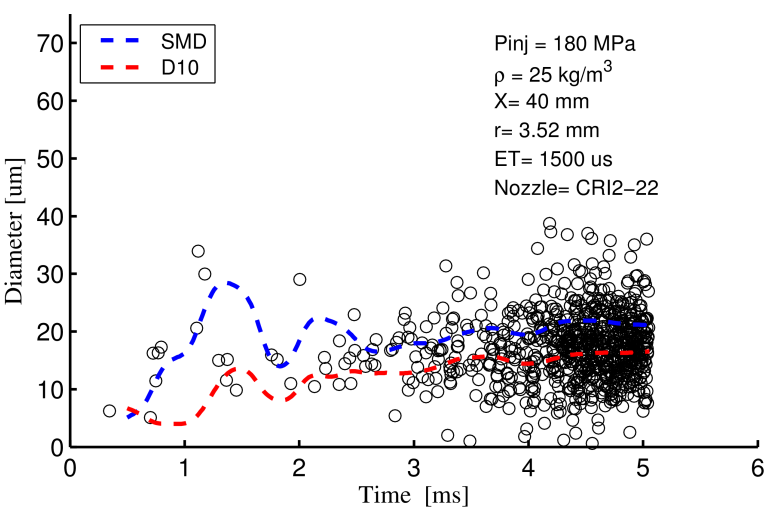

(d) Pinj= 180MPa, Nozz=CRI2-22

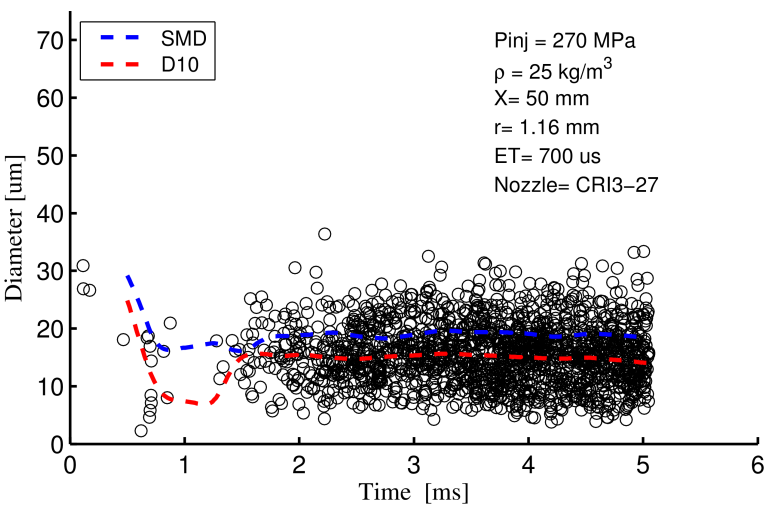

(f) Pinj= 270MPa, Nozz=CRI3-27

Fig. 6.11 Transient droplet diameter profiles $\rho_{a}=25 \mathrm{~kg} / \mathrm{m}^{3}$.

The equations 2.49 and 2.50 from Hiroyasu [64] and Vlad [196] were efforts to predict the droplet diameter. A similar expression was found to fit the experimental data obtained from the measurements (equation 6.1). It was found that the injection 


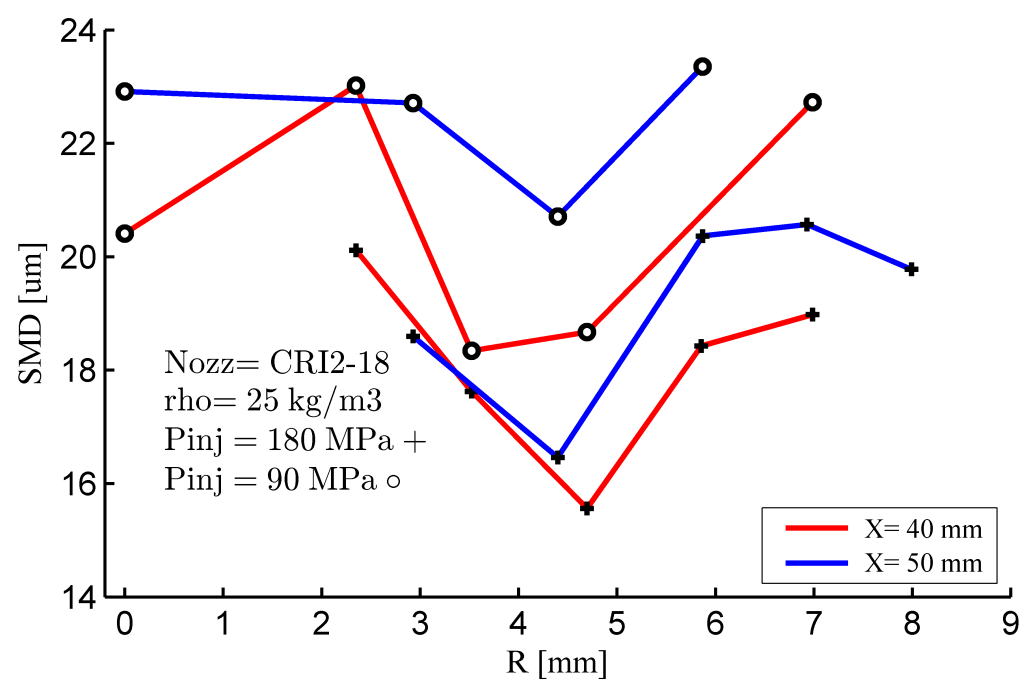

(a) Droplet diameters radial profile CRI2-18

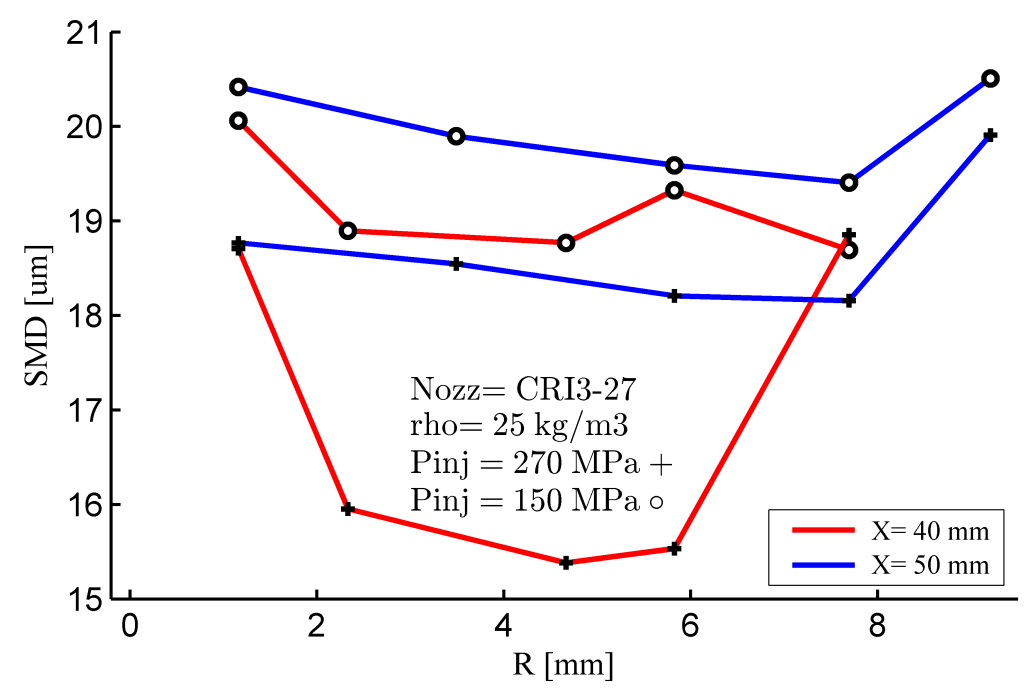

(b) Droplet diameters radial profile CRI3-27

Fig. 6.12 Radial droplet diameter profiles $\rho_{a}=25 \mathrm{~kg} / \mathrm{m}^{3}$.

pressure has less influence than the previous expressions due to the power coefficient being -0.096 , instead of -0.135 and -0.18 as it was found in Hiroyasu's and Vlad's works respectively. The same can be said about the ambient density that has a power coefficient of 0.022 instead of 0.121 and 0.311 .

$$
S M D=1.50324 \Delta P^{-0.096} \rho_{a m b}{ }^{0.022} D_{0}^{0.571} x^{0.022}
$$




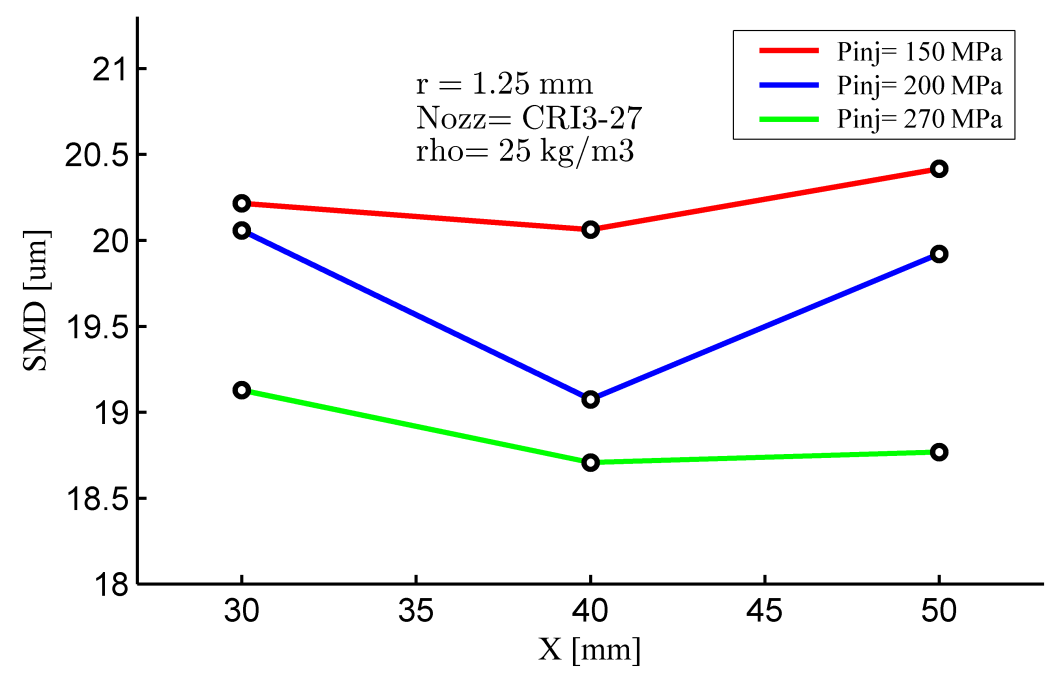

(a) Droplet diameters axial profile nozz=CRI3-

27

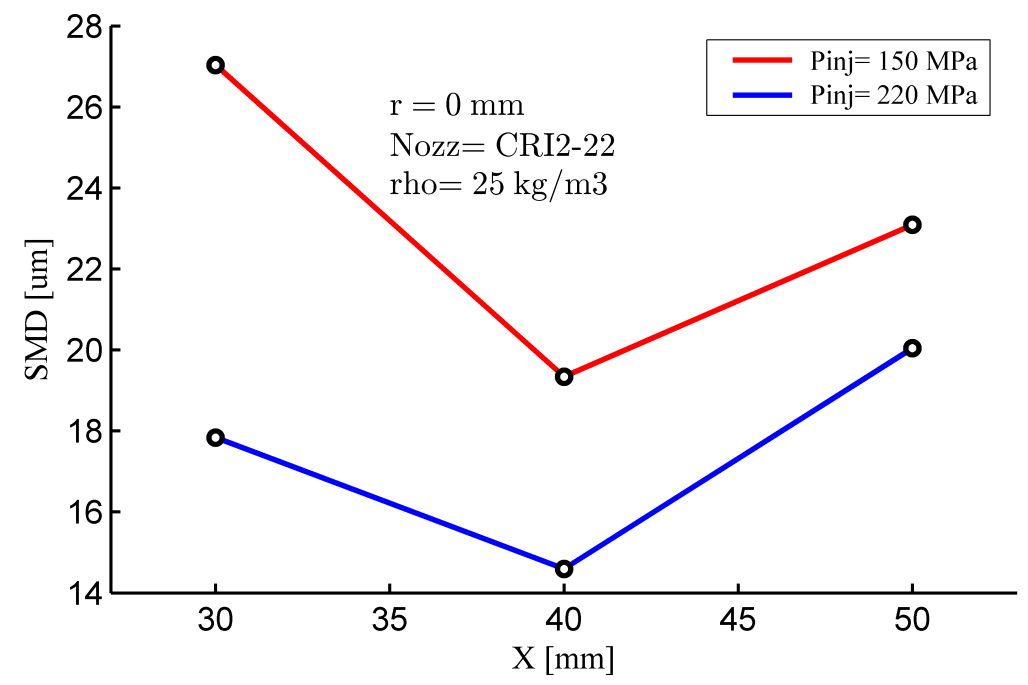

(b) Droplet diameters axial profile nozz $=\mathrm{CRI} 2-$

22

Fig. 6.13 Axial droplet diameter profiles $\rho_{a}=25 \mathrm{~kg} / \mathrm{m}^{3}$.

This new expression has R-square factor of $84.4 \%$ over the measured data quite similar to Vlad's expression which was about $84 \%$. It is interesting to point out that SMD measurements at very high injection pressures like $270 \mathrm{MPa}$, are also included in the fitted data. This means that the expression is representative over the whole test plan and for the three injectors, for low and very high injection pressures. 


\subsubsection{Nozzle comparison}

In figures $6.14 \mathrm{a}$ to $6.14 \mathrm{c}$ a comparison of the SMD transient profiles are shown. Some conclusions can be extracted from these plots, some of them mostly surprising. Firstly, it can be seen on figure 6.14a how the nozzle CRI2-22 produces close to the orifice ( $\mathrm{x}=30$ $\mathrm{mm} \mathrm{r} \approx 2.5 \mathrm{~mm}$ ) smaller diameters than the other nozzles, even if the other injectors have a smaller orifices. This behavior could be caused by differences in hole conicity. It is probable that the injector CRI2-18 possesses less conicity which produces higher diameters. This could be due to the higher internal hydraulic losses in the nozzle, leading to a higher pressure drop between the feeding line and the actual orifice inlet. It can also be due to a drastic reduction of the effective outlet diameter produced by cavitation [196].

Further downstream and away from the spray axis, towards the spray periphery, the diameters become practically equal $(\mathrm{x}=40 \mathrm{r} \approx 4.7, \mathrm{x}=50 \mathrm{r} \approx 7.8)$, in these zones is probed that the ambient plays a bigger role on the diameter distribution than injection parameters and injector characteristics.

\subsection{Conclusions}

This section summarizes the chapter and presents the main conclusions extracted from the microscopic characterization of the three injectors. In this chapter, a methodology for Phase Doppler Anemometry (PDPA) measurements on a multi-hole diesel injector was developed. Several key considerations were taken into account in this methodology: The windows for PDPA optical access must be clean, since fuel impregnated in these could preclude the droplets velocity acquisition. Some parts, including a device for spray isolation, were designed and manufactured to fulfill this goal. Taking into account that only one spray is measured, the isolation device captures all except three of the sprays (including the spray of interest). The two plumes accompanying the main spray were thought to conserve the actual air entrainment and thus the spray behavior. The spray of interest was aligned horizontally to ease the way that the PDPA measurements 


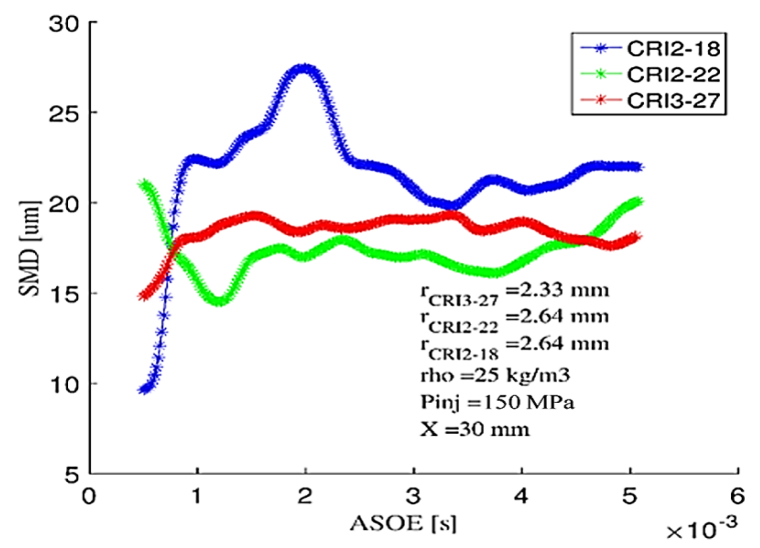

(a)

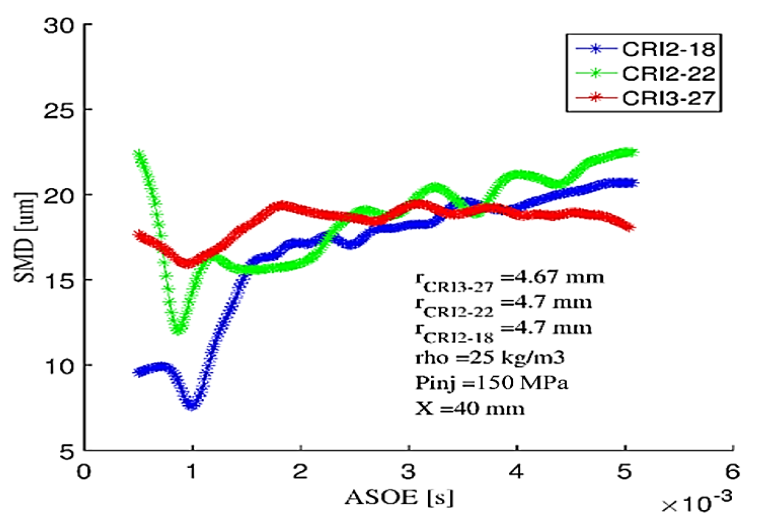

(b)

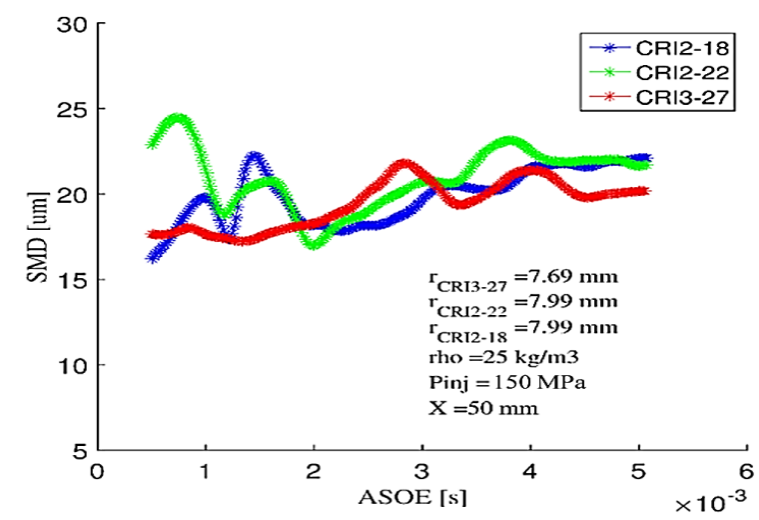

(c)

Fig. 6.14 SMD trends injector comparison at several positions away from the nozzle.

are carried out.

The spray plume was lined up by means of the MIE-Scattering macroscopic optical technique. Images were acquired for several injection events and spray contours were detected and processed with a purpose-built Matlab tool. At each time step a spray axis inclination was estimated using the centroids from instantaneous contours. Also, preliminary droplet velocity measurements were made to check the effectiveness of the alignment and spray isolation strategies. After confirming this effectiveness, a test plan covering low and very high injections pressures are carried out over the three injectors. The following goals were overcome during this characterization: 
- Both geometrical characterization and spray alignment had very low measurement error. Radial velocity profiles show that PDPA measurements with this set-up configuration preserved the spray behavior.

- A geometrical characterization of the diesel injector was carried out. The opening angle was estimated with a standard deviation of $0.43^{\circ}$.

- The injectors were successfully installed in the test rig and the manufactured parts. The device for spray isolation kept both emitter front and top windows clean and measurements were made without any issue.

- A methodology of spray alignment was presented as well. MIE-Scattering technique was used to achieve this goal. Liquid contours were captured with a fast camera. Spray axis inclination was estimated by means of centroids which were calculated at each time step using the detected contours. The standard deviation of this calculation was $0.22^{\circ}$.

- Preliminary PDPA velocity measurements were made, results were compared with theoretical approaches and seem to fit well with R-square factors between $89.9 \%$ and $96.6 \%$. It can be concluded that the spray isolation device was effective since the spray of interest had a typical behavior.

- The velocity and SMD data concentration at the leading edge of the spray are significantly decreased by the injection pressure increment. For this reason fitted radial velocity profiles were adjusted at low injection pressure.

- The SMD trends show consistently that droplets in the spray center are bigger. This was attributed to the phenomenon of coalescence. This is more likely to occur in the spray center because of higher droplet density, and is also more likely to affect the droplets that reach further away because they follow a longer path through an environment filled with other droplets.

- The radial distribution of the SMD presents smaller variations than $15 \%$ for a given time. The axial distribution of the SMD shows a bathtub profile with a 
decrease followed by an increase. A formula was found to fit the SMD experimental data, taking into account the pressure delta, ambient density, the distance from the nozzle $(\mathrm{x})$ and nozzle diameter, fitting the experimental data with an Rsquare factor of $84.4 \%$. However, it has to be stated the processes that determine the local droplet size are complex and as such cannot be reproduced with high accuracy by a simple mathematical formula.

- Towards the spray periphery, the diameters become practically equal for all the injectors tested. This is because in these zones the ambient plays a bigger role on the diameter distribution than injection parameters and injector characteristics. 


\section{Chapter 7}

\section{Results and discussion:}

\section{Macroscopic characterization}

\subsection{Introduction}

In this chapter macroscopic results under evaporative and non-evaporative conditions are presented. The main objective of this chapter is to estimate the effects of injection and ambient parameters over the macroscopic parameters of the diesel spray. The figures $7.1 \mathrm{a}$ and $7.1 \mathrm{~b}$ show the penetration of the spray as a function of time obtained by ensemble averaging 10 consecutive injection events and all the sprays, following the same rolling-average algorithm described by Payri et al. [141] with an averaging window size of $200 \mu \mathrm{s}$. The algorithm is very similar to an Savitzky-Golay digital filter but accounting for multiple digital signals (the multiple test repetitions performed)[207].

The ensemble-averaged signal is then aligned in time with the SOI timing, which is estimated by performing a linear fit to the raw data set found in the first $20 \mathrm{~mm}$ of the penetration curves of all repetitions, for a given set of test conditions. A good estimation of the actual SOI for each test condition facilitates the time phasing of the penetration curves for comparison. In this chapter, continuous and dashed 


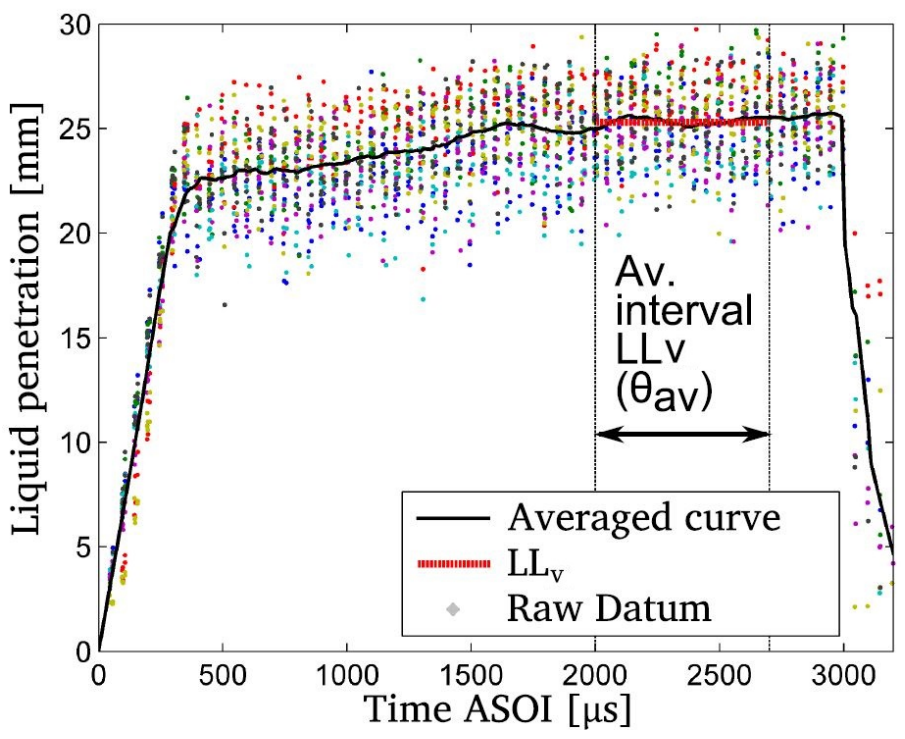

(a) Raw liquid phase penetration measurements and average value [14]

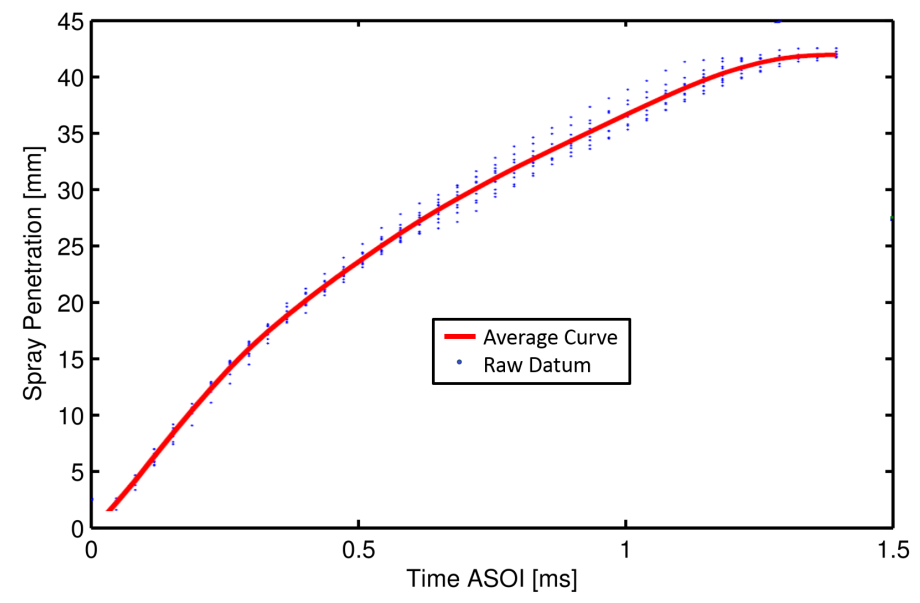

(b) Raw vapor penetration measurements and average curve

Fig. 7.1 Raw data from visualization

curves represent the vapor and liquid phases of the spray respectively, unless specified otherwise. 


\subsection{Spray development at isothermal conditions}

As it has been explained before, the MIE-scattering imaging technique is a powerful method for the study of the diesel spray since it gives direct and reliable information about the spray development. Even though the parameters extracted in these experiments are normally reduced to spray penetration and spreading angle, the information acquired in the images is much wider: for example, the definition of the aforesaid parameters can be adjusted in order to orient the investigation over different features of the spray. Furthermore, the images themselves are maps of the light scattered by the sprays and, even if it is difficult to relate this signal to quantitative measurements, they give fundamental insight about the evaporation process [14].

For these non-evaporative measurements the high density test rig described in chapter 4 is used. The ambient temperature was $293 \mathrm{~K}$ during the whole measurements. The high densities normally achieved in diesel engines were simulated by using a high molecular gas, as $\mathrm{SF}_{6}$ (commonly used in research for this purpose $[44,133,149,157]$ ). Furthermore, as it was proven in the literature consulted in chapter 3, shock waves are present under very high injection pressures and even at some common engine operating points [74], modifying the macroscopic spray behavior. In order to explore these effects at non-evaporative conditions without having to reach extremely high injection pressures, the shock waves appearance is enhanced by controlling the ambient gas speed of sound, promoting in this way supersonic jets. To this end three ambient gases are tested with different speed of sound (table 7.1).

Table 7.1 Speed of sound of gases used in non-evaporative measurements at 293K .

\begin{tabular}{ccc}
\hline \hline Gas & Speed of sound $[\mathrm{m} / \mathrm{s}]$ & Molecular weight $[\mathrm{g} / \mathrm{mol}]$ \\
\hline $\mathrm{SF}_{6}$ & 129.8 & 146.06 \\
$\mathrm{CO}_{2}$ & 256.48 & 44.01 \\
$\mathrm{~N}_{2}$ & 352.5 & 28.01 \\
\hline
\end{tabular}

The spray evolution captured by the MIE-scattering technique is shown in the figure 7.2. Images have been trimmed in the axial directions from their original size, for better fit in this figure. The contours detected for the liquid phase are plotted to 
scale over the original MIE-scattering images. In this case, the nozzle used is CRI3-27, rail pressure is $90 \mathrm{MPa}$, ambient density is $30.4 \mathrm{~kg} / \mathrm{m} 3$ and ambient temperature is $293 \mathrm{~K}$.

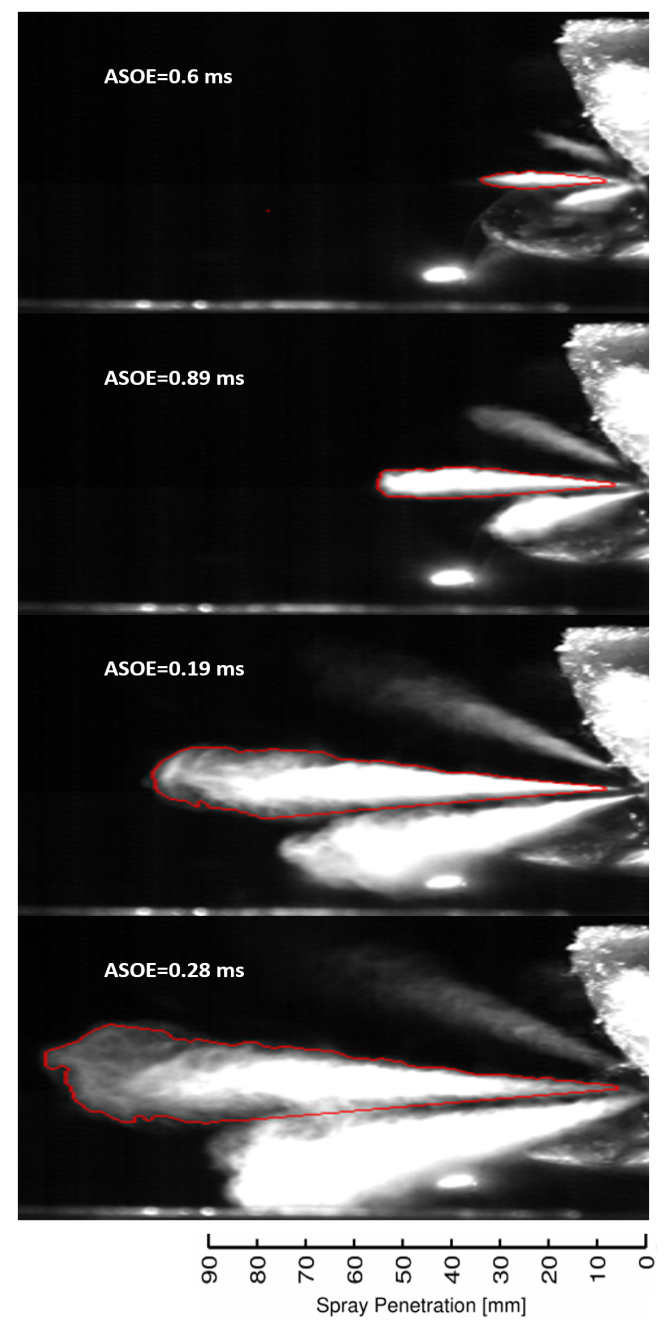

Fig. 7.2 Spray evolution captured by the MIE-scattering technique, Pinj=90MPa, $\rho_{a}=30.4 \mathrm{~kg} / \mathrm{m}^{3}$, gas $=\mathrm{SF}_{6}, \mathrm{Nozz}=\mathrm{CRI} 3-27$

\subsubsection{Test Plan}

For the MIE-scattering tests carried on the diesel spray in the high density test rig, different injection conditions have been tested. The injectors inside the high density test chamber were aligned under the same methodology described in section 6.4.1, 
using one single spray of the multi-hole nozzles for measurements. A wide range of injection pressures have been settled $(25,35,50,90,110,150,180,200,220,250$ and 270 $\mathrm{MPa}$ ) and ambient densities (between 3 and $30.4 \mathrm{~kg} / \mathrm{m}^{3}$ ). Nevertheless, the maximum ambient pressure supported by the high density test rig was $1 \mathrm{MPa}$, consequently, it limited the maximum ambient densities reached with each gas and they were highly dependent of the molecular weight. The ambient temperature was kept constant at 293K. A resume of the test matrix is presented in table 7.2 , where all the wide range of possible operating pressure conditions of a common-rail system are covered. For each operating point 10 repetitions were acquired and analyzed.

Table 7.2 Experimental conditions for isothermal sprays.

\begin{tabular}{|c|c|c|c|}
\hline Parameter & Injector & Ambient gas & Testing Conditions \\
\hline \multirow{3}{*}{ Injection Pressure [MPa] } & & $\mathrm{CO} 2$ & \multirow{3}{*}{$25 / 35 / 50 / 90 / 110 / 150 / 180 / 220 / 270$} \\
\hline & CRI3-27 & $\mathrm{SF}_{6}$ & \\
\hline & & $\mathrm{N} 2$ & \\
\hline \multirow{3}{*}{ Ambient density $\left[\mathrm{kg} / \mathrm{m}^{3}\right]$} & \multirow{3}{*}{ CRI3-27 } & $\mathrm{CO} 2$ & $3 / 7.6 / 10.8 / 15.2$ \\
\hline & & $\mathrm{SF}_{6}$ & $3 / 7.6 / 10.8 / 15.2 / 22.8 / 30.4$ \\
\hline & & $\mathrm{N} 2$ & $3 / 7.6 / 10.8$ \\
\hline \multirow{3}{*}{ Energizing Time [ms] } & & $\mathrm{CO} 2$ & \multirow{3}{*}{1.5} \\
\hline & CRI3-27 & $\mathrm{SF}_{6}$ & \\
\hline & & $\mathrm{N} 2$ & \\
\hline
\end{tabular}




\subsubsection{Effect of ambient density and injection pressure on pen- etration and spray angle}

The results from the macroscopic characterization under non-evaporative environment for the piezo-injector CRI3-27 are depicted in the figures $7.3 \mathrm{a}$ to $7.3 \mathrm{~d}$, the most noticeable trends shown by the penetration data in the figures are, the decrease in penetration with an increase in ambient density, because for a higher density of the entrained gas, more kinetic energy will be required by the spray to achieve the momentum transfer, and for this reason the spray penetrates slower. Also the injection pressure caused an increment, related with a momentum increment of the diesel spray as expected. These trends have been observed by many others researchers [16, 44, 59, 118, 133, 149, 157].

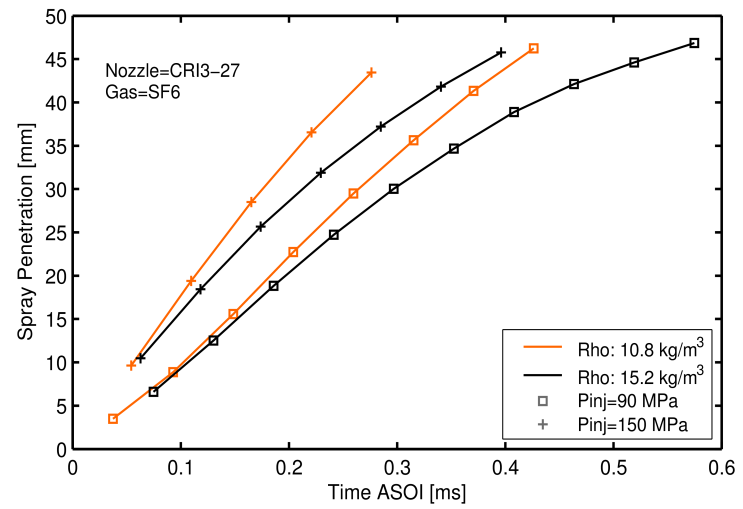

(a) $\operatorname{Pinj}=90,150 \mathrm{MPa}, \rho_{a}=10.8,15.2 \mathrm{~kg} / \mathrm{m}^{3}$

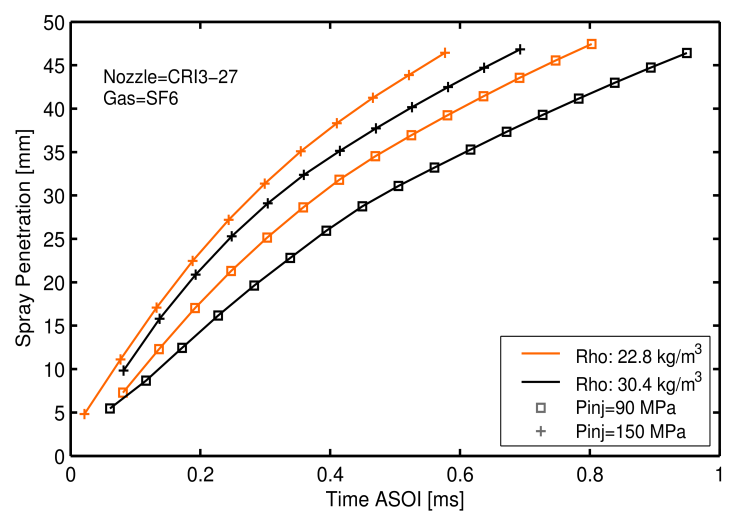

(c) Pinj=90, 150MPa, $\rho_{a}=22.8,30.4 \mathrm{~kg} / \mathrm{m}^{3}$

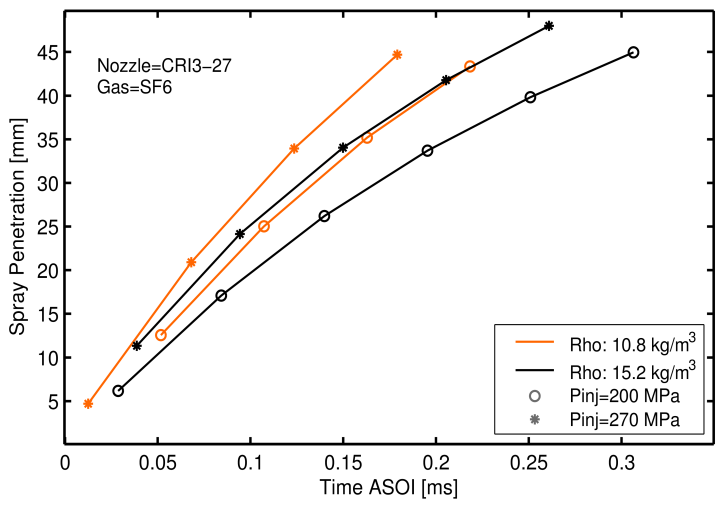

(b) Pinj=200, 270MPa, $\rho_{a}=10.8,15.2 \mathrm{~kg} / \mathrm{m}^{3}$

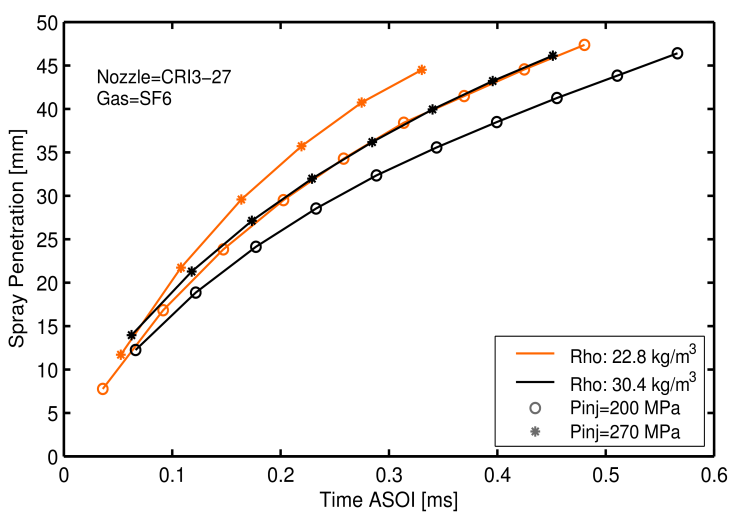

(d) Pinj=200, 270MPa, $\rho_{a}=22.8,30.4 \mathrm{~kg} / \mathrm{m}^{3}$

Fig. 7.3 Effect of ambient density and injection pressure over spray penetration, Nozz=CRI3-27 
Concerning the spreading angle (figure 7.4), the effect of the discharge density on this parameter appears to be higher than the effect of the injection pressure whereas this difference does not appear clearly on the penetration rate. It has to be said that the conclusion drawn here concerning the influence of the ambient density on spreading angle has been already formulated by other researchers [64, 118], the observations made on the effect of the injection pressure is still the subject of controversy.

Regarding the spreading angle measurements, care must be taken when analyzing these results with conventional optical techniques like macro-visualization of the spray because the parameters used during image processing affect the resulting spreading angle widely. For instance, the total standard deviation on the spreading angle for the reference testing conditions $\left(\mathrm{Pinj}=50 \mathrm{MPa}, \rho_{a m b}=22.8 \mathrm{~kg} / \mathrm{m}^{3}\right)$ is $1.5^{\circ}$, which represents about $9.7 \%$ of the measured spreading angle: $\theta=15.45^{\circ}$.

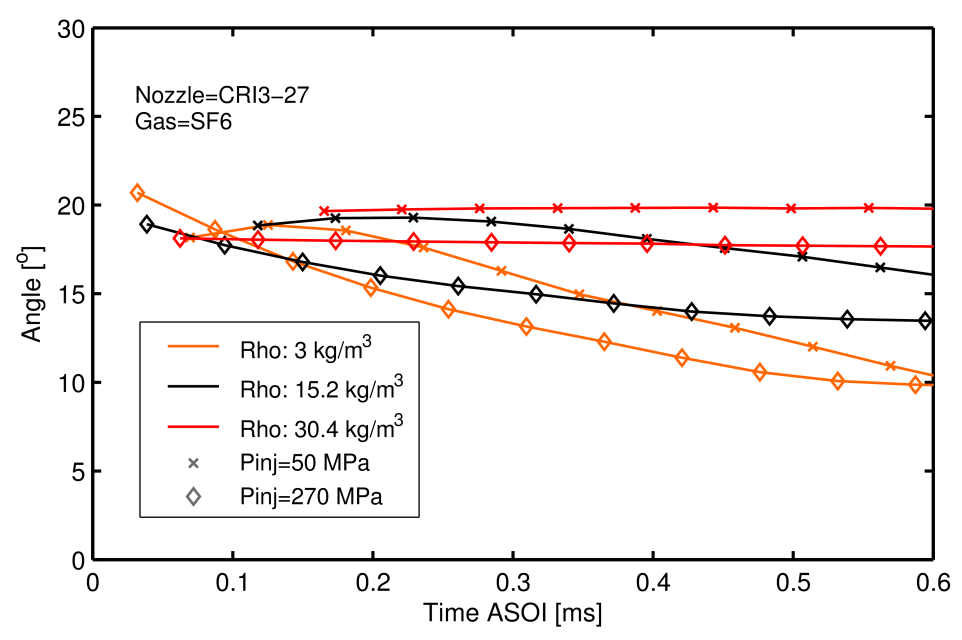

Fig. 7.4 Spray angle variation with $\rho_{a}$ and Pinj, Nozz=CRI3-27

In order to quantify the effect of each test conditions, the data obtained in the tests in $\mathrm{SF}_{6}$ atmosphere were used for a statistical analysis. The set of tests include the variation of several boundary conditions like ambient density, injection and ambient pressures. As described by Desantes et al. in [9], the penetration of the spray during the injection follows two behaviors: the first part characterized by a linear dependence 
with time $[14,16,118]$, which at a certain bending distance switches in a second behavior when the spray is fully developed and the penetration is proportional to the square root of time. The equations employed for the regression are the ones used by Payri et al. in [133] and they are presented below:

$$
S=k \rho_{a}^{a} \Delta P^{b} D_{0}{ }^{d} t^{e}
$$

Some other expressions consider as well the spray angle, since it has to be considered due to its dependence on nozzle orifice geometry and ambient and injection conditions [129]. In this case the spray tip penetration is obtained by the equation 7.2.

$$
S=k \rho_{a}^{a} \Delta P^{b} \tan (\theta / 2)^{c} D_{0}^{d} t^{e}
$$

Table 7.3 Typical parameters for penetration and exponents estimated from inert tests $\mathrm{SF}_{6}$.

\begin{tabular}{ccccc}
\hline \hline Exponent & Fit SF $_{6}$ Eq. 7.2 & CI SF $_{6}$ Eq. 7.2 & Fit SF $_{6}$ Eq. 7.1 & CI SF $_{6}$ Eq.7.1 \\
\hline$k$ & 0.4242 & {$[0.4173,0.4311]$} & 0.8516 & {$[0.8487,0.8545]$} \\
$a$ & -0.1673 & {$[-0.1795,-0.1551$} & -0.3537 & {$[-0.3680,-0.3393$} \\
$b$ & 0.2935 & {$[0.2874,0.2996]$} & 0.3079 & {$[-0.3680,-0.3393]$} \\
$c$ & -0.5876 & {$[-0.6145,-0.5607]$} & - & - \\
$d$ & 0.4688 & {$[0.4546,0.4831]$} & 0.6519 & {$[0.6398,0.6641]$} \\
$e$ & 0.5434 & {$[0.5353,0.5516]$} & 0.5864 & {$[0.5724,0.6003]$} \\
$R^{2}$ & $98.06 \%$ & - & $92.48 \%$ & - \\
\hline
\end{tabular}

The results demonstrate that all parameters included in both correlations play an important role. As a general comment, it can be observed that in both cases a good fit to the experimental data is found. The R-squared value in both cases suggests high confidence on the correlation results from the statistics point of view. Injection pressures up to $270 \mathrm{MPa}$ were included in the experimental data collected for these correlations. The experimental results appear to be very consistent with previous research in diesel spray characterizations at low and high ambient densities, the exponents agree with those previously consulted in literature, and they are depicted in table 2.6. The equation 7.2 showed the highest R-squared and thus the best correlation 
with this set of experimental data.

Furthermore, a correlation without very high injection pressures $(\operatorname{Pinj}<230 \mathrm{MPa})$ was obtained to appraise the real effect of these on the macroscopic behavior. In the table 7.4, the results of this non-linear regression can be seen.

Table 7.4 Typical parameters for penetration and exponents estimated from inert tests in $\mathrm{SF}_{6}$ without very high injection pressures.

\begin{tabular}{ccc}
\hline \hline Exponent & Fit $\mathrm{SF}_{6}$ Eq. 7.2 & $\mathrm{CI} \mathrm{SF}_{6}$ Eq.7.2 \\
\hline$k$ & 0.418 & {$[0.4109,0.425]$} \\
$a$ & -0.1575 & {$[-0.1696,-0.1454]$} \\
$b$ & 0.2887 & {$[0.2824,0.2949]$} \\
$c$ & -0.6018 & {$[-0.6281,-0.5755]$} \\
$d$ & 0.4663 & {$[0.4518,0.487]$} \\
$e$ & 0.5481 & {$[0.5402,0.5561]$} \\
$R^{2}$ & $98.25 \%$ & - \\
\hline
\end{tabular}

Again, there is a good agreement with the fitted curve using the correlation with the spreading angle, the exponents did not vary considerably which allows us to think that injection parameter effects over the macroscopic characteristics of the spray, under very high injection pressures considered in this thesis, are still the same. All coefficients obtained from this last correlation in table 7.4, fall into the confidence intervals from the correlation in table 7.3.

\subsubsection{Effect of gas properties on penetration and spray angle}

It is generally accepted in the research community that the behavior of the spray $[193,196]$ only depends on the ambient density, not on the ambient pressure, meaning that the experiments performed in the aforementioned and analyzed measurements, under the $\mathrm{SF}_{6}$ atmosphere, must representative of the real behavior of a diesel spray. However, the effect of ambient gas properties over macroscopic characteristics of the spray are not very well known. Some studies have found some interesting variations in spray structure $[16,133,157]$ using mono-orifice nozzles. However they used different illumination set-ups and test rigs for $\mathrm{N}_{2}$ and $\mathrm{SF}_{6}$ measurements. In their words, these 
variations in both tests did not make it possible to be conclusive about the differences observed.

The goal of this section is to explore these effects with a multi-hole injector and exploring a wide range of pressures up to $270 \mathrm{MPa}$ using the same test rig, illumination and optical setup. As it has been said before, three gases $\left(\mathrm{N}_{2}, \mathrm{CO}_{2}\right.$ and $\left.\mathrm{SF}_{6}\right)$ with three different speed of sounds are tested. In figures 7.5b the tip Mach number is shown as a function of time after injection. The velocity is obtained by numerical differentiation of the spray penetration in time, and the tip Mach number is calculated with the ratio between this velocity and the speed of sound for each gas.

As it has been mentioned before, ambient density affects the spray deceleration (figures 7.5b). By increasing the density (from 7.6 to $15.2 \mathrm{~kg} / \mathrm{m}^{3}$ ) the Mach curves are lower caused by a decrease of the velocity. In addition, it can be observed that for low injection pressures and high densities the spray quickly interacts with the ambient gas after the start of injection, causing spray deceleration to velocities lower than the speed of sound. Furthermore, for low injection pressures and low densities this decremental trend seems to be slower. This behavior was noted also by Roisman et al. [182], in his experiment the velocity was not exactly constant either, even during the first stage of the spray propagation. In Roisman's experiment, for ambient pressures less than certain value, the velocity initially grew, reached some maximum value, and then reduced. For ambient pressures higher than or equal than this value the tip velocity reduced immediately after injection. They stated that this behavior was maybe caused by the chosen characteristic time growth which was much smaller than the shutter camera time (time step) and thus some information was lost at the beginning of the injection.

In the figures $7.5 \mathrm{a}$ the effect of the ambient gas over spray penetration is depicted. An interesting finding is that at same ambient densities spray penetration seems to grow faster within the $\mathrm{SF}_{6}$ atmosphere than the others. This tendency is magnified when both environmental density and the injection pressure are increased. In order 

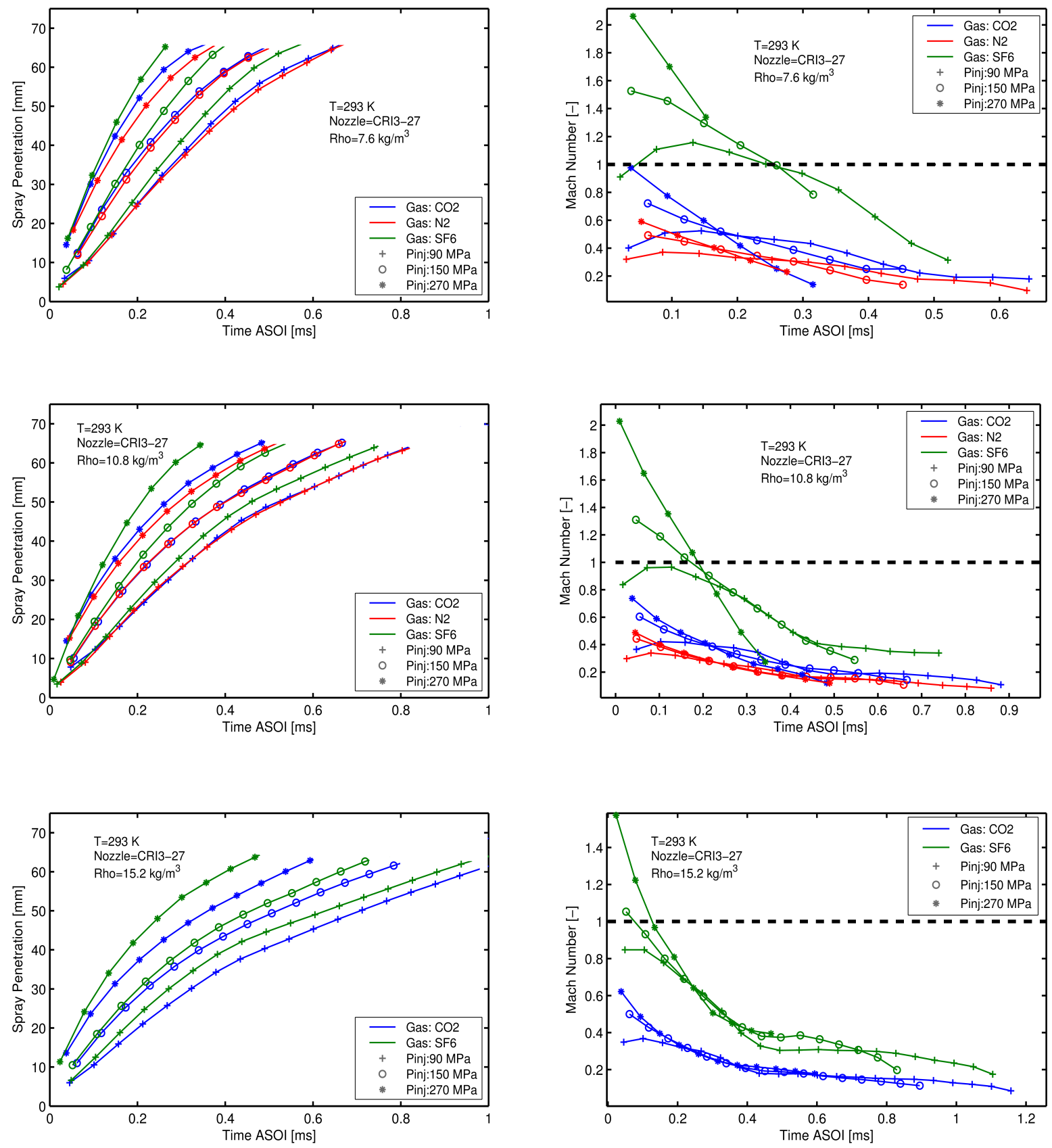

(a) Penetration evolution

(b) Mach number evolution

Fig. 7.5 Effect of gas properties on macroscopic characteristics of the spray, Nozz=CRI3-27

to quantify these variations, the table 7.5 depicts differences in penetration between the gases with the lowest and highest speed of sound $\left(\mathrm{SF}_{6}\right.$ and $\left.\mathrm{N}_{2}\right)$ numerically. $\mathrm{A}$ penetration of $65 \mathrm{~mm}$ is taken as a set point for each injection pressure, for the gas $\mathrm{SF}_{6}$ 
and the lowest density, thus, variations with densities and gas properties are estimated from this value. In the last 2 columns the quantification of these variations are shown. It is observed how for all cases under the $\mathrm{SF}_{6}$ atmosphere the spray penetrated longer. However it is interesting to point out that an increment of ambient density (from 7.6 to $10.8 \mathrm{~kg} / \mathrm{m}^{3}$ ), decreased the penetration variation for injection pressures lesser than $90 \mathrm{MPa}$ and it was augmented for injection pressures higher than $150 \mathrm{MPa}$. Thus, from this data, it can be concluded that in all cases were found penetration variations from gas to gas, nevertheless these variations were enhanced with increments of both ambient density and injection pressure.

Table 7.5 Penetration variations with ambient density and gas properties.

\begin{tabular}{ccccccc}
\hline \hline$\rho_{a}\left[\mathrm{~kg} / \mathrm{m}^{3}\right]$ & & & 7.6 & 10.8 & 7.6 & 10.8 \\
\hline Pinj $[\mathrm{MPa}]$ & Gas & $\mathrm{t}[\mathrm{s}]$ & \multicolumn{2}{c}{$\mathrm{S}[\mathrm{mm}]$} & \multicolumn{2}{c}{$\Delta \mathrm{S}$ gas $[\%]$} \\
\hline \multirow{2}{*}{50} & $\mathrm{SF}_{6}$ & \multirow{2}{*}{0.67} & 64.99 & 53.47 & \multirow{2}{*}{5.33} & \multirow{2}{*}{5.2} \\
& $\mathrm{~N}_{2}$ & & 61.52 & 50.69 & & \\
\hline \multirow{2}{*}{90} & $\mathrm{SF}_{6}$ & \multirow{2}{*}{0.56} & 65.35 & 55.86 & \multirow{2}{*}{8.39} & \multirow{2}{*}{6.72} \\
& $\mathrm{~N}_{2}$ & & 59.86 & 52.106 & & \\
\hline \multirow{2}{*}{150} & $\mathrm{SF}_{6}$ & \multirow{2}{*}{0.395} & 64.88 & 55.97 & \multirow{2}{*}{10.52} & \multirow{2}{*}{11.26} \\
& $\mathrm{~N}_{2}$ & & 58.06 & 49.66 & & \\
\hline \multirow{2}{*}{200} & $\mathrm{SF}_{6}$ & \multirow{2}{*}{0.329} & 65.24 & 58 & \multirow{2}{*}{10.3} & \multirow{2}{*}{14.81} \\
& $\mathrm{~N}_{2}$ & & 58.52 & 49.41 & & \\
\hline \multirow{2}{*}{270} & $\mathrm{SF}_{6}$ & \multirow{2}{*}{0.26} & 65.07 & 57.02 & \multirow{2}{*}{14.80} & \multirow{2}{*}{17.87} \\
& $\mathrm{~N}_{2}$ & & 55.43 & 46.83 & & \\
\hline
\end{tabular}

One possible explanation for these changes could be the different $\Delta P$ to achieve the desired density for each gas (due to molecular weight differences, $\mathrm{N}_{2}$ and $\mathrm{CO}_{2}$ need to be compressed much more). Nevertheless, if we take into account the coefficients on table 7.3 , the influence of $\Delta P$ over the spray penetration is affected by the exponent 0.2935 . Which means that $\Delta P$ differences only affect penetration in approx $0.8 \%$.

Other hypothesis was cavitation, which is specially enhanced by $\Delta P$, and within the $\mathrm{SF}_{6}$ atmosphere is most likely to happen due to the low back pressures needed to reach very high densities. Nevertheless, it is known that cavitation increases considerably the spray cone angle [157], and observing the figures 7.6 this is not happening. As it can be 
observed, the spray cone angle in the $\mathrm{SF}_{6}$ atmosphere is lower, which is consistent with the higher penetration reported before in this environment due to the conservation of momentum. In addition, it can be observed how injection pressure increments carried higher differences of spray angle between gases.

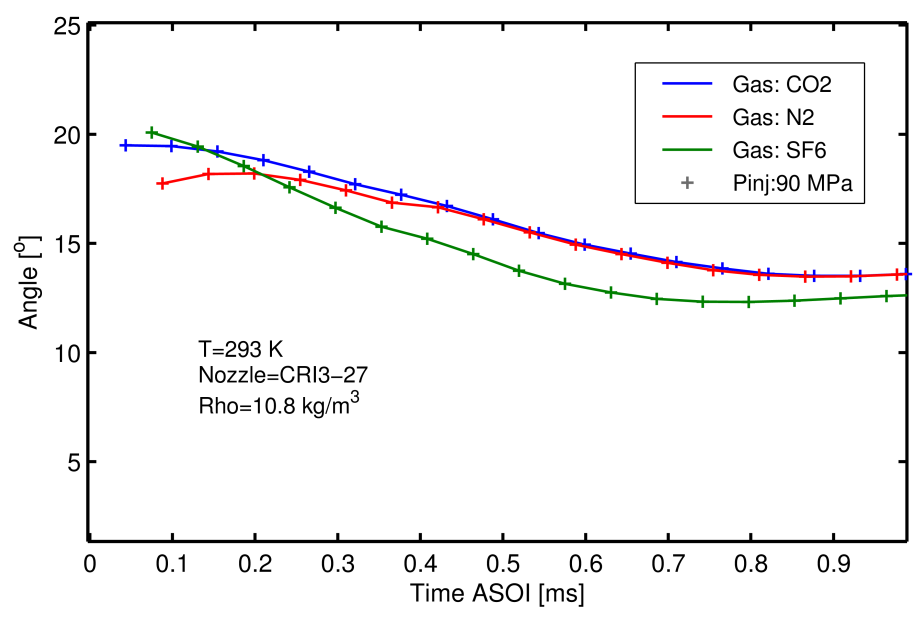

(a) Pinj $=90 \mathrm{MPa}, \rho_{a}=10.8 \mathrm{~kg} / \mathrm{m}^{3}$

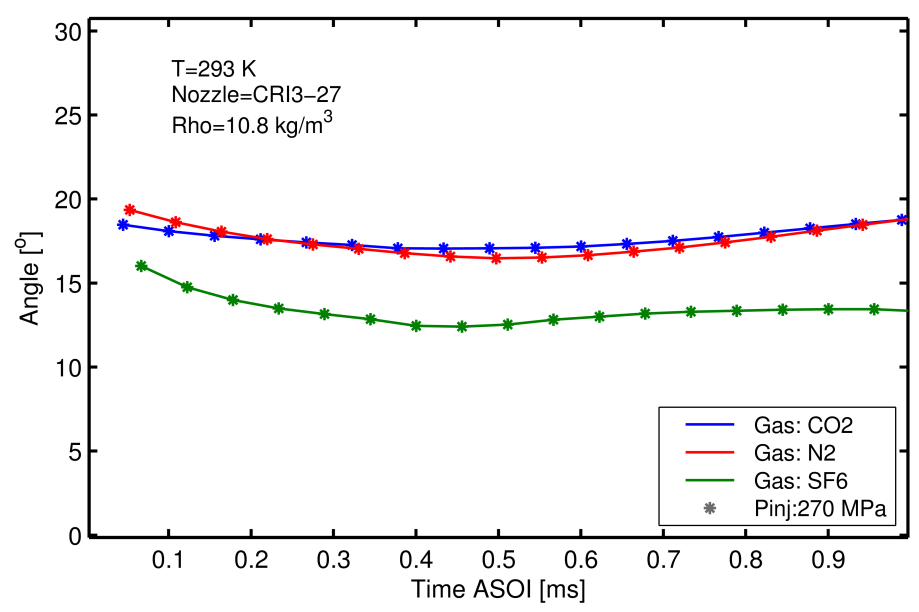

(b) Pinj=270MPa, $\rho_{a}=10.8 \mathrm{~kg} / \mathrm{m}^{3}$

Fig. 7.6 Effect of gas properties on spray angle

Furthermore, if we take a look at the curves in figures 7.5 once more, it can be seen that all trends near the transonic state $(0.8<\mathrm{M}<1.2)$ have a greater penetration growing rate. A great example is appreciated in $\mathrm{CO}_{2}$ penetrations, sprays injected at very high injection pressures $(270 \mathrm{MPa})$ and low densities $\left(7.6\right.$ and $\left.10.8 \mathrm{~kg} / \mathrm{m}^{3}\right)$, which 
are curves near the transonic state (figures 7.5b), a faster growth of $\mathrm{CO}_{2}$ penetrations curves was found when being compared the $\mathrm{N}_{2}$ penetrations. This can be caused by generated shock waves in the transition stage of penetration from subsonic to supersonic which is unlikely to happen under $\mathrm{N}_{2}$ atmosphere in the range of pressures that has been tested, since the maximum Mach within this atmosphere did not overpass 0.6. Thus, the transonic state is achieved under very high injection pressures in $\mathrm{CO}_{2}$ at low densities, and for all range of pressures tested in $\mathrm{SF}_{6}$ except for injection pressures less than $90 \mathrm{MPa}$ at high densities $\left(22.8\right.$ and $\left.30.4 \mathrm{~kg} / \mathrm{m}^{3}\right)$.

Notwithstanding these observations, the extend to which the shock waves affect the macroscopic parameters of the spray is currently unknown [157, 182], and the origin of the aforementioned variations could be related to the depression that is created behind the spray ambient impact region (the so-called Mach zone). Roisman et al. [182] demonstrated the importance of the interaction between the spray jet and the shock waves that develop in the ambient gas at the beginning of the injection for large enough injection velocities. They stated that this interaction explains not only the transient behavior of the spray tip velocity, but also the spray tip velocity increase in some cases, as it was observed and pointed out in the figures $7.5 \mathrm{~b}$.

Experiments for $\mathrm{CO}_{2}$ and $\mathrm{N}_{2}$ are also fitted with the equation 7.2. Since, at some aforementioned conditions, the subsonic state was achieved in more occasions under the $\mathrm{CO}_{2}$ atmosphere than within the $\mathrm{SF}_{6}$, because of speed of sound differences. It is obvious to assume that the coefficients of $\mathrm{CO}_{2}$ would be close to the $\mathrm{N}_{2}$ where the fuel was injected at subsonic conditions during all tests. The exponents obtained from these fittings are displayed in the table 7.6.

The figures 7.7 show the comparison of the observed penetration for each ambient gas, compared to those predicted by the equation 7.2. It can be seen how the penetration is specially well predicted in the full developed part of the spray (after 20mm) in all cases, when the ambient has the strongest influence over the penetration. It has to be 
Table 7.6 Typical parameters for penetration and exponents estimated from inert tests $\mathrm{CO}_{2}$ and $\mathrm{N}_{2}$.

\begin{tabular}{ccccc}
\hline \hline Exponent & Fit $\mathrm{CO}_{2}$ Eq. 7.2 & $\mathrm{CI} \mathrm{CO}_{2}$ Eq.7.2 & Fit $\mathrm{N}_{2}$ Eq. 7.2 & $\mathrm{CI} \mathrm{N}_{2}$ Eq.7.2 \\
\hline$k$ & 0.2502 & {$[0.2329,0.2676]$} & 0.3088 & {$[0.2861,0.3315]$} \\
$a$ & -0.1109 & {$[-0.1295,-0.0922]$} & -0.2096 & {$[-0.2297,-0.1395]$} \\
$b$ & 0.3669 & {$[0.3561,0.3776]$} & 0.3983 & {$[0.3828,0.4138]$} \\
$c$ & -0.7554 & {$[-0.8057,-0.7022]$} & -0.6001 & {$[-0.6693,-0.5309]$} \\
$d$ & 0.3852 & {$[0.3641,0.4063]$} & 0.4162 & {$[0.3821,0.4503]$} \\
$e$ & 0.5366 & {$[0.5206,0.5527]$} & 0.5950 & {$[0.5704,0.6195]$} \\
$R^{2}$ & $97.29 \%$ & - & $97.73 \%$ & - \\
\hline
\end{tabular}

mentioned as well that penetrations higher than $70 \mathrm{~mm}$ cannot be characterized, due to optical limitations.

\subsection{Spray development at evaporative conditions}

In this section, the liquid phase penetration results obtained at evaporative conditions via MIE-scattering (LL) are presented and compared to the vapor phase penetration data (S) measured via Schlieren technique. The measurements were carried out in the high pressure high temperature test facility [14] (section 4.4.1). The methodology for the measurements and the data processing are explained in chapter 4 . The effect of injection pressure, ambient density and temperature, is analyzed in the results. In addition, a correlation of the penetration is proposed with the aforementioned parameters, in order to quantify their influence. The figure 7.8 presents a time sequence of Schlieren and MIE-Scattering images of an injection event. In the sequence is depicted the typical behavior of evaporative diesel sprays; first, the fuel is injected into a hot ambient gas $\left(\mathrm{N}_{2}\right.$ in this case). Later on, the spray velocity and ambient density shear and atomize the liquid core and the spray entrains the surrounding hot gas which transfers energy to the liquid fuel and, downstream the liquid fuel eventually evaporates completely [207]. Ultimately, the vapor phase continues to penetrate, exchanging momentum with the ambient gas and progressively slowing down. 


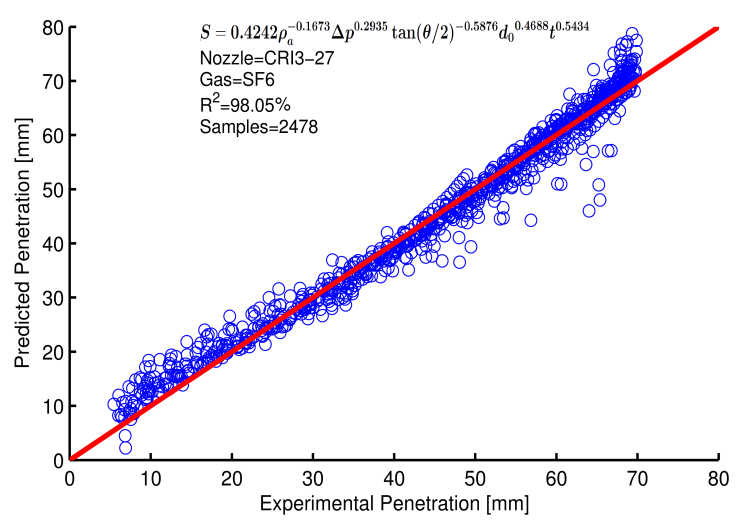

(a) Gas $\mathrm{SF}_{6}$

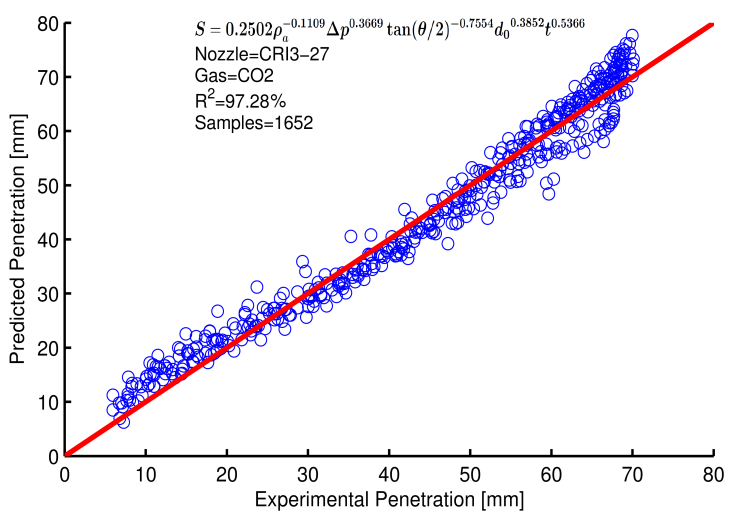

(b) Gas $\mathrm{CO}_{2}$

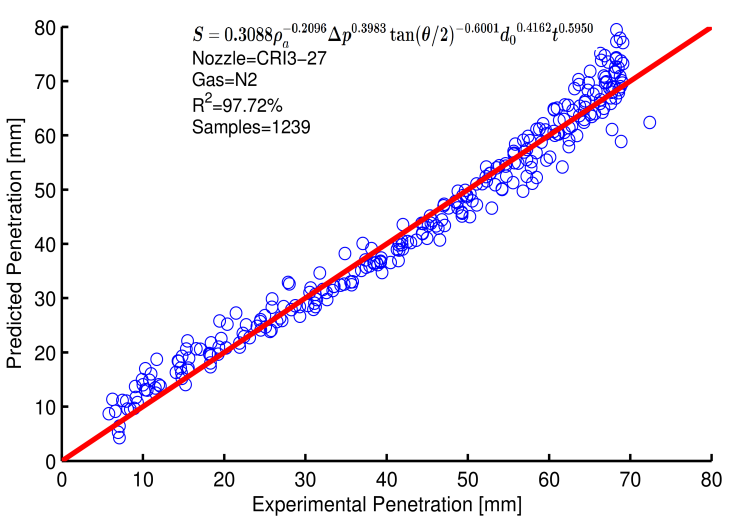

(c) Gas $\mathrm{N}_{2}$

Fig. 7.7 Experimental penetration versus predicted penetration by equation 7.2 considering exponents of tables 7.3 and 7.6

\subsubsection{Test Plan}

For the macroscopic characterization of the diesel spray under evaporative environment, different injection conditions have been tested. Experiments were carried out for a variety of representative engine values of injection pressures $(90,110,150,180,200,220$, 250 and $270 \mathrm{MPa}$ ) and ambient densities (between 20 and $40 \mathrm{~kg} / \mathrm{m}^{3}$ ). The ambient temperature was varied to achieve non-evaporative and evaporative conditions between $600 \mathrm{~K}$ and $900 \mathrm{~K}$. A resume of the test matrix is presented in table 7.7, where all the wide range of possible operating pressure conditions of a common-rail system are covered. For each operating points 10 repetitions were acquired and analyzed. 


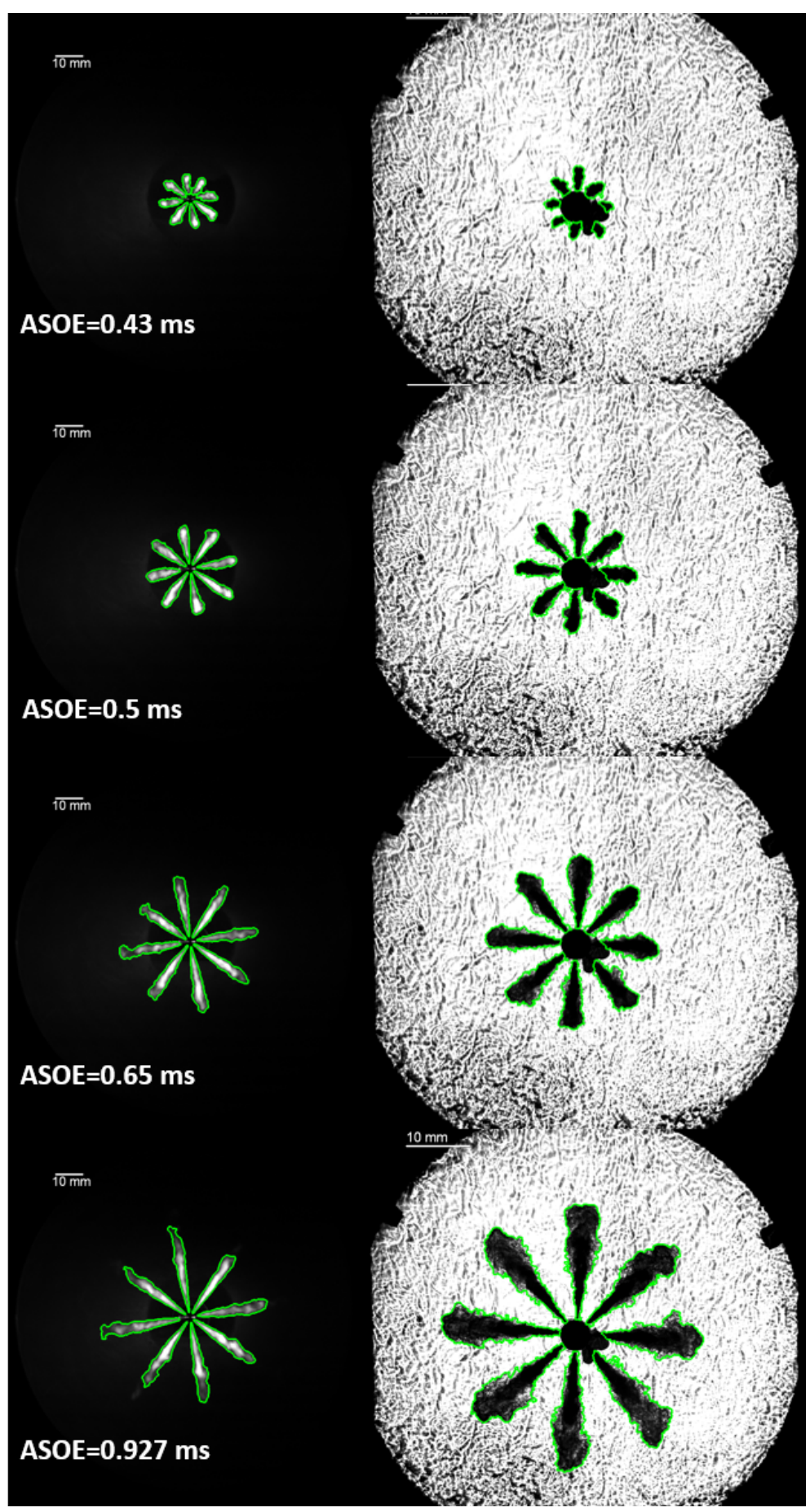

Fig. 7.8 Evaporative spray evolution (left) MIE-Scattering measurements, (right) Schlieren. $\rho_{a}=35 \mathrm{~kg} / \mathrm{m}^{3}$ Pinj=150MPa, $\mathrm{T}=800 \mathrm{~K}$, nozz $=\mathrm{CRI} 2-18$ 
Table 7.7 Experimental conditions for evaporative measurements.

\begin{tabular}{lcc}
\hline \hline Parameter & Injector & Testing Conditions \\
\hline & CRI2-18 & $90 / 110 / 150 / 180$ \\
Injection Pressure [MPa] & CRI2-22 & $90 / 110 / 150 / 180 / 220$ \\
& CRI3-27 & $90 / 110 / 150 / 180 / 200 / 250 / 270$ \\
\hline & CRI2-18 & $20 / 25 / 30 / 35 / 40$ \\
Ambient density $\left[\mathrm{kg} / \mathrm{m}^{3}\right]$ & CRI2-22 & $20 / 25 / 30 / 35 / 40$ \\
& CRI3-27 & $20 / 35 / 40$ \\
\hline & CRI2-18 & $600 / 650 / 700 / 750 / 800 / 900$ \\
Temperature $[\mathrm{K}]$ & CRI2-22 & $600 / 650 / 700 / 750 / 800 / 900$ \\
& CRI3-27 & $600 / 800 / 900$ \\
\hline & CRI2-18 & 1.5 \\
& CRI2-22 & 1.5 \\
& CRI3-27 & 0.7 \\
\hline
\end{tabular}

\subsubsection{Effect of ambient density on evaporating diesel sprays}

When considering evaporating diesel sprays, few of the most important parameters that have a significantly influence over the spray and combustion behavior are; the ambient density, ambient temperature and injection pressure. The ambient density and injection pressure act as a momentum sink and source respectively, while ambient temperature serves as evaporative energy source [207]. The figures 7.9a and 7.9b show a case of the nozzles CRI3-18 and CRI3-27 injecting at 180 and 200MPa respectively and three different ambient densities for each case.

The evolution in terms of penetration rate whilst changing ambient density has been described earlier when presenting the results at isothermal conditions. The higher 


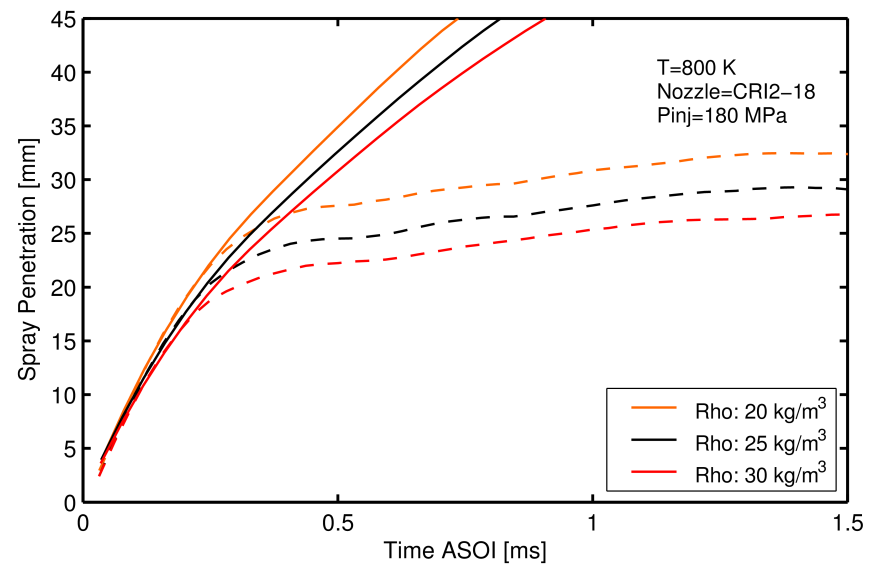

(a) Nozz $=$ CRI2-18

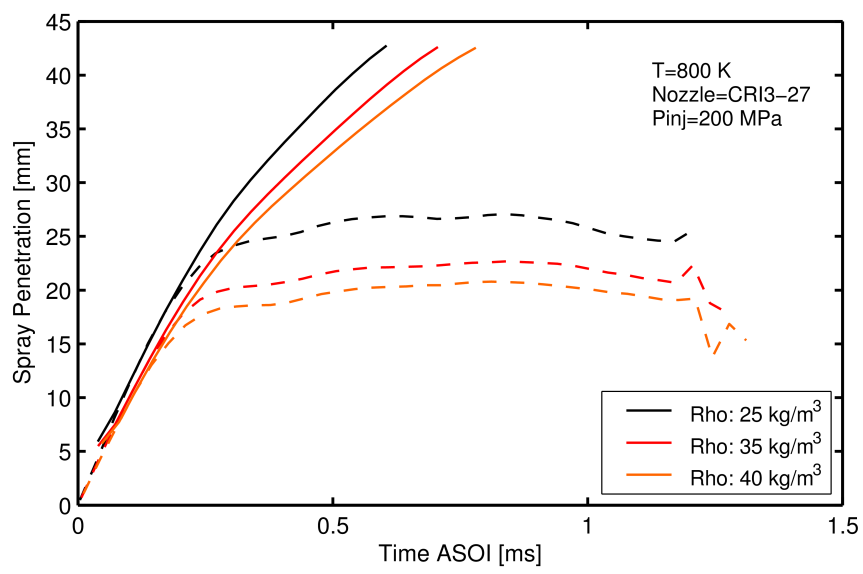

(b) Nozz=CRI3-27

Fig. 7.9 Effect of ambient pressure on evaporative sprays, (Solid line) Schlieren (dashline) MIE-Scattering

density of the gas introduces more inertia into the spray and thus the spray penetrates more slowly. This trend was similar, as expected, for all injectors.

\subsubsection{Effect of ambient temperature and injection pressure on vapor and liquid penetration}

The figures 7.10a and 7.10b depict a particular case of the nozzles CRI2-18 and CRI3-27 injecting diesel fuel at three different rail pressures and two different ambient temperatures. For a fixed ambient density, the vapor penetration curves collapse by 
ambient temperature values, whilst the liquid penetration curves collapse by injection pressure values. Thus the liquid penetration varies especially with ambient temperature (evaporative energy source to vaporize fuel), whilst the vapor penetration is especially affected by the injection pressure (momentum source). [14].

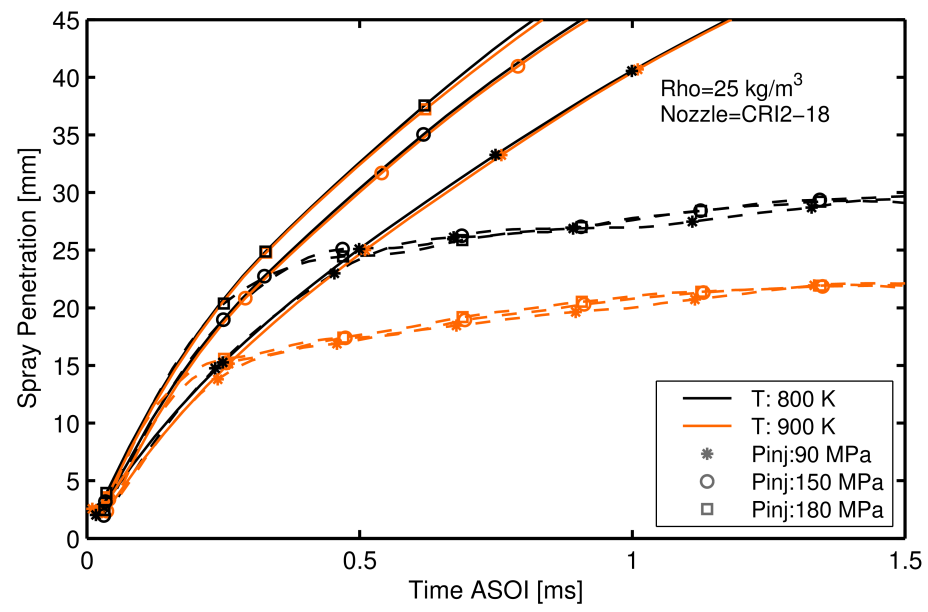

(a) Nozz $=$ CRI2-18

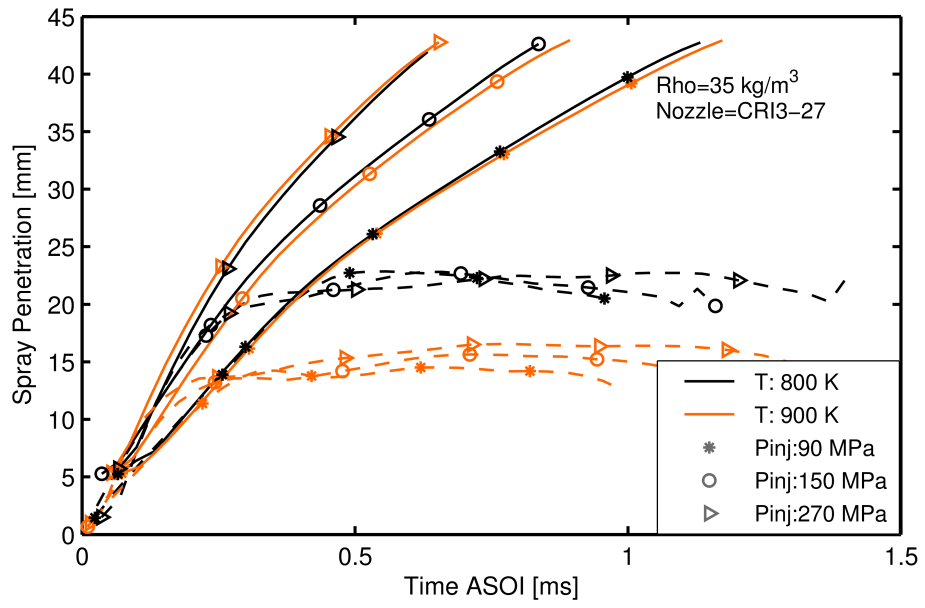

(b) Nozz=CRI3-27

Fig. 7.10 Effect of temperature and Pinj on evaporative spray, penetration(Solid line) Schlieren (dashline) MIE-Scattering

Since the vapor spray penetration is driven by momentum, changes in ambient temperature at constant ambient density does not influence the vapor spray penetration or spreading angle. This penetration behavior has been captured very well. Nevertheless for the spreading angle (figure 7.11), a small difference, not higher than $1^{o}$, is detected 
with temperature variations. This is not conclusive since this variation is smaller than the standard deviation of the spray angle at some conditions, for example, at $800 \mathrm{~K}$, Pinj=90MPa is $1.15^{\circ}$.

Furthermore there is another small effect usually reported [142, 145], that it is not experimentally observable as a clear tendency because variations of ambient pressure were not higher than $1.6 \%$. It is presented when both ambient pressure and ambient temperature are increased by keeping constant the ambient density. The momentum flux of the spray decreases and thus, so does the vapor penetration.

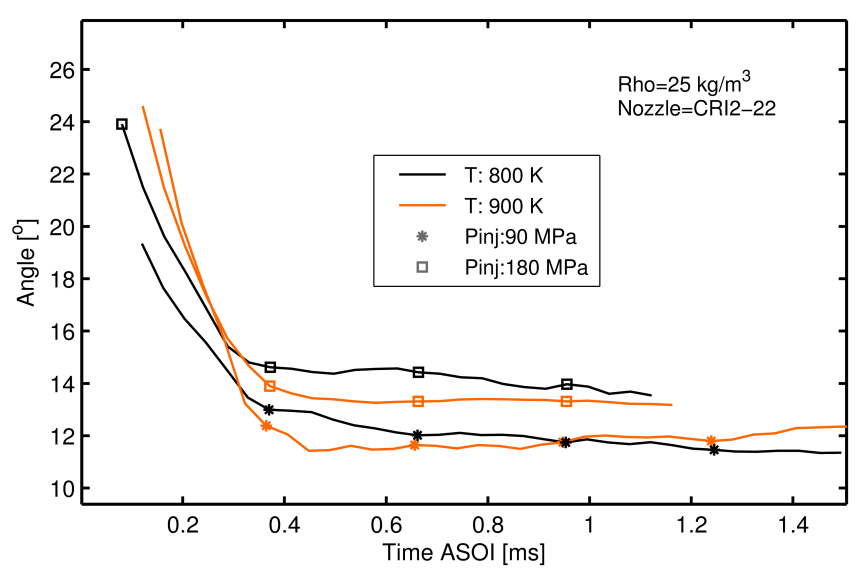

Fig. 7.11 Effect of ambient temperature and Pinj on spray cone angle, Nozz=CRI2-22

\subsubsection{Liquid length summary results}

For a global comparison of the data, the parameter $L L_{v}$ (liquid length average) is plotted versus the ambient density for several temperatures in the figures 7.12. The figures display a select group of liquid length values for all nozzles along an ambient density sweep. The rail pressure varied between 90MPa and 270MPa depending on the nozzle.

As expected, liquid lengths are inversely proportional to ambient temperature and ambient density [208], because the hotter ambient gas entrained provides more energy for the vaporization of a given mass of fuel and the decrease of momentum flux with ambient density. The temperature affects the viscosity of the air and the droplets 


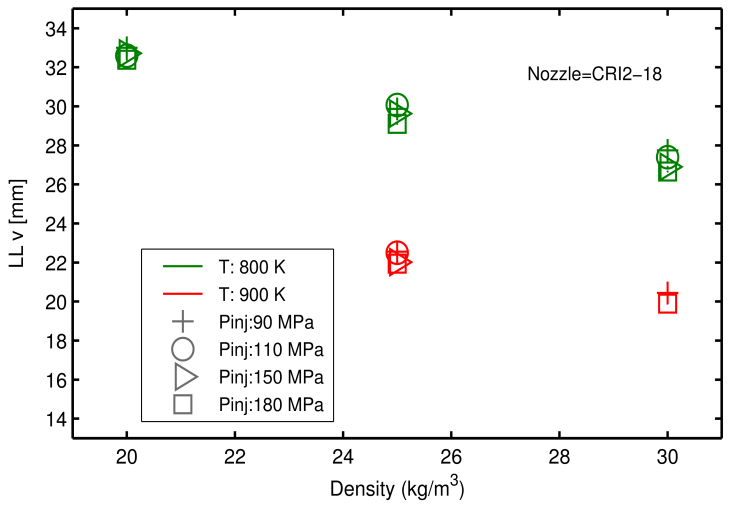

(a) Nozz $=$ CRI2-18

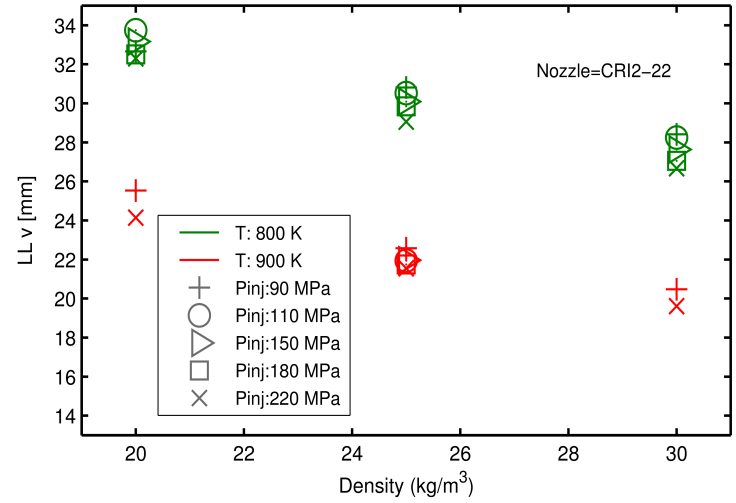

(b) Nozz=CRI2-22

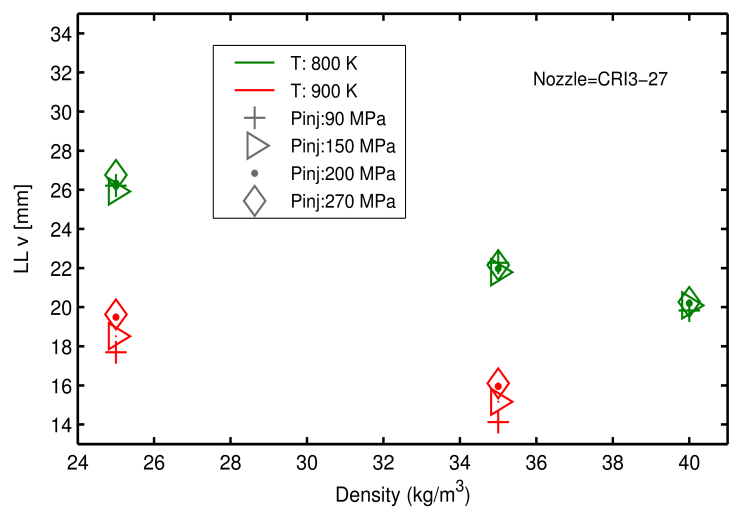

(c) Nozz $=$ CRI $3-27$

Fig. 7.12 Compendium of $L L_{v}$ for all evaporative test carried out in all injectors

diameter. In fact, when the ambient temperature is increased the droplet diameter is reduced due to fuel evaporation and due to a reduction in fuel surface tension.

As it can be seen in all the figures, the liquid penetration length is not affected by rail pressure. This is caused by the abundance of evaporative energy available. Therefore the rate of vaporization is influenced by rate of entrainment and mixing. Thus, as the fuel injection rate increases with injection pressure, the air entrainment increases proportionately, consequently maintaining the energy balance and liquid length [193]. Even for very high injection pressures like 270MPa, the behavior remained the same. Nevertheless, some small alterations can be seen in the injector CRI3-27 at high temperatures, but considering the standard deviation of the liquid penetration (approx 
$1.2 \mathrm{~mm})$, no conclusions can be made.

Properly predicting liquid lengths is of great interest for combustion chamber development. Siebers [194], presented a scaling law based on the fundamental physical processes that take place in the evaporative spray, allowing fast predictions of liquid length for single-component fuels. Furthermore Higgins et al. [62] proposed an alternative model which considers multi-component fuels, through basic thermodynamic properties of each component at reference conditions (equation 7.3). All the exponents in this equation have been adjusted to have the best fit to the experimental data.

$$
L L_{v}=k\left(\frac{\rho_{f}}{\rho_{a}}\right)^{a} B^{b} D_{0}
$$

Where $B$ is expressed in terms of the heat of vaporization and the specific heat of the fuel (equation 7.4)

$$
B=\frac{\sum_{i=1}^{N} Y_{i} h_{v a p, i}+\left(T_{b, \max }-T_{f}\right) \sum_{i=1}^{N} Y_{i} C_{p, l i q, i}}{C_{p, a i r}\left(T_{a m b}-T_{b, \max }\right) \sum_{i=1}^{N} Y_{i}}
$$

Where $T_{b, \max }$ is the maximum boiling temperature $T_{b}$ among the $N$ species and $Y_{i}$ is the mass fraction of species $i$. Moreover, the density ratio $\left(\rho_{f} / \rho_{a}\right)$ and $\mathrm{B}$ are evaluated using the atmospheric properties of the fuel, which is very convenient. The fuel properties can be found in the table 4.1. In the table 7.8 the exponents resulted from the fitting of the equation 7.3 with the experimental data, are shown. The fuel temperature at the outlet orifice $T_{f}$ was estimated from the data collected previously by Payri et al [139]. Higgins et al. [62] proposed values for $k, a$ and $b$. Nevertheless

Table 7.8 Exponents estimated from evaporative tests for $L L_{v}$ correlation.

\begin{tabular}{ccc}
\hline \hline Exponent & Fit Evap Eq. 7.3 & CI Evap Eq.7.3 \\
\hline$k$ & 0.0232 & {$[0.0163,0.0302]$} \\
$a$ & 0.6454 & {$[0.5667,0.7237]$} \\
$b$ & 0.7171 & {$[0.6446,0.7896]$} \\
$R^{2}$ & $91.22 \%$ & - \\
\hline
\end{tabular}

these values do not necessarily apply for any nozzle, fuel, and/or outside the test 
conditions covered. The figure 7.13 shows the comparison between the observed liquid length, for all evaporating conditions and all nozzles, together with the predicted by the correlation after the fitting. The correlation presented high level of accuracy as it can be seen in the figure.

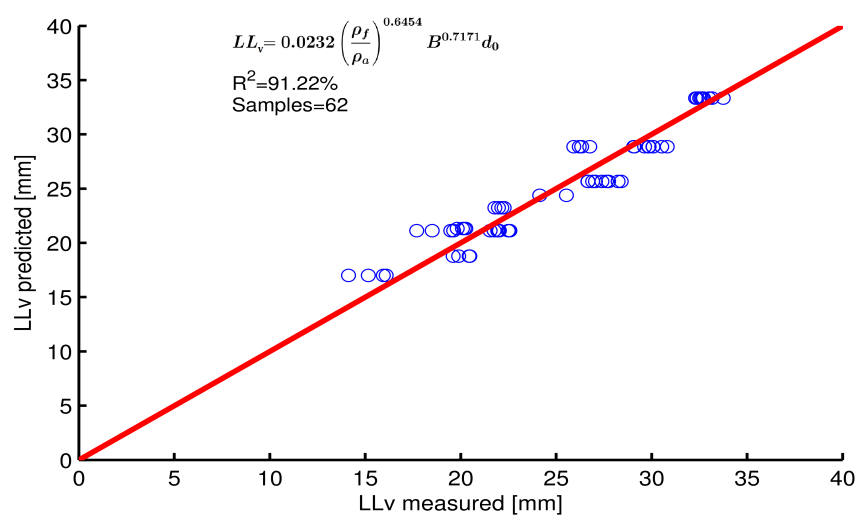

Fig. 7.13 Experimental $L L_{v}$ versus predicted $L L_{v}$ by equation 7.3 considering exponents of table 7.8

\subsubsection{Nozzle comparison}

The figures 7.14a and 7.14b depict a comparison of liquid and vapor penetration for all the nozzles. Overall, despite of the lower mass flow rate and the lower nozzle diameter of the piezo-driven injector CRI3-27 in comparison with the solenoid-driven CRI2-22, the nozzle CRI3-27 shows greater penetration rates in the later stages of the spray development (in average, time $>0.3 \mathrm{~ms}$ ). As it has been analyzed before in section 6.5.3, it is probable that the injectors CRI2-22 possesses higher conicity which produces smaller droplet diameters. Thus, the lower penetration of this nozzle could be caused by the turbulent velocity profiles produced by the cylindrical nozzles [202, 207], that enhance spray mixing and momentum exchange which in turn leads to slower tip penetration.

Moreover, in the case of liquid penetration, all trends collapse over the same value. This means that the ambient parameters had a greater influence over this parameter than nozzle characteristics. 


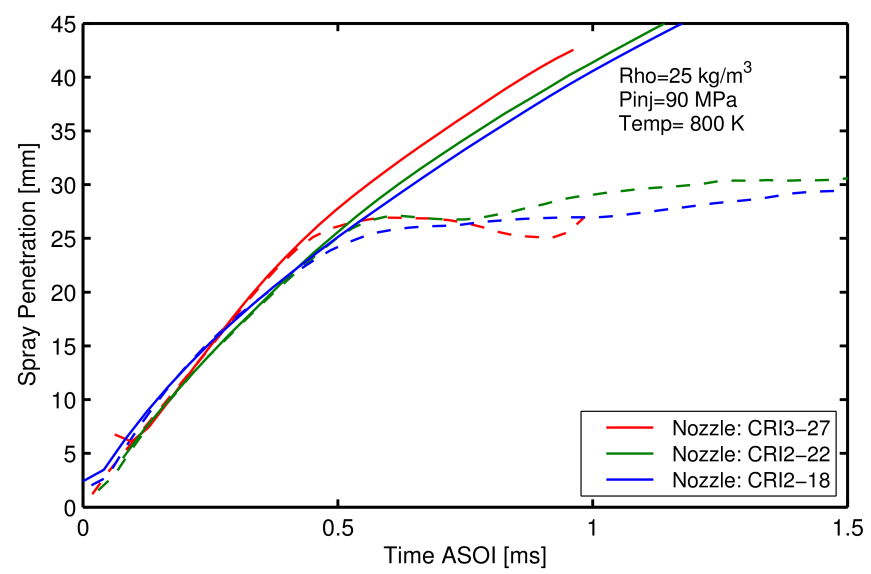

(a) Pinj $=90 \mathrm{MPa}, T_{a m b}=800 \mathrm{~K}, \rho_{a}=25 \mathrm{~kg} / \mathrm{m}^{3}$

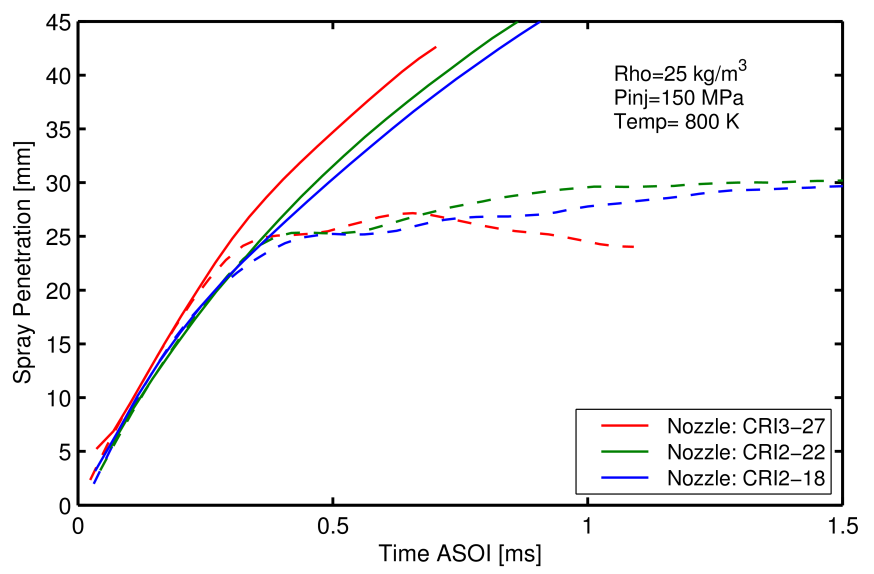

(b) Pinj=150MPa, $T_{a m b}=800 \mathrm{~K}, \rho_{a}=25 \mathrm{~kg} / \mathrm{m}^{3}$

Fig. 7.14 Nozzle comparison, liquid and vapor penetration, (Solid line) Schlieren (dashline) MIE-Scattering

\section{Spray-to-spray dispersion and repeatability}

The statistical dispersion of the measurements was analyzed in terms of the standard deviation. In order to analyze separately the contribution of the spray-to-spray dispersion from the test repeatability (shot-to-shot dispersion), the standard deviation was calculated in two different ways: estimating the average of the shot-to-shot dispersion measured in each orifice (shot-to-shot in figures 7.15) and the penetration dispersion average of all orifices (spray-to-spray in figures 7.16). Both measurements are a fundamental indicator of the injector performances. Even if the standard deviation 
of the measurements is strongly affected by the setup employed, this analysis allows, on the one hand, to have an idea of the reliability of the results and, on the other, to observe the injectors performance. The shot-to-shot dispersion of the measurements is higher for liquid visualization, this has been reported before and it is mainly caused due to the normal oscillation of $L L_{v}$ in diesel sprays around an average value, as a consequence of the atomization related and nozzle flow turbulences [164]. Concerning

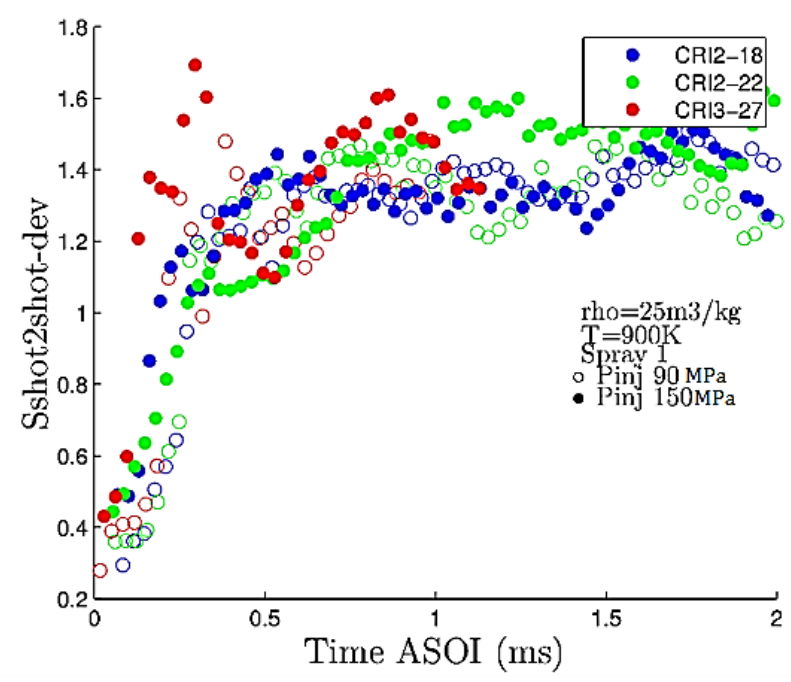

(a) MIE-Scattering, $T_{a m b}=900 \mathrm{~K}, \rho_{a}=25 \mathrm{~kg} / \mathrm{m}^{3}$

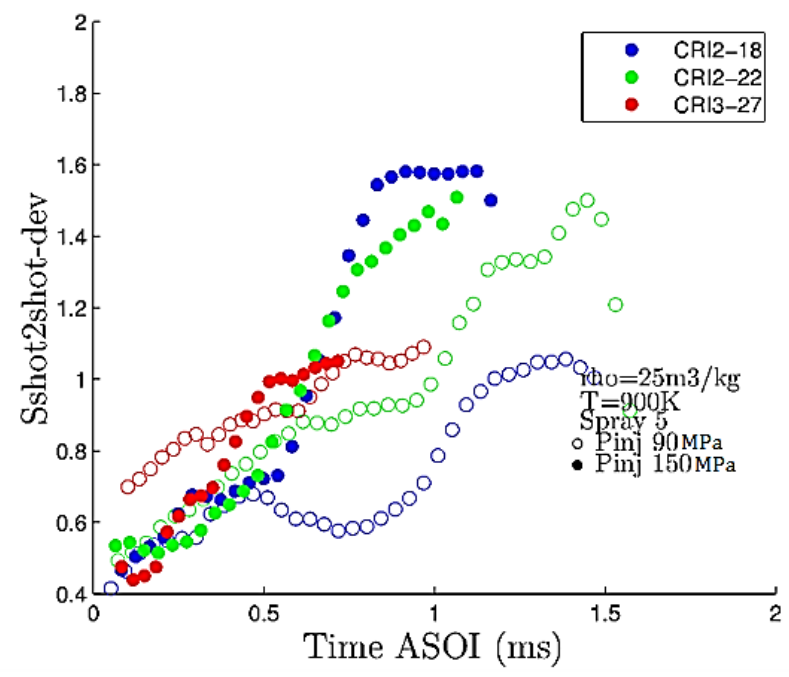

(b) Schlieren, $T_{a m b}=900 \mathrm{~K}, \rho_{a}=25 \mathrm{~kg} / \mathrm{m}^{3}$

Fig. 7.15 Shot to shot dispersion comparison for all injectors

the injection pressure effect over the injectors' behavior (figure 7.15b), it is observed 
that despite the great change in the injection pressure conditions, the dispersion in the vapor phase does not vary too much for the piezo injector CRI3-27. In the case of the solenoid injectors CRI2-18 and CRI2-22, this difference is higher. The reason for this behavior is probably an increase in the internal stresses that the needle supports when increasing the injection pressure.

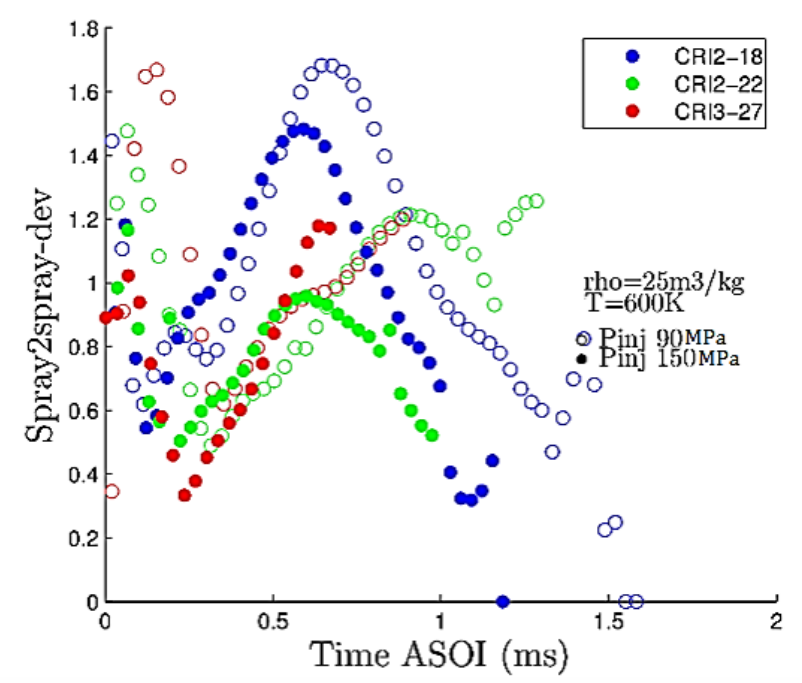

(a) MIE-Scattering, $T_{a m b}=600 \mathrm{~K}, \rho_{a}=25 \mathrm{~kg} / \mathrm{m}^{3}$

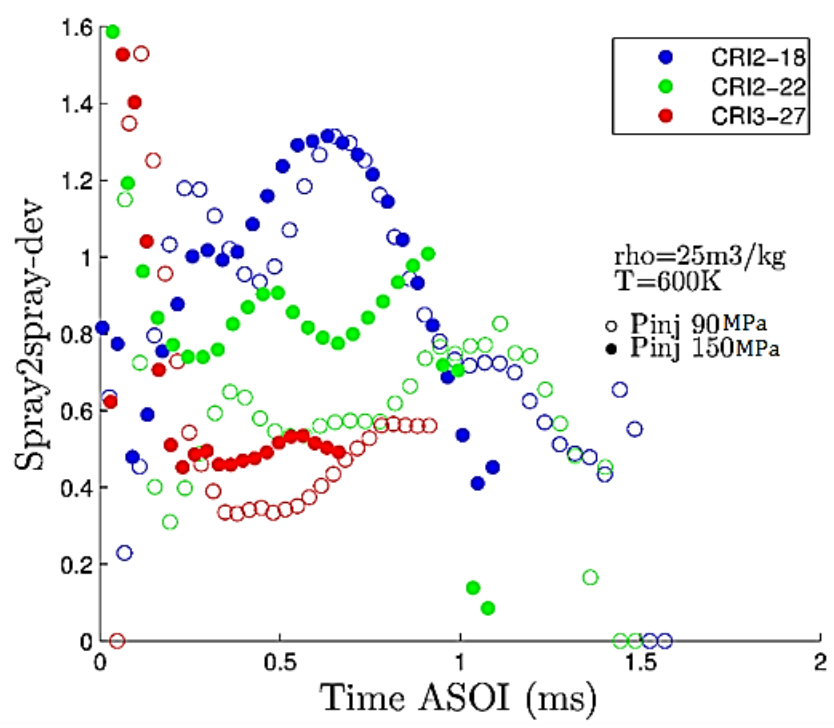

(b) Schlieren, $T_{a m b}=900 \mathrm{~K}, \rho_{a}=25 \mathrm{~kg} / \mathrm{m}^{3}$

Fig. 7.16 Spray to spray dispersion comparison for all injectors 
Moreover, the standard deviations obtained in the evaporative experiments, presented here for comparison, indicated good consistency of the results in terms of repeatability and spray-to-spray dispersion. The highest spray-to-spray standard deviations are also obtained for $L L_{v}$ (figure 7.16a). Nevertheless, in this case the dispersion is specially associated to setup issues (illumination and background homogeneity) as it has been already discussed in section 3.4. The spray-to-spray in Schlieren results (figure 7.16b) have shown that needle instabilities were higher in the solenoid injector CRI2-22. These are mainly caused during needle displacements, leading to the covering of some nozzle holes [15].

\subsection{Conclusions}

This section summarizes the chapter and presents the main conclusions extracted from the macroscopic characterization of the three injectors. The tests were developed under evaporative and isothermal conditions.

For the experiments carried out at isothermal conditions, a macroscopic characterization was made by means of the MIE-Scattering technique. The high density test rig described in 4.4.2 was used to this end. The ambient and injection parameters effects over the macroscopic characteristics of the sprays were analyzed.

Furthermore, as it has been reported in literature $[68,157]$ before, shock waves are present under very high injection pressures and even at some common engine operating points, modifying the macroscopic spray behavior. In order to explore these effects at non-evaporative conditions without having to reach extremely high injection pressures, shock waves appearance was enhanced by controlling the ambient gas speed of sound, promoting in this way supersonic jets. From the experimental macroscopic characterization at non-isothermal conditions, the following main conclusions are drawn:

- As expected, ambient density was a critical parameter for the spray development and it affected both spray penetration and spreading angle. The increment of 
ambient density caused an increase in $\theta$ and at the same time, a slower spray penetration.

- Two empirical predictive models with a high degree of accuracy, for spray penetration under isothermal conditions under the $\mathrm{SF}_{6}$ atmosphere, are presented and utilized to analyze the influence of ambient and injection properties on this macroscopic characteristic. A better level of confidence was obtained if the spray cone angle was taken into consideration. Thus, the equation 7.2 showed the highest $\mathrm{R}$-squared and the coefficients agreed with those consulted in the literature.

- There were not significant differences between the fitted data including very high injection pressures $($ Pinj $>230 \mathrm{MPa})$ and medium-low pressures $(\mathrm{Pinj}<230 \mathrm{MPa})$. Thus, for the $\mathrm{SF}_{6}$ atmosphere the influence of ambient and injection parameters kept the same behavior for pressures up to 270MPa.

- At same ambient densities spray penetration grew faster within the $\mathrm{SF}_{6}$ atmosphere than the others $\left(\mathrm{CO}_{2}\right.$ and $\left.\mathrm{N}_{2}\right)$ and had smaller spray cone angles. This tendency was enhanced when the environmental density was incremented and the injection pressure was decreased. Cavitation, as the cause of this effect, was discarded since cavitation effects are enhanced by $\Delta P$, which is higher under the $\mathrm{SF}_{6}$ atmosphere. Nevertheless the opposite effects expected for cavitation were found under this atmosphere. Additionally, $\Delta P$ was also suggested as a cause, however, observing the coefficients on table 7.3, the influence of $\Delta P$ over the spray penetration is affected by the exponent 0.2935 . Which means that $\Delta P$ differences only affect penetration in approx $0.8 \%$.

- Sprays under transonic state were achieved under very high injection pressures in $\mathrm{CO}_{2}$ at low densities, and for all range of pressures tested in $\mathrm{SF}_{6}$ except for injection pressures less than $90 \mathrm{MPa}$ at high densities $\left(22.8\right.$ and $\left.30.4 \mathrm{~kg} / \mathrm{m}^{3}\right)$. Within the $\mathrm{N}_{2}$ atmosphere in the range of pressures that has been tested, only subsonic sprays were obtained since the maximum Mach number was 0.6. 
- All trends near the transonic state $(0.8<\mathrm{M}<1.2)$ had a greater penetration. As it can be appreciated in $\mathrm{CO}_{2}$ Mach tip trends (figure 7.5), sprays injected at very high injection pressures $(270 \mathrm{MPa})$ and low densities $\left(7.6\right.$ and $10.8 \mathrm{~kg} / \mathrm{m}^{3}$ ) grew faster than $\mathrm{N}_{2}$ penetration curves. One possible explanation was that shock waves were generated in the transition stage of penetration from subsonic to supersonic, and the macroscopic changes could be related to the depression that is created behind the spray ambient impact region (the so-called Mach zone). These variations have been observed before [132, 133, 157, 183].

- Shock waves in the transition stage of penetration from subsonic to supersonic were unlikely to happen under $\mathrm{N}_{2}$ atmosphere in the range of pressures tested, since the maximum Mach number was 0.6. In the case of $\mathrm{CO}_{2}$ the transonic state was achieved under very high injection pressures at low densities, and for $\mathrm{SF}_{6}$ this state was reached with all range of pressures tested except for injection pressures less than 90MPa at high densities $\left(22.8\right.$ and $\left.30.4 \mathrm{~kg} / \mathrm{m}^{3}\right)$. Therefore, the subsonic state was achieved in more occasions under the $\mathrm{CO}_{2}$ atmosphere than within the $\mathrm{SF}_{6}$, because of speed of sound differences. Thus, the coefficients obtained from fitting $\mathrm{CO}_{2}$ and $\mathrm{N}_{2}$ were close to each other.

Moreover, for evaporative experiments, the constant-pressure flow high pressure high temperature test rig described in section 4.4.1 was the test rig selected. The liquid phase penetration results obtained at evaporative conditions via MIE-scattering were presented and compared to the vapor phase penetration data measured via Schlieren technique. From the experimental macroscopic characterization at evaporating conditions, the following main conclusions are drawn:

- The evolution in terms of penetration rate whilst changing ambient density is the same as isothermal measurements. Thus, the higher density of the gas introduces more inertia into the spray and thus the spray penetrated more slowly. Therefore, as expected, both vapor and liquid length were inversely proportional to ambient density, caused by the decrease of momentum flux with ambient density. 
- For a fixed ambient density, the vapor penetration curves collapsed by ambient temperature values, whilst the liquid penetration curves collapsed by injection pressure values. This means that the liquid penetration is controlled by ambient temperature, whilst the vapor penetration is controlled by injection pressure. Thus, the increment of injection pressure caused a significant increase on vapor penetration, but it did not have an observable effect over the liquid length. Consequently, liquid length was inversely proportional to ambient temperature, whilst this parameter did not affect the vapor penetration.

- Even for very high (Pinj>230MPa) injection pressures like 270MPa, the effects of ambient and injection parameters remained the same on liquid length. Nevertheless, some small alterations can be seen in the injector CRI3-27 at high temperatures of around $1.3 \mathrm{~mm}$, but considering the standard deviation of the liquid penetration (approx 1.2mm), no conclusions can be made.

- Liquid length experimental data was fitted with the empirical expression 7.3 that accounts for relative variations in boiling point temperature, specific heat, latent heat of vaporization, fuel density, and gas temperature and density, presenting high level of accuracy.

- In spite of lower mass flow rate and the lower nozzle diameter of the piezodriven injector CRI3-27 in comparison with the solenoid-driven CRI2-22, the nozzle CRI3-27 showed greater penetration rates in the later stages of the spray development (in average, time $>0.3 \mathrm{~ms}$ ). The CRI2-18 nozzle, showed the smallest penetration rate together with the smallest rate of injection and orifice diameters. 



\section{Chapter 8}

\section{Conclusions and future work}

\subsection{Introduction}

This chapter aims at drawing the main conclusions with respect to the work carried out along this thesis. The main goals reached in this investigation are presented relating the results obtained in the different phases of the investigation and putting them in a wider context.

The last section of this chapter proposes a list of the potential developments of the present work, indicating directions for new studies and possible improvements to the quality of the results presented in this thesis.

\subsection{Summary and conclusions}

The present thesis investigated the effect of the low and very high injection pressures over macroscopic and microscopic characteristics of the diesel spray using multi-hole nozzles. This work starts from the initial requirement by Jaguar \& Land Rover to characterize three different injectors; two solenoid driven injectors able to reach up to $180 \mathrm{MPa}$ and $220 \mathrm{MPa}$, and the last one, a piezo-driven injector able to reach up to 270MPa.

Taking advantage from the technology, equipment and facilities available at CMT- 
Motores Térmicos, different aspects of the injection process have been thoroughly studied. The nozzle internal flow, the fuel spray development macro and micro characteristics have been investigated applying a wide range of experimental techniques:

- Rate of injection for the characterization of the internal flow.

- Phase Doppler Anemometry to estimate the droplet velocities and diameters.

- MIE-scattering at isothermal and evaporative conditions, technique to investigate the spray development and evaporation.

- Schlieren to analyze the vapor spray development under evaporating conditions.

All the imaging evaporative tests have been performed in a high-pressure hightemperature facility, capable of reproducing the typical diesel engine in-cylinder conditions, in a wide and optical accessible test chamber. The wide section of the chamber allows to study the injection event in free field-like conditions, avoiding the direct interaction between the spray plumes and the surrounding walls, which introduces higher uncertainties in the results.

The high speed visualization of the isothermal liquid spray and the microscopic characterization, have been performed in a high density test rig facility, where ambient conditions are achieved with a gas with high molecular mass (Sulphur hexafluoride-SF 6 ) and varying ambient pressure. For both measurements, one out of all the sprays has been isolated and measured. For this, a device for spray isolation was designed and manufactured to keep lateral and top windows clean.

After the general introduction in Chapter 1, the Chapter 2 briefly reviews the historical development of injection systems in the automotive sector and defines the two types of generalized diesel injection configurations and the particularities of mixture preparation in each, focusing further on the direct injection systems. Then, the evolution of the fuel delivery systems is presented up to the multi-hole solenoid and piezo actuated injectors used in $D I$ engines. These types of injectors are described, first generally and 
then more particularly focusing on the three injectors used in this thesis. Lastly, the typical characteristics of internal flow and external spray are discussed, listing and briefly reviewing the majority of the studies done for the hardware used in this work. In Chapter 4, the experimental methodology followed and the equipment used in this work was exposed. A description of the experiments performed was made, exposing the physical principles behind the measurements, the hardware and the processing techniques.

In the Chapter 5, the rate of injection and the geometrical characterization were discussed. Regarding multiple injections, it was concluded that the dwell time variation causes a bathtub trend of the ROI over the total mass flow of the post-injection, this variation depends mainly on injection pressure, pilot injection ET and fuel properties. Finally, across the test matrix, the injector CRI2-18 presented slightly lower stabilized mass flow rates, which is attributed to its smaller total flow area and to its great losses probably caused by its internal geometry. The shot-to-shot dispersion amongst injections did not exceeded $5 \%$ for all injectors.

Chapter 6 bound together the results obtained when studying the spray from a microscopic point of view at isothermal conditions. A methodology for spray isolation and alignment was developed with a very low measurement error of $0.22^{\circ}$. PDPA velocity measurements were carried out, results were compared with theoretical approaches and seem to fit well with R-square factors between $89.9 \%$ and $96.6 \%$. An expression for SMD has been fitted. The R-square factor of $84.4 \%$ over the measured data and the coefficients were similar to other authors consulted in the bibliography. This correlation was representative over the whole test plan and for the three injectors, for low and very high injection pressures (270 MPa). Thus, no significant changes were observables for the range of pressures studied over microscopic characteristics of the spray. In addition, towards the spray periphery, the diameters became practically equal for all the injectors tested. This is because in these zones the ambient plays a bigger 
role on the diameter distribution than injection parameters and injector characteristics.

Chapter 7 focuses on the external spray macroscopic visualization. For nonevaporative measurements one spray has been isolated following the same methodology exposed in chapter 1 . The MIE-scattering optical was the technique selected due to its simplicity and the reliable information that can be gather from it. As it has been noted in the literature, some macroscopic variations in the spray with gas properties and shock wave appearance at common engine conditions have been reported. In order to estimate these effects and others that very high injection pressures would have over the spray structure, the shock waves appearance was enhanced by controlling the ambient gas speed of sound using three ambient gases with different speed of sound, promoting in this way supersonic jets in some cases. As expected, ambient density was a critical parameter for the spray development and its increment caused an increase in $\theta$ and at the same time, a slower spray penetration. Empirical models were proposed for tests under the $\mathrm{SF}_{6}$ atmosphere with a high degree of accuracy. In addition, by including the spray angle in these correlations the fitting was improved. It has been shown that the effect of injection and ambient parameters kept the same behaviors for very high injection pressures up to $270 \mathrm{MPa}$. When comparing test from different gases at same densities, it was found that all trends near the transonic state $(0.8<\mathrm{M}<1.2)$ had a greater penetration. One possible explanation was the generation of shock waves in the transition stage of penetration from subsonic to supersonic. These macroscopic changes could be related to the depression that is created behind the spray in the impact region (Mach Zone).

Regarding the evaporative tests, as expected, liquid penetration was controlled by ambient temperature and density, whilst the vapor penetration was controlled by injection pressure and ambient density. Thus, an increment of injection pressure caused a significant increase on vapor penetration and liquid length was inversely proportional to ambient temperature. A correlation for liquid length was proposed as well, with high level of accuracy. Furthermore, for very high injection pressures like 270MPa, 
the effects of ambient and injection parameters remained the same on liquid length. Finally the macroscopic characteristics from all injectors were compared, it was found that, in spite of lower mass flow rate and the lower nozzle diameter of the piezo-driven injector CRI3-27 in comparison with the solenoid-driven CRI2-22, the nozzle CRI3-27 showed greater penetration rates in the later stages of the spray development. The CRI2-18 nozzle, showed the smallest penetration rate together with the smallest rate of injection and orifice diameters.

\subsection{Future works}

There are many possible ways to continue the work presented in this thesis. This section proposes some interesting routes to continue developing tools and knowledge on diesel injection systems. Since the injection pressure is one of the most influential parameters in the pulverization of the fuel and thus in the homogeneity of the air-fuel mixture [35]. This leads to a continued interest of the automotive industry in increasing injection pressures in diesel systems. Thus, the research field in this aspect is still open and very high injection pressures, much higher that those explored in this thesis are now in process to become a reality in diesel injection systems.

- Regarding the internal flow, further ROI measurements on multiple injections and the influence of very high injection pressures over them would help to fully understand the role of injection pressure on multiple injection conditions. Moreover, momentum flux measurements enhancing shock waves by the use of gases with very low speed of sound, would be helpful in order to analyze the near-nozzle region of the spray and the effect of primary shock waves over the internal behavior of the injector.

- Further microscopical measurements comparing SMD trends and droplet velocities under subsonic, transonic and supersonic state. 
- Macroscopic visualization of the near and far-nozzle regions for non-evaporative sprays to visualize transonic and supersonic sprays by means of the Schlieren optical technique. Primary and secondary shock waves could be observed, processed and relationships between their development and the macroscopic characteristics of the spray could be established.

- Considering also other fuels. It would be interesting to evaluate the influence of gas properties on droplet distribution, and velocities considering the spray under subsonic, transonic and supersonic conditions. Together with fuel properties which also have a direct influence over macro and micro spray characteristics. 


\section{References}

[1] Aori, G., Hung, D. L. S., and Zhang, M. (2016). Effect of nozzle configuration on macroscopic spray characteristics of multi-hole fuel injectors under superheated conditions. Atomization and Sprays, 26(5):439-462.

[2] Arai, M., Tabata, M., Hiroyasu, H., and Shimizu, M. (1984). Disintegrating process and spray characterization of fuel jet injected by a diesel nozzle. In SAE Technical Paper 840275.

[3] Araneo, L., Coghe, A., Brunello, G., and Donde, R. (2000). Effects of fuel temperature and ambient pressure on a GDI swirled injector spray. SAE Technical Paper 2000-01-1901, (724):01-1901.

[4] Araneo, L., Soare, V., Payri, R., and Shakal, J. S. (2006). Setting up a PDPA system for measurements in a diesel spray. In Journal of Physics: Conference Series, volume 45, pages 85-93. Institute of Physics Publishing.

[5] Arcoumanis, C., Flora, H., Gavaises, M., Kampanis, N., and Horrocks, R. (1999). Investigation of cavitation in a vertical multi-hole diesel injector. SAE Paper 199901-0524.

[6] Arcoumanis, C., Gavaises, M., and French, B. (1997). Effect of fuel injection processes on the structure of diesel sprays. SAE Paper 970799.

[7] Armas, O., Mata, C., and Martínez-Martínez, S. (2012). Effect of diesel injection parameters on instantaneous fuel delivery using a solenoid-operated injector with different fuels. Revista Facultad de Ingeniería, 64:9-21.

[8] Arrègle, J. (1997). Análisis de la estructura y dinámica interna de chorros diesel. $\mathrm{PhD}$ thesis, E.T.S. Ingenieros Industriales. Universidad Politécnica de Valencia, Valencia.

[9] Arrègle, J., Pastor, J. V., and Ruiz, S. (1999). Influence of the injection parameters on diesel Spray characteristics. SAE Paper 1999-01-0200.

[10] Asihmin, V. I., Geller, Z. I., and Skobel'cyn, Y. A. (1961). Discharge of a real fluid from cylindrical orifices. Oil Industry, 9:135-172.

[11] Bachalo, W. (1994). Experimental methods in multiphase flows. International Journal of Multiphase Flow, 20:261-295.

[12] Bae, C., Yu, J., Kang, J., Kong, J., and Lee, K. O. (2002). Effect of nozzle geometry on the common-rail diesel spray. SAE Technical Paper 2002-01-1625. 
[13] Ball, C. G., Fellouah, H., and Pollard, A. (2012). The flow field in turbulent round free jets. Progress in Aerospace Sciences, 50:1-26.

[14] Bardi, M. PhD thesis, Valencia (Spain).

[15] Bardi, M., Bruneaux, G., Nicolle, A., and Colin, O. (2017). Experimental methodology for the understanding of soot-fuel relationship in diesel combustion: fuel characterization and surrogate validation.

[16] Bardi, M., Payri, R., Malbec, L.-M., Bruneaux, G., Pickett, L. M., Manin, J., Bazyn, T., and Genzale, C. L. (2012). Engine Combustion Network: Comparison of spray development, vaporization, and combustion in different combustion vessels. Atomization and Sprays, 22(10):807-842.

[17] Baumgarten, C. (2006). Mixture formation in internal combustion engine.

[18] Benajes, J., Molina, S., De Rudder, K., and Rente, T. (2006). Influence of injection rate shaping on combustion and emissions for a medium duty diesel engine. Journal of Mechanical Science and Technology, 20(9):1436-1448.

[19] Benajes, J., Pastor, J. V., Payri, R., and Plazas, A. H. (2004). Analysis of the influence of diesel nozzle geometry in the Injection rate characteristics. Journal of Fluids Engineering (ASME)., 126:63-71.

[20] Bermúdez, V., Payri, R., Salvador, F. J., and Plazas, A. H. (2005). Study of the influence of nozzle seat type on injection rate and spray behavior. ImechE. Journal of automobile engineering, 219(5):677-689.

[21] Boehner, W. and Hummel, K. (1997). Common rail injection system for commercial diesel vehicles. SAE Paper 970345.

[22] Bosch, W. (1966). The fuel rate indicator: A new measuring instrument for display of the characteristics of individual injection. SAE Technical Paper 660\%49.

[23] Bracho, G. (2011). Experimental and theoretical study of the direct diesel injection process at low temperatures. Phd thesis, Universidad Politécnica de Valencia, Valencia.

[24] Brulatout, J., Garnier, F., Mounaïm-Rousselle, C., and Seers, P. (2016). Calibration strategy of diesel-fuel spray atomization models using a design of experiment method. International Journal of Engine Research, 17(7):713-731.

[25] Brusiani, F., Falfari, S., and Pelloni, P. (2014). Influence of the diesel injector hole geometry on the flow conditions emerging from the nozzle. Energy Procedia, 45:749-758.

[26] Canaan, R., Dec, J. E., Green, R., and Daly, D. (1998). The influence of fuel volatility on the liquid-phase fuel penetration in a heavy-duty D.I. diesel engine. SAE Paper 980510.

[27] Carreres, M. (2016). Thermal effects influence on the diesel injector performance through a combined 1D modelling and experimental approach. PhD thesis, Universitat Politècnica de València. 
[28] Chehroudi, B., Chen, S.-H., Bracco, F. V., and Onuma, Y. (1985). On the intact core of full-cone sprays. SAE Paper 850126.

[29] Chung, N.-H., Oh, B.-G., and Sunwoo, M.-H. (2008). Modelling and injection rate estimation of common-rail injectors for direct-injection diesel engines. Proceedings of the Institution of Mechanical Engineers, Part D: Journal of Automobile Engineering, 222(6):1089-1001.

[30] Colebrook, C. F. (1939). Turbulent flows in pipes, with particular reference to the transition region between the smooth and rough pipe laws.

[31] Correas, D. (1998). Estudio teórico-experimental del chorro libre diesel isotermo. PhD thesis, E.T.S. Ingenieros Industriales. Universidad Politécnica de Valencia, Valencia.

[32] Cossali, G. E., Coghe, A., and Brunello, G. (1993). Effect of spray-wall interaction on air entrainment in a transient diesel spray. In SAE Technical Paper. SAE International.

[33] Dan, T., Yamamoto, T., Senda, J., and Fujimoto, H. (1997). Effect of nozzle configurations for characteristics of non-reacting diesel fuel spray. SAE Paper 970355.

[34] De la Morena, J. (2011). Estudio de la influencia de las características del flujo interno en toberas sobre el proceso de inyección diesel en campo próximo. $\mathrm{PhD}$ thesis, Universidad Politécnica de Valencia.

[35] Delacourt, E., Desmet, B., and Besson, B. (2005). Characterisation of very high pressure diesel sprays using digital imaging techniques. Fuel, 84(7-8):859-867.

[36] Dent, J. C. (1971). A basis for comparison of various experimental methods for studying spray penetration. SAE Paper 710571.

[37] Desantes, J. M., Garcia-Oliver, J. M., Pastor, J. M., and Ramirez-Hernandez, J. G. (2011). Influence of nozzle geometry on ignition and combustion for high-speed direct injection diesel engines under cold start conditions. Fuel, 90(11):3359-3368.

[38] Desantes, J. M., Lopez, J. J., Carreres, M., and López-Pintor, D. (2016). Characterization and prediction of the discharge coefficient of non-cavitating diesel injection nozzles. Fuel, 184:371-381.

[39] Desantes, J. M., Pastor, J. V., Payri, R., and Pastor, J. M. (2005). Experimental characterization of internal nozzle flow and diesel spray behavior. Part II: Evaporative conditions. Atomization and Sprays, 15(5):489-516.

[40] Desantes, J. M., Payri, R., Garcia, A., and Manin, J. (2009). Experimental study of biodiesel blends' effects on diesel injection processes. Energy \&6 Fuels, 23(6):3227-3235.

[41] Desantes, J. M., Payri, R., Garcia-Oliver, J. M., and Salvador, F. J. (2007). A contribution to the understanding of isothermal diesel spray dynamics. Fuel, 86(7-8):1093-1101. 
[42] Desantes, J. M., Payri, R., Salvador, F. J., and Gil, A. (2006). Development and validation of a theoretical model for diesel spray penetration. Fuel, 85(7-8):910-917.

[43] Desantes, J. M., Payri, R., Salvador, F. J., and Gimeno, J. (2003). Measurements of spray momentum for the study of cavitation in diesel injection nozzles. $S A E$ Technical Paper 2003-01-0703.

[44] Desantes, J. M., Payri, R., Salvador, F. J., and Soare, V. (2005). Study of the influence of geometrical and injection parameters on diesel Sprays characteristics in isothermal conditions. SAE Technical Paper 2005-01-0913.

[45] Doudou, A. and Maslouhi, A. (2007). A macro-microscopic investigation of highpressure sprays injected by a common rail system. Journal of Mechanical and Science Technology, 21:1284-1292.

[46] Dumouchel, C. (2008). On the experimental investigation on primary atomization of liquid streams. Experiments in Fluids, 45(3):371-422.

[47] Espey, C. and Dec, J. E. (1995). The effect of TDC temperature and density on the liquid-phase fuel penetration in a D.I. diesel engine. SAE Paper 952456.

[48] Fansler, T. D. and Parrish, S. E. (2015). Spray measurement technology: a review. Measurement Science and Technology, 26(1):012002.

[49] Fox, T. A. and Stark, J. (1989). Discharge coefficients for miniature fuel injectors. Proc. Inst. Mech Engrs, 203:75-78.

[50] Ganippa, L. C., Andersson, S., and Chomiak, J. (2000). Transient measurements of discharge coefficients of diesel nozzles. SAE Paper 2000-01-2788, (724).

[51] Gavaises, M. and Andriotis, A. (2006). Cavitation inside multi-hole injectors for large diesel engines and its effect on the near-nozzle spray structure. SAE Technical Paper 2006-01-1114, 2006(724).

[52] Gimeno, J. (2008). Desarrollo y aplicación de la medida de flujo de cantidad de movimiento de un chorro diesel. PhD thesis, E.T.S. Ingenieros Industriales, Universidad Politécnica de Valencia.

[53] Gimeno, J., Bracho, G., Martí-Aldaraví, P., and Peraza, J. E. (2016). Experimental study of the injection conditions influence over n-dodecane and diesel sprays with two ECN single-hole nozzles. Part I: Inert atmosphere. Energy Conversion and Management, 126:1146-1156.

[54] Gravesen, P., Branebjerg, J., and Jensen, O. S. (1993). Microfluidics-a review. J. Micromech. Microeng, 3:168-182.

[55] Gupta, J. G. and Agarwal, A. K. (2016). Macroscopic and microscopic spray characteristics of diesel and karanja biodiesel blends. SAE Technical Paper 2016-010869 .

[56] Ha, J. Y., Hayashi, A., Tanabe, H., Sato, G. T., Kuniyoshi, H., and Fujimoto, H. (1983). Investigation on the initial part and the spray formation delay of diesel spray. SAE Paper 830451. 
[57] Hall, G. W. (1963). Analytical determination of the discharge characteristics of cylindrical-tube orifices. Journal of Mechanical Engineering Science, 5:91.

[58] Han, D. and Mungal, M. (2001). Direct measurement of entrainment in reacting/nonreacting turbulent jets. Combustion and Flame, 124(3):370-386.

[59] Hay, P. and Jones, P. L. (1972). Comparaison of the various correlations for spray penetration. SAE Paper 720776.

[60] Hessel, R. P. and Reitz, R. D. (2002). diesel engine injection rate-shape optimization using genetic algorithms and multi-dimensional modeling for a range of operating modes. 12th International Multidimensional Engine Modeling User's Group Meeting at the SAE Congress, pages 1-5.

[61] Heywood, J. B. (1988). Internal combustion engine fundamentals, volume 21.

[62] Higgins, B., Mueller, C. J., and Siebers, D. L. (1999). Measurements of fuel effects on liquid-phase penetration in DI sprays. In SAE transactions, volume 108, pages 630-643.

[63] Hinze, J. O. (1975). Turbulence. McGraw-Hill New York.

[64] Hiroyasu, H. and Arai, M. (1990). Structures of fuel sprays in diesel engines. In SAE Technical Paper 900475.

[65] Hiroyasu, H., Arai, M., and Tabata, M. (1989). Empirical equations for the Sauter mean diameter of diesel spray. SAE Paper 890464.

[66] Hiroyasu, H., Shimizu, M., and Arai, M. (1982). The breakup of high speed jet in a high pressure gaseous atmosphere. In ICLASS-82, pages 69-74.

[67] Hsiang, L.-P. and Faeth, G. (1992). Near-limit drop deformation and secondary breakup. International Journal of Multiphase Flow, 18(5):635-652.

[68] Huang, W., Wu, Z., Gao, Y., and Zhang, L. (2015). Effect of shock waves on the evolution of high-pressure fuel jets. Applied Energy, 159:442-448.

[69] Hung, C. C., Martin, J. K., and Koo, J.-Y. (1997). Injection pressure effects upon droplet behavior in Transient diesel Sprays. SAE Paper 970053.

[70] Husberg, T., Manente, V., Ehleskog, R., and Andersson, S. (2006). Fuel flow impingement measurements on multi-orifice diesel nozzles. SAE Paper 2006-01-1552.

[71] Hwang, J., Park, Y., Kim, K., Lee, J., and Bae, C. (2017). Improvement of diesel combustion with multiple injections at cold condition in a constant volume combustion chamber. Fuel, 197:528-540.

[72] Idelchik, I. E. (1968). Memento des pertes de charge. Eyrolles Paris.

[73] Jia, T. M., Li, G. X., Yu, Y. S., and Xu, Y. J. (2016a). Effects of ultra-high injection pressure on penetration characteristics of diesel spray and a two-mode leading edge shock wave. Experimental Thermal and Fluid Science, 79:126-133. 
[74] Jia, T. M., Li, G. X., Yu, Y. S., and Xu, Y. J. (2016). Propagation characteristics of induced shock waves generated by diesel spray under ultra-high injection pressure. Fuel, 180:521-528.

[75] Jia, T.-M., Yu, Y.-S., and Li, G.-X. (2017). Experimental investigation of effects of super high injection pressure on diesel spray and induced shock waves characteristics. Experimental Thermal and Fluid Science, 85(Supplement C):399-408.

[76] Jicha, M., Jedelsky, J., Otahal, J., and Slama, J. (2002). Influence of some geometrical parameters on the characteristics of effervescent atomization. ILASSEurope Zaragoza.

[77] Jing, D. (2015). Experimental and numerical studies of fuel spray. PhD thesis, University of Birmingham.

[78] Johnson, T. V. (2012). Vehicular emissions in review. SAE International Journal of Engines, 5(2):2012-01-0368.

[79] Jordan, C. (1979). Calculus of finite differences. Chelsea Publishing Company, New York, 3rd edition.

[80] Juneja, H., Ra, Y., and Reitz, R. D. (2004). Optimization of injection rate shape using active control of fuel injection. SAE Technical Paper 2004-01-0530.

[81] Kastengren, A. L., Powell, C. F., Liu, Z., and Wang, J. (2009). Time resolved, three-dimensional mass distribution of diesel sprays measured with x-ray radiography. SAE Technical Paper 2009-01-0840.

[82] Kastengren, A. L., Powell, C. F., Wang, Y., Im, K.-S., and Wang, J. (2008). X-ray radiography measurements of diesel spray structure at engine-like ambient density. In ILASS 21st Annual Conference, Orlando, volume 19, pages 1031-1044.

[83] Kastengren, A. L., Tilocco, F. Z., Powell, C. F., Manin, J., Pickett, L. M., Payri, R., and Bazyn, T. (2012). Engine Combustion Network (ECN): Measurements of nozzle geometry and hydraulic behavior. Atomization and Sprays, 22(12):1011-1052.

[84] Kent, J. C. and Brown, G. M. (1983). Nozzle exit flow, characteristics for squareedged and rounded inlet geometries. Combust. Sci. Technol., 30:121-132.

[85] Kristensson, E., Araneo, L., Berrocal, E., Manin, J., Richter, M., Aldén, M., and Linne, M. (2011). Analysis of multiple scattering suppression using structured laser illumination planar imaging in scattering and fluorescing media. Optics Express, 19(14):13647-13663.

[86] Kuniyoshi, H., Tanabe, H., Sato, G. T., and Fujimoto, H. (1980). An investigation on the characteristics of diesel fuel spray. SAE Paper 800968.

[87] Lee, H.-K., Russell, M. F., and Bae, C. (2002). Mathematical model of diesel fuel injection equipment incorporating non-linear fuel injection. Proceedings of the Institution of Mechanical Engineers, Part D: Journal of Automobile Engineering, 216(3):191-204. 
[88] Lee, J., Kang, S., and Rho, B. (2003). Time-resolved analysis of turbulent mixing flow characteristics of intermittent multi-hole diesel spray using 2-D PDPA. JSME International Journal Series B Fluids and Thermal Engineering, 46(3):425-433.

[89] Lee, J. W., Min, K. D., Kang, K. Y., Bae, C. S., Giannadakis, E., Gavaises, M., and Arcoumanis, C. (2006). Effect of piezo-driven and solenoid-driven needle opening of common-rail diesel injectors on internal nozzle flow and spray development. International Journal of Engine Research, 7(6):489-502.

[90] Lee, S. H., Jeong, D. Y., Lee, J. T., Ryou, H. S., and Hong, K. (2005). Investigations on spray characteristics under ultra-high injection pressures conditions. International journal of automotive technology, 6(2):125-131.

[91] Lee, T., Leok, M., and McClamroch, N. H. (2011). Geometric numerical integration for complex dynamics of tethered spacecraft. Proceedings of the 2011 American Control Conference, (March):1885-1891.

[92] Lefebvre, A. H. (1988). Atomization and Sprays. CRC Press.

[93] Leick, P., Kastengren, A. L., Liu, Z., Wang, J., and Powell, C. F. (2009). X-Ray measurements of mass distributions in the near-nozzle region of sprays from standard multi-hole common-rail diesel injection systems. In Transportation, number July, pages 2009-2009.

[94] Lemmon, E. W., McLinden, M. O., and Friend, D. G. (2011). Thermophysical properties of fluid systems. In Linstrom, P. J. and Mallard, W. G., editors, NIST Chemistry WebBook, NIST Standard Reference Database Number 69.

[95] Levy, N., Amara, S., Champoussin, J.-C., and Guerrassi, N. (1997). Non-reactive diesel spray computations supported by PDA measurements. In SAE Technical Paper. SAE International.

[96] Lichtarowicz, A. K., Duggins, R. K., and Markland, E. (1965). Discharge coefficients for incompressible non-cavitating flow through long orifices. J. Mech. Engng Sci., 7(2):210-219.

[97] Lindström, M. (2009). Injector nozzle hole parameters and their influence on real DI diesel performance. pages 1-45.

[98] Liu, A. B., Mather, D., and Reitz, R. D. (1993). Modeling the effects of drop drag and breakup on fuel sprays. In SAE International Congress and Exposition, volume 298 , pages $1-6$.

[99] LMS (2010). Imagine.Lab AMESim v.10. User's manual.

[100] Lopez, J. J. (2003). Estudio teórico-experimental del chorro libre diesel no evaporativo y de su interacción con el movimiento del aire. PhD thesis, E.T.S. Ingenieros Industriales. Universidad Politécnica de Valencia, Valencia.

[101] Luckhchoura, V. (2010). Modeling of injection-rate shaping in diesel engine combustion. PhD thesis. 
[102] Luckhchoura, V., Peters, N., and Diwakar, R. (2011). Computational analysis of injection-rate shapes in a small-bore direct-injection diesel engine. International Journal of Engine Research, 12(2):145-168.

[103] Macian, V., Payri, R., Garcia, A., and Bardi, M. (2012). Experimental evaluation of the best approach for diesel spray images segmentation. Experimental Techniques, $36(6): 26-34$.

[104] Macian, V., Payri, R., Ruiz, S., Bardi, M., and Plazas, A. H. (2014). Experimental study of the relationship between injection rate shape and diesel ignition using a novel piezo-actuated direct-acting injector. Applied Energy, 118(APRIL):100-113.

[105] Mahr, B. (2002). Future and potential of diesel injection systems. In THIESEL 2002 Conference on Thermo- and Fluid-Dynamic Processes in diesel Engines, pages $5-17$.

[106] Manin, J. (2011). Analysis of mixing processes in liquid and vaporized diesel sprays through LIF and Rayleigh scattering measurements. PhD thesis, E.T.S. Ingenieros Industriales. Universidad Politécnica de Valencia, Valencia.

[107] Manin, J., Bardi, M., and Pickett, L. M. (2012). Evaluation of the liquid length via diffused back-illumination imaging in vaporizing diesel sprays. In Comodia, Fukuoka.

[108] Martí-Aldaraví, P. (2014). Development of a computational model for a simultaneous simulation of internal flow and spray break-up of the diesel injection process. Phd thesis, Universtitat Politècnica de València, Valencia.

[109] Martínez-Martínez, S., García Y, M., and Bermúdez, V. (2010). Experimental cells for diesel spray research. Number Chapter 3. InTech.

[110] Martínez-Martínez, S., Sánchez-C, F. A., Bermúdez, V., and Riesco-Ávila, J. M. (2010). Liquid sprays characteristics in diesel engines. Number Chapter 2. InTech.

[111] Mie, G. (1908). Beiträge zur Optik trüber Medien, speziell kolloidaler Metallösungen. Annalen der Physik, 330(3):377-445.

[112] Miesse, C. C. (1955). Correlation of experimental data on the disintegration of liquid jets. Industrial \& Engineering Chemistry, 47:1690-1695.

[113] Mohan, B., Yang, W., and Chou, S. K. (2013). Fuel injection strategies for performance improvement and emissions reduction in compression ignition engines - A review. Renewable and Sustainable Energy Reviews, 28(x):664-676.

[114] Mompó Laborda, J. M. (2014). Engineering large eddy simulation of diesel sprays. PhD thesis, Universitat Politècnica de València, Valencia (Spain).

[115] Moon, S., Gao, Y., Park, S., Wang, J., Kurimoto, N., and Nishijima, Y. (2015). Effect of the number and position of nozzle holes on in- and near-nozzle dynamic characteristics of diesel injection. Fuel, 150:112-122. 
[116] Mugele, R. A. and Evans, H. D. (1951). Droplet size distribution in sprays. Industrial \&f Engineering Chemistry, 43(6):1317-1324.

[117] Myong, K., Suzuki, H., Senda, J., and Fujimoto, H. (2006). Evaporation characteristics of multi-component fuel. Fuel, 85(17-18):2632-2639.

[118] Naber, J. D. and Siebers, D. L. (1996). Effects of gas density and vaporization on penetration and dispersion of diesel sprays. In SAE Paper 960034, volume 105, pages $82-111$. Society of Automotive Engineers, Inc., Warrendale, Pennsylvania, USA.

[119] Nakayama, Y. (1961). Action of the fluid in the air micrometer: first report, characteristics of small diameter nozzle and orifice. Bull. Jpn. Soc. Mech. Eng., $4(15): 516-524$.

[120] Neal, N. and Rothamer, D. (2016). Measurement and characterization of fully transient diesel fuel jet processes in an optical engine with production injectors. Experiments in Fluids, 57(10):155.

[121] Nishida, K., Jingyu, Z., Xianyin, L., and He, Z. (2017). Effects of micro-hole nozzle and ultra-high injection pressure on air entrainment, liquid penetration, flame lift-off and soot formation of diesel spray flame. International Journal of Engine Research, 18(1-2):51-65.

[122] Nishida, K., Zhang, W., and Manabe, T. (2007). Effects of micro-hole and ultra-high injection pressure on mixture properties of D.I. diesel spray. In $S A E$ Technical Paper. SAE International.

[123] Nishimura, T., Satoh, K., Takahashi, S., and Yokota, K. (1998). Effects of fuel injection rate on combustion and emission in a DI diesel engine. In SAE Technical Paper 981929.

[124] Nurick, W. H. (1976). Orifice cavitation and its effects on spray mixing. Journal of Fluids Engineering, 98:681-687.

[125] Ohrn, T. R., Senser, D. W., and Lefèbvre, A. H. (1991). Geometrical effects on discharge coefficients for plain-orifice atomizers. Atomization and Sprays, 1(2):137153.

[126] Park, S., Han Suh, Hyun Kyu, L., and Sik, C. Effect of cavitating flow on the flow and fuel atomization characteristics of biodiesel and diesel fuels. Energy and Fuels.

[127] Pastor, J. V., Garcia-Oliver, J. M., Pastor, J. M., and Zapata, L. D. (2007). Evaporating diesel spray visualization using a double-pass Shadowgraphy / Schlieren imaging. SAE technical Paper 200\%-24-0026.

[128] Pastor, J. V., Lopez, J. J., Garcia-Oliver, J. M., and Pastor, J. M. (2008). A 1D model for the description of mixing-controlled inert diesel sprays. Fuel, 87(1314):2871-2885. 
[129] Payri, F., Arrègle, J., Lopez, J. J., and Hermens, S. (2006). Effect of cavitation on the nozzle outlet flow, spray and flame formation in a diesel engine. SAE Paper 2006-01-1391.

[130] Payri, F., Bermúdez, V., Payri, R., and Salvador, F. J. (2004). The influence of cavitation on the internal flow and the spray characteristics in diesel injection nozzles. Fuel, 83(4-5):419-431.

[131] Payri, F., Lopez, J. J., Garcia, A., and De la Garza, O. A. (2013). Effects of cavitation in common-rail diesel nozzles on the soot formation process. $S A E$ Technical Paper.

[132] Payri, F., Payri, R., Bardi, M., and Carreres, M. (2014). Engine combustion network: Influence of the gas properties on the spray penetration and spreading angle. Experimental Thermal and Fluid Science, 53:236-243.

[133] Payri, F., Payri, R., Salvador, F. J., and Bardi, M. (2012). Effect of gas properties on diesel spray penetration and spreading angle for the ECN injectors. In ICLASS 2012, 12th Triennial International Conference on Liquid Atomization and Spray Systems, pages 1-8, Heidelberg.

[134] Payri, F., Payri, R., Salvador, F. J., and Gimeno, J. (2005). Comparison between different hole to hole measurement techniques in a diesel injection nozzle. $S A E$ Technical Paper 2005-01-2094.

[135] Payri, F., Torregrosa, A. J., and Payri, R. (2000). Evaluation through pressure and mass velocity distributions of the linear acoustical description of I. C. engine exhaust systems. Applied Acoustics, 60(4):489-504.

[136] Payri, R., Araneo, L., Shakal, J. S., and Soare, V. (2008). Phase doppler measurements: System set-up optimization for characterization of a diesel nozzle. Journal of Mechanical Science and Technology, 22(8):1620-1632.

[137] Payri, R., Bracho, G., Martí-Aldaraví, P., and Viera, A. (2017). Nozzle geometry size influence on reactive spray development: from Spray B to heavy duty applications. SAE Technical Paper 2017-01-0846, page 12.

[138] Payri, R., Garcia, A., Domenech, V., Durrett, R. P., and Plazas, A. H. (2012). An experimental study of gasoline effects on injection rate, momentum flux and spray characteristics using a common rail diesel injection system. Fuel, 97:390-399.

[139] Payri, R., Garcia-Oliver, J. M., Bardi, M., and Manin, J. (2012). Fuel temperature influence on diesel sprays in inert and reacting conditions. Applied Thermal Engineering, 35(March):185-195.

[140] Payri, R., Garcia-Oliver, J. M., Salvador, F. J., and Gimeno, J. (2005). Using spray momentum flux measurements to understand the influence of diesel nozzle geometry on spray characteristics. Fuel, 84(5):551-561.

[141] Payri, R., Gimeno, J., Bardi, M., and Plazas, A. H. (2013). Study liquid length penetration results obtained with a direct acting piezo electric injector. Applied Energy, 106(JUNE):152-162. 
[142] Payri, R., Gimeno, J., Bracho, G., and Vaquerizo, D. (2016). Study of liquid and vapor phase behavior on diesel sprays for heavy duty engine nozzles. Applied Thermal Engineering, 107:365-378.

[143] Payri, R., Gimeno, J., Martí-Aldaraví, P., and Giraldo, J. S. (2016). Methodology for Phase Doppler Anemometry measurements on a multi-hole diesel injector. Experimental Techniques, 41(2):1-8.

[144] Payri, R., Gimeno, J., Mata, C., and Viera, A. (2018). Rate of injection measurements of a direct-acting piezoelectric injector for different operating temperatures. Energy Conversion and Management, 154:387-393.

[145] Payri, R., Gimeno, J., Viera, J. P., and Plazas, A. H. (2012). Schlieren visualization of transient vapor penetration and spreading angle of a prototype diesel direct-acting piezoelectric injector. In ICLASS 2012, pages 1-8.

[146] Payri, R., Gimeno, J., Viera, J. P., and Plazas, A. H. (2013). Needle lift profile influence on the vapor phase penetration for a prototype diesel direct acting piezoelectric injector. Fuel, 113:257-265.

[147] Payri, R., Guardiola, C., Salvador, F. J., and Gimeno, J. (2004). Critical cavitation number determination in diesel injection nozzles. Experimental Techniques, 28(3):49-52.

[148] Payri, R., Margot, X., and Salvador, F. J. (2002). A numerical study of the influence of diesel nozzle geometry on the inner cavitating flow. SAE Technical Paper 2002-01-0215.

[149] Payri, R., Molina, S., Salvador, F. J., and Gimeno, J. (2004). A study of the relation between nozzle geometry, internal flow and sprays characteristics in diesel fuel injection systems. KSME International Journal, 18(7):1222-1235.

[150] Payri, R., Ruiz, S., Salvador, F. J., and Gimeno, J. (2007). On the dependence of spray momentum flux in spray penetration: Momentum flux packets penetration model. Journal of Mechanical Science and Technology, 21(7):1100-1111.

[151] Payri, R., Salvador, F. J., Garcia, A., and Gil, A. (2012). Combination of visualization techniques for the analysis of evaporating diesel sprays. Energy \& Fuels, 26:5481-5490.

[152] Payri, R., Salvador, F. J., Gimeno, J., and Bracho, G. (2008). A new methodology for correcting the signal cumulative phenomenon on injection rate measurements. Experimental Techniques, 32(February):46-49.

[153] Payri, R., Salvador, F. J., Gimeno, J., and Bracho, G. (2011). The effect of temperature and pressure on thermodynamic properties of diesel and biodiesel fuels. Fuel, 90(3):1172-1180.

[154] Payri, R., Salvador, F. J., Gimeno, J., and De la Morena, J. (2008). Macroscopic behaviour of diesel Sprays in the near-nozzle field. SAE Technical Paper 2008-010929. 
[155] Payri, R., Salvador, F. J., Gimeno, J., and De la Morena, J. (2011). Influence of injector technology on injection and combustion development, Part 2: Combustion analysis. Applied Energy, 88(4):1130-1139.

[156] Payri, R., Salvador, F. J., Gimeno, J., and Novella, R. (2010). Flow regime effects on non-cavitating injection nozzles over spray behavior. International Journal of Heat and Fluid Flow, 32(1):273-284.

[157] Payri, R., Salvador, F. J., Gimeno, J., and Soare, V. (2005). Determination of diesel sprays characteristics in real engine in-cylinder air density and pressure conditions. Journal Of Mechanical Science and Technology, 19(11):2040-2052.

[158] Payri, R., Salvador, F. J., Gimeno, J., and Viera, A. (2016). Effect of injection rate shaping over diesel spray development in non-reacting evaporative conditions. In Tschöke, H. and Marohn, R., editors, 10. Tagung diesel- und Benzindirekteinspritzung 2016, number 1, pages 133-152. Springer Vieweg.

[159] Payri, R., Salvador, F. J., Gimeno, J., and Zapata, L. D. (2008). diesel nozzle geometry influence on spray liquid-phase fuel penetration in evaporative conditions. Fuel, 87(7):1165-1176.

[160] Payri, R., Viera, J. P., Gopalakrishnan, V., and Szymkowicz, P. G. (2017). The effect of nozzle geometry over ignition delay and flame lift-off of reacting directinjection sprays for three different fuels. Fuel, 199:76-90.

[161] Payri, R., Viera, J. P., Gopalakrishnan, V., and Szymkowicz, P. G. (2017). The effect of nozzle geometry over the evaporative spray formation for three different fuels. Fuel, 188:645-660.

[162] Payri, R., Viera, J. P., Wang, H., and Malbec, L.-M. (2016). Velocity field analysis of the high density, high pressure diesel spray. International Journal of Multiphase Flow, 80:69-78.

[163] Pickett, L. M. (2005). Low flame temperature limits for mixing-controlled diesel combustion. Proceedings of the Combustion Institute, 30(2):2727-2735.

[164] Pickett, L. M., Genzale, C. L., Bruneaux, G., Malbec, L.-M., and Christiansen, C. (2010). Comparison of diesel spray combustion in different high-temperature, high-pressure facilities. SAE Int. J. Engines, 3:156-181.

[165] Pickett, L. M., Genzale, C. L., Manin, J., Malbec, L.-M., and Hermant, L. (2011). Measurement uncertainty of liquid penetration in evaporating diesel sprays. In ILASS Americas, 23rd Annual Conference on Liquid Atomization and Spray Systems, number May, Ventura, CA (USA). ILASS-Americas.

[166] Pickett, L. M., Kook, S., and Williams, T. C. (2009). Visualization of diesel spray penetration, cool-flame, ignition, high-temperature combustion, and soot formation using high-speed imaging. SAE Int. J. Engines, 2(1):439-459. 
[167] Pickett, L. M., Manin, J., Genzale, C. L., Siebers, D. L., Musculus, M. P. B., and Idicheria, C. A. (2011). Relationship between diesel fuel spray vapor penetration/dispersion and local fuel mixture fraction. SAE International Journal of Engines, 4(1):764-799.

[168] Pickett, L. M., Manin, J., Kastengren, A. L., and Powell, C. F. (2014). Comparison of near-field structure and growth of a diesel spray using light-based optical microscopy and x-ray radiography. SAE Technical Paper 2014-01-1412, pages 1044-1053.

[169] Pickett, L. M., Manin, J., Payri, R., Bardi, M., and Gimeno, J. (2013). Transient rate of injection effects on spray development. SAE Technical Paper 2013-24-0001.

[170] Piederrière, Y., Cariou, J., Guern, Y., Le Jeune, B., Le Brun, G., and Lotrian, J. (2004). Scattering through fluids: speckle size measurement and Monte Carlo simulations close to and into the multiple scattering. Optics Express, 12 (1):176-188.

[171] Pilch, M. and Erdman, C. A. (1987). Use of breakup time data and velocity history data to predict the maximum size of stable fragments for acceleration-induced breakup of a liquid drop. International Journal of Multiphase Flow, 13(6):741-757.

[172] Pribicevic, I. and Sattelmayer, T. (2012). Investigation of the diesel spray atomization process with use of Phase Doppler Anemometry at high injection pressures and at engine-like gas density. In 16th Int Symp on Applications of Laser Techniques to Fluid Mechanics.

[173] Qian, J. and Law, C. K. (1997). Regimes of coalescence and separation in droplet collision. Journal of Fluid Mechanics, 331:S0022112096003722.

[174] Ranz, W. E. (1958). Some experiments on orifice sprays. Can. J. Chem. Engng, August, page 175.

[175] Rayleigh, L. (1878). On the instability of jets. Proceedings of the London Mathematical Society, s1-10(1):4-13.

[176] Reitz, R. and Bracco., F. (1986). Mechanisms of breakup of round liquid jets. Encyclopedia of fluid mechanics 3.

[177] Reitz, R. D. (1978). Atomization and other breakup regimes of a liquid jet. PhD thesis.

[178] Reitz, R. D. and Bracco, F. V. (1979). On the dependence of spray angle and other spray parameters on nozzle design and operating conditions. SAE Paper 790494 .

[179] Reitz, R. D. and Bracco, F. V. (1982). Mechanism of atomization of a liquid jet. Physics of Fluids, 25(10):1730-1742.

[180] Reitz, R. D. and Diwakar, R. (1987). Structure of high-pressure fuel sprays. SAE Paper 870598. 
[181] Ricou, F. P. and Spalding, D. B. (1961). Measurements of entrainment by axisymmetrical turbulent jets. Journal of Fluid Mechanics, 11(01):21.

[182] Roisman, I., Araneo, L., and Tropea, C. (2007). Effect of ambient pressure on penetration of a diesel spray. International Journal of Multiphase Flow, 33(8):904920 .

[183] Roisman, I. and Tropea, C. (2005). Fluctuating flow in a liquid layer and secondary spray created by an impacting spray. International Journal of Multiphase Flow, 31(2):179-200.

[184] Sallam, K. A., Dai, Z., and Faeth, G. M. (2002). Liquid breakup at the surface of turbulent round liquid jets in still gases. International Journal of Multiphase Flow, 28:427-449.

[185] Salvador, F. J. (2003). Estudio teórico experimental de la influencia de la geometría de toberas de inyección Diésel sobre las características del flujo interno y del chorro. PhD thesis, E.T.S. Ingenieros Industriales. Universidad Politécnica de Valencia, Valencia.

[186] Salvador, F. J. (2007). Influencia de la cavitación sobre el desarrollo del chorro diesel. Reverté.

[187] Salvador, F. J., Plazas, A. H., Gimeno, J., and Carreres, M. (2014). Complete modelling of a piezo actuator last-generation injector for diesel injection systems. International Journal of Engine Research, 15(1):3-19.

[188] Sangiah, D. K. and Ganippa, L. C. (2010). Application of spray impingement technique for characterisation of high pressure sprays from multi-hole diesel nozzles. International Journal of Thermal Sciences, 49(2):409-417.

[189] Schlichting, H. (1978). Boundary-Layer Theory. McGraw-Hill.

[190] Schmidt, D. P. and Corradini, M. L. (2001). The internal flow of diesel fuel injector nozzles: a review. International Journal of Engine Research, 2(6):1-22.

[191] Schweitzer, P. H. (1937). Mechanism of disintegration of liquid jets. Journal of Applied Physics, 8:513-521.

[192] Settles, G. S. (2001). Schlieren and Shadowgraph Techniques. Springer Berlin Heidelberg, Berlin, Heidelberg.

[193] Siebers, D. L. (1998). Liquid-phase fuel penetration in diesel sprays. SAE Technical Paper 980809, pages 1-23.

[194] Siebers, D. L. (1999). Scaling liquid-phase fuel penetration in diesel sprays based on mixing-limited vaporization. SAE Technical Paper 1999-01-0528.

[195] Smallwood, G. J. and Gülder, O. L. (2000). Views on the structure of transient diesel sprays. Atomization and Sprays, 10:511-527. 
[196] Soare, V. (2007). Phase doppler measurement in diesel dense sprays: optimization of measurements and study of the orifice geometry influence over the spray at microscopic level. PhD thesis, E.T.S. Ingenieros Industriales. Universidad Politecnica de Valencia, Valencia.

[197] Soid, S. N. and Zainal, Z. A. (2011). Spray and combustion characterization for internal combustion engines using optical measuring techniques - a review. Energy, $36(2): 724-741$.

[198] Som, S., Aggarwal, S. K., El-Hannouny, E. M., and Longman, D. E. (2010). Investigation of nozzle flow and cavitation characteristics in a diesel injector. Journal of Engineering for Gas Turbines and Power, 132(4):042802.

[199] Soteriou, C., Andrews, R., and Smith, M. (1995). Direct injection diesel sprays and the effect of cavitation and hydraulic flip on atomization. SAE Paper 950080.

[200] Sou, A., Maulana, M. I., and Isozaki, K. (2008). Effects of nozzle geometry on cavitation in nozzles of pressure atomizers. Journal of Fluid Science and Technology, $3(5): 622-632$.

[201] Sterling, A. M. and Sleicher, C. A. (1975). The instability of capillary jets. Journal of Fluid Mechanics.

[202] Sun, Z.-Y., Li, G.-X., Chen, C., Yu, Y.-S., and Gao, G.-X. (2015). Numerical investigation on effects of nozzle's geometric parameters on the flow and the cavitation characteristics within injector's nozzle for a high-pressure common-rail DI diesel engine. Energy Conversion and Management, 89:843-861.

[203] Swantek, A. B., Kastengren, A. L., Duke, D. J., Tilocco, Z., Sovis, N., and Powell, C. F. (2015). Quantification of Shot-to-Shot variation in single hole diesel injectors. SAE International Journal of Fuels and Lubricants, 8(1):2015-01-0936.

[204] Tahmasebi, E., Lucchini, T., D'Errico, G., and Onorati, A. (2015). Numerical simulation of diesel injector internal flow field. Energy Procedia, 82:51-58.

[205] Venegas, O. (2014). Estudio del fenómeno de la cavitación en la inyección diesel mediante la visualización del flujo interno en orificios transparentes. PhD thesis, Universitat Politècnica de València.

[206] Viera, J. P. (2013). Análisis hidrodinámico de un cojinete cilíndrico de gas de superficie deformable. PhD thesis, Universidad Simón Bolívar.

[207] Viera, J. P. (2017). Experimental study of the effect of nozzle geometry on the performance of direct-injection diesel sprays for three different fuels. $\mathrm{PhD}$ thesis, Universidad Politécnica de Valencia.

[208] Viera, J. P., Payri, R., Swantek, A. B., Duke, D. J., Sovis, N., Kastengren, A. L., and Powell, C. F. (2016). Linking instantaneous rate of injection to X-ray needle lift measurements for a direct-acting piezoelectric injector. Energy Conversion and Management, 112:350-358. 
[209] Von Kuensberg Sarre, C., Kong, S.-c., and Reitz, R. D. (1999). Modeling the effects of injector nozzle geometry on diesel sprays. SAE Technical Paper 1999-010912, (724).

[210] Wakuri, Y., Fuji, M., Amitani, T., Tsuneya, R., Fujii, M., Amitani, T., and Tsnumeya, R. (1960). Studies of the penetration of a fuel spray in a diesel Engine. Bulletin of JSME, 3(9):123-130.

[211] Wan, Y. and Peters, N. (1999). Scaling of spray penetration with evaporation. Atomization and Sprays, 9(2):111-132.

[212] Wang, X., Huang, Z., Kuti, O. A., Zhang, W., and Nishida, K. (2010). Experimental and analytical study on biodiesel and diesel spray characteristics under ultra-high injection pressure. International Journal of Heat and Fluid Flow, 31(4):659-666.

[213] Wang, X., Huang, Z., Zhang, W., Abiola, O., and Nishida, K. (2011). Effects of ultra-high injection pressure and micro-hole nozzle on flame structure and soot formation of impinging diesel spray. Applied Energy, 88(5):1620-1628.

[214] Wang, Y., Qiu, L., Reitz, R. D., and Diwakar, R. (2014). Simulating cavitating liquid jets using a compressible and equilibrium two-phase flow solver. International Journal of Multiphase Flow, 63:52-67.

[215] Wang, Z., Ding, H., Wyszynski, M. L., Tian, J., and Xu, H. (2015). Experimental study on diesel fuel injection characteristics under cold start conditions with single and split injection strategies. Fuel Processing Technology, 131:213-222.

[216] White, F. M. (2004). Fluid mechanics. McGraw-Hill.

[217] Wu, K. J., Su, C. C., Steinberger, R. L., Santavicca, D. A., and Bracco, F. V. (1983). Measurements of the spray angle of atomizing jets. Journal of fluids Engineering, 105(4):406-410.

[218] Xu, M. and Hiroyasu, H. (1990). Development of a new optical technique for measuring diesel spray penetration. SAE Paper 90207\%.

[219] Xu, Q., Xu, M., Hung, D., Wu, S., Dong, X., Ochiai, H., Zhao, Z., Wang, C., and Jin, K. (2017). diesel Spray characterization at ultra-high injection pressure of DENSO $250 \mathrm{MPa}$ common rail fuel injection system. In SAE Technical Paper. SAE International.

[220] Yanfei, L., Guohong, T., Jun, Z., and Hongming, X. (2010). Comparative experimental study on microscopic spray characteristics of RME, GTL and diesel. SAE Technical Paper.

[221] Yao, C., Geng, P., Yin, Z., Hu, J., Chen, D., and Ju, Y. (2016). Impacts of nozzle geometry on spray combustion of high pressure common rail injectors in a constant volume combustion chamber. Fuel, 179:235-245.

[222] Yu, W., Yang, W., and Zhao, F. (2017). Investigation of internal nozzle flow, spray and combustion characteristics fueled with diesel, gasoline and wide distillation fuel (WDF) based on a piezoelectric injector and a direct injection compression ignition engine. Applied Thermal Engineering, 114:905-920. 
[223] Zhou, L. Y., Dong, S. F., Cui, H. F., Wu, X. W., Xue, F. Y., and Luo, F. Q. (2016). Measurements and analyses on the transient discharge coefficient of each nozzle hole of multi-hole diesel injector. Sensors and Actuators, A: Physical, 244:198-205. 
